Andréa Cancela da Cruz-Kaled

\title{
Variação temporal e espacial de larvas de invertebrados marinhos da Baía do Almirantado, Ilha Rei George, Antártica
}

Tese apresentada ao Instituto Oceanográfico da Universidade de São Paulo, como parte dos requisitos para obtenção do título de Doutor em Ciências, área de Oceanografia Biológica.

Orientadora: Prof $f^{a} \operatorname{Dr}^{\mathrm{a}}$ Thaïs Navajas Corbisier Co-orientadora: Prof ${ }^{a} \operatorname{Dr}^{a}$ Theresinha M. Absher 
Universidade de São Paulo

Instituto Oceanográfico

\section{VARIAÇÃO TEMPORAL E ESPACIAL DE LARVAS DE INVERTEBRADOS MARINHOS DA BAÍA DO ALMIRANTADO, ILHA REI GEORGE, ANTÁRTICA.}

\section{Andréa Cancela da Cruz-Kaled}

Tese apresentada ao Instituto Oceanográfico da Universidade de São Paulo, como parte dos requisitos para obtenção do título de Doutor em Ciências, área de Oceanografia Biológica.

Julgada em

Profa Dra Thaïs Navajas Corbisier

Instituto Oceanográfico da Universidade de São Paulo

Conceito

$\operatorname{Prof}(a) \operatorname{Dr}(a)$

Conceito

$\operatorname{Prof}(a) \operatorname{Dr}(a)$

Conceito

$\operatorname{Prof}(a) \operatorname{Dr}(\mathrm{a})$

Conceito

Prof(a) Dr(a)

Conceito 
Agradeço à Profa. Thaïs Navajas Corbisier não apenas pela orientação, mas também pela amizade, confiança e paciência. Obrigada por me receber no laboratório. Aprendi muito durante todos esses anos.

À Profa. Theresinha Absher, que me acompanha desde a graduação, pela orientação, incentivo e amizade no decorrer de todos esses anos.

Agradeço ao Conselho Nacional de Desenvolvimento Científico e Tecnológico (CNPq), pela bolsa de estudo concedida e ao Instituto Oceanográfico, pela infraestrutura.

À Secretaria da Comissão Interministerial para os Recursos do Mar (SECIRM), Marinha do Brasil e ao Clube Alpino Paulista (CAP), pelo apoio logístico durante as expedições à Antártica.

Ao Prof. Edmundo Ferraz Nonato e à Mônica Petti pelo auxílio na identificação de Pelagobia sp, entusiasmo e disponibilidade, sempre.

Ao Paulo Sumida e Mônica Petti pelas proveitosas discussões, especialmente durante a qualificação.

À Susete Christo e Yargos Kern pelo auxílio nas coletas.

Aos amigos das Operações Antárticas, que tornaram os dias frios e a distância da família mais amenos, com momentos de alegria e descontração.

À Sandra, sempre pronta, disposta e com a palavra certa...e ainda pela leitura crítica. Incansável...não posso esquecer do "café".

Ao Gabriel Monteiro, Paula Gheller, Luciana Yaginuma e Mauricio Shimabukuro pelos auxílios científico, estatístico e informático em várias etapas desse trabalho...amizade e incentivo. Além dos dias alegres e descontraídos.

À Karin Elbers pela organização dos dados, bibliografia e discussões.

À Andréa Green Koettker pela leitura e críticas na fase final.

Aos funcionários do IO, sempre dispostos, pela ajuda. Em especial ao pessoal da biblioteca, todos sempre atenciosos e prestativos. 
Ao Valter pelo auxílio técnico e aprendizado na informática, sempre solícito.

À todos do Laboratório de Ecologia de Meiobentos Marinho: Paula, Luciana, Gabriel, Maria Claudia, Maria, Noelle, Carol, Caia e Marcelo, pela ajuda e incentivo e pelas boas conversas...

Aos amigos do IO...San, Paula, Lu, Gabriel, Carol, MC, Mau, Ju, Mi, Pedro, Karin, Betina, Caia, Déa, Maria, André, João, Marcelo, Pris, Diego, Lizi, pelo convívio, proveitosas discussões e ótimos momentos.

Às sempre amigas, Su, Sté, Morgs, Ni, Mone, Cole, Beth, simplesmente por ouvirem...

À minha enorme família, sempre ao meu lado, especialmente meu pai, Carlos...base e sabedoria, pelo apoio e incentivo.

Ao Vilmar, pelo companheirismo e ajuda com nossa pequena.

Enfim, a todos que de alguma maneira contribuíram para a conclusão deste trabalho. 


\section{ÍNDICE}

LISTA DE TABELAS

LISTA DE FIGURAS

RESUMO $\quad$ xiii

$\begin{array}{lll}\text { ABSTRACT } & \text { xiv }\end{array}$

INTRODUÇÃO GERAL

Introdução 1

Área de Estudo $\quad 9$

Referências Bibliográficas $\quad 12$

CAPITUlo I. VARIAÇÃO ESPAÇO-TEMPORAL DE LARVAS DE INVERTEBRAdOS (EM profundidade até 30 metros) Na Baía do Almirantado, IlHa Rei George, ANTÁRTICA (2002/2004).

$\begin{array}{ll}\text { Introdução } & 18\end{array}$

Material e Métodos 23

Resultados 29

$\begin{array}{ll}\text { Discussão } & 60\end{array}$

Referências Bibliográficas $\quad 71$

CAPITULO II. VARIAÇÃO BATIMÉTRICA DA ABUNDÂNCIA DE LARVAS DE INVERTEBRADOS NA BAÍA do Almirantado, IlHa REI GEORGE, ANTÁRTiCA (2003/2004).

$\begin{array}{ll}\text { Introdução } & 77\end{array}$

Material e Métodos $\quad 81$

$\begin{array}{ll}\text { Resultados } & 86\end{array}$

$\begin{array}{ll}\text { Discussão } & 107\end{array}$

Referências Bibliográficas $\quad 111$

CONSIDERAÇÕES FINAIS 115

APÊNDICES 117 
Tabela I. Coordenadas geográficas das estações e áreas amostradas da Baía do Almirantado, Ilha Rei George, Antártica.

Tabela II. Abundância máxima do meroplâncton em diferentes locais na Antártica e o período de seu pico máximo (Adaptado de Vázquez et al., 2007).

Tabela III. Coordenadas geográficas das estações e áreas amostradas da Baía do Almirantado, Ilha Rei George, Antártica.

\section{LISTA DE FIGURAS}

Figura 01. Península Antártica e as Ilhas Shetlands do Sul (em destaque) (Simões et al., 2004).

Figura 02. Ilha Rei George (Simões et al., 2004).

Figura 03. Baía do Almirantado com as estações e áreas de coleta. Adaptado de Simões et al., 2004.

Figura 04. Variação temporal da temperatura média da água do mar $\left({ }^{\circ} \mathrm{C}\right)$ nas estações de coleta ( $\bar{x} \pm$ DP) . Outubro de 2002 a agosto de 2004. Baía do Almirantado.

Figura 05. Variação espaço-temporal da temperatura média da água do mar $\left({ }^{\circ} \mathrm{C}\right)(\bar{x} \pm$ IC). Primavera de 2002 a Inverno de 2004. Baía do Almirantado. MT=Área Martel; $\mathrm{ML}=$ Área Mackellar; EZ= Área Ezcurra; EBA= Área da entrada da baía. Pv02= Primavera de 2002; Ve03= Verão de 2003; Ot03= Outono de 2003; Pv03= Primavera de 2003; Ve04= Verão de 2004; Ot04= Outono de 2004; Iv04= Inverno de 2004. 
Figura 06. Variação temporal da salinidade média da água do mar nas estações de coleta ( $\bar{x} \pm$ DP). Outubro de 2002 a agosto de 2004. Baía do Almirantado.

Figura 07. Variação espaço-temporal da salinidade média da água do mar ( $\bar{x} \pm$ IC). Primavera de 2002 a Inverno de 2004. Baía do Almirantado. MT=Área Martel; $\mathrm{ML}=$ Área Mackellar; EZ = Área Ezcurra; EBA = Área da entrada da baía. Pv02= Primavera de 2002; Ve03= Verão de 2003; Ot03= Outono de 2003; Pv03= Primavera de 2003; Ve04= Verão de 2004; Ot04= Outono de 2004; Iv04= Inverno de 2004.

Figura 08. Variação temporal da velocidade média do vento $\left(\mathrm{m} \mathrm{s}^{-1}\right)$ nas estações de coleta ( $\bar{x} \pm$ DP). Outubro de 2002 a agosto de 2004. Baía do Almirantado.

Figura 09. Variação espaço-temporal da velocidade média do vento $\left(\mathrm{m}_{\mathrm{s}} \mathrm{s}^{-1}\right)(\bar{x} \pm \mathrm{IC})$. Primavera de 2002 a Inverno de 2004. Baía do Almirantado. MT=Área Martel; ML= Área Mackellar; EZ= Área Ezcurra; EBA= Área da entrada da baía. Pv02= Primavera de 2002; Ve03= Verão de 2003; Ot03= Outono de 2003; Pv03= Primavera de 2003; Ve04= Verão de 2004; Ot04= Outono de 2004; Iv04= Inverno de 2004.

Figura 10. Variação temporal da transparência média da água (m) nas estações de coleta ( $\bar{x} \pm$ DP). Outubro de 2002 a agosto de 2004. Baía do Almirantado.

Figura 11. Variação espaço-temporal da transparência média da água (m) ( $\bar{x} \pm \mathrm{IC})$. Primavera de 2002 a Inverno de 2004. Baía do Almirantado. MT=Área Martel; $\mathrm{ML}=$ Área Mackellar; EZ= Área Ezcurra; EBA= Área da entrada da baía. Pv02= Primavera de 2002; Ve03= Verão de 2003; Ot03= Outono de 2003; Pv03= Primavera de 2003; Ve04=Verão de 2004; Ot04= Outono de 2004; Iv04= Inverno de 2004. 
Figura 12. Variação temporal da concentração média de clorofila a $\left(\mu \mathrm{g} . \mathrm{l}^{-1}\right)$ nas estações de coleta ( $\bar{x} \pm$ DP). Outubro de 2002 a agosto de 2004. Baía do Almirantado.

Figura 13. Variação temporal da concentração média de feopigmentos $\left(\mu \mathrm{g} \cdot 1^{-1}\right)$ nas estações de coleta ( $\bar{x} \pm$ DP). Outubro de 2002 a agosto de 2004. Baía do Almirantado.

Figura 14. Concentração média de clorofila a $\left(\mu \mathrm{g} .1^{-1}\right)$ durante o período amostrado nas diferentes áreas ( $\bar{x} \pm$ IC). Primavera de 2002 a Inverno de 2004. Baía do Almirantado. $\mathrm{MT}=$ Área Martel; $\mathrm{ML}=$ Área Mackellar; $\mathrm{EZ}=$ Área Ezcurra; $\mathrm{EBA}=$ Área da entrada da baía. Pv02= Primavera de 2002; Ve03= Verão de 2003; Ot03= Outono de 2003; Pv03= Primavera de 2003; Ve04= Verão de 2004; Ot04= Outono de 2004; Iv04= Inverno de 2004.

Figura 15. Concentração média de feopigmentos $\left(\mu \mathrm{g} .1^{-1}\right)$ durante o período amostrado nas diferentes áreas ( $\bar{x} \pm$ IC). Primavera de 2002 a Inverno de 2004. Baía do Almirantado. $\mathrm{MT}=$ Área Martel; $\mathrm{ML}=$ Área Mackellar; $\mathrm{EZ}=$ Área Ezcurra; $\mathrm{EBA}=$ Área da entrada da baía. Pv02= Primavera de 2002; Ve03= Verão de 2003; Ot03= Outono de 2003; Pv03= Primavera de 2003; Ve04= Verão de 2004; Ot04= Outono de 2004; Iv04= Inverno de 2004.

Figura 16. Análise de componentes principais (PCA) para as variáveis ambientais. Baía do Almirantado. $\mathrm{MT}=$ Área Martel; $\mathrm{ML}=$ Área Mackellar; $\mathrm{EZ}=$ Área Ezcurra; $\mathrm{EBA}=$ Área da entrada da baía. Pv02= Primavera de 2002; Ve03= Verão de 2003; Ot03= Outono de 2003; Pv03= Primavera de 2003; Ve04= Verão de 2004; Ot04= Outono de 2004; Iv04= Inverno de 2004. 
Figura 17. Abundância média de larvas de invertebrados (Dados logaritmizados) coletadas em todo o período amostrado ( $\bar{x} \pm$ DP). Primavera de 2002 a Inverno de 2004. Baía do Almirantado. Pv02= Primavera de 2002; Ve03= Verão de 2003; Ot03= Outono de 2003; Pv03= Primavera de 2003; Ve04= Verão de 2004; Ot04= Outono de 2004; Iv04= Inverno de 2004.

Figura 18. Abundância média dos grupos de larvas de invertebrados (Dados logaritmizados) coletadas em todo o período amostrado nas áreas de coleta ( $\bar{x} \pm$ DP). Primavera de 2002 a Inverno de 2004. Baía do Almirantado. $\mathrm{MT}=$ Área Martel; $\mathrm{ML}=$ Área Mackellar; $\mathrm{EZ}=$ Área Ezcurra; EBA= Área da entrada da baía. Pv02= Primavera de 2002; Ve03= Verão de 2003; Ot03= Outono de 2003; Pv03= Primavera de 2003; Ve04= Verão de 2004; Ot04= Outono de 2004; Iv04= Inverno de 2004.

Figura 19. Percentagem relativa (\%) dos grupos de larvas de invertebrados coletadas em todo o período amostrado. Outubro de 2002 a agosto de 2004. Baía do Almirantado.

Figura 20. Percentagem relativa (\%) do número de larvas de invertebrados durante o período amostrado. Outubro de 2002 a agosto de 2004. Baía do Almirantado.

Figura 21. Variação temporal do número médio de larvas de Gastropoda (indivíduos.100 $\mathrm{m}^{-3}$ ) nas estações de coleta ( $\bar{x} \pm \mathrm{DP}$ ). Outubro de 2002 a agosto de 2004. Baía do Almirantado. 
Figura 22. Número médio de larvas de Gastropoda (indivíduos.100 $\mathrm{m}^{-3}$ ) durante o período amostrado nas áreas de coleta ( $\bar{x} \pm$ IC). Primavera de 2002 a Inverno de 2004. Baía do Almirantado. MT=Área Martel; $\mathrm{ML}=$ Área Mackellar; EZ= Área Ezcurra; EBA= Área da entrada da baía. Pv02= Primavera de 2002; Ve03= Verão de 2003; Ot03= Outono de 2003; Pv03= Primavera de 2003; Ve04= Verão de 2004; Ot04= Outono de 2004; Iv04= Inverno de 2004.

Figura 23. Variação temporal do número médio de larvas de Polychaeta (indivíduos.100 $\mathrm{m}^{-3}$ ) nas estações de coleta ( $\left.\bar{x} \pm \mathrm{DP}\right)$. Outubro de 2002 a agosto de 2004. Baía do Almirantado.

Figura 24. Número médio de larvas de Polychaeta (indivíduos.100 $\mathrm{m}^{-3}$ ) durante o período amostrado nas áreas de coleta $(\bar{x} \pm$ IC). Primavera de 2002 a Inverno de 2004. Baía do Almirantado. MT=Área Martel; $\mathrm{ML}=$ Área Mackellar; EZ= Área Ezcurra; EBA= Área da entrada da baía. Pv02= Primavera de 2002; Ve03= Verão de 2003; Ot03= Outono de 2003; Pv03= Primavera de 2003; Ve04= Verão de 2004; Ot04= Outono de 2004; Iv04= Inverno de 2004.

Figura 25. Variação temporal do número médio de larvas de Echinodermata (indivíduos.100 $\mathrm{m}^{-3}$ ) nas estações de coleta ( $\bar{x} \pm$ DP). Outubro de 2002 a agosto de 2004. Baía do Almirantado.

Figura 26. Número médio de larvas de Echinodermata (indivíduos. $100 \mathrm{~m}^{-3}$ ) durante o período amostrado nas áreas de coleta $(\bar{x} \pm \mathrm{IC})$. Primavera de 2002 a Inverno de 2004. Baía do Almirantado. MT=Área Martel; $\mathrm{ML}=$ Área Mackellar; EZ= Área Ezcurra; $\mathrm{EBA}=$ Área da entrada da baía. Pv02= Primavera de 2002; Ve03= Verão de 2003; Ot03= Outono de 2003; Pv03= Primavera de 2003; Ve04= Verão de 2004; Ot04= Outono de 2004; Iv04= Inverno de 2004. 
Figura 27. Variação temporal do número médio de larvas trocófora (indivíduos. $100 \mathrm{~m}^{-3}$ ) nas estações de coleta ( $\bar{x} \pm$ DP). Outubro de 2002 a agosto de 2004. Baía do Almirantado.

Figura 28. Número médio de larvas trocófora (indivíduos. $100 \mathrm{~m}^{-3}$ ) durante o período amostrado nas áreas de coleta ( $\bar{x} \pm$ IC). Primavera de 2002 a Inverno de 2004. Baía do Almirantado. $\mathrm{MT}=$ Área Martel; $\mathrm{ML}=$ Área Mackellar; $\mathrm{EZ}=$ Área Ezcurra; EBA= Área da entrada da baía. Pv02= Primavera de 2002; Ve03= Verão de 2003; Ot03= Outono de 2003; Pv03= Primavera de 2003; Ve04= Verão de 2004; Ot04= Outono de 2004; Iv04= Inverno de 2004.

Figura 29. Variação temporal do número médio de larvas de Nemertea (pilidium) (indivíduos.100 $\mathrm{m}^{-3}$ ) nas estações de coleta ( $\bar{x} \pm \mathrm{DP}$ ). Outubro de 2002 a agosto de 2004. Baía do Almirantado.

Figura 30. Número médio de larvas de Nemertea (pilidium) (indivíduos.100 $\mathrm{m}^{-3}$ ) durante o período amostrado nas áreas de coleta ( $\bar{x} \pm$ IC). Primavera de 2002 a Inverno de 2004. Baía do Almirantado. MT=Área Martel; ML= Área Mackellar; $\mathrm{EZ}=$ Área Ezcurra; $\mathrm{EBA}=$ Área da entrada da baía. Pv02= Primavera de 2002; Ve03= Verão de 2003; Ot03= Outono de 2003; Pv03= Primavera de 2003; Ve04= Verão de 2004; Ot04= Outono de 2004; Iv04= Inverno de 2004.

Figura 31. Análise de agrupamento por média ponderada (Índice de Bray-Curtis) considerando as densidades dos grupos do meroplâncton. Em vermelho os agrupamentos não significativamente distintos (SIMPROF).

Figura 32. Análise de escalonamento multidimensional não-métrica (nMDS) para as densidades do meroplâncton. Os agrupamentos obtidos no dendrograma da figura 29 foram sobrepostos no diagrama. 
Figura 33. Análise de escalonamento multidimensional não métrica (nMDS) considerando as densidades do meroplâncton nas estações de coleta nas XXI e XXII OABs. Os valores de densidade (indivíduos. $100 \mathrm{~m}^{-3}$ ) foram sobrepostos à ordenação. Também foram sobrepostos os grupos obtidos na análise de agrupamento (Índice de Bray-Curtis).

Figura 34. Baía do Almirantado com as estações e áreas de coleta. Adaptado de Simões et al., 2004.

Figura 35. Variação espaço-temporal da temperatura média da água do mar $\left({ }^{\circ} \mathrm{C}\right)$ ( $\bar{x} \pm$ IC). Primavera de 2003 a outono de 2004. Baía do Almirantado. PIS $=$ Martel Superfície; PIF= Martel Fundo; PIIS= Mackellar Superfície; PIIF= Mackellar Fundo; PIIIS= Ezcurra Superfície; PIIIF= Ezcurra Fundo; PIVS= Entrada da baía Superfície; PIVF= Entrada da baía Fundo. Pv03= Primavera de 2003; Ve04=Verão de 2004; Ot04= Outono de 2004.

Figura 36. Variação espaço-temporal da salinidade média da água do mar ( $\bar{x} \pm \mathrm{IC}$ ). Primavera de 2003 a outono de 2004. Baía do Almirantado. PIS= Martel Superfície; PIF= Martel Fundo; PIIS= Mackellar Superfície; PIIF= Mackellar Fundo; PIIIS= Ezcurra Superfície; PIIIF= Ezcurra Fundo; PIVS= Entrada da baía Superfície; PIVF= Entrada da baía Fundo. Pv03= Primavera de 2003; Ve04= Verão de 2004; Ot04= Outono de 2004.

Figura 37. Variação espaço-temporal da velocidade média do vento $\left(\mathrm{m} . \mathrm{s}^{-1}\right.$ ) (dados pontuais, referentes à hora da coleta) ( $\bar{x} \pm$ IC). Primavera de 2003 a outono de 2004. Baía do Almirantado. PIS= Martel Superfície; PIF= Martel Fundo; PIIS= Mackellar Superfície; PIIF= Mackellar Fundo; PIIIS= Ezcurra Superfície; PIIIF= Ezcurra Fundo; PIVS= Entrada da baía Superfície; PIVF= Entrada da baía Fundo. Pv03= Primavera de 2003; Ve04= Verão de 2004; Ot04= Outono de 2004 . 
Figura 38. Variação espaço-temporal da transparência média da água (m) ( $\bar{x} \pm \mathrm{IC}$ ). Primavera de 2003 a outono de 2004. Baía do Almirantado. PIS= Martel Superfície; PIF= Martel Fundo; PIIS= Mackellar Superfície; PIIF= Mackellar Fundo; PIIIS= Ezcurra Superfície; PIIIF= Ezcurra Fundo; PIVS= Entrada da baía Superfície; PIVF= Entrada da baía Fundo. Pv03= Primavera de 2003; Ve04= Verão de 2004; Ot04= Outono de 2004.

Figura 39. Concentração média de clorofila a $\left(\mu \mathrm{g} .1^{-1}\right)$ durante o período amostrado ( $\bar{x} \pm$ IC). Primavera de 2003 a outono de 2004. Baía do Almirantado. PIS= Martel Superfície; PIF= Martel Fundo; PIIS= Mackellar Superfície; PIIF= Mackellar Fundo; PIIIS= Ezcurra Superfície; PIIIF= Ezcurra Fundo; PIVS= Entrada da baía Superfície; PIVF= Entrada da baía Fundo. Pv03= Primavera de 2003; Ve04=Verão de 2004; Ot04= Outono de 2004.

Figura 40. Concentração média de feopigmentos $\left(\mu \mathrm{g} .1^{-1}\right)$ durante o período amostrado ( $\bar{x} \pm$ IC). Primavera de 2003 a outono de 2004. Baía do Almirantado. PIS $=$ Martel Superfície; PIF= Martel Fundo; PIIS= Mackellar Superfície; PIIF= Mackellar Fundo; PIIIS= Ezcurra Superfície; PIIIF= Ezcurra Fundo; PIVS= Entrada da baía Superfície; PIVF= Entrada da baía Fundo. Pv03= Primavera de 2003; Ve04=Verão de 2004; Ot04= Outono de 2004.

Figura 41. Análise de componentes principais (PCA) para as variáveis ambientais. Baía do Almirantado. PIS= Martel Superfície; PIF= Martel Fundo; PIIS= Mackellar Superfície; PIIF= Mackellar Fundo; PIIIS= Ezcurra Superfície; PIIIF= Ezcurra Fundo; PIVS= Entrada da baía Superfície; PIVF= Entrada da baía Fundo. Pv03= Primavera de 2003; Ve04= Verão de 2004; Ot04= Outono de 2004. 
Figura 42. Abundância média de larvas de invertebrados (Dados logaritmizados) coletadas em todo o período amostrado ( $\bar{x} \pm$ DP). Primavera de 2003 a outono de 2004. Baía do Almirantado. $P v=$ Primavera de 2003; Ve= Verão de 2004; Ot= Outono de 2004; S= Superfície; F= Fundo.

Figura 43. Abundância média dos grupos de larvas de invertebrados (indivíduos.100 $\mathrm{m}^{-3}$ ) coletadas em todo o período amostrado nas áreas de coleta ( $\bar{x} \pm$ DP). Primavera de 2003 a outono de 2004. Baía do Almirantado. $\mathrm{MT}=$ Área Martel; $\mathrm{ML}=$ Área Mackellar; $\mathrm{EZ}=$ Área Ezcurra; EBA= Área da entrada da baía. Pv03= Primavera de 2003; Ve04= Verão de 2004; Ot04= Outono de 2004.

Figura 44. Percentagem relativa (\%) dos grupos de larvas de invertebrados coletadas em todo o período amostrado. Outubro de 2003 a abril de 2004. Baía do Almirantado.

Figura 45. Percentagem relativa (\%) do número de larvas de invertebrados durante o período amostrado. Outubro de 2003 a abril de 2004. Baía do Almirantado.

Figura 46. Número médio de larvas de Gastropoda (indivíduos.100 $\mathrm{m}^{-3}$ ) durante o período amostrado ( $\bar{x} \pm$ IC). Primavera de 2003 a outono de 2004. Baía do Almirantado. PIS= Martel Superfície; PIF= Martel Fundo; PIIS= Mackellar Superfície; PIIF= Mackellar Fundo; PIIIS= Ezcurra Superfície; PIIIF= Ezcurra Fundo; PIVS= Entrada da baía Superfície; PIVF= Entrada da baía Fundo. Pv03= Primavera de 2003; Ve04= Verão de 2004; Ot04= Outono de 2004. 
Figura 47. Número médio de larvas de Polychaeta (indivíduos.100 $\mathrm{m}^{-3}$ ) durante o período amostrado ( $\bar{x} \pm$ IC). Primavera de 2003 a outono de 2004. Baía do Almirantado. PIS = Martel Superfície; PIF= Martel Fundo; PIIS= Mackellar Superfície; PIIF= Mackellar Fundo; PIIIS= Ezcurra Superfície; PIIIF= Ezcurra Fundo; PIVS= Entrada da baía Superfície; PIVF= Entrada da baía Fundo. Pv03= Primavera de 2003; Ve04= Verão de 2004; Ot04= Outono de 2004.

Figura 48. Número médio de larvas de Echinodermata (indivíduos.100 $\mathrm{m}^{-3}$ ) durante o período amostrado ( $\bar{x} \pm \mathrm{IC}$ ). Primavera de 2003 a outono de 2004. Baía do Almirantado. PIS= Martel Superfície; PIF= Martel Fundo; PIIS= Mackellar Superfície; PIIF= Mackellar Fundo; PIIIS= Ezcurra Superfície; PIIIF= Ezcurra Fundo; PIVS= Entrada da baía Superfície; PIVF= Entrada da baía Fundo. Pv03= Primavera de 2003; Ve04= Verão de 2004; Ot04= Outono de 2004.

Figura 49. Número médio de larvas trocófora (indivíduos. $100 \mathrm{~m}^{-3}$ ) durante o período amostrado ( $\bar{x} \pm$ IC). Primavera de 2003 a outono de 2004. Baía do Almirantado. PIS= Martel Superfície; PIF= Martel Fundo; PIIS= Mackellar Superfície; PIIF= Mackellar Fundo; PIIIS= Ezcurra Superfície; PIIIF= Ezcurra Fundo; PIVS= Entrada da baía Superfície; PIVF= Entrada da baía Fundo. Pv03= Primavera de 2003; Ve04= Verão de 2004; Ot04= Outono de 2004.

Figura 50. Número médio de larvas de Nemertea (pilidium) (indivíduos.100 $\mathrm{m}^{-3}$ ) durante o período amostrado ( $\bar{x} \pm$ IC). Primavera de 2003 a outono de 2004. Baía do Almirantado. PIS= Martel Superfície; PIF= Martel Fundo; PIIS= Mackellar Superfície; PIIF= Mackellar Fundo; PIIIS= Ezcurra Superfície; $\mathrm{PIIIF}=$ Ezcurra Fundo PIVS= Entrada da baía Superfície $; \mathrm{PIVF}=$ Entrada da baía Fundo. Pv03= Primavera de 2003; Ve04= Verão de 2004; Ot04= Outono de 2004. 
Figura 51. Análise de agrupamento por média ponderada (Índice de Bray-Curtis) considerando as densidades dos grupos do meroplâncton. Em vermelho os agrupamentos não distintos significativamente (SIMPROF). Baía do Almirantado. PIS= Martel Superfície; PIF= Martel Fundo; PIIS= Mackellar Superfície; PIIF= Mackellar Fundo; PIIIS= Ezcurra Superfície; PIIIF= Ezcurra Fundo; PIVS= Entrada da baía Superfície; PIVF= Entrada da baía Fundo. Pv03= Primavera de 2003; Ve04= Verão de 2004; Ot04= Outono de 2004.

Figura 52. Análise de escalonamento multidimensional não-métrica (nMDS) para as densidades do meroplâncton. Os agrupamentos obtidos no dendrograma acima foram sobrepostos no diagrama. Baía do Almirantado. PIS= Martel Superfície; PIF= Martel Fundo; PIIS= Mackellar Superfície; PIIF= Mackellar Fundo; PIIIS= Ezcurra Superfície; PIIIF= Ezcurra Fundo; PIVS= Entrada da baía Superfície; PIVF= Entrada da baía Fundo. Pv03= Primavera de 2003; Ve04= Verão de 2004; Ot04= Outono de 2004.

Figura 53. Análise de escalonamento multidimensional não métrica (nMDS) considerando as densidades do meroplâncton nas estações de coleta na XXII OAB. Os valores de densidade (indivíduos. $100 \mathrm{~m}^{-3}$ ) foram sobrepostos à ordenação. Também foram sobrepostos os grupos obtidos na análise de agrupamento (Índice de Bray-Curtis). 
A Baía do Almirantado (Ilha Rei George, Antártica) possui diversas pequenas enseadas de águas rasas, que sustentam uma abundante fauna bentônica. O regime de marés e de ventos é responsável pelo hidrodinamismo na baía e pela interação com as águas do Estreito de Bransfield. Portanto, trata-se de uma área que pode apresentar uma elevada abundância de larvas de invertebrados marinhos. A distribuição espaço-temporal de larvas pelágicas em águas rasas costeiras da Baía do Almirantado foi estudada entre outubro de 2002 e maio de 2003, e outubro de 2003 e agosto de 2004 em 12 estações rasas (0 a 15 m, ou até 30 m). Também foram amostradas, sazonalmente, quatro estações de maior profundidade, entre 0 a $30 \mathrm{~m}$ e 30 a $130 \mathrm{~m}$ da coluna de água, entre outubro de 2003 e abril de 2004. Amostras de plâncton foram coletadas com rede cônica de plâncton com malha de $150 \mu \mathrm{m}$ nas três enseadas da baía (Martel, Mackellar e Ezcurra) e na entrada do seu canal principal. Larvas de diferentes grupos ocorreram em todo o período de estudo. No primeiro ano, a abundância total foi maior que no segundo e, em especial, no verão. As larvas véliger de Gastropoda foram mais abundantes, representando $84 \%$ do total do meroplâncton, no primeiro ano de amostragem. No ano seguinte, larvas trocófora foram predominantes (31\% do total), seguidas de Gastropoda e Nemertea. Os resultados mostraram uma evidente variação interanual da densidade e da composição do meroplâncton, mas sem um padrão nítido de sazonalidade para determinados grupos. O congelamento da baía no inverno do primeiro ano de amostragem (2002) pode ter afetado a reprodução dos invertebrados bentônicos e a produção de larvas. Quanto à distribuição batimétrica, a abundância média do meroplâncton total foi maior na camada profunda do que na de superfície, na primavera-verão, mas espacialmente a densidade foi semelhante entre as áreas nas distintas camadas. A variabilidade na abundância e composição larval pode estar relacionada à hidrografia e a padrões reprodutivos das espécies bentônicas com desenvolvimento indireto, cujos ciclos reprodutivos são afetados por características ambientais. Em termos gerais, o meroplâncton coletado na Baía do Almirantado foi qualitativamente similar (quanto aos grupos de larvas) ao descrito para outras partes da Antártica.

Palavras-chave: meroplâncton, larvas de invertebrados, distribuição, Baía do Almirantado, Antártica 
Admiralty Bay (King George Island, Antarctica) has many small inlets of shallow waters, which supports an abundant benthic fauna. Tidal and wind regime are responsible for the hydrodynamics in the bay and for the interaction with the waters of the Bransfield Strait. Therefore, it is an area that can present a high abundance of marine invertebrate larvae. Spatio-temporal distribution of pelagic larvae in shallow coastal waters of Admiralty Bay was studied between October of 2002 and May of 2003, and October of 2003 and August of 2004 in twelve shallow stations ( 0 to $15 \mathrm{~m}$, or up to $30 \mathrm{~m}$ ). Four deeper stations were also seasonally sampled ( 0 to $30 \mathrm{~m}$ and 30 to $130 \mathrm{~m}$ of water column) between October of 2003 and April of 2004. Plankton samples were collected with a conical net, with mesh size of 150 $\mu \mathrm{m}$, in the three inlets of the bay (Martel, Mackellar and Ezcurra) and in the entrance of its main channel. Larvae of different groups occurred in the whole studied period. In the first year, the total abundance was higher than in the second and, especially, in the summer. The veliger larvae of Gastropoda were more abundant, representing $84 \%$ of the total meroplankton in the first year of sampling. In the following year, trochophore larvae were predominant (31\% of the total), followed by Gastropoda and Nemertea. The results showed an evident interannual composition and density variation of meroplankton, but without a clear pattern of seasonality for certain groups. The freezing of the bay in the winter of the first year could have influenced the benthic invertebrate's reproduction and larvae production. Regarding to the bathymetric distribution, the mean abundance of the total meroplankton was higher in the deeper layer than in the surface in spring-summer, however, spatially the density was similar among the areas in the different layers. The variability in the larval composition and abundance may be related to the local hydrography and specific reproductive pattern of the benthic species with indirect development, whose reproductive cycles are affected by environmental characteristics. In general terms, the meroplankton collected in Admiralty Bay was qualitatively similar (in view of the larval groups) to the described for other parts of Antarctica.

Key-words: meroplankton, invertebrate larvae, distribution, Admiralty Bay, Antarctica 


\section{INTRODUÇÃO GERAL}

A maioria das 170.000 espécies em 23 de 31 filos de animais invertebrados, com algum representante marinho, tem desenvolvimento indireto com larva que pode diferir dos adultos em tamanho, forma, habitat, modo de nutrição e/ou habilidade para mover-se. Consequentemente, o ciclo de vida da maioria dos animais marinhos é "bifásico", com a transição entre as fases sendo frequentemente uma rápida série de mudanças morfológicas, comportamentais e fisiológicas chamada de metamorfose (Young et al., 2006).

Não há uma definição geral aceita de "larva" que compreenda todos os critérios evolutivos, genéticos, morfológicos, entre outros (Stanwell-Smith et al., 1999). A definição de larva depende de se o foco é sobre a estrutura, evolução, história de vida, sequência de desenvolvimento ou atributos ecológicos. Entretanto, uma definição mais abrangente do o que é uma larva é dada por Young et al. (2006), , embora sem incluir aspectos de dispersão, alimentação ou seleção de habitat:

"Uma larva é um estágio pós-embrionário do ciclo de vida o qual difere morfologicamente do adulto e é capaz de locomoção independente".

Organismos do meroplâncton são estágios larvais que despendem somente uma parte do seu ciclo de vida no plâncton (Nybakken, 2001). São transportados pelas correntes oceânicas por algum tempo, antes de sua metamorfose até a fase adulta bentônica ou nectônica (Sumich \& Morrissey, 2004).

As formas do corpo de invertebrados e de suas formas larvais são diversas e esse grande número de formas larvais tem nomes específicos. Não é incomum encontrar larvas com nomes diferentes no ciclo de vida da mesma espécie (Young et al., 2006).

Invertebrados marinhos são frequentemente sésseis ou têm somente uma mobilidade limitada quando adultos. Para muitas espécies uma fase larval livre pode ter uma grande importância para a dispersão e consequentemente para o fluxo gênico, do qual a estrutura espacial e genética das espécies depende. Estes organismos bentônicos exibem uma grande diversidade no padrão do desenvolvimento (Poulin et al., 2001). 
Cerca de $70 \%$ de todos os invertebrados marinhos apresenta desenvolvimento pelágico e, ao que parece, esse padrão de reprodução tem evidentes vantagens. Segundo Barnes et al. (2001), estas podem ser devido a:

1. Exploração de recursos alimentares temporários providos pela floração de fitoplâncton.

2. Colonização de novos habitats.

3. Expansão da distribuição geográfica.

4. Evitar uma catástrofe associada com a falta do habitat adequado.

5. Evitar o mesmo local do adulto e competição intra-específica.

6. Exposição de diversas desovas para o máximo grau de diversidade do habitat.

De acordo com Thorson (1950), os invertebrados de altas latitudes apresentariam desenvolvimento direto e ausência de larvas pelágicas para permitir o sucesso reprodutivo em condições ambientais críticas e imprevisíveis e os limitados períodos de produção de fitoplâncton em conexão com temperaturas de água muito baixas. E, ainda, a dominância de desenvolvimento não pelágico no Ártico e Antártica seria também funcional para a região de mar profundo, a terceira grande região nos mares com baixas temperaturas e condições alimentares pobres.

$\mathrm{O}$ argumento desse, agora clássico, artigo foi mais tarde desenvolvido (Thorson, 1950) e então ampliado por Mileikovsky (1971) que designou a tendência de evitar estágios pelágicos larvais como a "Lei de Thorson". Entretanto, os dados da própria "Lei de Thorson" sugerem que evitar a larva pelágica é uma tendência e não uma regra (Clarke, 1992).

Os estudos mais recentes têm mostrado evidências de que as idéias de Thorson não devem ser generalizadas para todas as espécies antárticas e têm gerado controvérsias entre os pesquisadores. Uma relação de espécies bentônicas antárticas com larvas pelágicas planctotróficas ou lecitotróficas foi apresentada por Pearse et al. (1991), assim como foram registrados estágios larvais de ascídias, decápodes e cirripédios (Foster, 1987) e equinodermos (Pearse et al., 1991; Pearse, 1994) no Estreito de McMurdo, bem como larvas de gastrópodes (Absher et al., 2003) e larvas de invertebrados pelágicos (Freire et al., 2006) na Baía do Almirantado, Ilha Rei George. 
Arntz et al. (1994) estimam que o número de espécies com desenvolvimento indireto, particularmente com larvas planctotróficas, é relativamente menor do que quando comparado ao número total de espécies bentônicas antárticas. Esses autores sugerem que as espécies de águas rasas, citadas por Pearse et al. (1991), seriam exceções à "Lei de Thorson". Shreeve \& Peck (1995), por outro lado, sugerem que os resultados obtidos no Mar de Bellingshausen, somado aos dados para equinodermos de Bosch \& Pearse (1990) e Pearse (1994) no Estreito de McMurdo, são contrários às idéias de Thorson. A proporção de espécies de equinodermos com larvas pelágicas em relação às espécies com desenvolvimento direto é a mesma na Antártica e em região temperada da costa da Califórnia. No Mar de Bellingshausen, as larvas de sete filos diferentes ocorreram predominantemente em regiões costeiras, e Shreeve \& Peck (1995) acreditam que estudos em áreas costeiras rasas, sob o gelo ou próximas do gelo, podem revelar um número muito maior de organismos com desenvolvimento indireto.

Entretanto, as abundâncias dos picos larvais em áreas polares são estimadas ser 2 a 6 ordens de magnitude menores, quando comparadas às abundâncias de zonas temperadas (Stanwell-Smith et al., 1999; Arntz \& Gili, 2001). As baixas abundâncias são explicadas pelo transporte das larvas sob grandes escalas temporais devido à redução da sincronia de desova e à lenta razão de desenvolvimento das larvas (StanwellSmith et al., 1999).

No entanto, uma importante característica ecológica notada por Thorson (1950) foi a tendência dessas poucas espécies polares que se reproduzem por larva pelágica serem as mais abundantes. A correlação entre desenvolvimento larval pelágico e alta abundância em invertebrados polares também foi observada em águas antárticas (Clarke, 1992), onde muitas das espécies mais comuns e numericamente abundantes têm larva pelágica (Stanwell-Smith et al., 1999).

Trabalhos sobre o meroplâncton na Antártica nos últimos 25 anos mostraram que há alta diversidade e abundância de formas larvais de invertebrados marinhos bentônicos (Foster, 1987; Shreeve \& Peck, 1995; Bhaud et al., 1999; Stanwell-Smith et al., 1999; Absher et al., 2003; Thatje et al., 2003; Sewell, 2005; Freire et al., 2006; Sewell, 2006; Vázquez et al., 2007).

As comunidades bentônicas são das mais ricas e de maior biomassa dos ecossistemas antárticos, um paradoxo quando se considera a produção primária local, baixa e restrita ao final da primavera e começo do verão. A ausência de uma variação 
batimétrica de temperatura com relevância biológica faz com que a maioria das espécies bentônicas apresente um padrão de distribuição muito amplo, com várias espécies mais características de menores profundidades atingindo até 500 a $1000 \mathrm{~m}$ de profundidade (Arntz et al., 1994). Apesar disso, é na zona costeira rasa (<20 m de profundidade) que a distribuição é mais complexa, apresentando não apenas um nítido padrão de zonação vertical (Bromberg et al., 2000), mas também um complexo padrão de distribuição em manchas (Nonato et al., 2000; Bromberg, 2004). Primariamente, os padrões de distribuição são gerados por fatores físicos, especialmente, o efeito do gelo. Este pode se expressar no congelamento da região entre marés, no congelamento do fundo através de "anchor-ice" e do impacto de "icebergs" junto ao fundo, evidenciado por suas cicatrizes, perturbando ou mesmo defaunando as comunidades bentônicas e criando um mosaico de comunidades em diferentes estágios de sucessão (Dayton et al., 1974; Gutt, 2000). Processos biológicos são mais efetivos na estruturação de comunidades de maiores profundidades onde o efeito físico do gelo é menor. O ambiente mais profundo é mais estável e menos afetado por impactos físicos do que os ambientes mais rasos (Arntz et al., 1994).

Vários autores concordam com a alta diversidade da fauna bentônica antártica, cuja composição e abundância dependem primariamente da qualidade do sedimento (Jazdzewski \& Sicinski, 1993). A comunidade bentônica da Enseada Martel, na Ilha Rei George, tem sido objeto de estudos ecológicos desde 1990 (Wägele \& Brito, 1990; Skowronski et al., 1998; Bromberg et al., 2000; Nonato et al., 2000; Skowronski \& Corbisier, 2002) e, esses estudos também corroboram os altos valores de densidade e biomassa de bentos na zona costeira rasa (Corbisier et al., 2004).

Segundo Clarke \& Johnston (2003), a fauna de Bivalvia e Gastropoda da Antártica é provavelmente a melhor descrita entre os grupos de invertebrados marinhos bentônicos. Quanto à reprodução, a incubação é assumida como característica comum para bivalves antárticos, embora isto tenha sido descrito para relativamente poucas espécies. Interessante é que justamente as três espécies de bivalves mais abundantes no Estreito de McMurdo (Adamussium colbecki, Laternula elliptica e Limatula hodgsoni) têm estágios de desenvolvimento pelágico. As demais, que excedem 60 espécies de bivalves, são caracterizadas por desenvolvimento não-planctônico (Pearse et al., 1986). Na Baía do Almirantado, a distribuição e abundância de larvas pelágicas de gastrópodes 
bentônicos foram associadas com picos de produção primária no fim de janeiro e fevereiro, em três períodos de verão consecutivos (Absher et al., 2003).

Dentre o grupo Polychaeta, são conhecidas mais de 800 espécies (Knox \& Lowry, 1977), sendo bem possível que na Antártica ocorram mais de 1000 espécies. As estratégias reprodutivas descritas são bastante variáveis no grupo. Quando, no desenvolvimento, há produção de larvas pelágicas, Fetzer (2004) encontrou-as dentro da área de distribuição dos adultos, que geralmente mostram desova permanente na coluna de água. A hidrografia local pareceu ter pouco efeito sobre o deslocamento deste tipo de larva. Entretanto, Scheltema et al. (1997) descreveram as larvas desse grupo com habilidade de dispersão passiva por longas distâncias e também capacidade para atrasar o assentamento. Ao que parece, a variedade e complexidade de características do ciclo de vida refletem na ecologia dessas larvas.

Exemplares do Filo Echinodermata são coletados em quase todas as expedições biológicas na Antártica, sendo grandes e conspícuos e, geralmente, bem descritos (Clarke \& Johnston, 2003). Alguns dos equinodermos mais abundantes em McMurdo também produzem larva pelágica planctotrófica (Odontaster validus, O. meridionalis, Porania antarctica, Sterechinus neumayeri e Ophionotus victoriae). Estas espécies são abundantes em águas rasas ao redor do continente antártico, mas são mal representadas em águas subantárticas, sendo portanto espécies antárticas típicas (Pearse, 1994). A disponibilidade de alimento e a predação durante a fase pelágica não parecem ser fatores decisivos para a sobrevivência das larvas para as estrelas do mar Odontaster validus e O. meridionalis, as quais desovam suas larvas no inverno (Stanwell-Smith \& Peck, 1998).

A espécie Parborlasia corrugatus (Filo Nemertea), extremamente comum em águas rasas da Antártica, é um grande predador e saprófago (Gibson, 1983). Larvas pilidium de $P$. corrugatus são presentes durante todo o ano em águas ao redor da Antártica (Pearse \& Bosch, 1986; Pearse et al., 1991; Rogers et al., 1998), o que leva a supor que sua reprodução seja contínua.

Apesar de todos os trabalhos citados, o número de larvas pelágicas e, particularmente, de larvas planctotróficas descritas é ainda muito pequeno em relação ao número total de espécies bentônicas na Antártica, como comentado mais anteriormente. 
Em termos espaciais, o número e os tipos larvais diminuem com a distância da costa e da cobertura de gelo marinho permanente (Shreeve \& Peck, 1995).

Em relação à densidade do meroplâncton, a variação da salinidade e temperatura na coluna de água devido à água de degelo e descarga de rios, representa uma barreira física para a maioria das larvas, como foi observado por Fetzer (2004).

Além disso, a variação sazonal na radiação solar, disponibilidade de luz, temperatura da água e cobertura de gelo são reconhecidos como fatores que podem levar à alta variabilidade na produção primária, tendo um grande impacto sobre a abundância e distribuição da fauna pelágica (Kaufmann et al., 2003). Uma maior concentração de fitoplâncton provê estoque de alimento necessário para o sucesso reprodutivo e sobrevivência larval (Marrari et al., 2008). Por outro lado, a presença de diversos estágios de desenvolvimento larval de uma determinada espécie dentro de um curto período de tempo e em uma região onde o desenvolvimento tende a ser lento, sugere que a reprodução ocorra durante um longo período e que a larva tem uma longa fase planctônica (Shreeve \& Peck, 1995).

A dispersão dos organismos do meroplâncton depende da distribuição dos adultos e da hidrodinâmica predominante (Pedrotti \& Fenaux, 1992). Sewell (2006) acrescenta ainda que a sua distribuição é influenciada pelas diferenças nas condições hidrográficas. A hidrologia local pode criar condições desfavoráveis para o deslocamento das larvas e pode contribuir para a retenção do meroplâncton em áreas de desova (Scheltema, 1988).

A maioria das larvas dos invertebrados, especialmente aquelas dependentes de cílios para propulsão, deslocam-se muito mais lentamente do que as correntes horizontais (Mileikovsky, 1973; Chia et al., 1984; Young, 1995). Por isso, é comum assumir que a dispersão dessas larvas tem relação direta ao fluxo das correntes, sendo que as larvas são transportadas pelas correntes oceânicas como partículas passivas (Shanks et al., 2003). A dispersão de algumas larvas é consistente com essa hipótese, enquanto outros tipos de larvas exercem algum controle sobre a sua dispersão (Shanks et al., 2003). Alguns estudos sugerem que estas últimas larvas podem regular sua distribuição vertical e, portanto, influenciar sua dispersão horizontal através de afundamento ou natação. Entretanto, o quanto essas larvas podem influenciar esse transporte na coluna de água até o assentamento não está esclarecido (Shanks et al., 2002). 
A estratificação vertical do meroplâncton também pode resultar de mecanismos físicos (temperatura, salinidade, mistura de massas de água) e/ou biológicos (alimento, predação) (Garland et al., 2002).

Na Baía do Almirantado, com o início do verão austral (novembro a março), inicia-se o suprimento das larvas ou juvenis provenientes da coluna de água ou do sedimento de regiões adjacentes (Freire et al., 2006).

Em termos gerais, o meroplâncton coletado na Baía do Almirantado é qualitativamente similar ao descrito em outras partes da Antártica por Shreeve \& Peck (1995), Stanwell-Smith et al. (1999), Sewell (2005; 2006) e Vázquez et al. (2007).

O presente estudo descreve a distribuição vertical e horizontal das larvas de invertebrados marinhos bentônicos da Baía do Almirantado, Antártica e as suas relações com as condições hidrográficas. 
Com o objetivo de ampliar as observações prévias, no presente estudo investigou-se a ocorrência e abundância de larvas de invertebrados marinhos bentônicos em áreas costeiras da Baía do Almirantado, Antártica, e a sua variação espaço-temporal em relação a variáveis ambientais.

Os dados obtidos foram utilizados para testar as seguintes hipóteses:

i. Ocorre variação espacial elou temporal na densidade e diversidade de larvas na região costeira da Baía do Almirantado;

ii. A comunidade meroplanctônica difere quanto à densidade e diversidade em relação à profundidade da coluna de água;

iii. Os padrões de abundância e distribuição larval estão relacionados com variáveis oceanográficas.

Para testar as hipóteses foram propostos os seguintes objetivos específicos:

- Analisar a ocorrência e abundância das larvas de invertebrados bentônicos marinhos espacialmente na Baía do Almirantado e em períodos sazonais entre outubro de 2002 a maio de 2003 e outubro de 2003 a agosto de 2004;

- Investigar possíveis variações na abundância e diversidade larval em função da profundidade;

- Correlacionar a abundância e distribuição larval com variáveis oceanográficas, tais como temperatura, salinidade, transparência da água, concentração de clorofila $a$, profundidade local e velocidade do vento. 
A Ilha Rei George é a maior do Arquipélago Shetlands do Sul, localizado a noroeste da Península Antártica (Figura 01). Está situada na zona de transição entre o clima Antártico e sub-Antártico, embora as características são predominantes de condições Antárticas (Bitanja, 1995).

A Baía do Almirantado está localizada no setor central da Ilha Rei George $\left(62^{\circ} 08^{\prime} \mathrm{S} ; 58^{\circ} 27^{\prime} \mathrm{W}\right)$ e abriga uma superfície líquida de cerca de $122 \mathrm{~km}^{2}$ (Figura 02). Com uma profundidade máxima de $530 \mathrm{~m}$ e um volume de água estimado em $24 \mathrm{~km}^{3}$, esta baía possui três enseadas principais, Martel, Mackellar e Ezcurra. A entrada da baía está orientada para o sul-sudeste e comunica-se com o Estreito de Bransfield através de um canal de $500 \mathrm{~m}$ de profundidade. O comprimento da linha de costa é de aproximadamente $85 \mathrm{~km}$, sendo um pouco mais da metade ocupada por glaciares (Rakusa-Suszcewski, 1995). Uma secção transversal na área central da baía configura o formato em "U”, típico das regiões de fiordes (Lipski, 1987).

Estudos realizados por Pruszak (1980) indicam que os ventos oeste e norte, quando predominantes, fazem com que as águas superficiais sejam levadas para fora da baía em direção ao Estreito de Bransfield. Em contrapartida, ocorre o influxo de águas profundas do estreito para o interior da mesma, predominantemente por sua margem sudoeste (Absher et al., 2003). Os padrões de circulação de água superficial foram descritos por Pruszak (1980) e nos primeiros $100 \mathrm{~m}$ a camada de água apresenta correntes com velocidade de 0,3 a 1,0 m.s ${ }^{-1}$. De acordo com este modelo, o vento ao atingir a velocidade de 4,0 m.s. $\mathrm{s}^{-1}$ tem uma grande influência nos movimentos da camada de água superficial, até uma profundidade de $30 \mathrm{~m}$.

As marés são semidiurnas com desigualdades diurnas, com uma variação máxima de 2,5 m. O regime de marés e ventos propicia o transporte de larvas e interação com as águas do Estreito de Bransfield. Ressurgências frequentes, distintas camadas de água proveniente de degelo e uma mistura vertical de toda a coluna d'água são típicas da Baía do Almirantado (Rakusa-Suszczewski,1995).

A temperatura e a salinidade da água são relativamente estáveis ao longo da baía, com valores médios de $0^{\circ} \mathrm{C}$ e 33 , respectivamente. Essas variáveis ambientais parecem estar relacionadas diretamente às águas da Convergência Antártica que 
circulam pelo Estreito de Bransfield, e cujos gradientes oceânicos estão presentes na Enseada Martel, com amplitudes similares e relativamente estáveis (Jazdewski et al., 1986).

A zona costeira ao redor da Antártica é caracterizada por uma marcada sazonalidade na produção de fitoplâncton. Os níveis de clorofila podem exceder 30 $\mathrm{mg} \cdot \mathrm{m}^{-3}$ no verão, mas são muito baixos no inverno quando a presença de gelo marinho estabiliza a coluna de água e muito do material particulado assenta (Clarke, 1992).

Brandini \& Rebello (1994) relacionaram as variações temporais na concentração de clorofila em um período de verão com mudanças no regime de ventos e hidrografia na Baía do Almirantado. Embora a turbulência limite a abundância de fitoplâncton em águas abertas na Antártica, ela pode ter um efeito positivo em ambientes costeiros pelágicos devido ao aumento da concentração de microfitobentos ressuspendido.

No período de verão, as concentrações médias de clorofila aumentam de dezembro a fevereiro. Tal fato pode estar relacionado a eventos de ressurgência que ocorrem em janeiro devido à troca de água da Baía do Almirantado com o Estreito de Bransfield em função da maior intensidade dos ventos. A forte turbulência ressuspende diatomáceas bentônicas do sedimento em regiões mais internas da baía e, após o cessar dos ventos fortes durante as duas primeiras semanas de fevereiro, a clorofila acumula-se na coluna d'água (Brandini \& Rebello, 1994).

$\mathrm{Na}$ Baía do Almirantado, as concentrações de nutrientes e suas variações sazonais são mais influenciadas por processos hidrodinâmicos (relacionados às marés e a fatores meteorológicos) dentro da baía do que pelos processos biológicos associados à produção primária (Rakusa-Suszczewski,1995). 


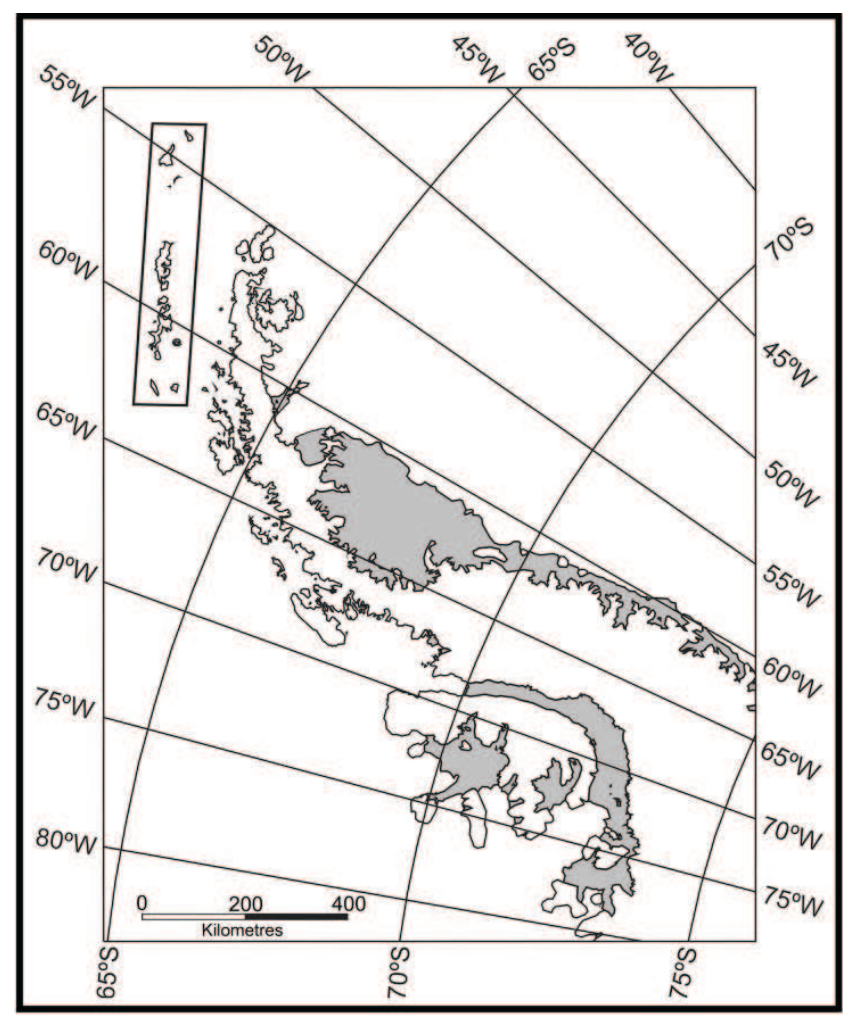

Figura 01. Península Antártica e as Ilhas Shetlands do Sul (em destaque) (Simões et al., 2004).

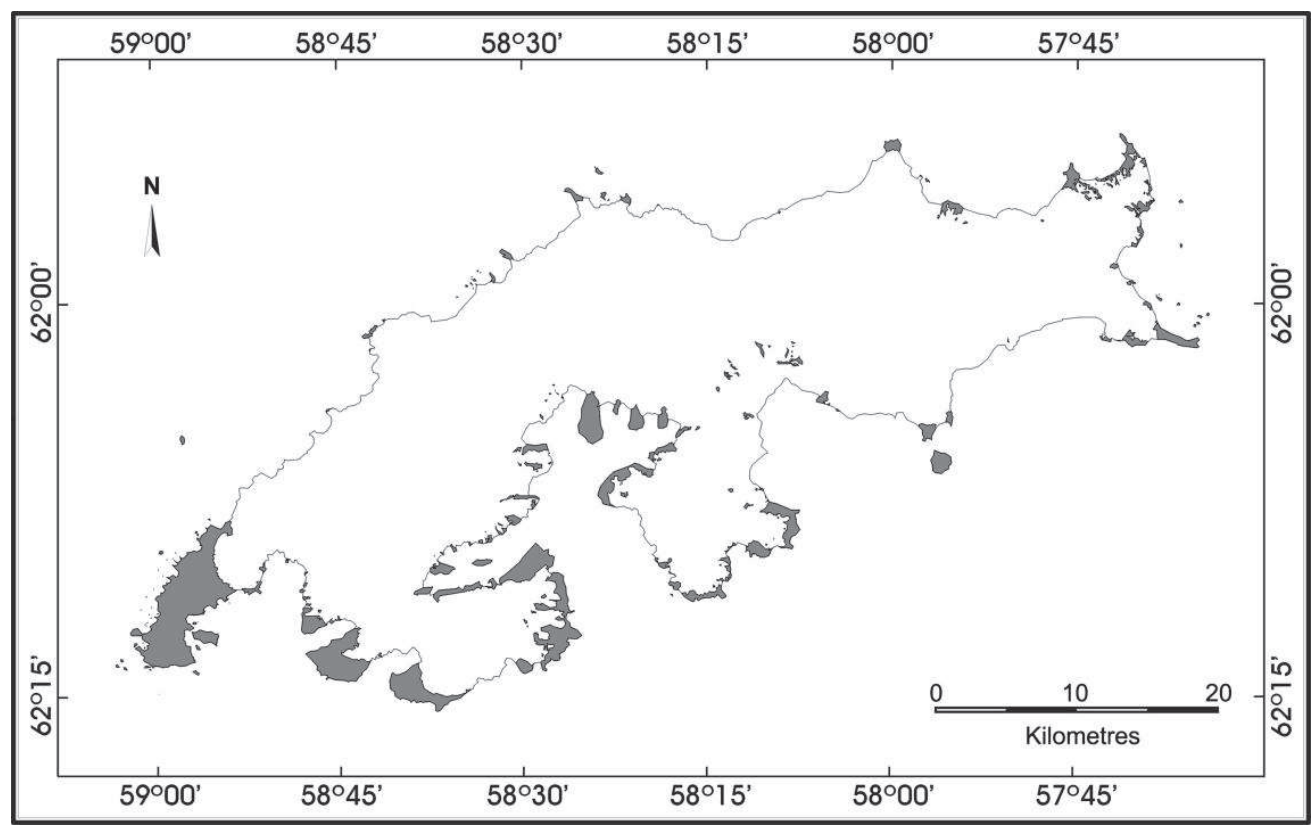

Figura 02. Ilha Rei George (Simões et al., 2004). 


\section{REFERÊNCIAS BIBLIOGRÁFICAS}

Absher, T.M.; Boehs, G.; Feijó, A.R. \& Cruz, A.C. 2003. Pelagic larvae of benthic gastropods from shallow Antarctic waters of Admiralty Bay, King George Island. Polar Biol., 26(6): 359-364.

Arntz, W.E.; Brey, T. \& Gallardo, V.A. 1994. Antarctic Zoobenthos. Oceanogr. Mar. Biol. Annu. Rev., 32: 241-304.

Arntz, W.E. \& Gili, J.M. 2001. A Case for Tolerance in Marine Ecology: Let Us Not Put out the Baby with the Bathwater. Scientia Mar., 65(Suppl. 2): 283-299.

Barnes, R.S.K.; Calow, P.; Olive, P.J.W.; Golding, D.W. \& Spicer, J.I. 2001. The Invertebrates: a synthesis. Oxford, Blackwell Science, 507p.

Bhaud, M.; Koubbi, P.; Razouls, S.; Tachon, O. \& Accornero, A. 1999. Description of planktonic polychaete larvae from Terre Adélie and the Ross Sea (Antarctica). Polar Biol., 22: 329-340.

Bitanja, R. 1995. The local surface energy balance of the Ecology Glacier, King George Island, Antarctica: measurements and modelling. Antarct. Sci., 7(3): 315-325.

Bosch, I. \& Pearse, J.S. 1990. Developmental types of shallow water asteroids of McMurdo Sound, Antarctica. Mar. Biol., 104: 41-46.

Brandini, F.P. \& Rebello, J. 1994. Wind effect on hydrography and chlorophyll dynamics in the coastal pelagial of Admiralty Bay, King George Island, Antarctica. Antarct. Sci., 6(4): 433-442.

Bromberg, S. 2004. A macrofauna bentônica da zona costeira rasa e o seu papel na trama trófica da enseada Martel, Baía do Almirantado (Ilha Rei George, Antártica). Ênfase para o grupo Polychaeta (Annelida). Tese de Doutorado, Universidade de São Paulo, Instituto Oceanográfico, 240p.

Bromberg, S.; Nonato, E.F.; Corbisier, T.N.; Petti, M.A.V. 2000. Polychaete distribution of the near shore zone of Martel Inlet, Admiralty Bay (King George Island, Antarctica). Bull. Mar. Sci., 67(1): 175-188.

Chia, F.S.; Buckland-Nicks, J. \& Young, C.M. 1984. Locomotion of marine invertebrate larvae: a review. Can. J. Zool., 62: 1205-1222. 
Clarke, A. 1992. Reproduction in the Cold: Thorson Revisited. Invertebr. Reprod. Dev., 22: $175-184$.

Clarke, A. \& Johnston, N.M. 2003. Antarctic Marine Benthic Diversity. Oceanogr. Mar. Biol. Annu. Rev., 41: 47-114.

Corbisier, T.N.; Petti, M.A.V.; Skowronski, R.S.P. \& Brito, T.A.S. 2004. Trophic relationships in the nearshore zone of Martel Inlet (King George Island, Antarctica): $\delta 13 \mathrm{C}$ stable isotope analysis. Polar Biol., 27: 75-82.

Dayton, P.K.; Robilliard, G.A.; Paine, R.T. \& Dayton, L.B. 1974. Biological accomodation in the benthic community at McMurdo Sound, Antarctica. Ecol. Monog., 44: 105-128.

Fetzer, I. 2004. Reproduction strategies and distribution of larvae and juveniles of benthic soft-bottom invertebrates in the Kara Sea (Russian Artic). Tese de Doutorado, Universidade de Bremen, 242p.

Foster, B.A. 1987. Composition and abundance of zooplankton under the spring sea-ice of McMurdo Sound, Antarctica. Polar Biol., 8: 41-48.

Freire, A.S.; Absher, T.M.; Cruz-Kaled, A.C.; Kern, Y. \& Elbers, K.L. 2006. Seasonal variation of pelagic invertebrate larvae in the shallow Antarctic waters of Admiralty Bay (King George Island). Polar Biol., 29(4): 294-302.

Garland, E.D.; Zimmer, C.A. \& Lentz, S.J. 2002. Larval distributions in inner-shelf waters: the roles of wind-driven cross-shelf currents and diel vertical migrations. Limnol. Oceanogr., 47: 803-817.

Gibson, R. 1983. Antarctic nemerteans: the anatomy, distribution and biology of Parborlasia corrugatus (McIntosh, 1876) (Heteronemertea, Lineidae). Antarct. Res. Ser., 39: 289-316.

Gutt, J. 2000. Some "driving forces" structuring communities of the sublittoral Antarctic macrobenthos. Antarct. Sci., 72(3): 297-373.

Jazdzewski, K.; Jurasz, W.; Kittel, W.; Presler, E.; Presler, P. \& Sicinski, J. 1986. Abundance and biomass estimates of the benthic fauna in Admiralty Bay, King George Island, South Shetland Islands. Polar Biol., 6(1): 5-16. 
Jazdzewski, K. \& Sicinski, J. 1993. Zoobenthos. 12.1. General remarks. In: RakuzaSuszczewski, S. (ed). The maritime Antarctic coastal ecosystem of Admiralty Bay. Department of Antarctic Biology, Polish Academy of Science, Warsaw, 8395.

Kaufmann, R.S.; Fisher, E.C.; Gill, W.H.; Kingh, A.L.; Laubacher, M. \& Sullivan, B. 2003. Temporal patterns in the distribution, biomass and community structure of macrozooplankton and micronekton within Port Foster. Deception Island, Antarctica. Deep Sea Res. II, 50: 1765-1785.

Knox, G.A. \& Lowry, J.K. 1977. A comparison between the benthos of the Southern Ocean and the North Polar Ocean with special reference to the Amphipoda and the Polychaeta. In: Dunbar, M.J. (ed). Polar oceans. Arctic Institute of North America, Calgary, 423-462.

Lipski, M. 1987. Variations of physical conditions, nutrients and chlorophyll a contents in Admiralty Bay (King George Island,South Shetland Islands, 1979). Pol. Polar Res., 8: 307-332.

Marrari, M.; Daly, K.L. \& Hu, Chuanmin. 2008. Spatial and temporal variability of SeaWiFS chlorophyll- $\alpha$ distributions west of the Antarctic Peninsula: Implications for krill production. Deep-Sea Res. II, 55: 377-392.

Mileikovsky, S.A. 1971. Types of larval development in marine bottom invertebrates, their distribution and ecological significance: a reevaluation. Mar. Biol., 10: 193213.

Mileikovsky, S.A. 1973. Speed of active movement of pelagic larvae of marine bottom invertebrates and their ability to regulate their vertical position. Mar. Biol., 23: $11-17$.

Nonato, E.F.; Brito, T.A.S.; Paiva, P.C.; Petti, M.A.V. \& Corbisier, T.N. 2000. Benthic megafauna of the nearshore zone of Martel Inlet (King George Island, South Shetland Islands, Antarctica): depth zonation and underwater observations. Polar Biol., 23: 580-588.

Nybakken, J.W. 2001. Marine Biology: an ecological approach. São Francisco, Benjamin Cummings, 516p. 
Pearse, J.S. 1994. Cold-water echinoderms break “Thorson's Rule”. In: Young, C.M. \& Eckelbarger, K.J. (eds). Reproduction, larval biology and recruitment of the deepsea benthos. New York, Columbia University Press, 26-43.

Pearse, J.S. \& Bosch, I. 1986. Are the feeding larvae of the commonest antarctic asteroid really demersal? Bull. Mar. Sci., 39: 477-484.

Pearse, J.S.; Bosch, I.; Mcclintock, J.B.; Marinovic, B. \& Britton, R. 1986. Contrasting tempos of reproduction by shallow-water animals in McMurdo Sound, Antarctica. Antarct. J. US., 31: 182-184.

Pearse, J.S.; McClintock, J.B. \& Bosch, I. 1991. Reproduction of Antarctic benthic marine invertebrates: tempos, modes and timing. Am. Zool., 31: 65-80.

Pedrotti, L.S. \& Fenaux, L. 1992. Dispersal of echinoderm larvae in a geographical area marked by upwelling (Ligurian Sea, NW Mediterranean). Mar. Ecol. Prog. Ser., 86: 217-227.

Poulin, É.; Boletzky, S.V. \& Féral, J.P. 2001. Combined ecological factors permit classification of developmental patterns in benthic marine invertebrates: a discussion note. J. Exp. Mar. Biol. Ecol., 257: 109-115.

Pruszak, Z. 1980. Current circulation in the water of Admiralty Bay (region of Arctowski Station on King George Island). Pol. Polar Res., 1: 55-74.

Rakusa-Suszczewski, S. 1995. The hydrography of Admiralty Bay and its inlets, coves and lagoons (King George Island, Antarctica). Pol. Polar Res., 16: 61-70.

Rogers, A.D.; Clarke, A. \& Peck, L.S. 1998. Population genetics of the Antarctic heteronemertean Parborlasia corrugatus from the South Orkney Islands. Mar. Biol., 131: 1-13.

Scheltema, R.S. 1988. Initial evidence for the transport of teleplanic larvae of benthic invertebrates across the East Pacific barrier. Biol. Bull., 174: 145-152.

Scheltema, R.S. ; Blake, J.A. \& Williams, I.P. 1997. Planktonic larvae of Spionid and Chaetopterid polychaetes from off the West coast of the Antarctic Peninsula. Bull. Mar. Sci., 60(2): 396-404.

Sewell, M.A. 2005. Examination of the meroplankton community in the south-western Ross Sea, Antarctica, using a collapsible plankton net. Polar Biol., 28: 119-131. 
Sewell, M.A. 2006. The meroplankton community of the northern Ross Sea: a preliminary comparison with the McMurdo Sound region. Antarct. Sci., 18(4): 595-602.

Shanks, A.L.; Largier, J.; Brink, L.; Brubaker, J. \& Hooff, R. 2002. Observations on the distribution of meroplankton during a downwelling event and associated intrusion of the Chesapeake Bay estuarine plume. J. Plankton Res., 24: 319-416.

Shanks, A.L.; Largier, J. \& Brubaker, J. 2003. Observations on the distribution of meroplankton during an upwelling event. J. Plankton Res., 25: 645-667.

Shreeve, R.S. \& Peck, L.S. 1995. Distribution of pelagic larvae of benthic marine invertebrates in the Bellingshausen Sea. Polar Biol., 15: 369-374.

Simões, J.C.; Arigony-Neto, J. \& Bremer, U.F. 2004. O uso de mapas antárticos em publicações. Pesq. Antart. Bras., 4: 191-197.

Skowronski, R.S.P.; Corbisier, T.N. 2002. Meiofauna distribution in Martel Inlet, King George Island (Antarctica): sediment features versus food availability. Polar Biol., 25: 126-134.

Skowronski, R.S.P.; Corbisier, T.N. \& Robles, F.R. 1998. Meiofauna along a coastal transect in Admiralty Bay, King George Island (Antarctica). Pesq. Antart. Bras., 3: $117-132$.

Stanwell-Smith, D.P. \& Peck, L.S. 1998. Temperature and embryonic development in relation to spawning and field occurrence of larvae of 3 Antarctic echinoderms. Biol. Bull., 194: 44-52.

Stanwell-Smith, D.; Peck, L.S.; Clarke, A.; Murray, A.W.A. \& Todd, C.D. 1999. The distribution, abundance and seasonality of pelagic marine invertebrate larvae in the maritime Antarctic. Philos. Trans. R. Soc. London B, 354: 471-484.

Sumich, J.L. \& Morrissey, J.F. 2004. Introduction to the biology of marine life. Sudbury, Mass., US, Jones and Bartlett Publishers. 449p.

Thatje, S.; Schnack-Schiel, S. \& Arntz, W.E. 2003. Developmental trade-offs in subAntarctic meroplankton communities and the enigma of low decapod diversity in high southern latitudes. Mar. Ecol. Prog. Ser., 260: 195-207. 
Thorson, G. 1950. Reproduction and larval ecology of marine bottom invertebrates. Biol. Rev., 25: 1-45.

Vázquez, E.; Ameneiro, J.; Putzeys, S.; Gordo, C. \& Sangra, P. 2007. Distribution of meroplankton communities in the Bransfield Strait, Antarctica. Mar. Ecol. Prog. Ser., 338: 119-129.

Wägele, J.W. \& Brito, T.A.S. 1990. Die sublitorale fauna der maritimen Antarktis Erste unterwasserbeobachtungen in der Admiralitaetsbucht. Natur. Mus., 120: 269-282.

Young, C.M. 1995. Behavior and locomotion during the dispersal phase of larval life. In: McEdward, L.R. (ed). Ecology of Marine Invertebrate Larvae. Boca Raton, CRC Press, 249-278.

Young, C.M.; Sewell, M.A. \& Rice, M.E. 2006. Atlas of Marine Invertebrate Larvae. London, Academic Press. 646p. 
Capitulo I. VARiação espaço-temporal de laRvas de inVERTEbrados (EM profundidade até 30 metros) na Baía do Almirantado, Ilha Rei George, ANTÁRTICA (2002/2004).

\section{INTRODUÇÃO}

A história de vida da maioria das espécies de macroinvertebrados bentônicos envolve uma fase larval, a qual precede a metamorfose até a forma do adulto, exibindo um ciclo de vida bento-pelágico (Thorson, 1950; Mileikovsky, 1971; Pechenik, 1999). A ocorrência de larvas no mar depende do padrão temporal da reprodução e do padrão do ciclo de vida associados às variáveis ambientais.

Os resultados das primeiras expedições à Antártica mostraram uma escassez geral de larvas de invertebrados, fato que deu mais embasamento à proposta de Thorson (1950), conhecida como "Lei de Thorson", inicialmente formulada para as águas árticas (Shreeve \& Peck, 1995). De acordo com Thorson (1950), os invertebrados de altas latitudes têm desenvolvimento direto e ausência de larvas pelágicas para permitir o seu sucesso reprodutivo em condições ambientais críticas e imprevisíveis.

Relações de espécies bentônicas antárticas com larvas pelágicas planctotróficas ou lecitotróficas foram apresentadas na década de 1990 e evidenciaram que as idéias de Thorson não deveriam ser generalizadas para todas as espécies antárticas (Foster, 1987; Bosch \& Pearse, 1990; Pearse et al., 1991; Pearse, 1994; Shreeve \& Peck, 1995; Stanwell-Smith et al., 1999).

Para muitos dos grupos de invertebrados bentônicos, a proporção de espécies de águas rasas com desenvolvimento pelágico na Antártica é similar ao encontrado em qualquer outra região (Pearse et al., 1991). Stanwell-Smith et al. (1999) estimaram que o número total de espécies de invertebrados marinhos na Antártica que produzem larvas pelágicas era provavelmente entre 100-150, valores aproximados ao encontrado por Bowden et al. (2009), que estimaram um total de 99 espécies bentônicas com desenvolvimento indireto.

$\mathrm{Na}$ Antártica, alguns dos invertebrados marinhos bentônicos com desenvolvimento indireto são predominantes em regiões de águas rasas produtivas $(<30$ 
m), que são frequentemente perturbadas por formações de "anchor ice", e a produção de numerosas larvas pelágicas planctotróficas pode representar uma estratégia para a colonização dessas áreas (Pearse et al., 1991). Os distúrbios por ação de gelo na zona costeira rasa na Antártica favorecem espécies com mobilidade e aquelas com desenvolvimento pelágico larval. Modelos mostram que habitat instáveis favorecem espécies com alta capacidade de dispersão (como as com larvas planctônicas), mais aptas para a recolonização (Poulin et al., 2002).

Existem poucos trabalhos sobre a ecologia do zooplâncton em águas rasas costeiras ou baías da Antártica e, apenas em 1994, programas internacionais foram estabelecidos pelo Scientific Commitee on Antarctic Research (SCAR) para ampliar o conhecimento sobre a sua ecologia costeira e de plataforma continental. O conhecimento em águas rasas restringe-se aos estudos realizados na Baía do Almirantado, Ilha Rei George, em período de verão (listados em Absher et al., 2003; Freire et al., 1993; 2006), na Baía Prydz (76º $\left.68^{\circ} \mathrm{S}\right)$ (Hosie et al., 1997), na plataforma do Mar de Weddell (Boysen-Ennen \& Piatkowski, 1988) e do Mar de Ross e McMurdo (Sewell, 2005; 2006).

Na Baía do Almirantado foram registradas diferentes associações de espécies zooplanctônicas, no início e fim de verão, por Menshenina \& Rakusa-Suzczewski (1992), Freire et al. (1993; 2006) e Santos (1995). A variação da composição e abundância do zooplâncton entre o início e o fim do verão foi associada à diferença de temperatura e à disponibilidade de alimento e luz. Larvas de poliquetas ocorreram tanto no início como no fim do verão (Santos, 1995; Freire et al., 1993; 2006). Larvas de moluscos apresentaram variação temporal, ocorrendo em abundância no fim do verão e sendo quase ausentes no início do verão (Absher et al., 2003; Freire et al., 2006). Esses fatos sugerem que as larvas de invertebrados podem ser encontradas diferencialmente ao longo do verão, devido à variação de temperatura, aos padrões reprodutivos das espécies, às interações das larvas com os outros organismos planctônicos e à variação na quantidade e qualidade de recurso alimentar.

A maior variabilidade no número de larvas em águas costeiras na Antártica foi atribuída à sazonalidade, mais do que ao local ou profundidade (Stanwell-Smith et al., 1999). No entanto, a abundância de meroplâncton na Baía do Almirantado foi também variável dependendo da localização geográfica, além da época do ano (Freire et al., 2006). 
Embora a ocorrência de larvas planctotróficas tenda a ser sazonal, sua produção pode não estar diretamente relacionada com a floração de fitoplâncton no meio do verão na Antártica. Essas larvas não mostram nenhuma evidência de inanição e quando a abundância de fitoplâncton é muito baixa, elas podem "alimentar-se" de recursos menos comuns, como as bactérias (Pearse et al., 1991). Para espécies na região Antártica, a reprodução contínua parece ser comum (Pearse et al., 1991; Clarke, 1992). Então, esses recursos alternativos de alimento podem vir a ser explorados pelas larvas, como a matéria orgânica dissolvida, além das bactérias (Rivkin et al., 1991; Chiantore et al., 2002).

A perda de larvas parece ser controlada principalmente por dois fatores: o tempo despendido no plâncton, quando ficam expostas à predação, e/ou sua dependência do plâncton como recurso alimentar (Thorson, 1950). A duração da fase planctônica e a distância transportada dependem do período do desenvolvimento específico de cada espécie. O comprimento da fase larval dentro de uma mesma espécie pode variar em função de condições ambientais (Pearse et al., 1991) e é a duração no plâncton que determina a distância que a larva pode ser transportada (Mileikovsky, 1971).

Vázquez et al. (2007) relacionaram a presença das larvas meroplanctônicas com a profundidade e massas de água. Correntes podem aumentar a dispersão larval mas também criar barreiras físicas que limitam o transporte das larvas (Scheltema, 1986). Além disso, o deslocamento de larvas de um determinado local por correntes pode ser compensada pela entrada de larvas de populações adjacentes (Bowden et al., 2009).

Além disso, a variação sazonal na radiação solar, disponibilidade de luz, temperatura da água e cobertura de gelo, são conhecidos por resultar em alta variabilidade na produção primária e podem ter um grande impacto sobre a abundância e distribuição da fauna pelágica (Kaufmann et al., 2003).

Entretanto, a reprodução e o ciclo de vida de muitos invertebrados marinhos antárticos com larvas pelágicas não são necessariamente acoplados com a fase de floração do fitoplâncton no verão (Mincks et al., 2007). Segundo Bowden et al. (2009), a disponibilidade de alimento para os juvenis é o fator mais crítico na história de vida de invertebrados bentônicos de altas latitudes, quando comparada com o tempo de desova, o modo de desenvolvimento, e/ou a duração da fase larval propriamente dita. 
Estudos sobre as relações entre as condições oceanográficas na Antártica e a distribuição e abundância do meroplâncton são relativamente numerosos. Distintos padrões foram descritos na tentativa de explicar a variação da composição da comunidade meroplanctônica. Entretanto, aquela correlação e como atuam as variáveis ambientais não está evidente (Foster, 1987; Shreeve \& Peck, 1995; Bhaud et al., 1999; Stanwell-Smith et al., 1999; Absher et al., 2003; Thatje et al., 2003; Sewell, 2005; Freire et al., 2006; Sewell, 2006; Vázquez et al., 2007; Bowden et al., 2009).

São poucos os estudos sobre a distribuição sazonal e ocorrência de meroplâncton durante um ano na Antártica. Stanwell-Smith et al. (1999) na Ilha Signy e Bowden et al. (2009) na Baía Ryder são os únicos trabalhos que estudaram a comunidade meroplanctônica ao longo de um ciclo anual. A escassez de investigação é provavelmente uma consequência de problemas inerentes à amostragem e identificação.

O presente estudo investiga as mudanças temporais na ocorrência, abundância e composição de larvas pelágicas de invertebrados marinhos bentônicos em áreas rasas da Baía do Almirantado, Antártica, entre outubro de 2002 e maio de 2003, e de outubro de 2003 a agosto de 2004. 
Neste estudo, teve-se como objetivo estudar a ocorrência e abundância de larvas de invertebrados marinhos bentônicos em áreas costeiras da Baía do Almirantado, Antártica, e a sua variação temporal num período bianual, em relação a variáveis ambientais na camada da coluna de água até $30 \mathrm{~m}$.

As hipóteses que foram consideradas neste trabalho são:

1. Há variação espaço-temporal na abundância de larvas de invertebrados marinhos bentônicos na Baía do Almirantado?

2. Se existe variação, essa variação está relacionada com que variáveis oceanográficas? 


\section{MATERIAIS E MÉtOdOS}

As coletas na Baía do Almirantado foram realizadas em 12 estações rasas ( 0 a $15 \mathrm{~m}$ ou até $30 \mathrm{~m}$ ) (Figura 03) (Tabela I), sazonalmente. A lancha oceanográfica SKUA e um bote inflável foram utilizados para o deslocamento e amostragens.

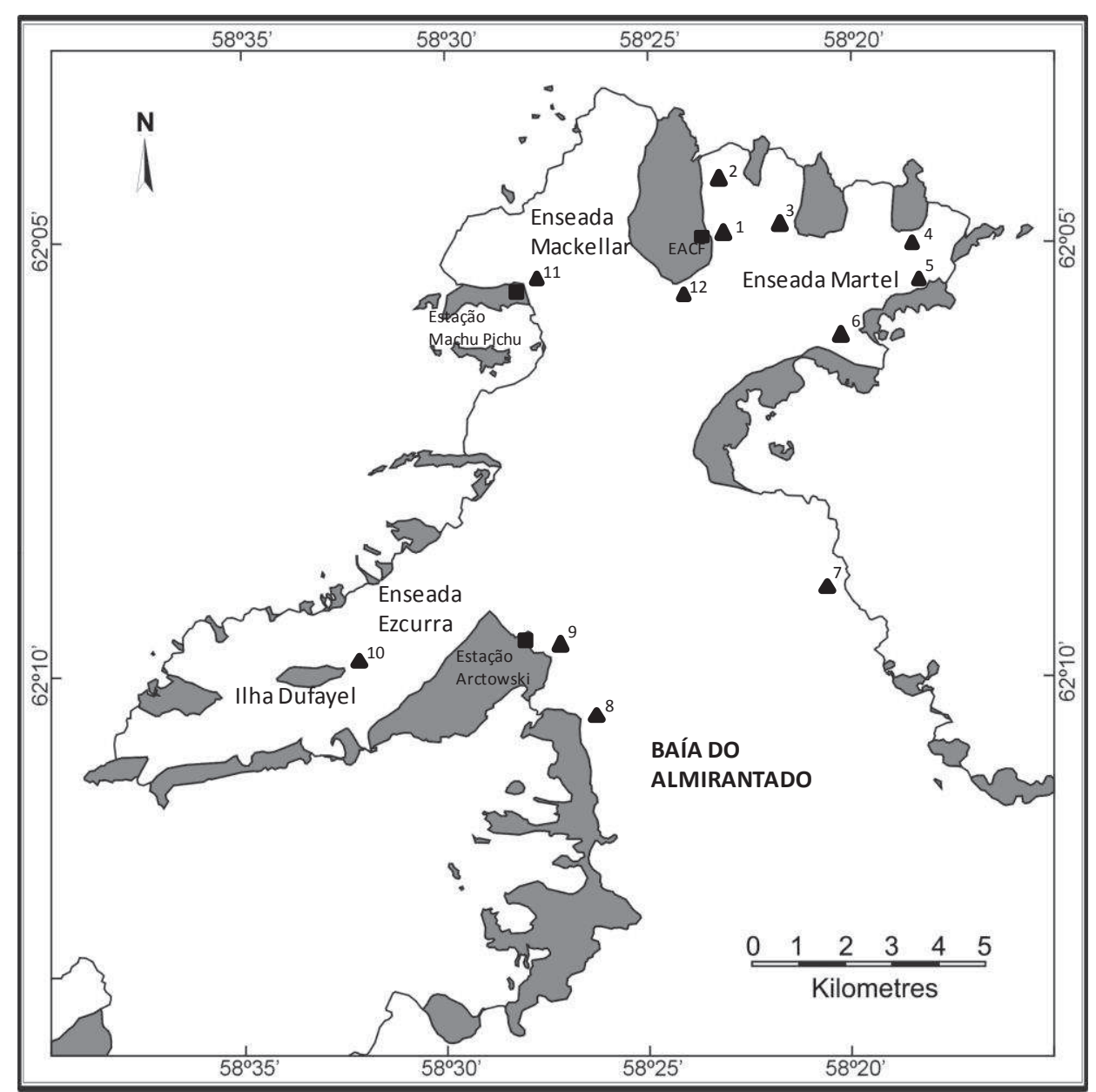

Figura 03. Baía do Almirantado com as estações e áreas de coleta. Adaptado de Simões et al., 2004. 
Tabela I. Coordenadas geográficas das estações e áreas amostradas da Baía do Almirantado, Ilha Rei George, Antártica.

\begin{tabular}{|c|c|c|}
\hline ESTAÇÃO & COORDENADA & ÁREA \\
\hline 1. Ferraz & $\begin{array}{c}62^{\circ} 05,097^{\prime} \mathrm{S} \\
58^{\circ} 23,211^{\prime} \mathrm{W}\end{array}$ & \multirow{6}{*}{ Martel } \\
\hline 2. Yellow Point & $\begin{array}{c}62^{\circ} 04,237^{\prime} \mathrm{S} \\
58^{\circ} 23,159^{\prime} \mathrm{W}\end{array}$ & \\
\hline 3. Stenhouse & $\begin{array}{c}62^{\circ} 04,525^{\prime} \mathrm{S} \\
58^{\circ} 22,075^{\prime} \mathrm{W}\end{array}$ & \\
\hline 4. Punta Ullman & $\begin{array}{c}62^{\circ} 05,006^{\prime} \mathrm{S} \\
58^{\circ} 20,447^{\prime} \mathrm{W}\end{array}$ & \\
\hline 5. Precious Point & $\begin{array}{c}62^{\circ} 04,928^{\prime} \mathrm{S} \\
58^{\circ} 18,428^{\prime} \mathrm{W}\end{array}$ & \\
\hline 6. Lussish & $\begin{array}{c}62^{\circ} 06,158^{\prime} \mathrm{S} \\
58^{\circ} 19,703^{\prime} \mathrm{W}\end{array}$ & \\
\hline 7. Vieville & $\begin{array}{c}62^{\circ} 08,717^{\prime} \mathrm{S} \\
58^{\circ} 20,077^{\prime} \mathrm{W}\end{array}$ & \multirow{3}{*}{$\begin{array}{c}\text { Entrada da Baía do } \\
\text { Almirantado }\end{array}$} \\
\hline 8. Sphinx & $\begin{array}{c}62^{\circ} 11,059^{\prime} \mathrm{S} \\
58^{\circ} 25,442^{\prime} \mathrm{W}\end{array}$ & \\
\hline 9. Arctowski & $\begin{array}{c}62^{\circ} 09,862^{\prime} \mathrm{S} \\
58^{\circ} 27,072^{\prime} \mathrm{W}\end{array}$ & \\
\hline 10. Dufayel & $\begin{array}{c}62^{\circ} 09,876^{\prime} \mathrm{S} \\
58^{\circ} 32,354^{\prime} \mathrm{W}\end{array}$ & Ezcurra \\
\hline 11. Machu Pichu & $\begin{array}{c}62^{\circ} 05,369^{\prime} \mathrm{S} \\
58^{\circ} 27,845^{\prime} \mathrm{W}\end{array}$ & \multirow{2}{*}{ Mackellar } \\
\hline 12. Punta Plaza & $\begin{array}{c}62^{\circ} 05,572^{\prime} \mathrm{S} \\
58^{\circ} 24,686^{\prime} \mathrm{W}\end{array}$ & \\
\hline
\end{tabular}

Para o estudo da comunidade meroplânctonica, foram consideradas para as análises 384 amostras coletadas na XXI Operação Antártica Brasileira (OAB) (2002/2003) e XXII OAB (2003/2004) nas estações.

As amostragens tiveram periodicidade mensal entre outubro de 2002 e maio de 2003, e de outubro de 2003 a agosto de 2004. Este trabalho faz parte do projeto: "Interação plâncton-bentos - Estudos de diferentes ciclos de vida de invertebrados marinhos com larvas pelágicas, bênticas ou desenvolvimento direto" (CNPq processo 680044/00-0); coordenado pela Profa Dra Theresinha Monteiro Absher da Universidade Federal do Paraná - Centro de Estudos do Mar. 


\section{AMOSTRAGEM NAS ESTAÇÕES:}

Em cada uma das 12 estações foram realizados dois arrastos oblíquos consecutivos do fundo, em profundidade de até $30 \mathrm{~m}$, variando conforme a profundidade local, com rede cônica de plâncton com diâmetro da boca de $60 \mathrm{~cm}$ e malha de $150 \mu \mathrm{m}$, provida de fluxômetro. Nas coletas, a rede foi lançada próximo ao fundo com a embarcação parada e arrastada a uma velocidade aproximada de dois nós, durante cinco minutos, em período diurno. Essas coletas foram realizadas com o mesmo método de Freire et al. (1993; 2006) e Absher et al. (2003) com a finalidade de comparação dos resultados.

\section{TRATAMENTO DAS AMOSTRAS:}

As amostras, obtidas após cada arrasto, foram fixadas em formaldeído a 4\% neutralizado com tetraborato de sódio e acondicionadas em frascos plásticos etiquetados para posterior triagem, identificação e quantificação. A triagem e a identificação das larvas meroplanctônicas foram feitas sob microscópio estereoscópico da Marca Nikon (com aumento de 60 a 100 vezes) no Laboratório de Bentos Antártico do Instituto Oceanográfico/USP.

As larvas foram classificadas segundo os critérios de Smith (1977), Todd et al. (1996), Stanwell-Smith et al. (1997), Boltovskoy (1999) e Young (2006).

\section{VARIÁVEIS AMBIENTAIS:}

Concomitantemente à coleta das amostras de plâncton, foram mensuradas as seguintes variáveis ambientais: temperatura e salinidade da água de superfície, a $15 \mathrm{~m}$ e a $30 \mathrm{~m}$ de profundidade; transparência da água; velocidade do vento, e anotada a fase da maré. Foi utilizado um termômetro simples de coluna de mercúrio para medir a temperatura e um refratômetro da marca Atago (escala de 1/100) para o registro da salinidade da água coletada com garrafa de Van Dorn. Foram utilizado um disco de Secchi de cor branca com $25 \mathrm{~cm}$ de diâmetro para a medida a transparência da água e um anemômetro eletrônico portátil para avaliação da velocidade do vento.

Para a determinação da concentração de clorofila $a$ e feopigmentos foram obtidas amostras da água da superfície, a $15 \mathrm{~m}$ e a $30 \mathrm{~m}$ de profundidade, com uma 
garrafa de Van Dorn. As amostras de água de cerca de dois litros foram acondicionadas em garrafas plásticas e armazenadas em sacos plásticos pretos para o transporte até o laboratório de Biologia II da Estação Antártica Comandante Ferraz (EACF), onde foram filtradas em bomba a vácuo, usando-se filtros Whatman GF/C. Os filtros foram congelados e estocados para posterior extração e processamento pelo método de Strickland \& Parsons (1968) nos Laboratórios do Centro de Estudos do Mar da Universidade Federal do Paraná (CEM/UFPR).

\section{TRATAMENTO DOS DADOS:}

Visando uma melhor interpretação dos dados, os períodos do ano foram agrupados e denominados da seguinte maneira:

Período 1: outubro de 2002 - Primavera de 2002 (Pv02);

Período 2: dezembro de 2002 e janeiro de 2003 - Verão de 2003 (Ve03);

Período 3: março a maio de 2003 - Outono de 2003 (Ot03);

Período 4: outubro e novembro de 2003 - Primavera de 2003 (Pv03);

Período 5: dezembro de 2003 a fevereiro de 2004 - Verão de 2004 (Ve04);

Período 6: março a maio de 2004 - Outono de 2004 (Ot04);

Período 7: junho e agosto de 2004 - Inverno de 2004 (Iv04)

As estações de coleta também foram agrupadas em áreas para uma melhor interpretação dos resultados:

Área Martel: Estações 1 à 6 (MT);

Área Mackellar: Estações 11 e 12 (ML);

Área Ezcurra: Estação 10 (EZ);

Entrada da Baía do Almirantado: Estações 7 à 9 (EBA)

Os dados de abundância das larvas obtidos com a triagem e identificação, foram expressos de acordo com o volume de água filtrada em cada arrasto, determinado 
através da seguinte equação:

$\mathrm{V}=\pi^{*} \mathrm{r} 2 * \mathrm{~F}^{*} \Delta$ rotação, onde:

$\mathrm{r}=$ raio da rede $(0,30 \mathrm{~m})$;

$\mathrm{F}=$ fator de aferição do fluxômetro $(0,6566)$;

$\Delta$ rotação $=$ diferença entre número de rotação inicial e final do fluxômetro em cada arrasto.

O volume médio calculado foi de $112,3 \mathrm{~m}^{3}$. Para calcular a densidade larval, padronizada em indivíduos. $100 \mathrm{~m}^{-3}$, dividiu-se o número de indivíduos identificado pelo volume do respectivo arrasto, multiplicando-se por 100.

A densidade total do número de larvas de invertebrados foi comparada entre as áreas (considerando todo o período) e entre os períodos amostrados (considerando todas as áreas) através de análises de variância (ANOVA TWO-WAY), com nível de significância de $\alpha=0,05$ (Zar, 1996), bem como os dados referentes às variáveis ambientais e a concentração de clorofila $a$ e feopigmentos (entre as áreas e períodos amostrados). O teste de comparações múltiplas do tipo LSD foi empregado a posteriori para avaliar as diferenças (Zar, 1996).

Para comparar as áreas de coleta nos períodos do ano, quanto às variáveis ambientais, foi utilizada a análise multivariada de ordenação do tipo PCA (análise de componentes principais) (Legendre \& Legendre, 1983; Valentin, 2000), com a utilização das médias das áreas de coleta por período do ano. As variáveis ambientais foram padronizadas $(x-\bar{x} / \mathrm{DP})$ para essa análise.

Análise de agrupamento das áreas de coleta, por período do ano, quanto à composição do meroplâncton foi realizada com o índice de Bray-Curtis, com os dados de densidade transformados por $\log (\mathrm{x}+1)$ e utilização do método da média ponderada. Foi aplicado o teste SIMPROF para verificar os grupos significantes (Clarke \& Warwick, 2001).

Diferenças na composição do meroplâncton entre áreas de coleta e períodos do ano também foram analisadas por meio da análise de ordenação multidimensional não métrica (nMDS) a partir de matrizes de similaridade com a utilização do índice de BrayCurtis (Clarke \& Warwick, 2001). Os dados referentes ao número de larvas de 
invertebrados foram transformados para escala logarítmica por $\log (\mathrm{x}+1)$. Os grupos formados na análise de agrupamento foram sobrepostos ao diagrama do nMDS.

Para as análises de variância foi utilizado o programa Statistica, Versão 7.0, e para as análises multivariadas (PCA e nMDS) o software PRIMER, Versão 6.1 (Clarke \& Gorley, 2006). 


\section{RESULTADOS}

\section{VARIÁVEIS AMBIENTAIS:}

A temperatura média da água do mar variou entre $-2,5^{\circ} \mathrm{C}$ no mês de outubro de 2002 na estação 7, localizada na entrada na Baía do Almirantado, em Vieville, e $+2,25^{\circ} \mathrm{C}$ na estação 10 (Enseada Ezcurra), no mês de janeiro de 2003 (Figura 04). A variação da temperatura foi similar, durante o período, em todas as estações de coleta.

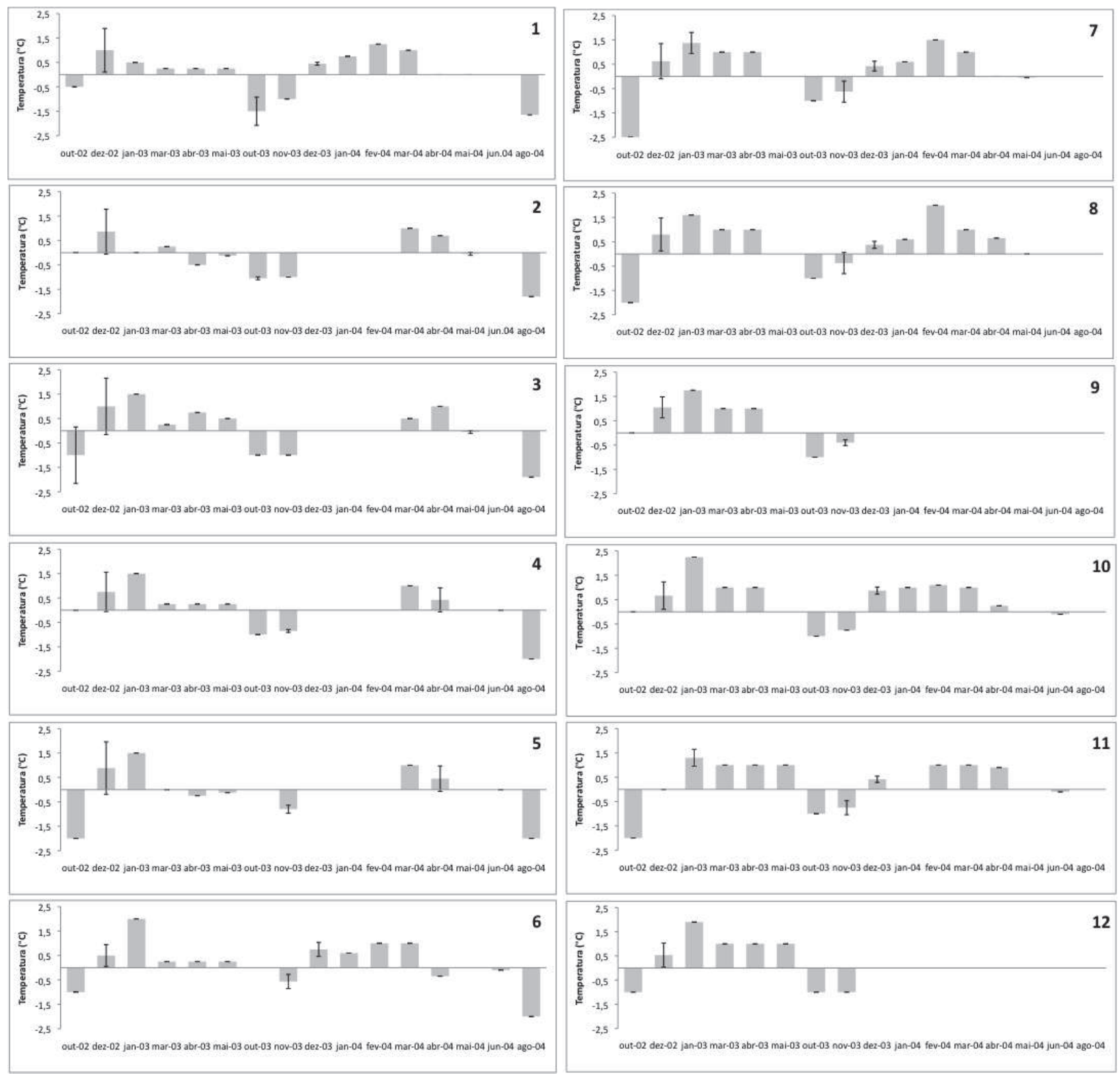

Figura 04. Variação temporal da temperatura média da água do mar $\left({ }^{\circ} \mathrm{C}\right)$ nas estações de coleta ( $\bar{x} \pm$ DP). Outubro de 2002 a agosto de 2004. Baía do Almirantado. 
A temperatura média da água ( \pm desvio padrão) variou entre $-1,5{ }^{\circ} \mathrm{C}$ na primavera de 2002 nas estações localizadas na Enseada Mackellar $( \pm 0,57)$ e na entrada da Baía do Almirantado $( \pm 1,18)$ e $+1,0^{\circ} \mathrm{C}$ no verão de 2003 nas estações localizadas na Enseada Ezcurra $( \pm 0,87)$ e na entrada da Baía do Almirantado $( \pm 0,60)$.

A análise de variância mostrou diferença significativa entre os períodos $\operatorname{amostrados}(F=84,42 ; p<0,001)$; entre as áreas amostradas $(F=9,48 ; p<0,001)$ e também na interação entre períodos e áreas $(F=3,47 ; \mathrm{p}<0,001)$. O teste LSD mostrou semelhança entre os meses de verão (2003 e 2004) e outono (2003 e 2004); e entre os de primavera (2002 e 2003) e inverno de 2004 (Figura 05).

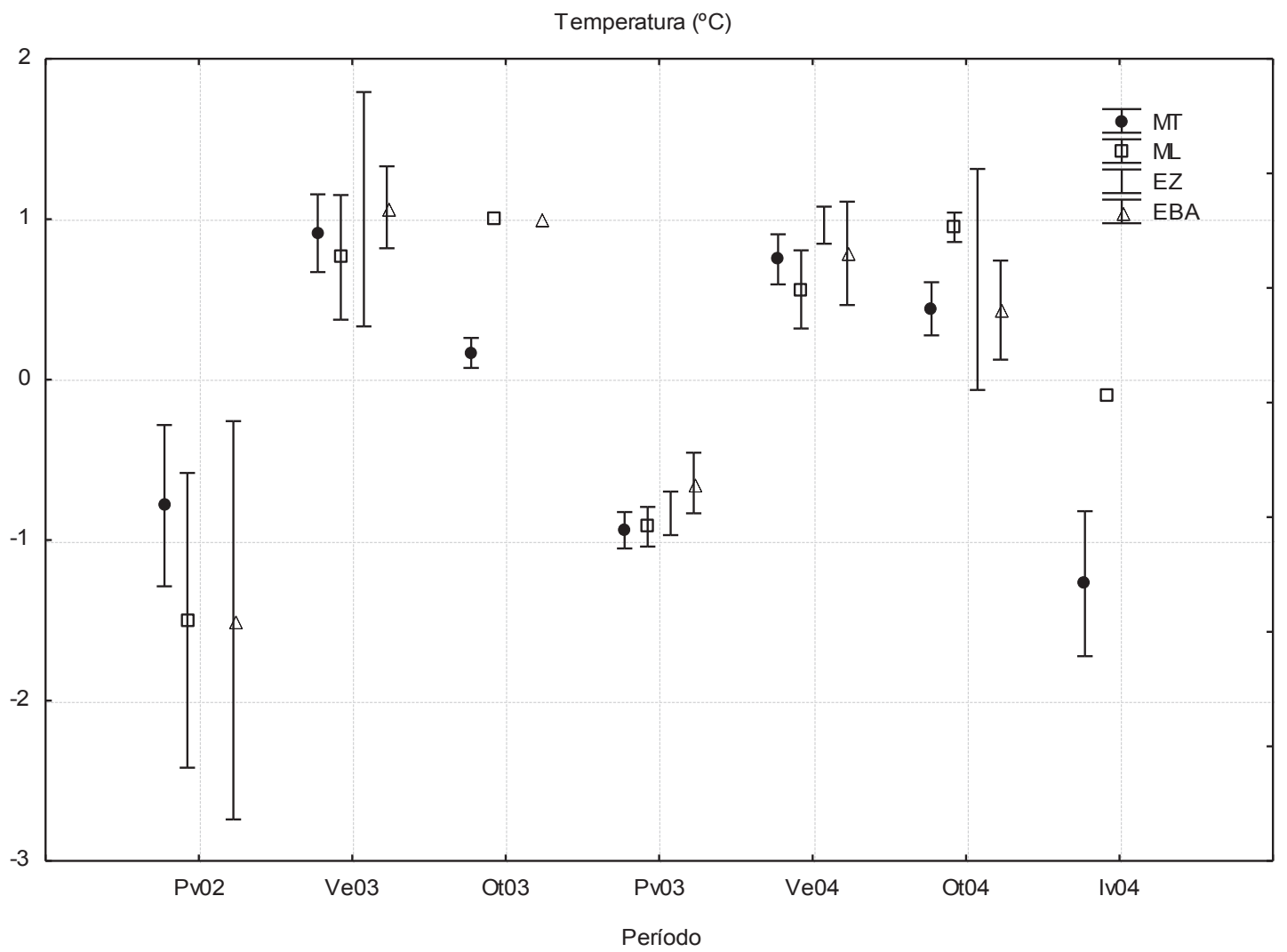

Figura 05. Variação espaço-temporal da temperatura média da água do mar $\left({ }^{\circ} \mathrm{C}\right)(\bar{x} \pm$ IC). Primavera de 2002 a Inverno de 2004. Baía do Almirantado. MT=Área Martel; $\mathrm{ML}=$ Área Mackellar; EZ $=$ Área Ezcurra; EBA $=$ Área da entrada da baía. Pv02= Primavera de 2002; Ve03= Verão de 2003; Ot03= Outono de 2003; Pv03= Primavera de 2003; Ve04= Verão de 2004; Ot04= Outono de 2004; Iv04= Inverno de 2004. 
A salinidade média da água do mar variou entre 30 no mês de março de 2004 na estação 6, localizada na Enseada Martel, e, 39 na estação também localizada na Enseada Martel, Precious Point (5) no mês de outubro de 2002 (Figura 06).
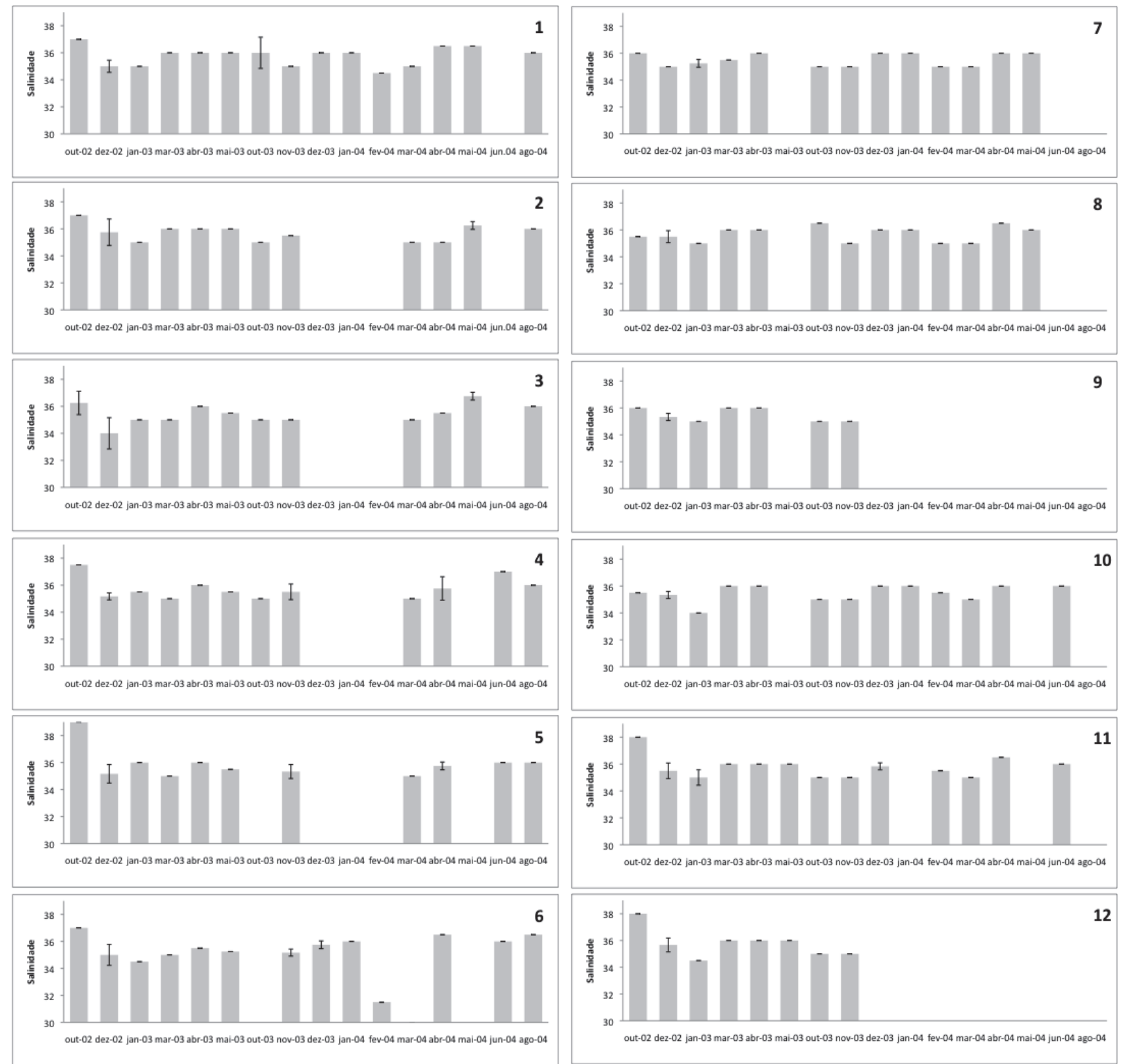

Figura 06. Variação temporal da salinidade média da água do mar nas estações de coleta ( $\bar{x} \pm$ DP). Outubro de 2002 a agosto de 2004. Baía do Almirantado. 
A salinidade média da água ( \pm desvio padrão) durante o período amostrado variou entre 35 nos meses do verão de $2003( \pm 0,65)$ e primavera de 2003 nas Enseada Ezcurra $( \pm 0,26)$ e Mackellar $( \pm 0,23)$, e $38( \pm 0,62)$ na primavera de 2002 na Enseada Mackellar. Houve variação significativa entre os períodos amostrados ( $\mathrm{F}=14,71$; $\mathrm{p}<0,001)$ e também a interação entre períodos e áreas $(\mathrm{F}=2,37 ; \mathrm{p}<0,001)$. Por outro lado, quando analisada a variação entre as áreas, não houve diferença significativa $(F=2,67 ; p=0,07)$. $O$ teste LSD mostrou diferença significativa entre a primavera de 2002, área Martel e Mackellar e os demais locais e períodos (Figura 07).

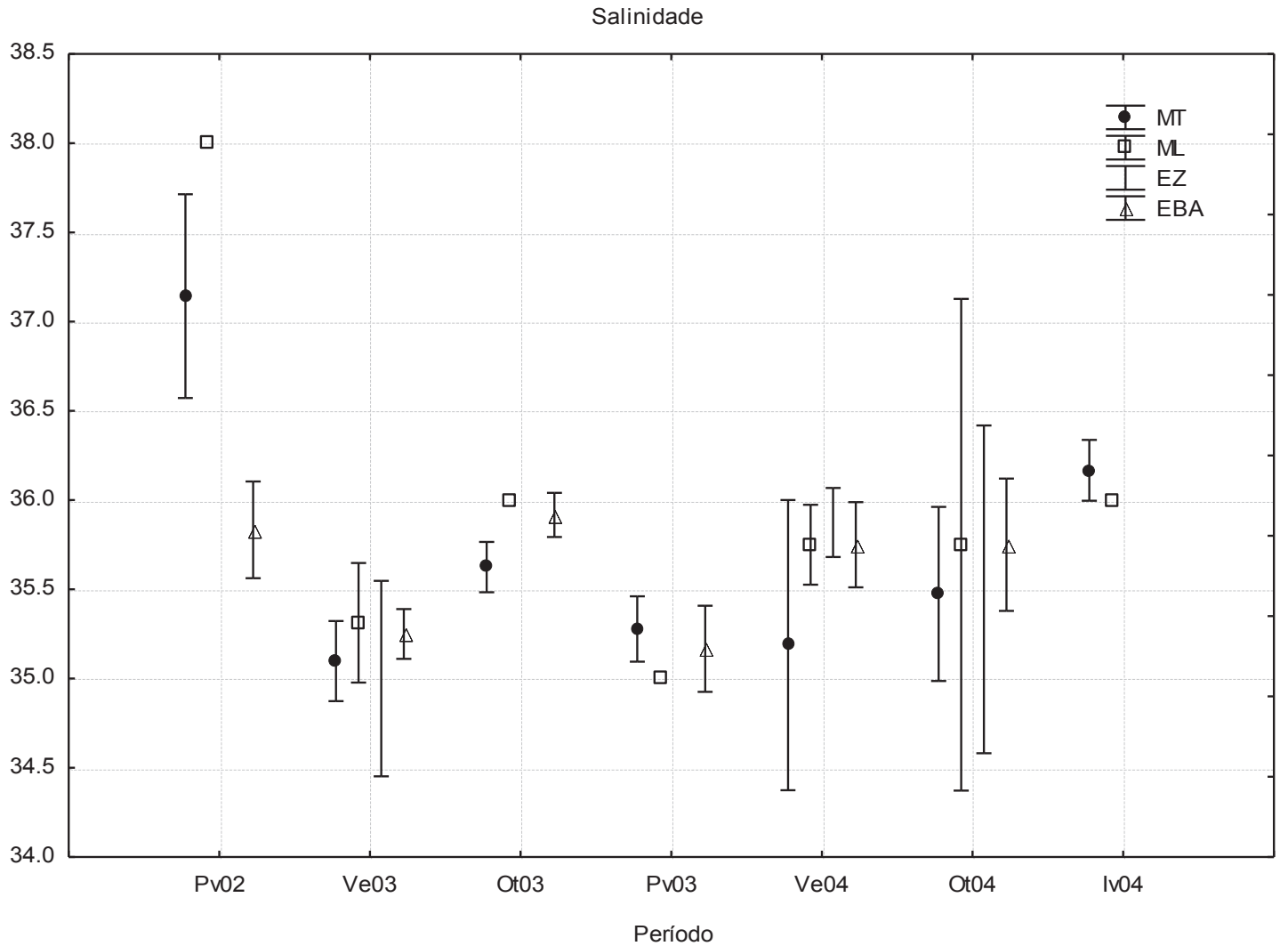

Figura 07. Variação espaço-temporal da salinidade média da água do $\operatorname{mar}(\bar{x} \pm \mathrm{IC})$. Primavera de 2002 a Inverno de 2004. Baía do Almirantado. MT=Área Martel; $\mathrm{ML}=$ Área Mackellar; EZ $=$ Área Ezcurra; EBA = Área da entrada da baía. Pv02= Primavera de 2002; Ve03= Verão de 2003; Ot03= Outono de 2003; Pv03= Primavera de 2003; Ve04= Verão de 2004; Ot04= Outono de 2004; Iv04= Inverno de 2004. 
A velocidade média do vento variou entre sem vento $\left(0 \mathrm{~m} \cdot \mathrm{s}^{-1}\right)$ em diversas estações amostradas durante o período e velocidade máxima de $20 \mathrm{~m} \cdot \mathrm{s}^{-1}$ nas estações Vieville (7) e Sphinx (8), localizadas na entrada da baía, no mês de outubro de 2002 (Figura 08). É preciso considerar que esses dados foram pontuais, referentes à hora da coleta.
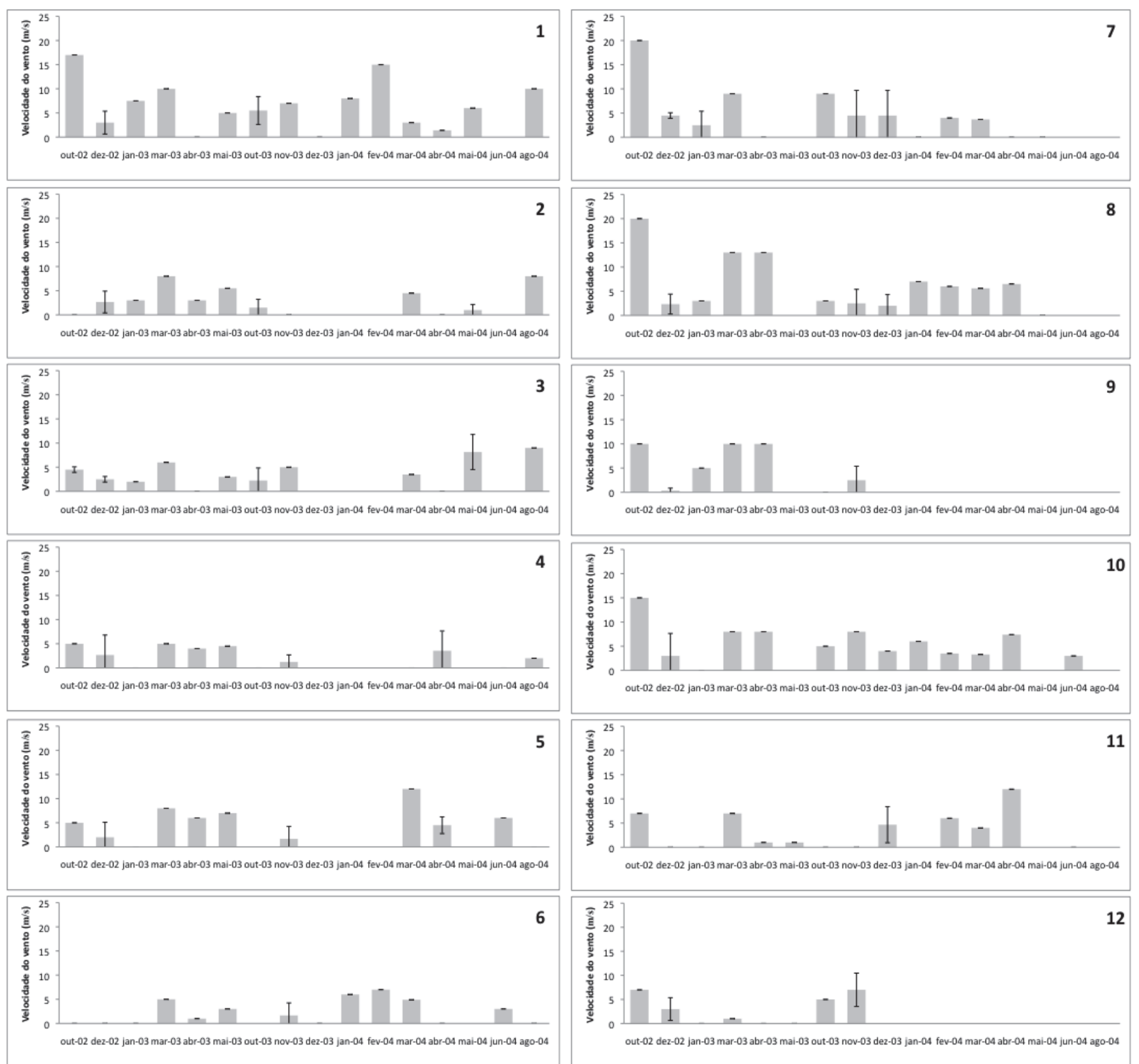

Figura 08. Variação temporal da velocidade média do vento $\left(\mathrm{m} \cdot \mathrm{s}^{-1}\right)$ nas estações de coleta ( $\bar{x} \pm$ DP). Outubro de 2002 a agosto de 2004. Baía do Almirantado. 
A velocidade média do vento ( \pm desvio padrão), quando analisadas a interação entre períodos e áreas, variou entre $0 \mathrm{~m} . \mathrm{s}^{-1}$ no inverno de $2004 \mathrm{e} 16,66 \mathrm{~m} . \mathrm{s}^{-1}( \pm 5,16)$ na primavera de 2002, nas estações localizadas no canal principal da entrada da baía. Houve variação significativa entre os períodos amostrados $(F=20,96 ; p<0,001)$, entre as áreas amostradas $(\mathrm{F}=7,13 ; \mathrm{p}<0,001)$, bem como a interação entre períodos e áreas $(\mathrm{F}=5,53 ; \mathrm{p}<0,001)$. $\mathrm{O}$ teste LSD mostrou semelhança entre a área Ezcurra e as estações localizadas na entrada da baia no período da primavera de 2002, com maiores velocidades de ventos (Figura 09).

Velocidade do Vento (m.s-1)

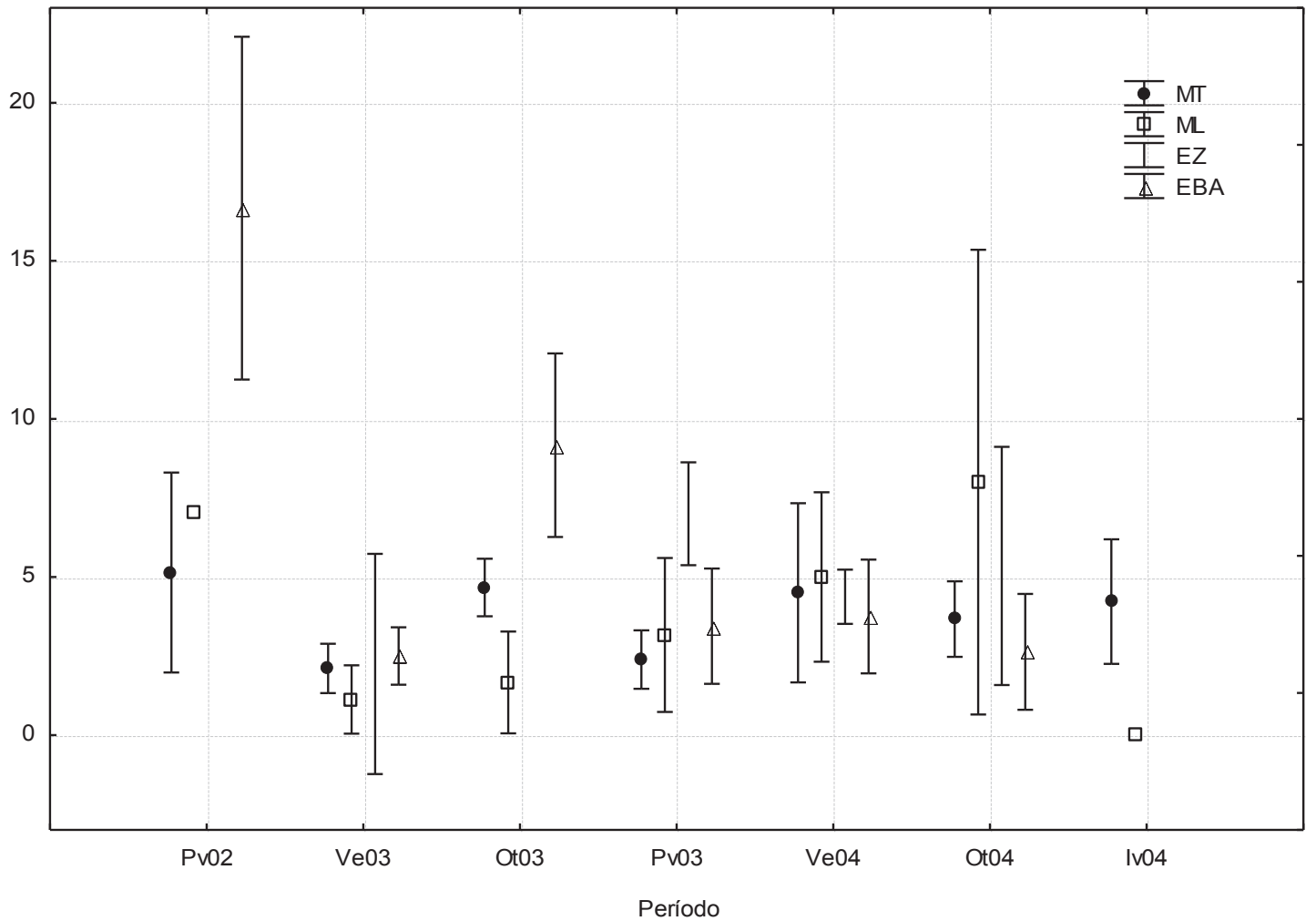

Figura 09. Variação espaço-temporal da velocidade média do vento $\left(\mathrm{m}^{-1} \mathrm{~s}^{-1}\right)(\bar{x} \pm \mathrm{IC})$. Primavera de 2002 a Inverno de 2004. Baía do Almirantado. MT=Área Martel; $\mathrm{ML}=$ Área Mackellar; EZ $=$ Área Ezcurra; EBA $=$ Área da entrada da baía. Pv02= Primavera de 2002; Ve03= Verão de 2003; Ot03= Outono de 2003; Pv03= Primavera de 2003; Ve04= Verão de 2004; Ot04= Outono de 2004; Iv04= Inverno de 2004. 
A transparência média da água variou entre $0,7 \mathrm{~m}$ na estação Lussich (6), localizada na Enseada Martel, no mês de março de 2004 e 31 m na estação Dufayel (10), na Enseada Ezcurra, no mês de outubro de 2002 (Figura 10).
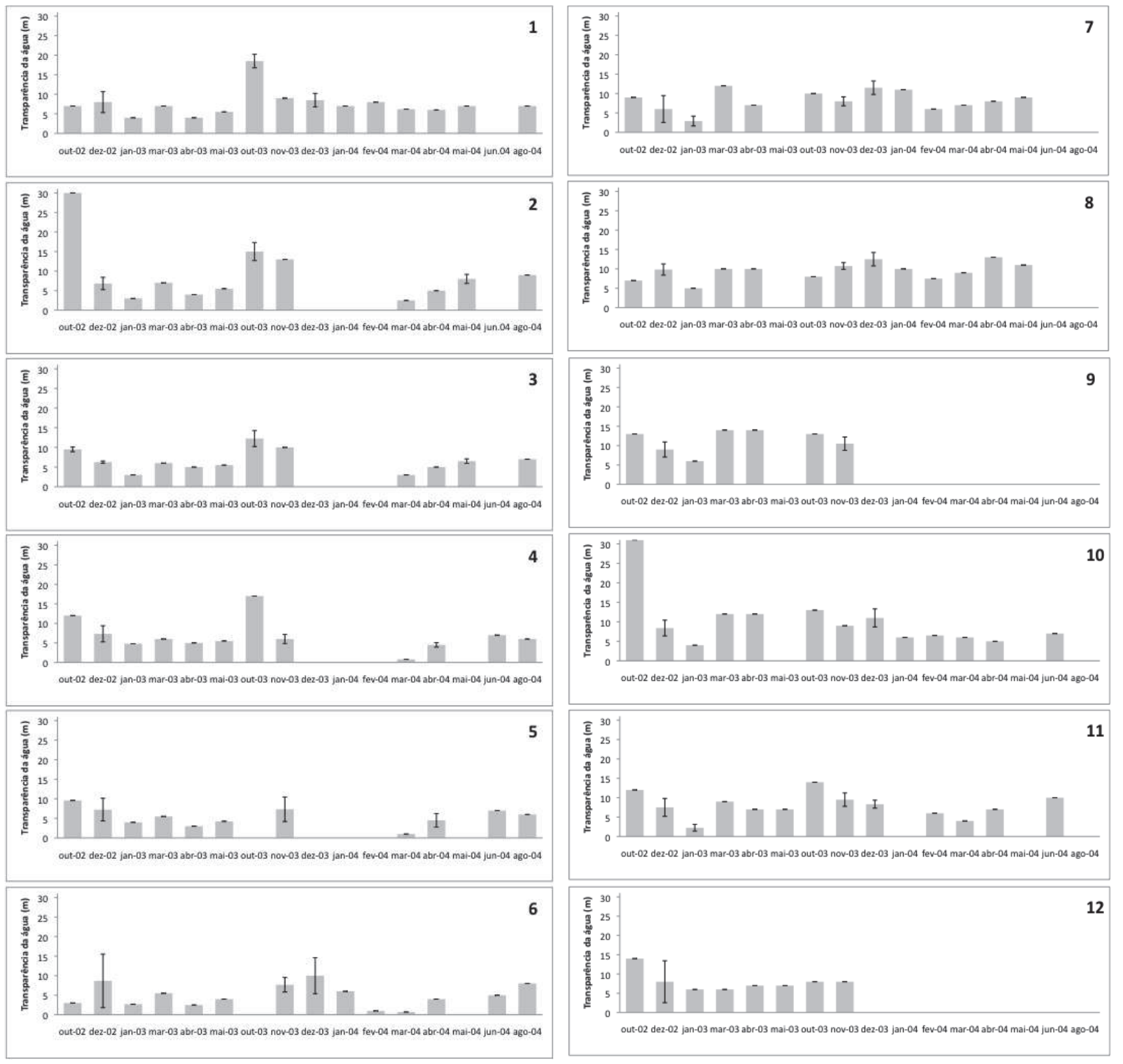

Figura 10. Variação temporal da transparência média da água (m) nas estações de coleta ( $\bar{x} \pm$ DP). Outubro de 2002 a agosto de 2004. Baía do Almirantado. 
A variável transparência da água diferiu significativamente entre os períodos amostrados $(\mathrm{F}=28,26 ; \mathrm{p}<0,001)$, entre as áreas $(\mathrm{F}=18,75 ; \mathrm{p}<0,001)$, e a interação entre períodos e áreas foi também significativa $(\mathrm{F}=6,85 ; \mathrm{p}<0,001)$ (Figura 11$)$, e o teste LSD indicou as estações localizadas na área Ezcurra, na primavera de 2002, com os maiores valores médios $(31 \mathrm{~m} ; \pm 2,65)$, diferindo das demais.

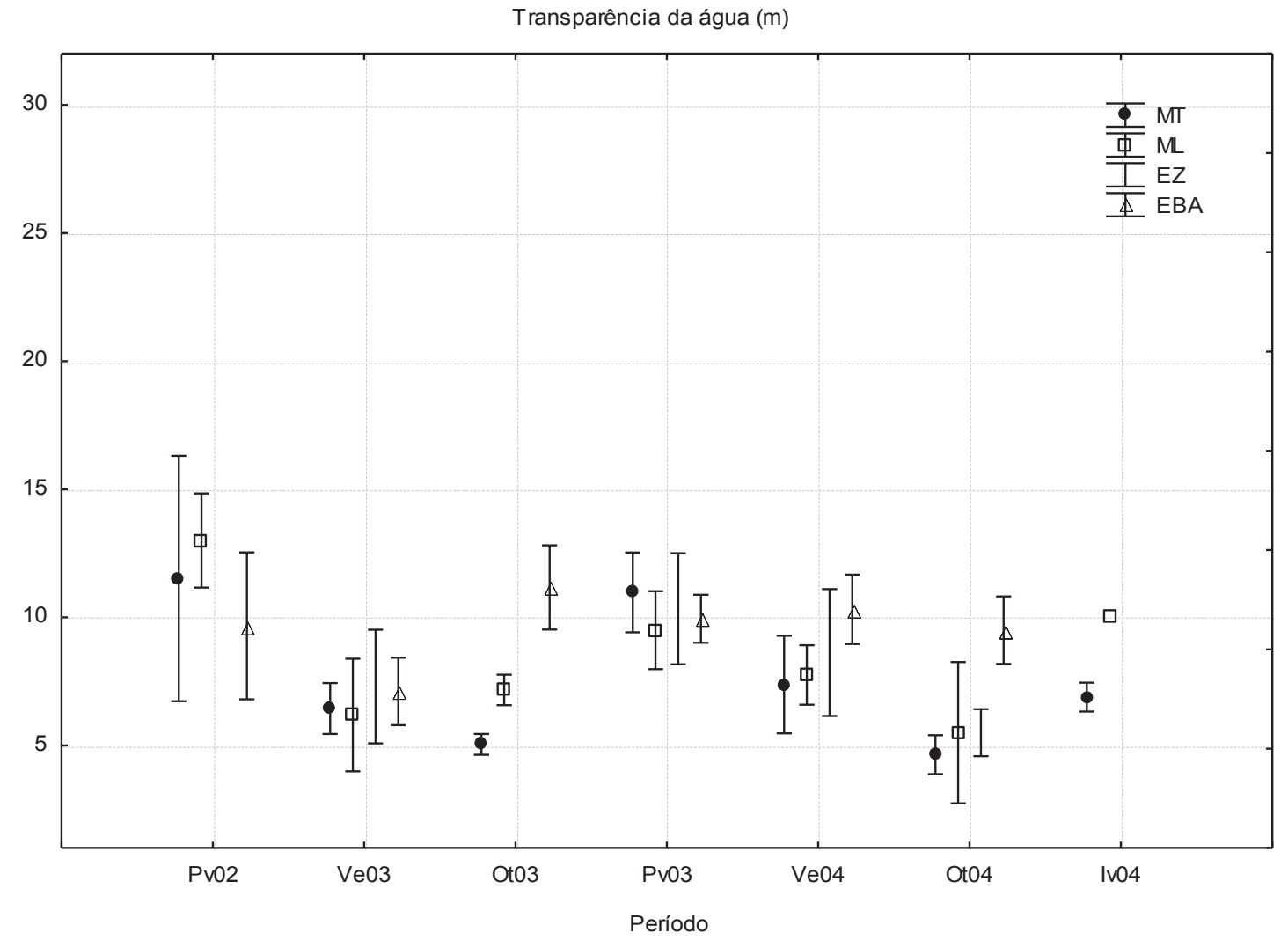

Figura 11. Variação espaço-temporal da transparência média da água (m) ( $\bar{x} \pm \mathrm{IC})$. Primavera de 2002 a Inverno de 2004. Baía do Almirantado. MT=Área Martel; ML= Área Mackellar; EZ= Área Ezcurra; EBA= Área da entrada da baía. Pv02= Primavera de 2002; Ve03= Verão de 2003; Ot03= Outono de 2003; Pv03= Primavera de 2003; Ve04= Verão de 2004; Ot04= Outono de 2004; Iv04= Inverno de 2004.

A concentração média de clorofila $a$ variou entre $0,011 \mu \mathrm{g} .1^{-1}$ no mês de outubro de 2002 na estação localizada em Punta Plaza (12) e 0,888 $\mu \mathrm{g} .1^{-1}$ no mês de fevereiro de 2004 na estação localizada na Enseada Mackellar, Machu Picchu (11) (Figura 12). 


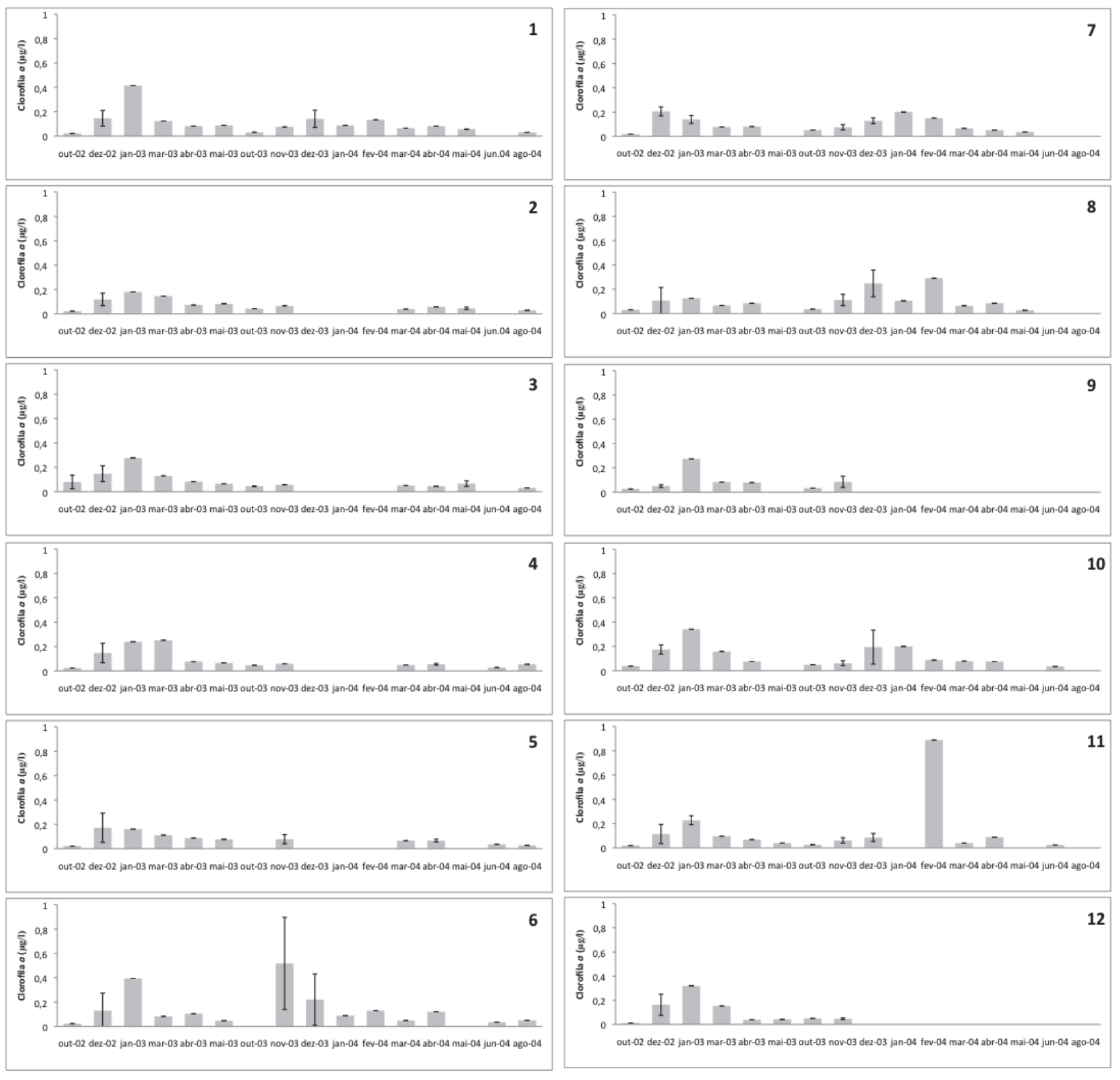

Figura 12. Variação temporal da concentração média de clorofila $a\left(\mu \mathrm{g} .1^{-1}\right)$ nas estações de coleta $(\bar{x} \pm$ DP $)$. Outubro de 2002 a agosto de 2004. Baía do Almirantado.

A concentração média de feopigmentos variou entre $0,009 \mu \mathrm{g} . \mathrm{l}^{-1}$ no mês de outubro de 2003 na estação localizada na Enseada Martel, Ponta Ulmann (4), e 0,588 $\mu \mathrm{g} .1^{-1}$ no mês de janeiro de 2003 na estação 1, também localizada na Enseada Martel, Ferraz (Figura 13). 


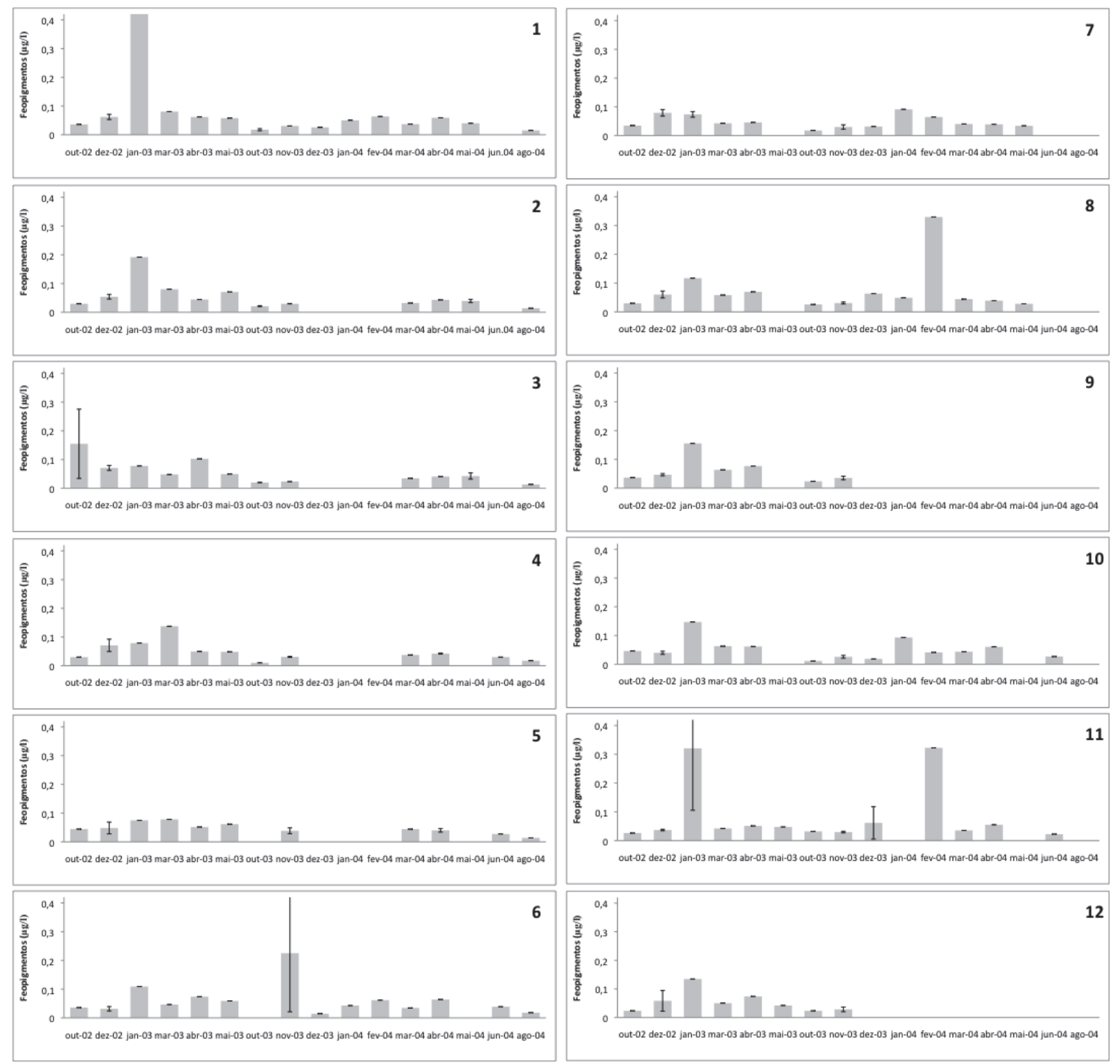

Figura 13. Variação temporal da concentração média de feopigmentos $\left(\mu \mathrm{g} \cdot 1^{-1}\right)$ nas estações de coleta ( $\bar{x} \pm$ DP). Outubro de 2002 a agosto de 2004. Baía do Almirantado.

A análise de variância mostrou que as diferenças na concentração média de clorofila $a$ entre os períodos amostrados foram significativas $(\mathrm{F}=13,48 ; \mathrm{p}<0,001)$ (Figura 14), porém, quando comparadas entre as áreas $(\mathrm{F}=0,00 ; \mathrm{p}=0,99)$ e a interação entre períodos e áreas $(\mathrm{F}=1,18 ; \mathrm{p}=0,27)$ não houve variação significativa da variável analisada. 
As concentrações de feopigmentos também foram significativamente diferentes apenas entre os períodos amostrados $(\mathrm{F}=4,32 ; \mathrm{p}<0,001)$, e, similares entre as áreas amostradas $(\mathrm{F}=0,35 ; \mathrm{p}=0,69)$ e a interação entre períodos e áreas também não foi significativa $(\mathrm{F}=1,19 ; \mathrm{p}=0,26)$ (Figura 15$)$.

O teste LSD mostrou diferença entre os meses de verão de ambos os anos, com os maiores valores, em relação aos demais com valores médios menores quando analisada a concentração média da variável clorofila $a$. Quando comparada a concentração de feopigmentos, o teste LSD mostrou semelhança entre o período de verão de ambos os anos na área Ezcurra (maiores valores) e estes diferindo dos demais.

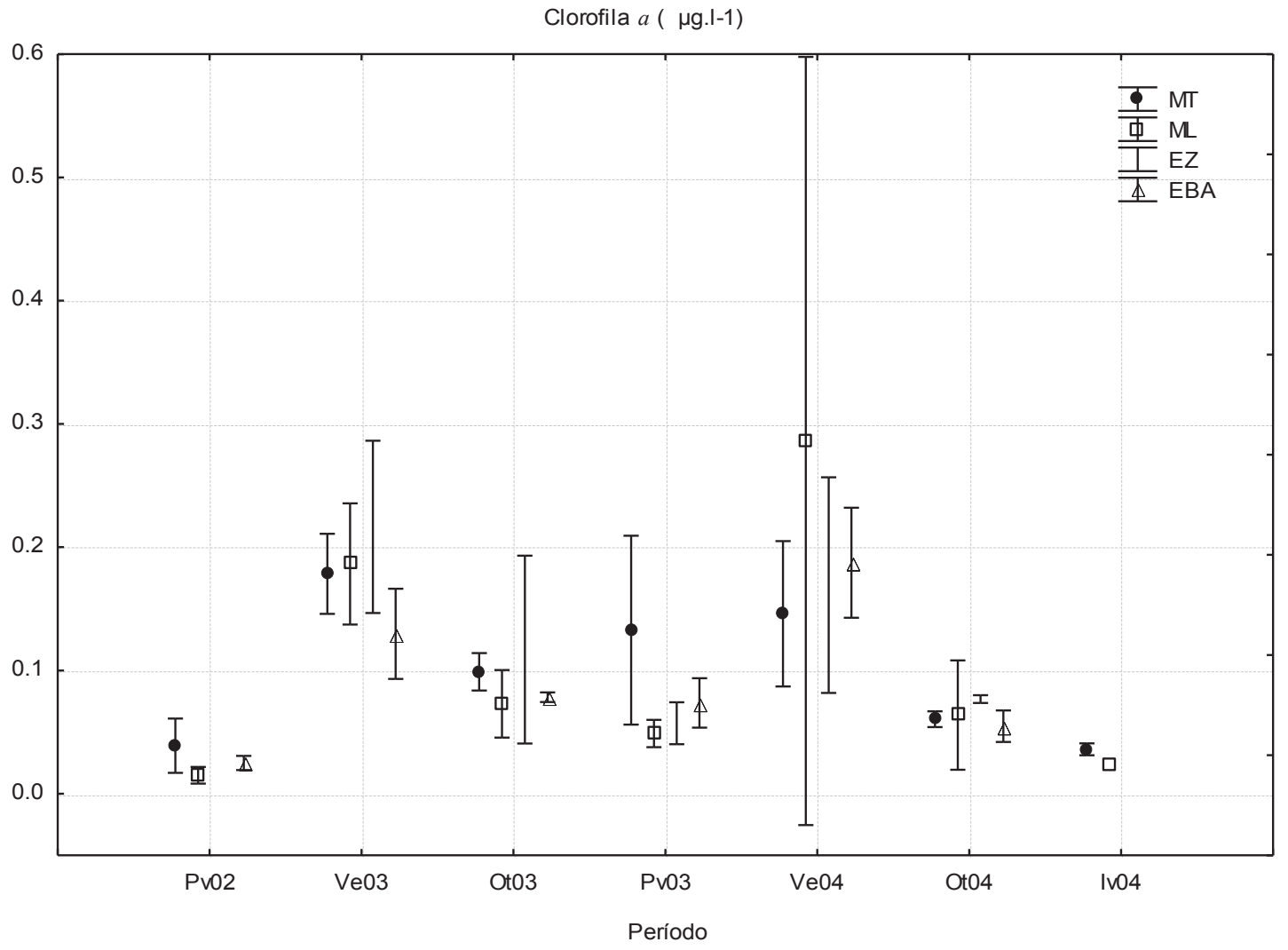

Figura 14. Concentração média de clorofila $a\left(\mu \mathrm{g} \cdot 1^{-1}\right)$ durante o período amostrado nas diferentes áreas $(\bar{x} \pm$ IC). Primavera de 2002 a Inverno de 2004. Baía do Almirantado. $\mathrm{MT}=$ Área Martel; $\mathrm{ML}=$ Área Mackellar; $\mathrm{EZ}=$ Área Ezcurra; $\mathrm{EBA}=$ Área da entrada da baía. Pv02= Primavera de 2002; Ve03= Verão de 2003; Ot03= Outono de 2003; Pv03= Primavera de 2003; Ve04= Verão de 2004; Ot04= Outono de 2004; Iv04= Inverno de 2004. 


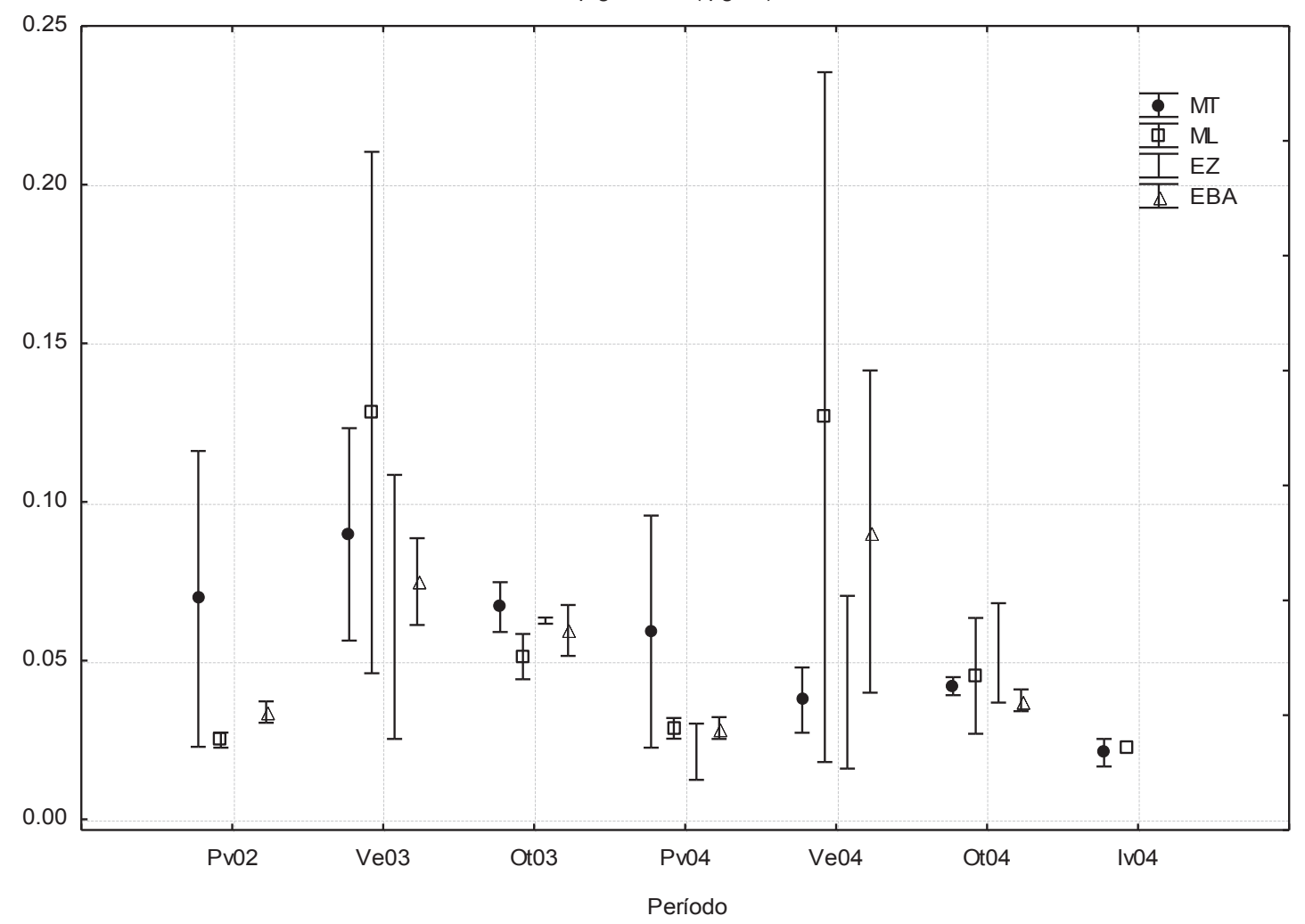

Figura 15. Concentração média de feopigmentos $\left(\mu \mathrm{g} . \mathrm{l}^{-1}\right)$ durante o período amostrado nas diferentes áreas $(\bar{x} \pm$ IC). Primavera de 2002 a Inverno de 2004. Baía do Almirantado. $\mathrm{MT}=$ Área Martel; $\mathrm{ML}=$ Área Mackellar; EZ= Área Ezcurra; $\mathrm{EBA}=$ Área da entrada da baía. Pv02= Primavera de 2002; Ve03= Verão de 2003; Ot03= Outono de 2003; Pv03= Primavera de 2003; Ve04= Verão de 2004; Ot04= Outono de 2004; Iv04= Inverno de 2004.

$\mathrm{Na}$ análise de componentes principais (PCA) o eixo 1 explicou 47,7\% da variação dos dados, com os valores médios de clorofila $a$, feopigmentos e temperatura por período das áreas de coleta com as maiores contribuições, enquanto que o eixo 2 explicou 19,0\% da variação, com maior influência das variáveis salinidade e transparência da água (Figura 16).

Mais à direita do gráfico estão as áreas coletadas na primavera de $2002 \mathrm{com}$ menores temperaturas e concentrações de clorofila $a$ e feopigmentos e ventos mais intensos. Mais à esquerda, no verão de 2003, houve menores ventos e maiores valores de clorofila $a$ e feopigmentos. Na porção superior do gráfico, com menores valores de clorofila $a$, feopigmentos, salinidade e transparência da água, estão as áreas amostradas 
nos períodos de primavera de 2003 e outono e inverno de 2004 . O outono de 2003 e o verão de 2004 tiveram características intermediárias entre a primavera de 2002 e o verão de 2003.

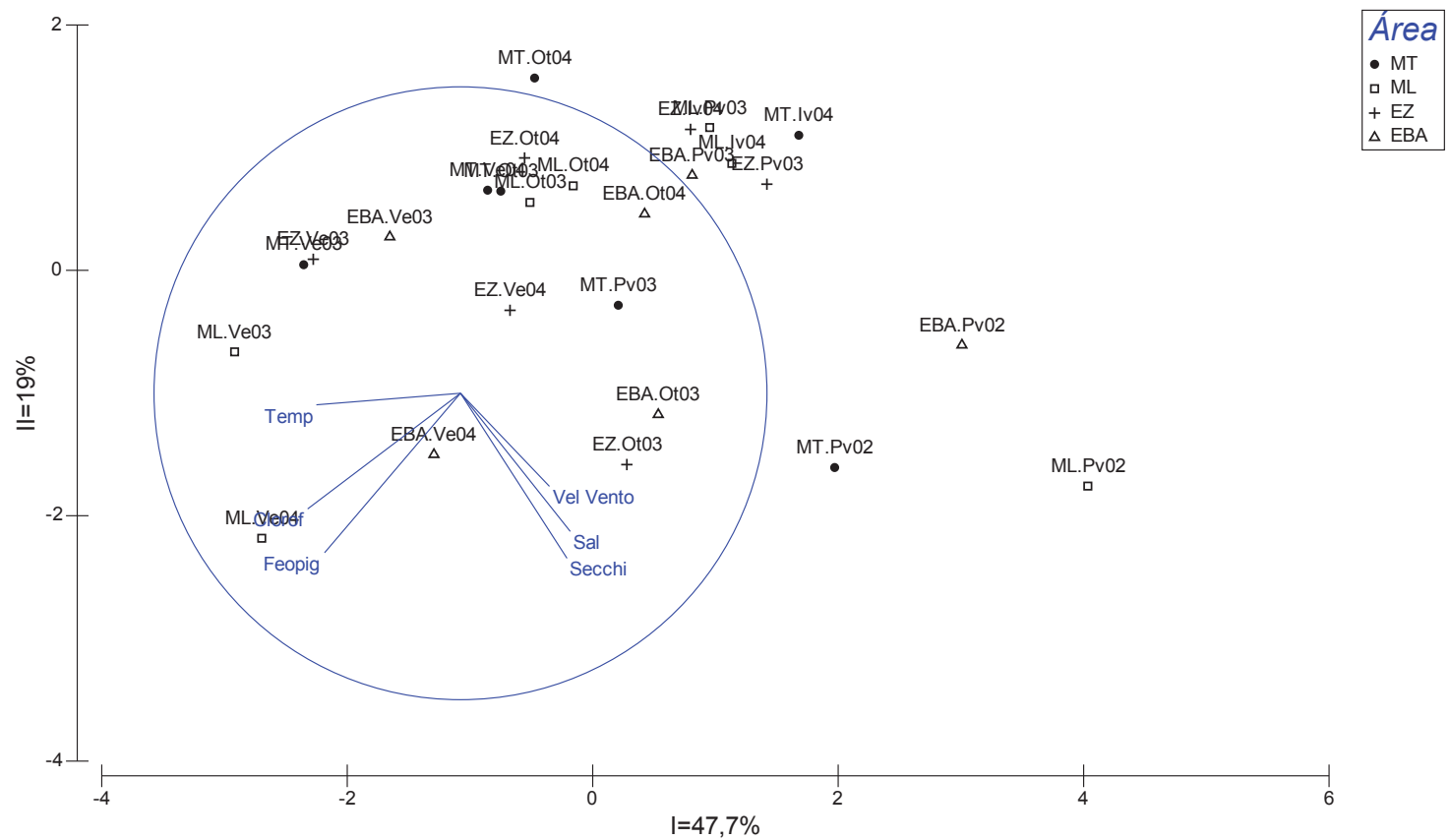

Figura 16. Análise de componentes principais (PCA) para as variáveis ambientais. Baía do Almirantado. $\mathrm{MT}=$ Área Martel; $\mathrm{ML}=$ Área Mackellar; $\mathrm{EZ}=$ Área Ezcurra; EBA= Área da entrada da baía. Pv02= Primavera de 2002; Ve03= Verão de 2003; Ot03= Outono de 2003; Pv03= Primavera de 2003; Ve04= Verão de 2004; Ot04= Outono de 2004; Iv04= Inverno de 2004. 
VARIÁVEIS BIOLÓGICAS:

Um total de 90.004 larvas foi coletado na coluna d'água até $30 \mathrm{~m}$ de profundidade, durante todo o período do estudo. Uma grande variabilidade temporal na densidade do meroplâncton foi observada durante o período de estudo.

A densidade média do meroplâncton entre os dois anos foi significativamente diferente $(\mathrm{F}=1,07 ; \mathrm{p}<0,001)$. No primeiro ano, a densidade larval foi maior no período de verão $\left(69,54\right.$ indivíduos. $\left.100 \mathrm{~m}^{-3} \pm 350,04\right)$, enquanto que no segundo ano a maior densidade foi observada no outono (13,59 indivíduos.100 $\left.\mathrm{m}^{-3} \pm 19,03\right)$ (Figura 17).

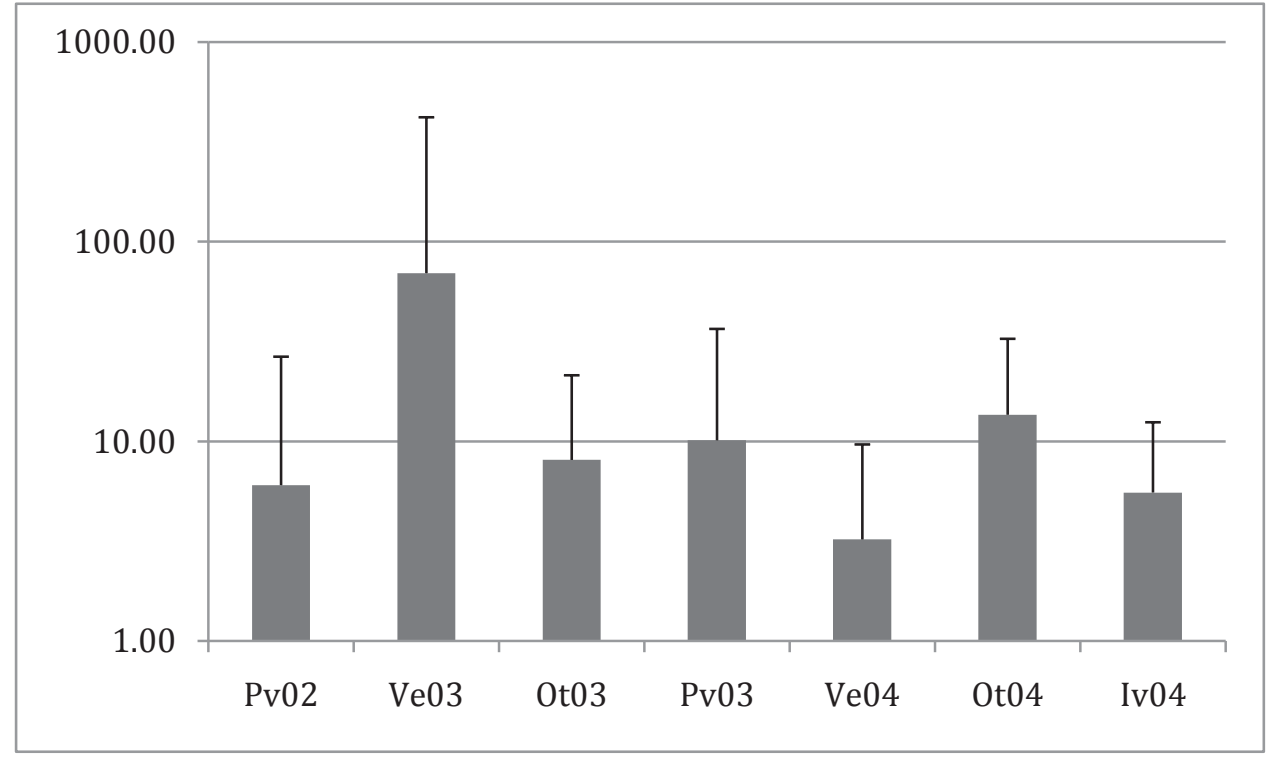

Figura 17. Abundância média de larvas de invertebrados (Dados logaritmizados) coletadas em todo o período amostrado $(\bar{x} \pm$ DP). Primavera de 2002 a Inverno de 2004. Baía do Almirantado. Pv02= Primavera de 2002; Ve03= Verão de 2003; Ot03= Outono de 2003; Pv03= Primavera de 2003; Ve04= Verão de 2004; Ot04= Outono de 2004; Iv04= Inverno de 2004.

A maior abundância de larvas foi observada na Enseada Mackellar, com 252,08 indivíduos. $100 \mathrm{~m}^{-3}$ no verão de 2003. As larvas foram ausentes ou tiveram abundâncias muito baixas na Enseada Ezcurra, sendo ausentes na primavera de 2002 e com 1,09 indivíduos. $100 \mathrm{~m}^{-3}$ no verão de 2004 (Figura 18). 


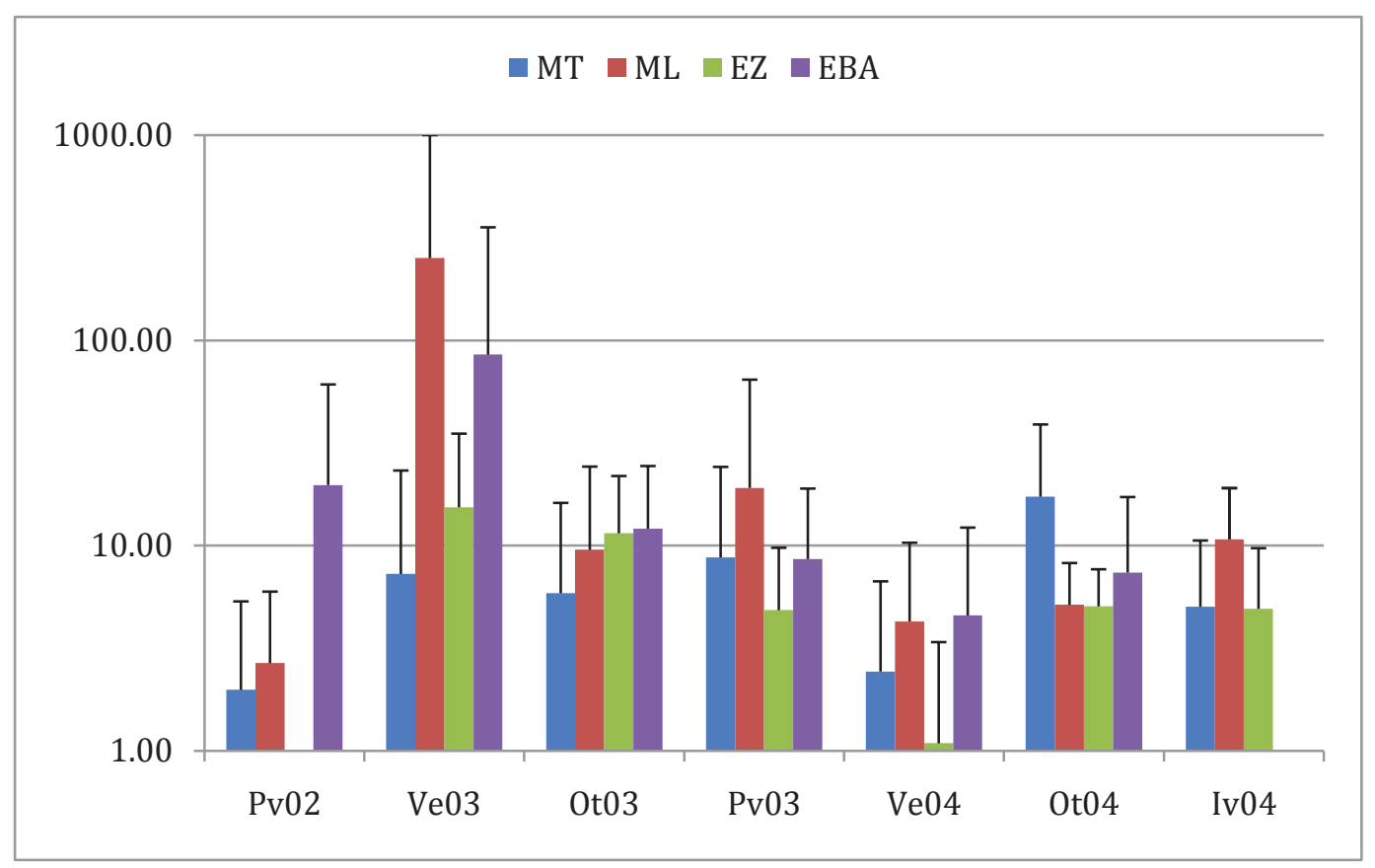

Figura 18. Abundância média das larvas de invertebrados (Dados logaritmizados) coletadas em todo o período amostrado nas áreas de coleta $(\bar{x} \pm$ DP). Primavera de 2002 a Inverno de 2004. Baía do Almirantado. $\mathrm{MT}=$ Área Martel; $\mathrm{ML}=$ Área Mackellar; EZ $=$ Área Ezcurra; EBA $=$ Área da entrada da baía. Pv02= Primavera de 2002; Ve03= Verão de 2003; Ot03= Outono de 2003; Pv03= Primavera de 2003; Ve04= Verão de 2004; Ot04= Outono de 2004; Iv04= Inverno de 2004.

Larvas de diferentes grupos estiveram presentes em todo o período. O grupo de larvas de Gastropoda foi dominante durante o período ( $71 \%$ do total), seguido por larvas de Nemertea do tipo pilidium (11\%) e larvas do tipo trocófora (8\%) (Figura 19). 


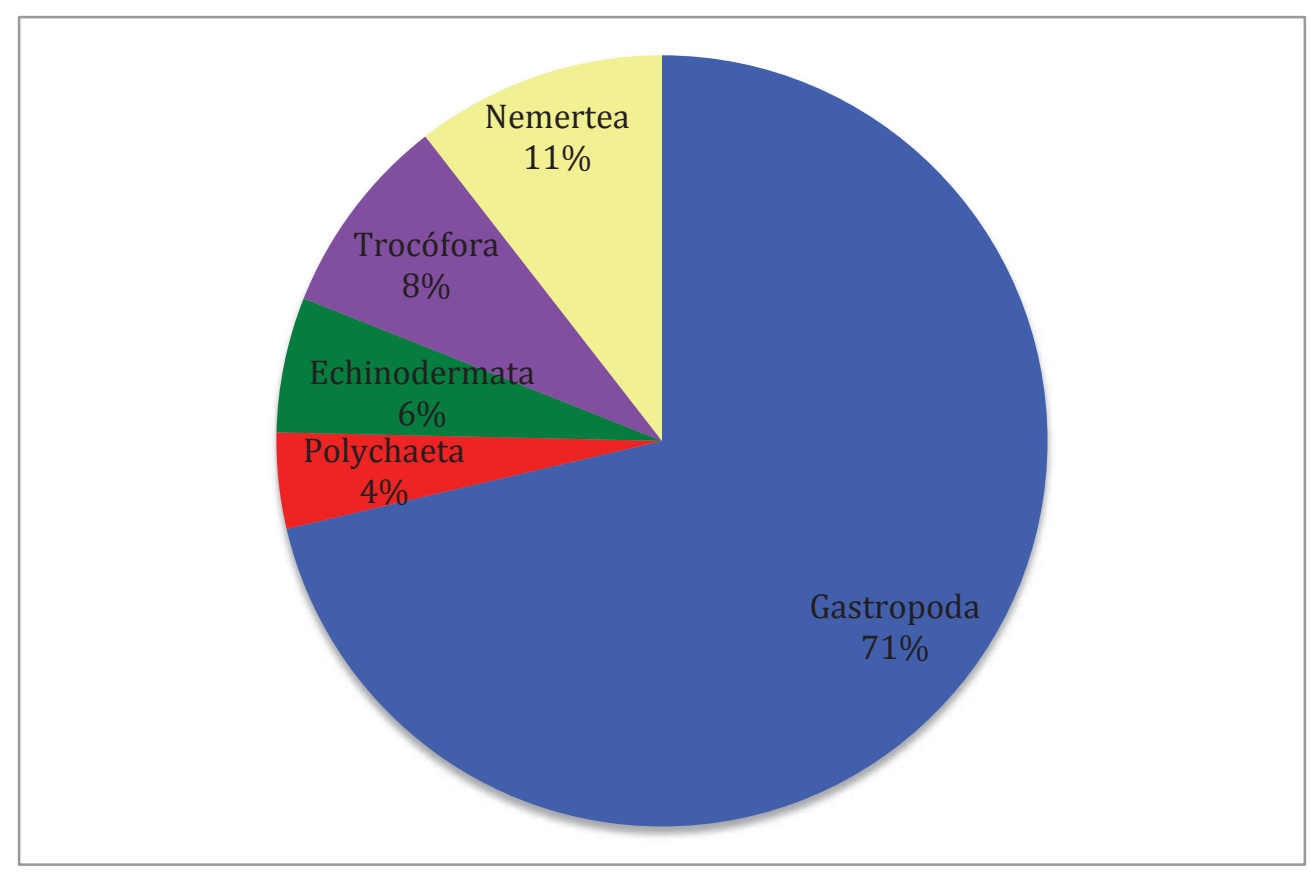

Figura 19. Percentagem relativa (\%) dos grupos de larvas de invertebrados coletadas em todo o período amostrado. Outubro de 2002 a agosto de 2004. Baía do Almirantado.

Uma grande variabilidade temporal na abundância relativa dos grupos do meroplâncton foi observada durante o período de estudo. As larvas de Gastropoda foram predominantes nas coletas dos meses entre outubro de 2002 e janeiro de 2003, enquanto que nos meses seguintes, entre março e novembro de 2003, as larvas de Echinodermata foram mais representativas. As larvas de Nemertea (pilidium) estiveram presentes durante todo um ano, entre março de 2003 a fevereiro de 2004, enquanto as larvas de Polychaeta e do tipo trocófora foram mais representativas no final do período de amostragem, entre fevereiro a agosto de 2004 (Figura 20). 


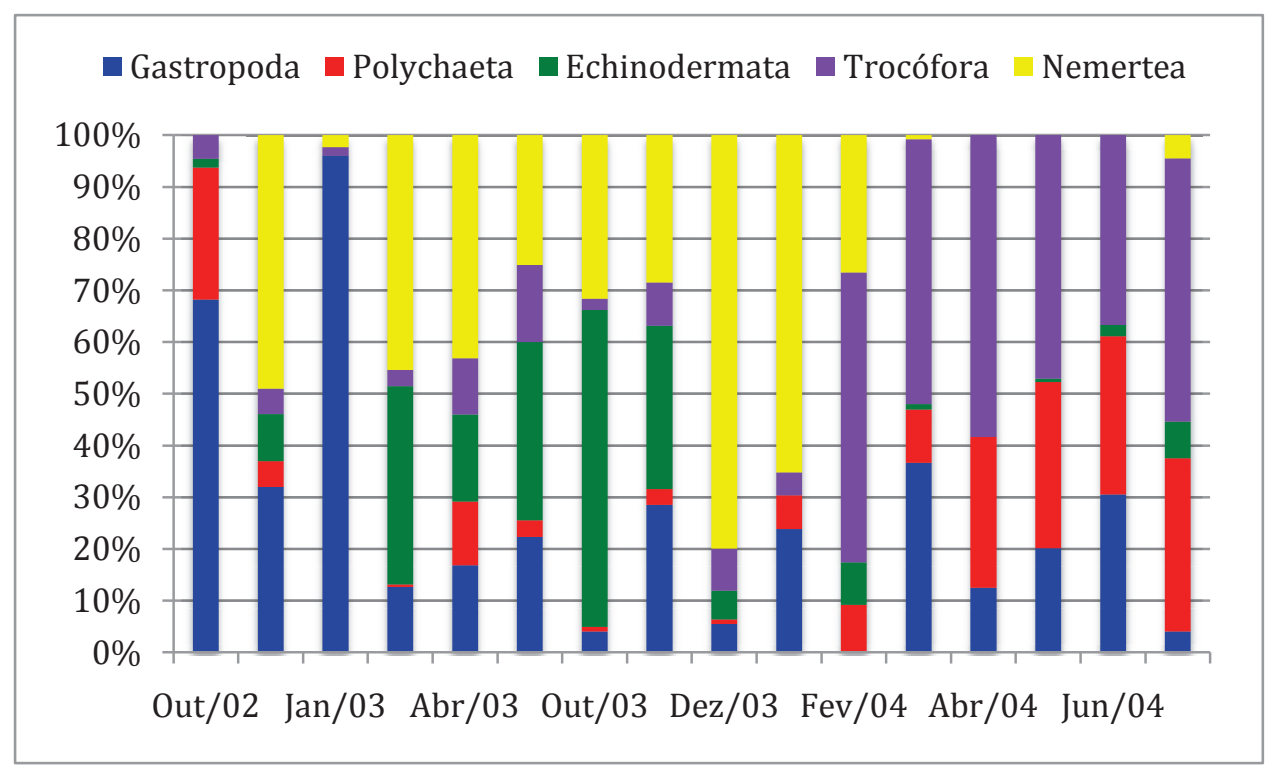

Figura 20. Percentagem relativa (\%) do número de larvas de invertebrados durante o período amostrado. Outubro de 2002 a agosto de 2004. Baía do Almirantado.

Larvas véliger de Gastropoda foram mais abundantes na estação 12 (Punta Plaza) no mês de janeiro de 2003 (1930,41 indivíduos. $\left.100 \mathrm{~m}^{-3}\right)$, em oposição a algumas estações de coleta em que foram ausentes (Figura 21). 

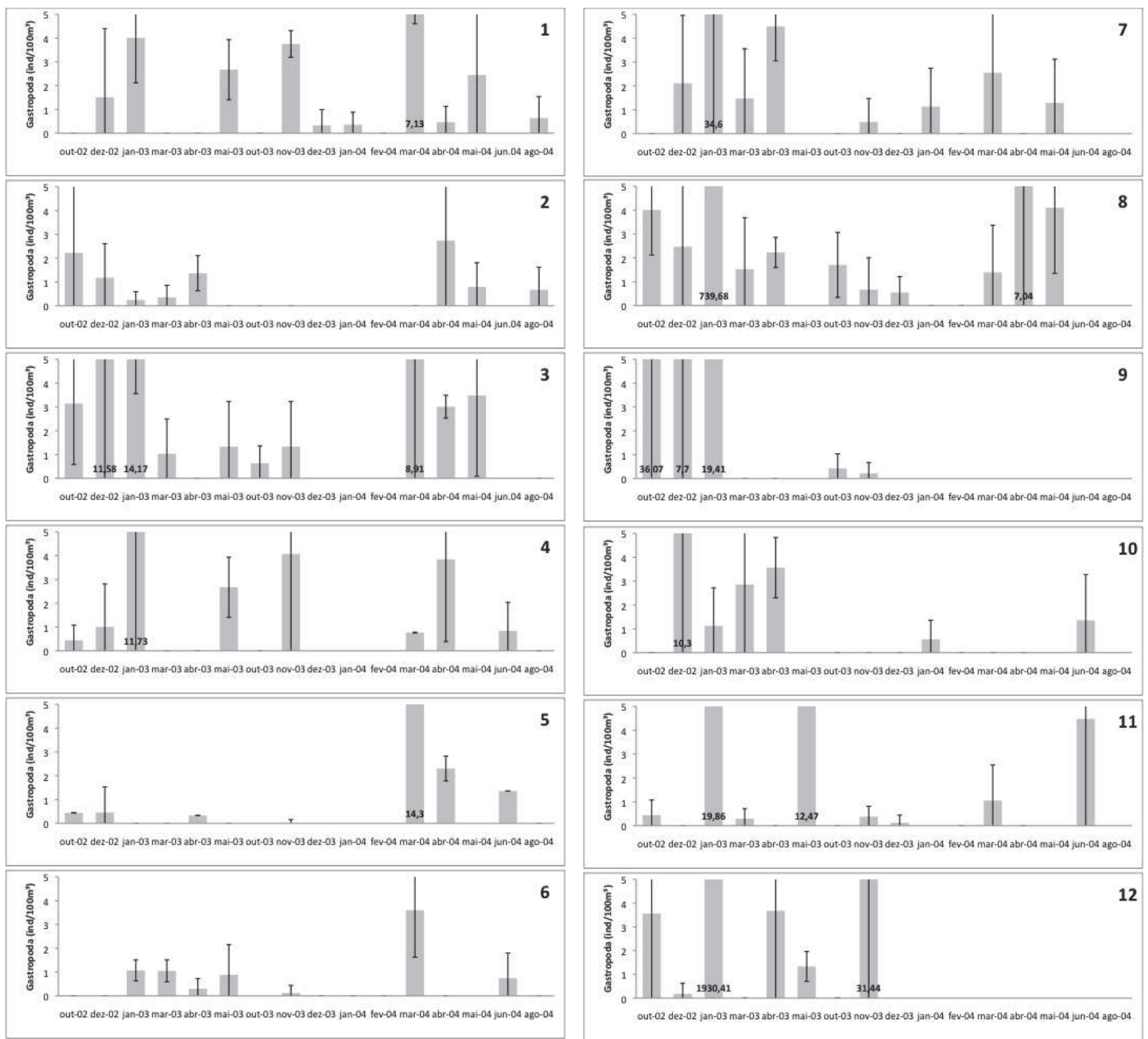

Figura 21. Variação temporal do número médio de larvas de Gastropoda (indivíduos.100 $\mathrm{m}^{-3}$ ) nas estações de coleta $(\bar{x} \pm \mathrm{DP})$. Outubro de 2002 a agosto de 2004. Baía do Almirantado. 
O maior pico de densidade de larvas véliger de Gastropoda ocorreu no verão de 2003 na área Mackellar (246,33 indivíduos. $100 \mathrm{~m}^{-3}$ ). Não houve diferença significativa na variável analisada entre os períodos amostrados $(\mathrm{F}=2,23 ; \mathrm{p}=0,05)$, entre as áreas $(\mathrm{F}=0,76 ; \mathrm{p}=0,46)$, nem mesmo na interação entre períodos e áreas $(\mathrm{F}=1,14 ; \mathrm{p}=0,31)$ (Figura 22).

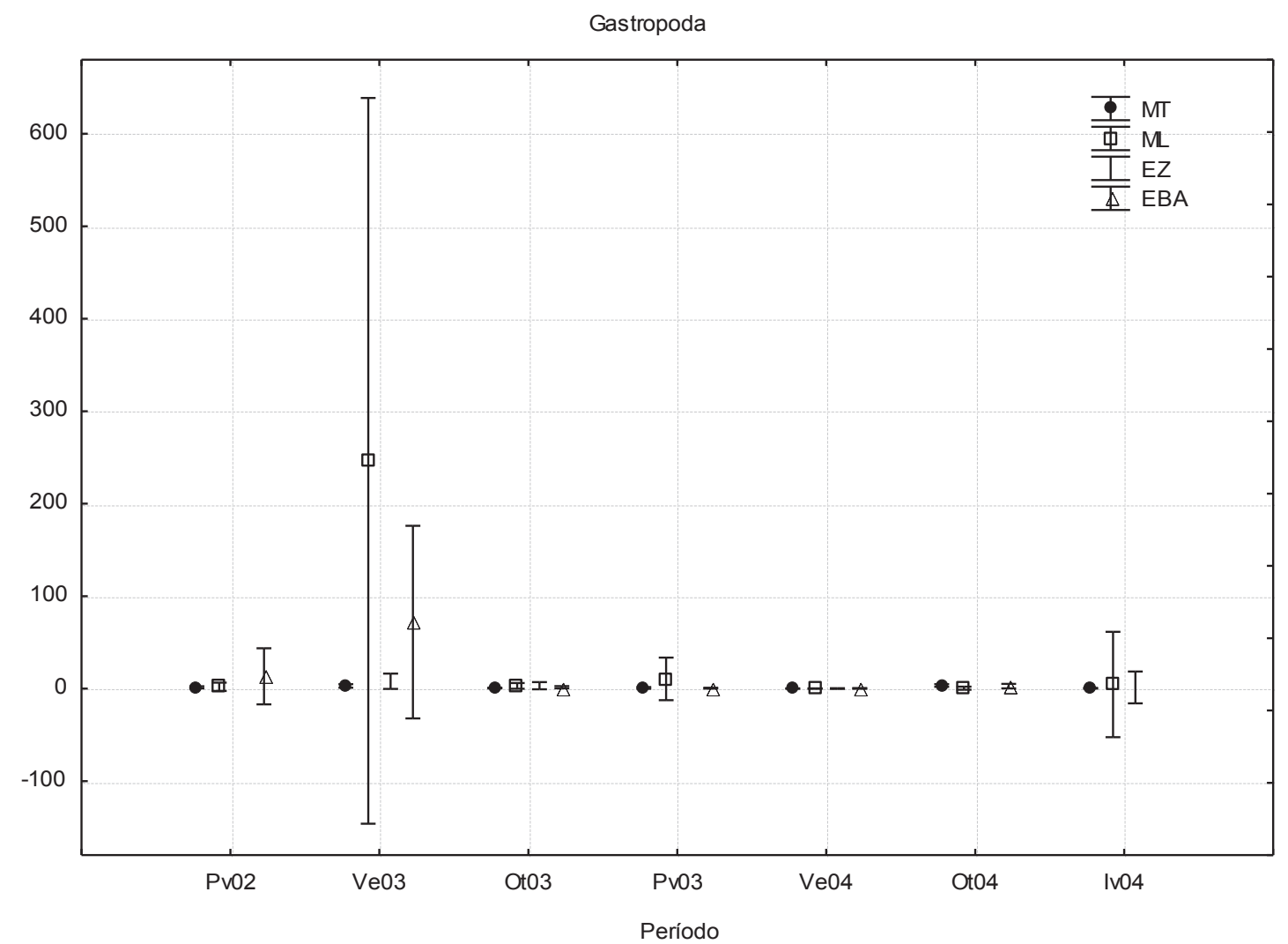

Figura 22. Número médio de larvas de Gastropoda (indivíduos.100 $\mathrm{m}^{-3}$ ) durante $\mathrm{o}$ período amostrado nas áreas de coleta $(\bar{x} \pm$ IC). Primavera de 2002 a Inverno de 2004. Baía do Almirantado. MT=Área Martel; $M L=$ Área Mackellar; EZ= Área Ezcurra; EBA= Área da entrada da baía. Pv02= Primavera de 2002; Ve03= Verão de 2003; Ot03= Outono de 2003; Pv03= Primavera de 2003; Ve04= Verão de 2004; Ot04= Outono de 2004; Iv04= Inverno de 2004. 
A estação 8 (Sphinx), localizada na entrada da baía, foi a que teve o maior número médio de larvas de Polychaeta (16,48 indivíduos. $\left.100 \mathrm{~m}^{-3}\right)$, no mês de outubro de 2002. A ausência dessas larvas pode ser observada em diversas estações amostradas em diferentes períodos (Figura 23).
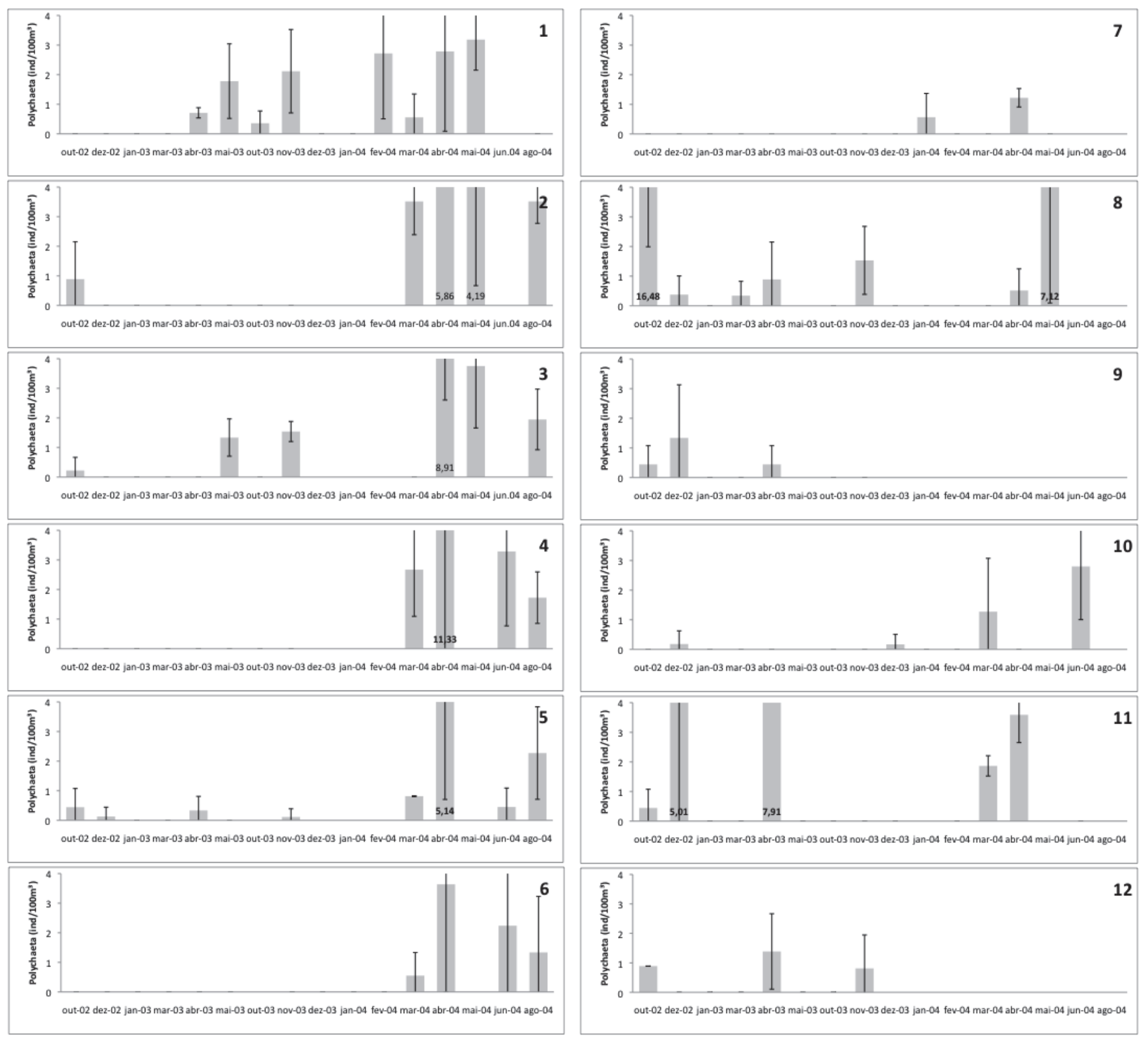

Figura 23. Variação temporal do número médio de larvas de Polychaeta (indivíduos.100 $\left.\mathrm{m}^{-3}\right)$ nas estações de coleta $(\bar{x} \pm \mathrm{DP})$. Outubro de 2002 a agosto de 2004. Baía do Almirantado. 
A maior densidade média no número de larvas de Polychaeta ocorreu na primavera de 2002 nas estações localizadas na entrada da Baía do Almirantado (5,64 indivíduos. $100 \mathrm{~m}^{-3}$ ). A análise de variância indicou haver diferença significativa das densidades entre os períodos amostrados $(F=3,21 ; p<0,001)$ e também a interação entre períodos e áreas $(\mathrm{F}=2,33 ; \mathrm{p}<0,001)$, porém, não houve diferença significativa entre as áreas $(\mathrm{F}=0,43 ; \mathrm{p}=0,64)$. $\mathrm{O}$ teste LSD mostrou igualdade entre os períodos de baixa densidade (média menor que 1,47 indivíduos. $100 \mathrm{~m}^{-3}$ ) e entre os períodos de maiores densidades (média maior que 2,72 indivíduos.100 $\mathrm{m}^{-3}$ ), os quais diferiram entre si (Figura 24).

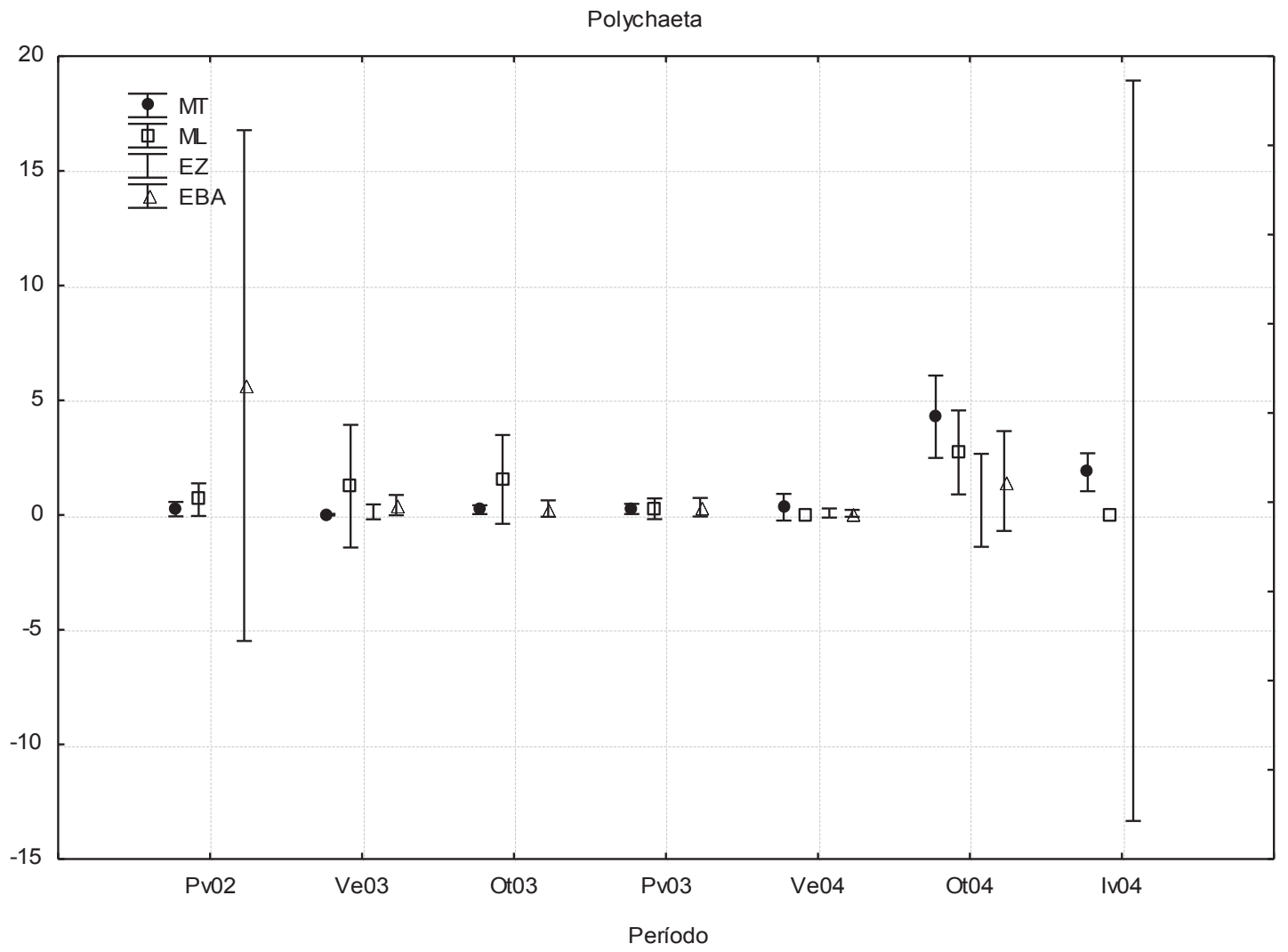

Figura 24. Número médio de larvas de Polychaeta (indivíduos. $100 \mathrm{~m}^{-3}$ ) durante o período amostrado nas áreas de coleta $(\bar{x} \pm$ IC). Primavera de 2002 a Inverno de 2004. Baía do Almirantado. MT=Área Martel; $M L=$ Área Mackellar; EZ $=$ Área Ezcurra; EBA $=$ Área da entrada da baía. Pv02= Primavera de 2002; Ve03= Verão de 2003; Ot03= Outono de 2003; Pv03= Primavera de 2003; Ve04= Verão de 2004; Ot04= Outono de 2004; Iv04= Inverno de 2004. 
Em algumas coletas, a ausência de larvas também pôde ser observada em distintas estações, quando analisada a densidade média no número de larvas de Echinodermata, para a qual, o valor máximo foi observado na estação 1 (Ferraz), localizada na Enseada Martel, com densidade de 11,78 indivíduos. $100 \mathrm{~m}^{-3}$ no mês de novembro de 2003 (Figura 25).
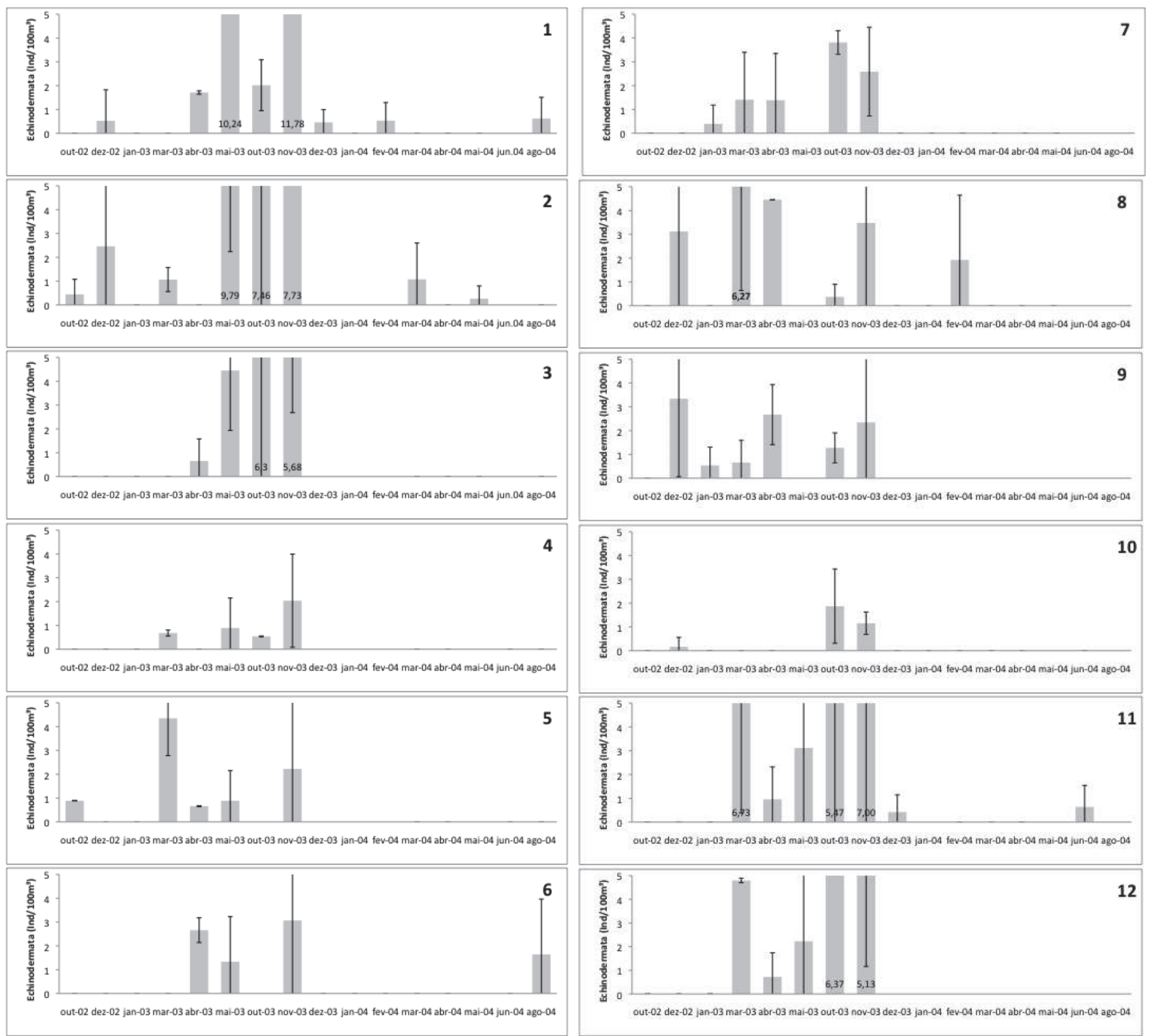

Figura 25. Variação temporal do número médio de larvas de Echinodermata (indivíduos. $\left.100 \mathrm{~m}^{-3}\right)$ nas estações de coleta $(\bar{x} \pm \mathrm{DP})$. Outubro de $2002 \mathrm{a}$ agosto de 2004. Baía do Almirantado. 
Valores mais expressivos no número de larvas de Echinodermata foram observados no outono e primavera de 2003 (densidade média maior que 2,18 indivíduos. $100 \mathrm{~m}^{-3}$ ); estes períodos diferiram estatisticamente dos demais períodos amostrados $(\mathrm{F}=13,10 ; \mathrm{p}<0,001)$. Não houve diferença significativa quando comparadas as áreas amostradas $(\mathrm{F}=1,83 ; \mathrm{p}=0,16)$, e a interação entre períodos e áreas também não mostrou diferenças significativas $(\mathrm{F}=1,54 ; 0,07)$ (Figura 26).

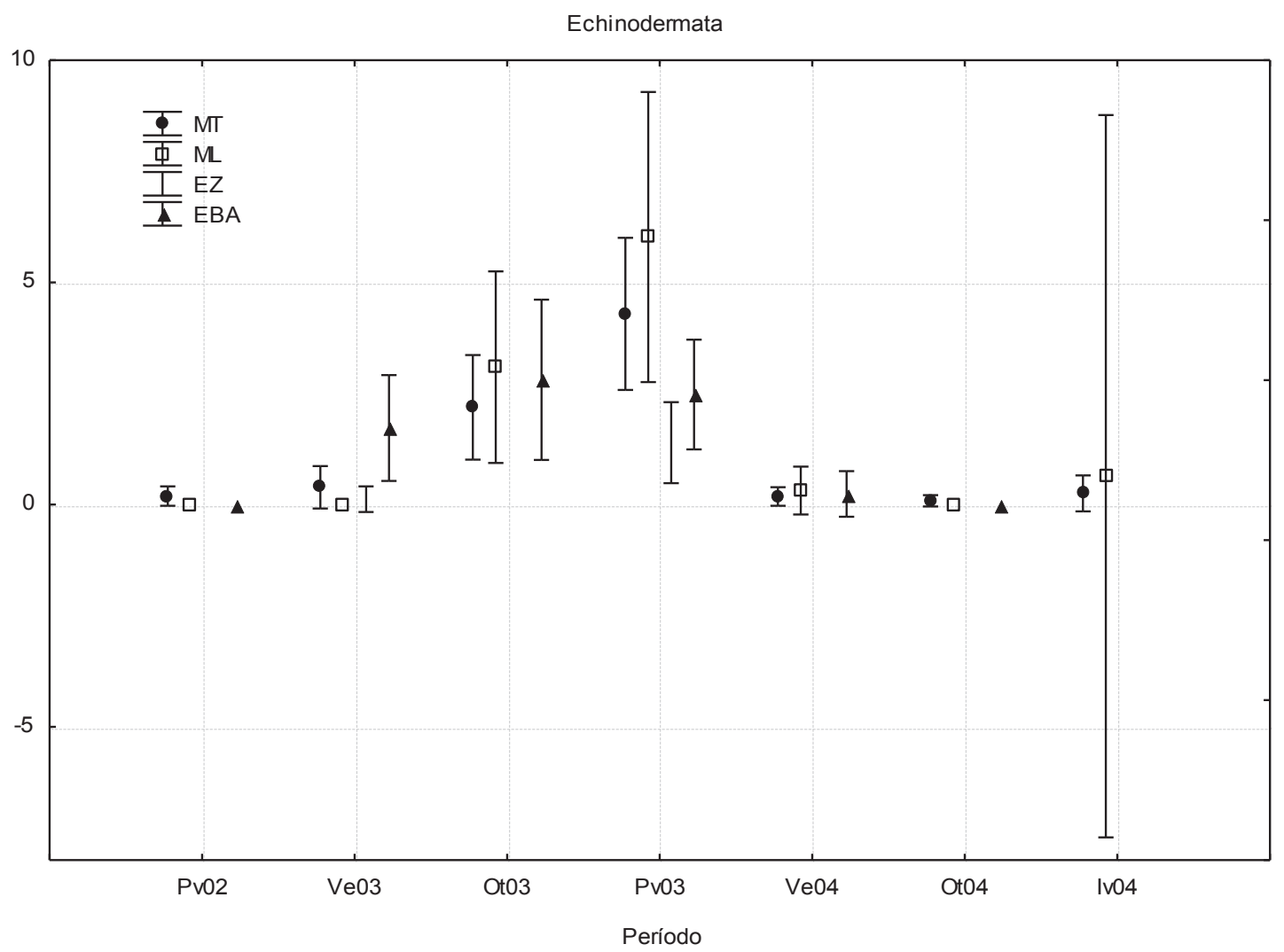

Figura 26. Número médio de larvas de Echinodermata (indivíduos.100 $\mathrm{m}^{-3}$ ) durante o período amostrado nas áreas de coleta $(\bar{x} \pm$ IC). Primavera de 2002 a Inverno de 2004. Baía do Almirantado. MT=Área Martel; $M L=$ Área Mackellar; EZ= Área Ezcurra; EBA= Área da entrada da baía. Pv02= Primavera de 2002; Ve03= Verão de 2003; Ot03= Outono de 2003; Pv03= Primavera de 2003; Ve04= Verão de 2004; Ot04= Outono de 2004; Iv04= Inverno de 2004. 
A variação no número de larvas do tipo trocófora foi de zero, em várias estações durante o período de coleta, a 32,71 indivíduos. $100 \mathrm{~m}^{-3}$ observado no mês de abril de 2004 na estação 3 (Stenhouse), localizada na Enseada Martel (Figura 27).
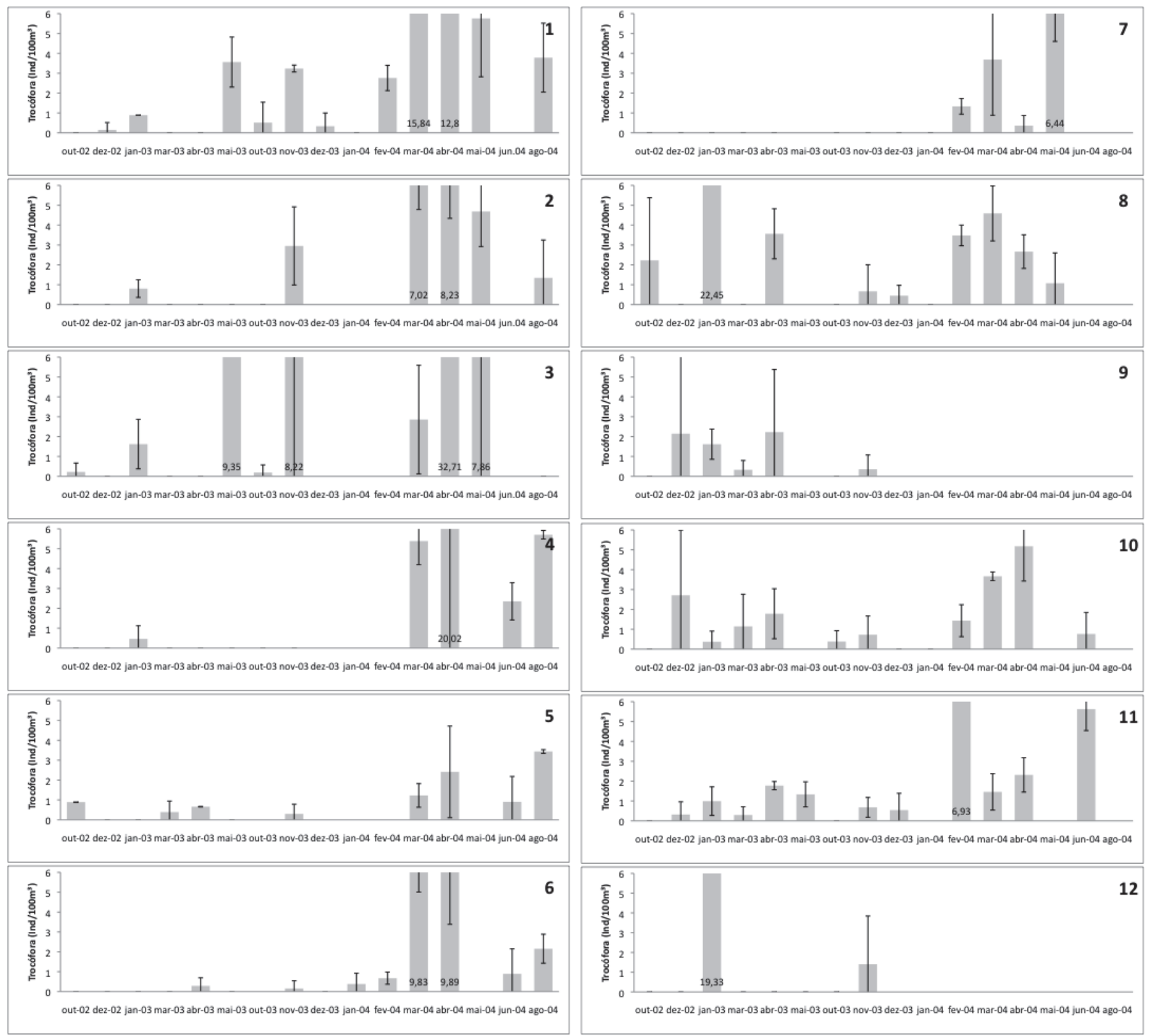

Figura 27. Variação temporal do número médio de larvas trocófora (indivíduos. $100 \mathrm{~m}^{-3}$ ) nas estações de coleta $(\bar{x} \pm$ DP). Outubro de 2002 a agosto de 2004. Baía do Almirantado. 
Quando analisada a densidade de larvas do tipo trocófora, valores mais expressivos foram observados no outono de 2004 na área Martel (9,55 indivíduos.100 $\left.\mathrm{m}^{-3}\right)$, diferindo estatisticamente dos períodos de menor densidade, $(\mathrm{F}=3,64 ; \mathrm{p}<0,001)$, e a interação entre períodos e áreas foi também significativa $(F=2,06 ; p<0,001)$. Porém, não houve diferença significativa quando comparadas as áreas amostradas $(\mathrm{F}=0,25$; $\mathrm{p}=0,77$ ) (Figura 28).

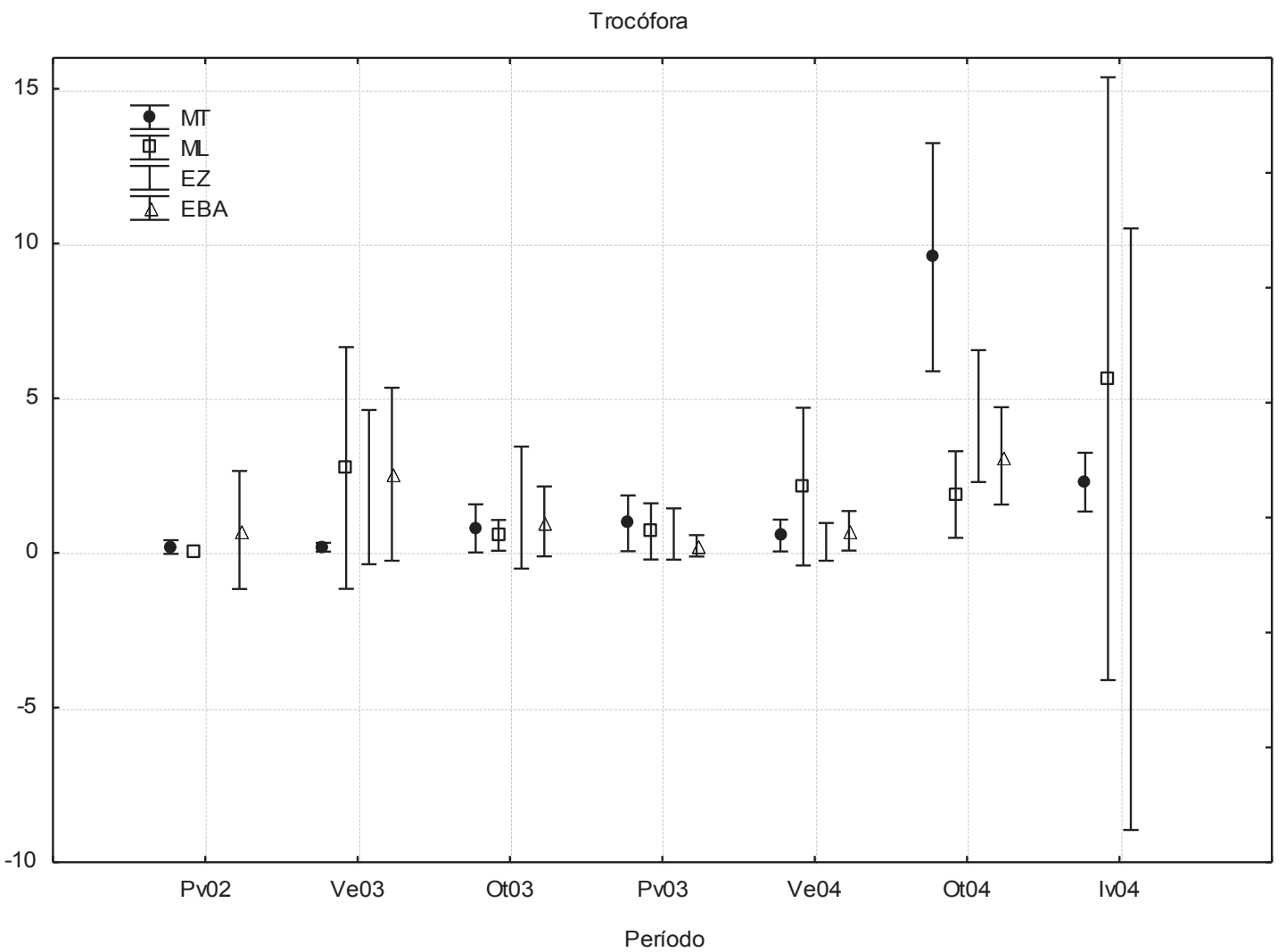

Figura 28. Número médio de larvas trocófora (indivíduos. $100 \mathrm{~m}^{-3}$ ) durante o período amostrado nas áreas de coleta $(\bar{x} \pm$ IC). Primavera de 2002 a Inverno de 2004. Baía do Almirantado. MT=Área Martel; ML= Área Mackellar; EZ= Área Ezcurra; EBA= Área da entrada da baía. Pv02= Primavera de 2002; Ve03= Verão de 2003; Ot03= Outono de 2003; Pv03= Primavera de 2003; Ve04= Verão de 2004; Ot04= Outono de 2004; Iv04= Inverno de 2004. 
Quando analisada a densidade média no número de larvas de Nemertea, pilidium, o maior valor foi observado na estação 9 (Arctowski) no mês de dezembro de 2002 (21,59 indivíduos. $\left.100 \mathrm{~m}^{-3}\right)$. Em algumas estações de coleta essas larvas estiveram ausentes (Figura 29).

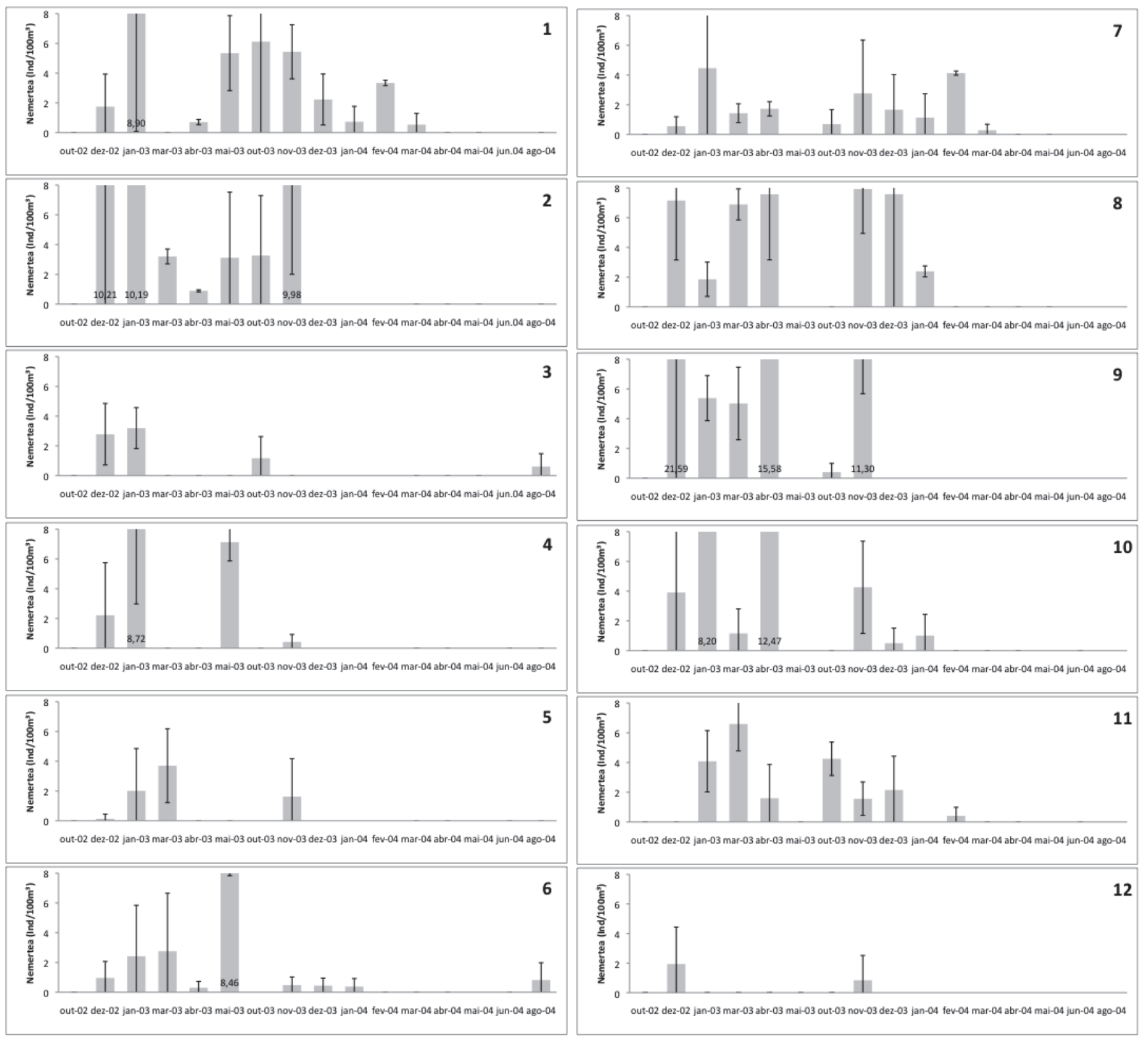

Figura 29. Variação temporal do número médio de larvas de Nemertea (pilidium) (indivíduos. $100 \mathrm{~m}^{-3}$ ) nas estações de coleta $(\bar{x} \pm \mathrm{DP})$. Outubro de 2002 a agosto de 2004. Baía do Almirantado. 
Houve diferença significativa na densidade das larvas de Nemertea (pilidium) entre os períodos amostrados $(\mathrm{F}=5,18 ; \mathrm{p}<0,001)$. Na primavera de 2002 , outono e inverno de 2004 as larvas desse grupo estiveram ausentes ou foram pouco representativas. O teste LSD mostrou que os períodos de menor densidade diferiram significativamente dos demais (densidade média menor que 4,98 indivíduos. $100 \mathrm{~m}^{-3}$ ). Entre as áreas amostradas e a interação entre períodos e áreas não apresentou diferença significativa $(\mathrm{F}=0,44 ; \mathrm{p}=0,64$ e $\mathrm{F}=0,76 ; \mathrm{p}=0,73$; respectivamente) (Figura 30 ).

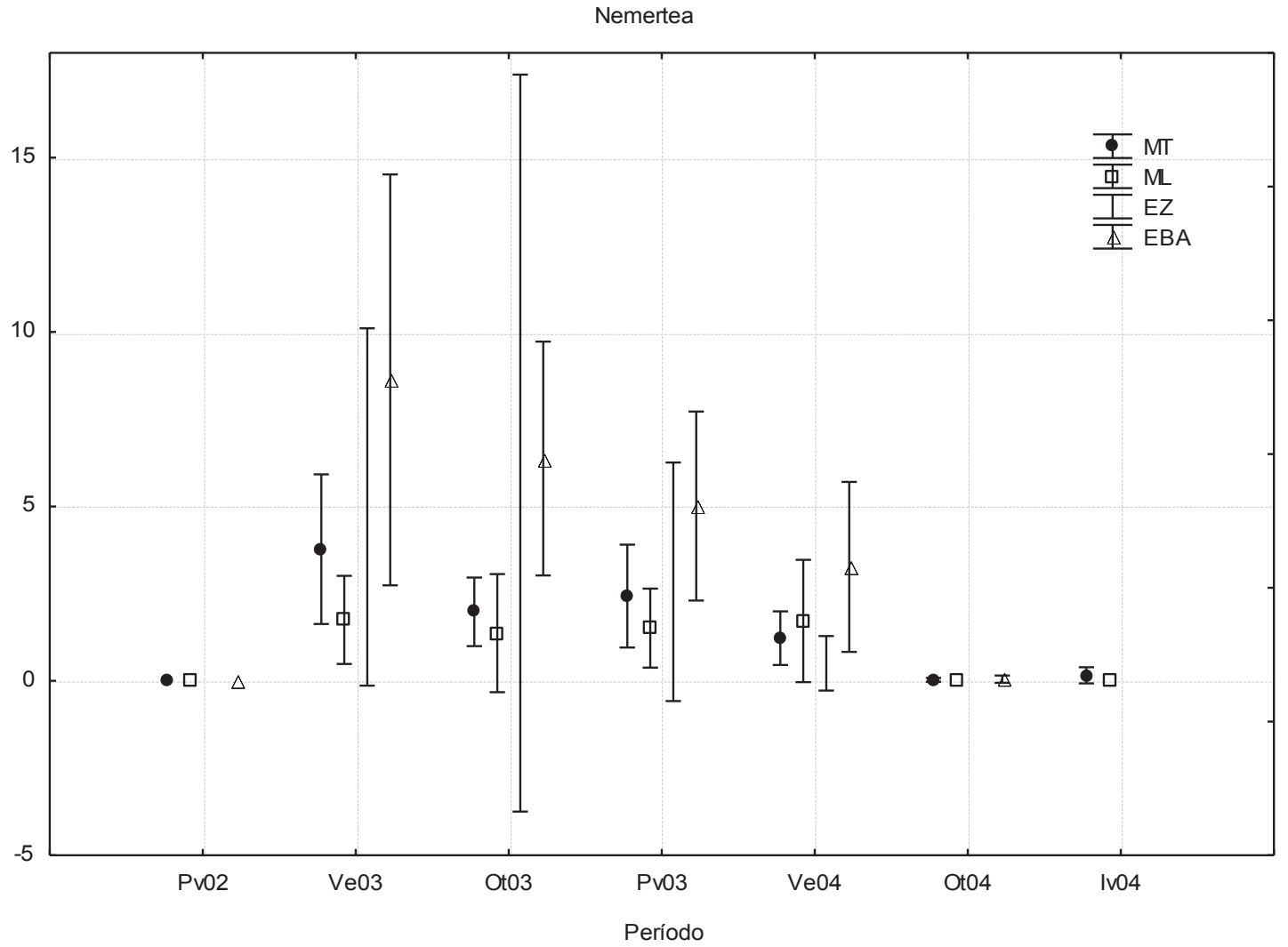

Figura 30. Número médio de larvas de Nemertea (pilidium) (indivíduos.100 $\mathrm{m}^{-3}$ ) durante o período amostrado nas áreas de coleta $(\bar{x} \pm$ IC $)$. Primavera de 2002 a Inverno de 2004. Baía do Almirantado. MT=Área Martel; ML=Área Mackellar; EZ $=$ Área Ezcurra; EBA $=$ Área da entrada da baía. Pv02= Primavera de 2002; Ve03= Verão de 2003; Ot03= Outono de 2003; Pv03= Primavera de 2003; Ve04= Verão de 2004; Ot04= Outono de 2004; Iv04= Inverno de 2004. 
Na Figura 31 é mostrado o dendrograma resultante da análise de agrupamento das estações, com o uso do coeficiente de similaridade de Bray-Curtis. Essa análise foi realizada com todas as amostras das XXI e XXII OABs separadas por áreas. A análise de agrupamento mostrou a área Ezcurra, amostrada na primavera de 2002, significativamente diferente dos demais grupos e cinco grupos principais com mais de $50 \%$ de similaridade, embora a diferença não tenha sido significativa (SIMPROF). O primeiro grupo (G1) foi formado pelas coletas realizadas no período do verão de 2004 nas quatro áreas. As coletas realizadas no outono e primavera de 2003, além das áreas Martel e Ezcurra amostradas no verão de 2003 formaram um segundo grupo (G2) com $60 \%$ de similaridade. Um terceiro grupo (G3) foi formado pelas estações de coleta localizadas no canal principal da entrada da Baía do Almirantado, coletadas na primavera de 2002 e no verão de 2003, além das estações localizadas na área Mackellar (verão de 2003). Um quarto grupo (G4) foi formado pelas estações amostradas no outono e inverno de 2004 em toda a Baía do Almirantado. Um último grupo (G5) foi formado pelas estações localizadas nas áreas Martel e Mackellar amostradas na primavera de 2002.

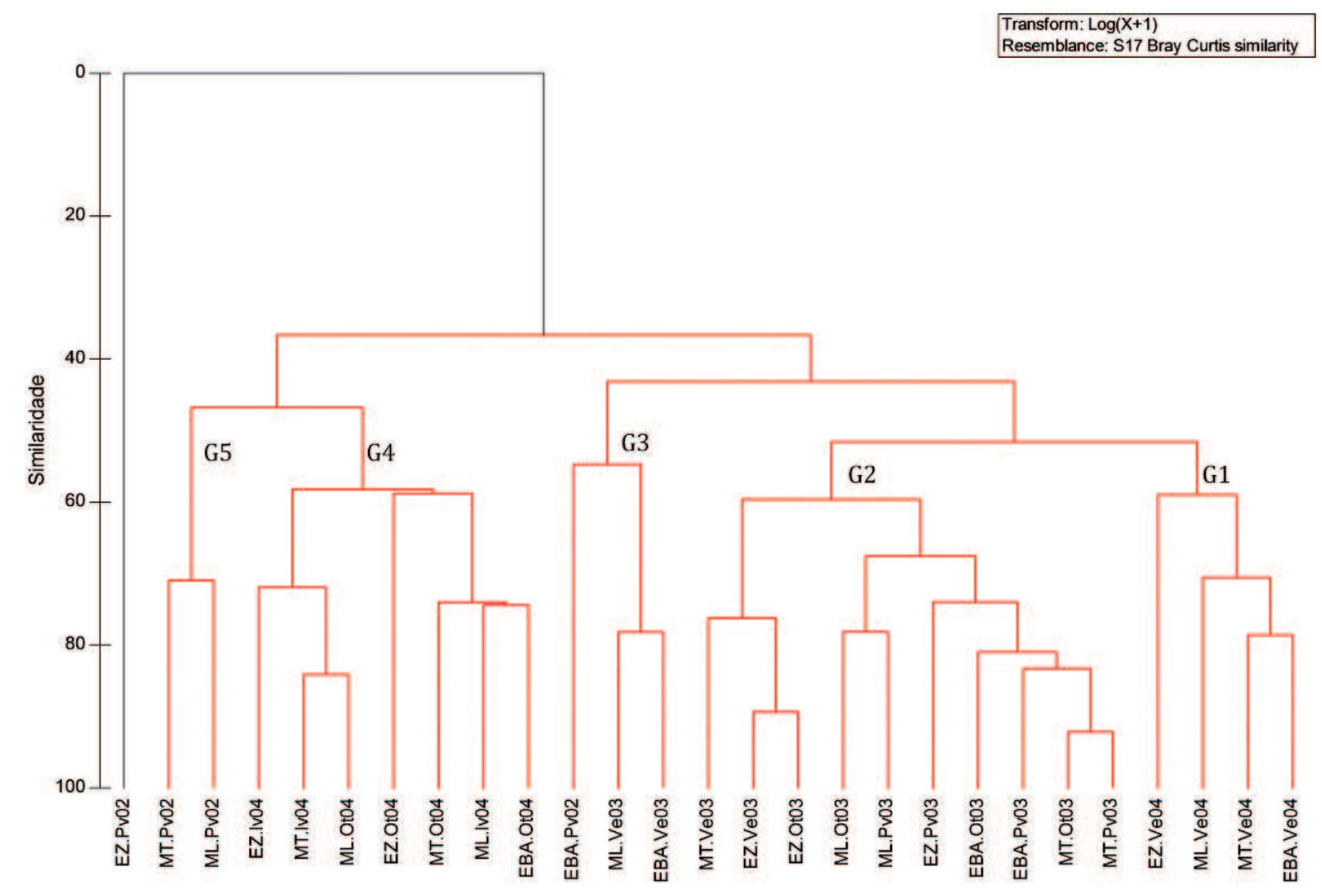

Figura 31. Análise de agrupamento por média ponderada (Índice de Bray-Curtis) considerando as densidades dos grupos do meroplâncton. Em vermelho os agrupamentos não significativamente distintos (SIMPROF). 
A análise de escalonamento multidimensional não-métrica (nMDS), com a abundância dos grupos principais do meroplâncton, separou as amostras em grupos mais ou menos coincidentes com os encontrados na análise de agrupamento, evidenciando as diferenças entre estes grupos, com estresse de 0,18 (Figura 32). Nessa figura foi excluída a área Ezcurra no período da primavera de 2002 para melhor interpretação. Ficou mais evidente a separação dos grupos pela variável período: verão, primavera e outono de 2003 não se distinguiram, verão de 2004 foi um pouco mais distinto desses últimos períodos, e primavera de 2002, outono e inverno de 2004 foram mais similares e separados dos outros períodos.

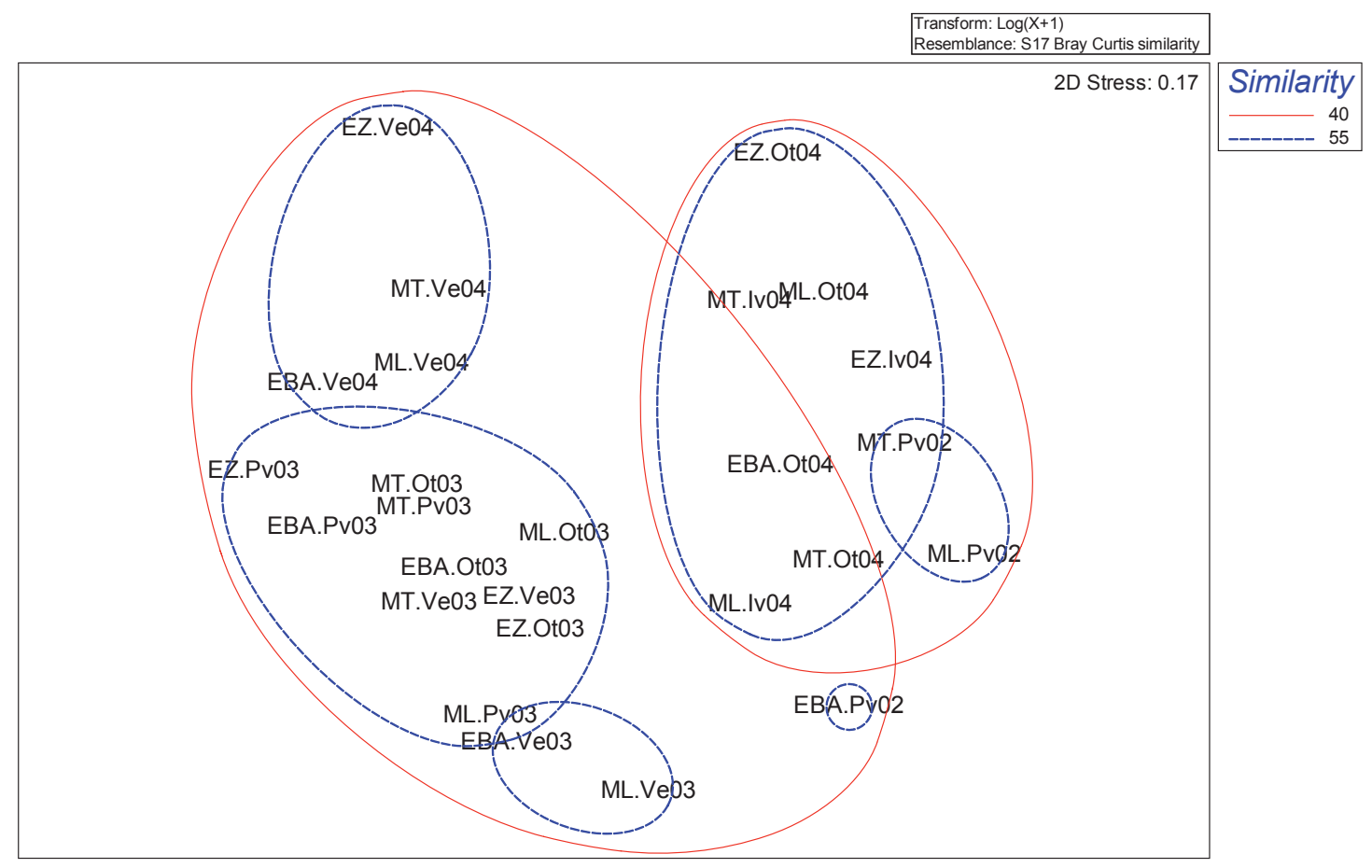

Figura 32. Análise de escalonamento multidimensional não-métrica (nMDS) para as densidades do meroplâncton. Os agrupamentos obtidos no dendrograma da figura 29 foram sobrepostos no diagrama.

As densidades de alguns grupos do meroplâncton foram sobrepostas ao diagrama do nMDS para compreender qual seu efeito na diferença no padrão de distribuição das enseadas (Figura 33). Larvas de Gastropoda foram mais representativas na área Mackellar e nas estações localizadas na entrada da Baía do Almirantado no período do verão de 2002. Na sobreposição da densidade de larvas de Polychaeta podem-se observar valores mais representativos nas coletas realizadas na primavera de 
2002, outono e inverno de 2004, em todas as estações amostradas. Larvas de Echinodermata foram mais expressivas nas coletas realizadas no outono e primavera de 2003 em todas as áreas amostradas. Quando analisada a densidade de larvas do tipo pilidium, Nemertea, essas apresentaram valores mais representativos nas estações localizadas na entrada da Baía do Almirantado, entre o verão e primavera de 2003. Já as larvas do tipo trocófora apresentaram as maiores densidades nas estações localizadas na área Martel, nos períodos de outono e inverno de 2004. Porém, estiveram presentes em todas as áreas durante ambos os períodos.

Em síntese, o primeiro grupo (G1) foi caracterizado por maior densidade de larvas de Nemertea, do tipo pilidium. O segundo grupo formado (G2) foi caracterizado por uma maior densidade de larvas de Nemertea, Echinodermata e poucas do tipo trocófora. Já o terceiro grupo (G3) formado apresentou maior densidade de larvas de Gastropoda, Polychaeta, trocófora e Nemertea. O quarto grupo foi caracterizado pela presença de larvas do tipo trocófora e de Polychaeta. E no último grupo (G5) formado, a quantidade de larvas foi pouco representativa. 

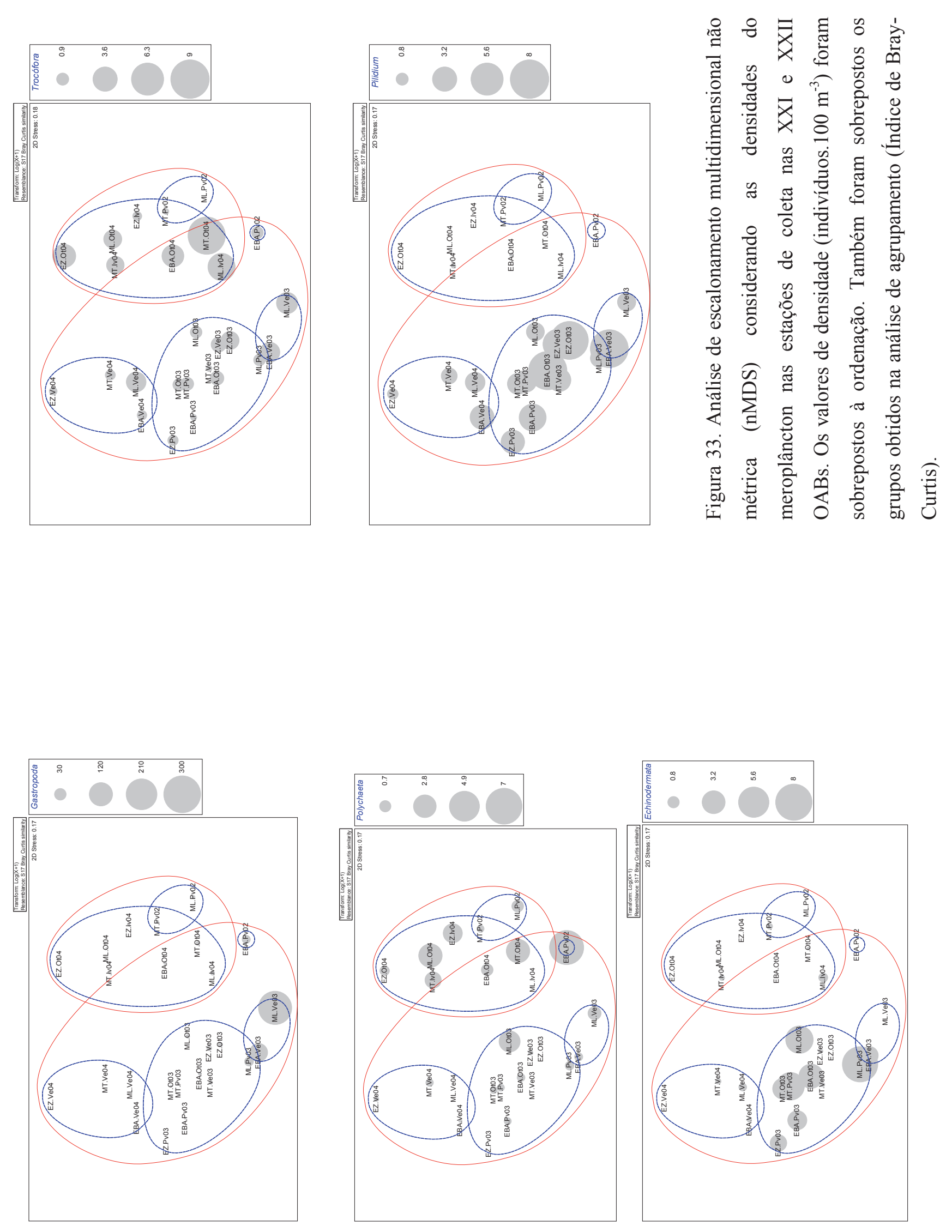


\section{DIscussão}

\section{VARIÁVEIS AMBIENTAIS}

As variáveis ambientais na Baía do Almirantado, como a temperatura e a salinidade da água, parecem estar relacionadas diretamente às águas da Convergência Antártica que circulam pelo Estreito de Bransfield (Rakusa-Suszczewski, 1996), com amplitudes similares e relativamente estáveis na baía (Jazdewski et al., 1986).

A temperatura da água foi menor nos períodos de primavera e inverno, e mais alta no verão e outono, como esperado. Os valores de salinidade um pouco menores nos períodos de verão e primavera de 2003 podem estar relacionados ao degelo da baía. As altas salinidades observadas na Enseada Mackellar na primavera de 2002 estão em desacordo com os valores de salinidade média registrada em outros trabalhos na baía, que variaram de 32,9 a 36,5 (Jazdzewski et al., 1986; Lipski, 1987; Absher et al., 2003; Lange et al., 2007). Os altos valores registrados no presente estudo podem ser devido a um erro de análise, uma vez que a salinidade é relativamente estável ao longo da baía (Jazdzewski et al., 1986).

A transparência média da água foi de 5 a $14 \mathrm{~m}$, exceto em uma coleta, e foi maior nos períodos de primavera e um pouco menor no verão e outono. Brandini \& Rebello (1994) relacionaram a variação da transparência da água com a velocidade do vento. A profundidade máxima de camada eufótica em períodos sem turbulência foi de 30 m, similar ao reportado por Lipski (1987) na baía, em período de verão. A transparência também pode ser reduzida pela turbidez causada por sedimentos em suspensão em áreas adjacentes às geleiras e induzida pelo derretimento de descarga da água no meio marinho (Pichlmaier et al., 2004).

De maneira geral, os valores médios da intensidade do vento foram superiores a $4 \mathrm{~m} \cdot \mathrm{s}^{-1}$ na Baía do Almirantado, no período do estudo. Os ventos com intensidade média maiores do que $4 \mathrm{~m} \cdot \mathrm{s}^{-1}$ têm uma maior influência sobre a circulação da camada de água da superfície até $30 \mathrm{~m}$ na baía do que o fluxo das marés (Pruszak, 1980). Ventos com essa intensidade podem transportar as águas superficiais para fora das enseadas e causar um efeito de ressurgência e/ou turbulência nas áreas internas (Pruszak, 1980).

Em relação às concentrações de clorofila $a$, no geral, estas foram baixas na Baía do Almirantado. Os valores médios encontrados (entre 0,03 a 0,28 $\mu \mathrm{g} .1^{-1}$ ) foram 
similares aos obtidos anteriormente na baía (Freire et al., 2006) e estão dentro dos limites descritos em outro estudo desenvolvido no mesmo período de verão 2003/2004 na Baía do Almirantado (entre 0,1 a 1,7 $\mu \mathrm{g} .1^{-1}$ ) (Lange et al., 2007).

A média geral da concentração de clorofila $a$ na baía $\left(0,11 \mu \mathrm{g} .1^{-1} \pm 0,02\right)$ ficou abaixo da média geral reportada por estes últimos autores $\left(0,44 \mu \mathrm{g} \cdot 1^{-1} \pm 0,29\right)$. Tal diferença pode ser atribuída ao fato de que no presente trabalho a média foi calculada para um período de quase dois anos e em uma área mais ampla da baía, enquanto que no de Lange et al. (2007), apenas no período de verão e na parte mais interna da baía.

Langue et al. (2007) ressaltaram, ainda, que a abundância do fitoplâncton na Baía do Almirantado foi baixa quando comparada aos valores observados em outras áreas na Antártica. Tal fato pode estar relacionado à intensa mistura vertical na coluna de água (como conseqüência de ventos fortes) na baía e à troca de água com o Estreito de Bransfield e/ou, ainda, à limitação de luz devido à alta turbidez (Brandini \& Rebello, 1994).

A concentração média de clorofila $a$ foi maior do que a concentração de feopigmentos em todo o período amostrado, indicando fitoplâncton ativo. Durante o verão foram observadas as maiores médias de clorofila $a: 0,14 \mu \mathrm{g} \cdot 1^{-1}( \pm 0,08)$ no mês de dezembro de 2002, 0,25 $\mu \mathrm{g} .1^{-1}( \pm 0,09)$ no mês de janeiro de 2003 e 0,28 $\mu \mathrm{g} .1^{-1}( \pm 0,29)$, no verão de 2003/2004, a concentração mais elevada. Além de estar relacionada à maior radiação solar (Freire et al., 2006), a concentração de clorofila $a$ durante o período de acumulação máxima também pode ter contribuição de origem bentônica por ressuspensão do microfitobentos, que é muito abundante em sedimentos da zona costeira rasa da Enseada Martel (Skowronski et al., 2009).

Nos períodos de verão, as concentrações médias de clorofila $a$ aumentaram de dezembro a janeiro ou fevereiro. Tal fato pode estar relacionado ao crescimento de fitoplâncton na camada eufótica nesse período de maior luminosidade e/ou a eventos de ressurgência que ocorrem em janeiro devido à troca de água da Baía do Almirantado com o Estreito de Bransfield em função da maior intensidade dos ventos. A forte turbulência ressuspende diatomáceas bêntônicas do sedimento em regiões mais internas da baía e, após o cessar dos ventos fortes durante as duas primeiras semanas de fevereiro, a clorofila acumula-se na coluna de água (Brandini \& Rebello, 1994). Embora os dados de ventos do presente estudo tenham sido pontuais, sua velocidade, em média, alta pode ter causado esse efeito. 
Brandini \& Rebello (1994) relacionaram variações temporais na concentração de clorofila com mudanças no regime de ventos e hidrografia na Baía do Almirantado, em período de verão. Embora a turbulência causada por ventos na coluna de água limite a abundância de fitoplâncton em águas abertas na Antártica, isto pode ter um efeito positivo (aumento da concentração de microfitobentos ressuspendido) em ambientes costeiros.

A análise conjunta das variáveis ambientais mostrou principalmente a separação da primavera de 2002 do verão de 2003. Na primavera de 2002, a transparência de água e os ventos foram maiores, enquanto que a temperatura foi baixa, assim como a concentração de clorofila $a$; no verão de 2003 esses fatores foram o inverso. Por outro lado, a primavera de 2003, o outono de 2004 e o inverno de 2004 foram mais similares quanto às variáveis consideradas, com valores baixos de clorofila a. O outono de 2003 e o verão de 2004 tiveram características intermediárias. Como pode se verificar mais adiante, a composição do meroplâncton refletiu, em parte, essas diferenças temporais.

\section{MEROPLÂNCTON}

A maior variabilidade no número de larvas em águas costeiras na Antártica foi atribuída à sazonalidade, mais do que ao local ou à profundidade (Stanwell-Smith et al., 1999). Na Baía do Almirantado, o meroplâncton ocorreu em todos os períodos do ano, mas sua abundância foi variável entre os dois anos, dependendo da época do ano e da localização geográfica. No primeiro ano a abundância total foi maior que no segundo e, em especial, no verão, sendo que a abundância máxima no primeiro ano de amostragem (2002/2003) foi observada em janeiro de 2003 com 666,54 indivíduos.100 m enquanto que no segundo ano de amostragem (2003/2004), em abril de 2004 (24,64 indivíduos. $100 \mathrm{~m}^{-3}$ ), em estações localizadas no setor interno da Baía do Almirantado, na Enseada Martel.

Esses valores estão de acordo com as densidades encontradas anteriormente na baía e em outras regiões na Antártica, embora sejam bem inferiores aos reportados para baías onde a retenção de larvas pode ocorrer (Tabela II). Sewell (2005) sugere a ocorrência de uma maior densidade do meroplâncton em locais semi-fechados de regiões polares pelo fato de que as larvas possam ser retidas nesses habitats. Tendo 
essas áreas um fluxo de correntes restrito, quando comparadas com outros sistemas do tipo fiorde em regiões temperadas, há um maior grau de retenção de larvas nestes sistemas na Antártica. Há evidências do fato pela observação das densidades de meroplâncton encontradas no Fiorde Ellis (Kirkwood, 1993 apud Vázquez et al., 2007) (Tabela II). A Baía do Almirantado está sujeita a ventos intensos e há troca de água com o Estreito de Bransfield (Pruzak, 1980), em especial da camada até $30 \mathrm{~m}$ de profundidade, e, desse modo, pode não ocorrer tal retenção. No entanto, comparações quantitativas do número de larvas devem ser feitas com cautela devido às diferenças nos equipamentos utilizados, profundidade de amostragem e, particularmente, em relação ao tamanho da malha da rede de plâncton (Vázquez et al., 2007).

Tabela II. Abundância máxima do meroplâncton em diferentes locais na Antártica e o período de seu pico máximo (Adaptado de Vázquez et al., 2007).

\begin{tabular}{|c|c|c|c|c|c|}
\hline LOCAL & $\begin{array}{c}\text { ABUNDÂNCIA } \\
\text { (indivíduos. } \\
\mathrm{m}^{-3} \text { ) }\end{array}$ & $\begin{array}{l}\text { MALHA DA } \\
\text { REDE }(\mu \mathrm{m})\end{array}$ & $\begin{array}{c}\text { PICO } \\
\text { MáXIMO }\end{array}$ & $\begin{array}{c}\text { PERÍODO } \\
\text { AMOSTRADO }\end{array}$ & AUTOR \\
\hline Ilha Ongul & 228 & 100 & Jan - Fim & 1 ano & $\begin{array}{l}\text { Tanimura et al. } \\
\text { (1986) }\end{array}$ \\
\hline Fiorde Ellis & 889 & & Jan - Meados & 1 ano & $\begin{array}{l}\text { Kirkwood (1993) } \\
\text { apud Vázquez } \\
(2007)\end{array}$ \\
\hline $\begin{array}{l}\text { Mar de } \\
\text { Bellingshausen }\end{array}$ & $\approx 20$ & 200 & & Nov-Dez & $\begin{array}{l}\text { Shreeve \& Peck } \\
(1995)\end{array}$ \\
\hline Ilha Signy & 2,74 & 100 & Fev-Mar & 2 anos & $\begin{array}{l}\text { Stanwell-Smith et } \\
\text { al. (1999) }\end{array}$ \\
\hline $\begin{array}{l}\text { Estreito de } \\
\text { McMurdo }\end{array}$ & 3 & 100 & & $\begin{array}{l}\text { Nov-Fim/ } \\
\text { Dez-Início }\end{array}$ & Sewell (2005) \\
\hline $\begin{array}{l}\text { Baía do } \\
\text { Almirantado }\end{array}$ & 15 & 150 & Mar & $\begin{array}{c}\text { Dez-Mai } \\
2 \text { anos }\end{array}$ & Freire et al. (2006) \\
\hline $\begin{array}{l}\text { Estreito de } \\
\text { Bransfield }\end{array}$ & 8,43 & $250-80$ & & Jan-Início & Vázquez et al.(2007) \\
\hline Baía Ryder & 54,4 & 100 & Nov/2002 & $\begin{array}{l}\text { Mar/2001- } \\
\text { Ago/2002 }\end{array}$ & $\begin{array}{l}\text { Bowden et al. } \\
(2009)\end{array}$ \\
\hline $\begin{array}{l}\text { Baía do } \\
\text { Almirantado }\end{array}$ & 6,67 & 150 & Janeiro/2003 & $\begin{array}{l}\text { Out/2002- } \\
\text { Ago/2004 }\end{array}$ & Presente estudo \\
\hline
\end{tabular}

Os picos máximos foram observados no verão (janeiro/2003), que coincidiram com os obtidos em janeiro ou fevereiro-março, em diversos estudos realizados durante um ano (Tabela II). 
Em relação à densidade do meroplâncton, a variação sazonal na radiação solar, disponibilidade de luz, temperatura da água e cobertura de gelo são fatores conhecidos por resultar em alta variabilidade na produção primária e podem ter um grande impacto sobre a abundância e distribuição da fauna pelágica (Kaufmann et al., 2003). Além disso, a variação da salinidade e temperatura na coluna de água, devido à entrada de água de degelo e descarga de rios, pode representar uma barreira física para a maioria das larvas, como foi observado por Fetzer (2004).

A abundância média de meroplâncton na Baía do Almirantado mostrou uma diferença interanual já descrita por outros autores (Stanwell-Smith et al., 1999; Absher et al., 2003; Freire et al., 2006; Bowden et al., 2009). Segundo Powell (2001), a variação interanual na abundância larval é um fenômeno comum entre os invertebrados marinhos. Freire et al. (2006) relacionaram a diferença da concentração larval entre dois anos na Baía do Almirantado com as variações das condições ambientais, especialmente a temperatura.

Em termos gerais, a composição do meroplâncton coletado na Baía do Almirantado foi qualitativamente similar ao descrito anteriormente na baía (Freire et al., 2006) e em outras partes da Antártica por Shreeve \& Peck (1995), Stanwell-Smith et al. (1999), Sewell (2005; 2006), Vázquez et al. (2007) e Bowden et al. (2009). No entanto, a diversidade de tipos de larvas foi aparentemente menor na baía que em outras áreas, possivelmente porque esses autores subdividiram os tipos de larvas em morfotipos e as larvas foram classificadas morfologicamente em unidades taxonômicas operacionais (OTUs). Morfotipos distintos podem incluir diferentes fases de desenvolvimento de um mesmo filo (Stanwell-Smith et al., 1999; Bowden et al., 2009).

Os resultados de Freire et al. (2006) e Absher et al. (2003) referentes ao meroplâncton indicaram uma marcada sazonalidade dos eventos reprodutivos na Baía do Almirantado. A sucessão de larvas de invertebrados de acordo com a sazonalidade parece ser similar em todos os estudos na Antártica, de modo geral, e indica as diferentes estratégias reprodutivas através do tempo, em especial de invertebrados com mobilidade (Bowden et al., 2009).

$\mathrm{Na}$ baía, larvas véliger de Gastropoda foram o grupo mais abundante, representando $84 \%$ do total do meroplâncton no primeiro ano de amostragem; e no segundo ano de estudo, larvas trocófora foram as predominantes (31\% do total), seguidas de Gastropoda e Nemertea. Na mesma baía, as larvas véliger de moluscos 
compreenderam $80 \%$ do meroplâncton, as de Polychaeta, entre 7 e $11 \%$, seguidas das larvas de Echinodermata e Nemertea em ambos os anos amostrados (Freire et al., 2006). Em um local semifechado, o Fiorde Ellis, larvas de Echinodermata e Ascidiacea (ou Urochordata) foram as mais abundantes (Kirkwood, 1993 apud Vázquez et al., 2007). Sewell (2005) relaciona esta ocorrência com o fato de que as larvas possam ser retidas nesse hábitat.

Por outro lado, em três locais costeiros próximos da Ilha Adelaide, as larvas de Polychaeta foram as mais abundantes, seguidas das de Mollusca e Echinodermata (Bowden et al., 2009). Em mar aberto, no Estreito de Bransfield, as larvas de Polychaeta também foram dominantes $(67,4 \%)$, seguidas de larvas de Echinodermata (Vázquez et al., 2007).

Segundo Vázquez et al. (2007), com base no pequeno número de estudos sobre o meroplâncton na Antártica, podem-se distinguir três comunidades meroplanctônicas: uma em ambientes semifechados, como da Baía do Almirantado e Fiorde Ellis, outra em águas costeiras rasas, como nas Ilhas Signy e Orkney (Stanwell-Smith et al., 1999) e na Ilha Adelaide, e a de mar aberto (Vázquez et al, 2007). No entanto, a Baía do Almirantado é um ambiente com características geomorfológicas distintas as quais são responsáveis pela ocorrência de vários fenômenos oceanográficos que são típicos de regiões costeiras do tipo fiorde, tais como circulação gerada por marés, ressurgências costeiras e correntes geradas por vento (Lipski, 1987). A dinâmica oceanográfica característica da baía pode ser responsável pela composição do meroplâncton. Por outro lado, a variação da abundância de grupos de invertebrados do bentos com desenvolvimento indireto na área também pode determinar a composição do meroplâncton. Stanwell-Smith et al. (1999) estimaram que o número total de espécies de invertebrados marinhos na Ilha Signy, Antártica que produzem larvas pelágicas seria provavelmente entre 100-150 e Bowden et al. (2009) estimaram um total de 99 espécies bentônicas com desenvolvimento indireto na Baía Ryder. O número de invertebrados marinhos bentônicos com desenvolvimento indireto não foi estimado para a Baía do Almirantado, mas muitas das espécies de águas rasas mais abundantes, como os equinodermos Sterechinus neumayeri, Odontaster validus e Ophionotus victoriae, o gastrópode Nacella concinna e o nemertino Parborlasia corrugatus (Nonato et al., 2000), têm larva planctônica (Picken, 1980; Bosch et al., 1987; Bosch \& Pearse, 1990; Pearse et al., 1991). 
Em termos de composição taxonômica, houve variações da abundância relativa dos diferentes grupos de larvas ao longo do período de quase dois anos na baía, que puderam ser separadas em três períodos principais, e em especial o primeiro ano (fevdez/2003) do segundo (fev-jun/2004). Quando analisadas as estações do ano também ocorreram variações na composição taxonômica: na primavera de 2002 e verão de 2003 as larvas véliger de Gastropoda foram predominantes; no outono e primavera de 2003 foram predominantes larvas de Echinodermata e Nemertea e larvas do tipo trocófora e de Polychaeta também estiveram presentes, mas em menores proporções; no outono e inverno de 2004 larvas do tipo trocófora foram mais abundantes e larvas de Polychaeta e de Gastropoda também foram representativas nesse período. Freire et al. (2006) observaram similaridade na composição taxonômica entre os dois anos analisados na Baía do Almirantado, mas com variações entre períodos do ano relacionados à sazonalidade de eventos reprodutivos, assim como Bowden et al. (2009) na Baía Ryder.

No presente estudo, larvas de Gastropoda estiveram sempre presentes, mas a maior densidade de larvas de Gastropoda foi observada no primeiro ano, em especial, no mês de janeiro de 2003 e pode estar relacionada à maior concentração de clorofila no mesmo período. O gastrópode Nacella concinna é uma das espécies mais comuns até profundidades de $25 \mathrm{~m}$ na Baía do Almirantado (Nonato et al., 2000). De acordo com Powell (2001), os eventos de desova de $N$. concinna estão associados à floração de fitoplâcton. A maior concentração de fitoplâncton provê estoque de alimento necessário para o sucesso reprodutivo e sobrevivência larval (Marrari et al., 2008). Absher et al. (2003), Freire et al. (2006) e Bowden et al. (2009) também relacionaram a maior abundância as larvas de gastrópodes no final do verão com a floração de fitoplâncton e temperaturas mais elevadas da água. No entanto, em 2004, as maiores densidades foram observadas nos meses de março, maio e junho (outono-início do inverno), após as maiores concentrações de clorofila de dezembro a fevereiro (verão) e quando ocorreram maiores valores médios de salinidade nos meses de maio e junho e coincidentes com a queda da temperatura média da água. Variáveis que não foram analisadas podem ser responsáveis por essas variações interanuais.

As maiores densidades de larvas de Polychaeta foram observadas no segundo ano, nos meses de março a agosto de 2004 (outono-inverno). Stanwell-Smith et al. (1999) relacionaram as altas densidades dessas larvas com o pico da floração de fitoplâncton no meio do verão e Bowden et al. (2009) também verificaram sua maior 
abundância no verão em conjunto com o início do florescimento do fitoplâncton de verão. Porém, no presente estudo essa relação não pôde ser evidenciada. Freire et al. (2006) também observaram uma variação interanual notável da dominância dessas larvas na baía. É possível que ocorra uma relação da distribuição dos adultos com a ocorrência das larvas, assim como observada por Fetzer (2004) e Vázquez et al. (2007). Além disso, a variação sazonal observada para essas larvas pode ser produto da desova de diferentes espécies de poliquetas na baía.

Alguns autores observaram a dominância de larvas de Polychaeta tanto em ambientes abertos como de águas costeiras (Tanimura et al., 1986; Shreeve \& Peck, 1995; Stanwell-Smith et al., 1999; Sewell, 2005; Sewell et al., 2006). No entanto, a dominância dessas larvas na Antártica também pode estar relacionada à identificação errônea de uma espécie pelágica Pelagobia sp. como larva (Sewell, 2006). Nas amostras coletadas na baía, o poliqueta pelágico Pelagobia $s p$. correspondeu a $2 \%$ e $41 \%$, em média, do total do meroplâncton (2002/2003 e 2003/2004, respectivamente) (observação pessoal).

Larvas de Echinodermata foram mais significativas nos meses de abril-maio (outono) e outubro-novembro de 2003 (primavera), no primeiro ano. As espécies mais comuns de Echinodermata na Enseada Martel são Odonaster validus (Asteroidea), Sterechinus neumayeri (Echinoidea) e Ophionotus victoriae (Ophiuroidea) (Nonato et $a l ., 2000)$. A relação entre a produção primária e a reprodução e a produção de larvas dessas espécies não ficou evidente, assim como em anos anteriores (Freire et al., 2006), e diferentes períodos e locais de desova têm sido registrados para as mesmas, que podem ter uma permanência das larvas no plâncton mais estendida (Chiantore et al., 2002; Bowden et al., 2009). Larvas de Echinodermata tem maior tolerância a baixas salinidades do que adultos, predominando a hidrodinâmica local como responsável pela distribuição dessas larvas (Fetzer, 2004).

De maneira geral, larvas do tipo trocófora foram mais abundantes no segundo ano, nos meses de fevereiro a agosto de 2004 (fim do verão até o inverno) (densidade média maior que 0,6 indivíduos. $100 \mathrm{~m}^{-3}$ ), mas com valores menores que os encontrados por Freire et al. (2006). Esses autores encontraram as maiores densidades médias nos meses de outono-início do inverno, período coincidente com o do presente estudo. Entretanto, Arntz \& Gili (2001) relacionaram o pico máximo dessas larvas com águas mais quentes no período de verão, assim como Bowden et al. (2009) verificaram a 
abundância máxima de larvas de moluscos no verão, o que sugere seu acoplamento com o pulso sazonal de produção primária das altas latitudes.

Larvas de Nemertea (pilidium) estiveram presentes durante ambos os anos na Baía do Almirantado, com densidades médias de 3,48 indivíduos. $100 \mathrm{~m}^{-3}( \pm 7,12)$ no primeiro ano de amostragem e 1,54 indivíduos.100 $\mathrm{m}^{-3}( \pm 3,27)$ em 2004, valores menores aos registros de Sewell (2005) e Vázquez et al. (2007). Esses autores relacionaram a abundância de larvas pilidium às correntes locais. No presente estudo, larvas pilidium foram observadas durante todo o ano, o que sugere desova permanente na coluna de água. Freire et al. (2006) também verificaram essa constância e uma diferença interanual na baía, em anos anteriores. Larvas de Nemertea foram também observadas durante todo o ano em amostras no Mar de Bellingshausen (Shreeve \& Peck, 1995), Ilhas Signy (Stanwell-Smith et al., 1999) e Hatera Point, Ilha Adelaide (Bowden et al., 2009), sugerindo que este é um padrão geral. Essas larvas podem alimentar-se de restos celulares e bactérias (Peck, 1993) e, portanto, não são dependentes exclusivamente do principal florescimento de fitoplâncton (Bowden et al., 2009).

Quanto à variação espacial da comunidade do meroplâncton entre os locais na Baía do Almirantado, as maiores densidades de larvas de Gastropoda foram observadas na área Mackellar e na entrada da baía. Larvas de Polychaeta estiveram distribuídas de maneira mais ou menos uniforme por todas as áreas da baía, assim como as densidades de larvas de Echinodermata. Já as larvas do tipo pilidium de Nemertea, apresentaram valores mais representativos nas estações localizadas na entrada da Baía do Almirantado e também na margem esquerda da Enseada Martel. Em relação às larvas do tipo trocófora, estas apresentaram as maiores densidades nas estações localizadas na área Martel, porém estiveram presentes em todas as áreas durante ambos os períodos. Embora a abundância da maioria dos grupos do meroplâncton tenha sido variável quanto à área de maior densidade, houve uma tendência de valores mais expressivos de larvas nas enseadas do que no canal principal, assim como observado por Freire et al. (2006) e pode ser devido à geomorfologia das enseadas, o que provavelmente determina a formação de redemoinhos, que podem contribuir para retenção de larvas na área (Absher et al., 2003; Freire et al., 2006).

A Baía do Almirantado congelou no ano de 2002/2003 entre junho e agosto de 2002 (observação pessoal). Essa condição parece ter se refletido na reprodução dos 
invertebrados marinhos bentônicos e na produção de larvas no primeiro ano de estudo, uma vez que as densidades de larvas foram maiores do que em 2003/2004. A produção de larvas de Gastropoda e Nemertea provavelmente foi influenciada pelo congelamento da baía. Larvas véliger foram mais abundantes no período de primavera e verão logo após o degelo da baía e relacionadas com temperaturas mais altas. Larvas pilidium, ao contrário, foram predominantes entre o outono e a primavera no ano seguinte ao congelamento, coincidentes com maiores concentrações de clorofila no verão e ventos mais amenos. Larvas de Polychaeta foram expressivas nas coletas da primavera de 2002, com valores maiores valores médios de intensidade de ventos. Larvas trocófora e de Polychaeta foram mais abundantes nos períodos de outono e inverno de 2004, com menores concentrações de clorofila e transparência da água. A variação interanual é um fenômeno comum entre os invertebrados marinhos (Powell, 2001) e essa variação temporal da comunidade do meroplâncton é decorrente das variações de um conjunto de fatores ambientais.

De maneira geral, a maioria dos grupos estudados não exibiu um nítido padrão espaço-temporal de abundância que poderia implicar em sazonalidade propriamente dita. Mincks et al. (2007) também não encontraram padrão específico para o recrutamento de invertebrados marinhos bentônicos antárticos. Sugerem, ainda, que esse recrutamento exibe variabilidade espaço-temporal e parece estar desacoplado da floração do fitoplâncton. Em contraste com essa proposta, Bowden et al. (2009) sugerem que a desova larval da maioria dos invertebrados com desenvolvimento planctônico está acoplado ao pulso sazonal de produção primária, exceto as larvas de Nemertea e de Asteroidea. Na Baía do Almirantado, as larvas véliger foram mais abundantes no período de verão de 2003, coincidentes com as maiores concentrações de clorofila. Entretanto, não ficou evidente a correlação entre a distribuição e abundância da comunidade do meroplâncton com as complexas variáveis ambientais na Baía do Almirantado.

Os resultados mostram uma variação interanual evidente, mas não um padrão nítido de sazonalidade para alguns grupos. A variabilidade na abundância larval pode estar relacionada à hidrologia local e padrões reprodutivos específicos das espécies bentônicas com desenvolvimento indireto, cujos ciclos reprodutivos são afetados por características ambientais (Pearse et al., 1991). Vázquez et al. (2007) também relacionaram a abundância do meroplâncton com as condições ambientais e hidrografia 
local. O congelamento da baía no inverno do primeiro ano de amostragem (2002) pode ter afetado a reprodução dos invertebrados bentônicos e a produção de larvas. $\mathrm{O}$ ciclo de vida dos organismos no ecossistema costeiro marinho antártico depende do ciclo anual e das variações interanuais da cobertura do gelo marinho (Ducklow et al., 2007).

Como os organismos meroplanctônicos estão sujeitos aos processos passivos de transporte, um melhor conhecimento da hidrografia da área é necessário para uma interpretação dos padrões de distribuição observados. A dispersão desses organismos depende da distribuição de adultos e da hidrodinâmica predominante (Pedrotti \& Fenaux, 1992). Sewell (2006) acrescenta ainda que a sua distribuição é influenciada pelas diferenças nas condições hidrográficas. A hidrologia local pode criar condições desfavoráveis para o deslocamento das larvas, mas também contribui para a retenção do meroplâncton em áreas de desova (Scheltema, 1988). 


\section{REFERÊNCIAS BIBLIOGRÁFICAS}

Absher, T.M.; Boehs, G.; Feijó, A.R. \& Cruz, A.C. 2003. Pelagic larvae of benthic gastropods from shallow Antarctic waters of Admiralty Bay, King George Island. Polar Biol., 26(6):359-364.

Arntz, W.E. \& Gili, J.M. 2001. A Case for Tolerance in Marine Ecology: Let Us Not Put out the Baby with the Bathwater. Scientia Mar., 65(Suppl. 2): 283-299.

Boltovskoy, D. 1999. South Atlantic Zooplankton. Leiden, The Netherlands, Backhuys Publishers. 1706p.

Bosch, I.; Beuchamp, K.B.; Steele, M.E. \& Pearse, J.S. 1987. Development, metamorphosis, and sazonal abundance of embryos and larvae of the Antarctic sea urchin Sterechinus neumaryeri. Biol. Bull., 173:126-135.

Bosch, I. \& Pearse, J.S. 1990. Developmental types of shallow water asteroids of McMurdo Sound, Antarctica. Mar. Biol., 104:41-46.

Bowden, D.A.; Clarke, A. \& Peck, L. 2009. Seasonal variation in the diversity and abundance of pelagic larvae of Antarctic marine invertebrates. Mar. Biol., 156:2033-2047.

Boysen-Ennen, E. \& Piatkowski, U. 1988. Meso and macrozooplankton communities in the Weddell Sea, Antarctica. Polar Biol., 9:17-35.

Brandini, F.P. \& Rebello, J. 1994. Wind effect on hydrography and chlorophyll dynamics in the coastal pelagial of Admiralty Bay, King George Island, Antarctica. Antarct. Sci., 6(4): 433-442.

Chiantore, M.; Cattaneo-Vietti, R. Elia, L. \& Antonini, M.G.M. 2002. Reprodution and condition of scallop Adamussim colbecki (Smith 1902), the sea-urchin Sterechinus neumayeri (Meissner 1990) and the sea-star Odonaster validus (Koeller 1911) at Terra Nova Bay (Ross Sea):different strategies related to inter-annual variations in food availability. Polar Biol., 25:251-255.

Clarke, A. 1992. Reproduction in the Cold: Thorson Revisited. Invertebr. Reprod. Dev., 22: $175-184$. 
Clarke, K.R. \& Gorley, R.N. 2006. PRIMER V.6.1: User Manual/Tutorial. Plymouth, PRIMER-E Ltd. 190p.

Clarke, K.R. \& Warwick, R.M. 2001. Change in marine communities: an approach to statistical analysis and interpretation. 2nd ed. Plymouth, PRIMER-E Ltd. 172p.

Ducklow, H.W.; Baker, K.; Martinson, D.G.; Quetin, L.B.; Ross, R.M.; Smith, R.C.; Stammerjohn, S.E.; Vernet, M. \& Fraser, W. 2007. Marine pelagic ecosystems:the West Antarctic Peninsula. Phil. Trans. R. Soc. B, 362:67-94.

Fetzer, I. 2004. Reproduction strategies and distribution of larvae and juveniles of benthic soft-bottom invertebrates in the Kara Sea (Russian Artic). Tese de Doutorado, Universidade de Bremen, 242p.

Foster, B.A. 1987. Composition and abundance of zooplankton under the spring sea-ice of McMurdo Sound, Antarctica. Polar Biol., 8:41-48.

Freire, A.S.; Coelho M.J.C. \& Bonecker. S.L.C. 1993. Short term spatial-temporal distribution pattern of zooplankton in Admiralty Bay (Antarctica). Polar Biol., 13(7):433-439.

Freire, A.S.; Absher, T.M.; Cruz-Kaled, A.C.; Kern, Y. \& Elbers, K.L. 2006. Seasonal variation of pelagic invertebrate larvae in the shallow Antarctic waters of Admiralty Bay (King George Island). Polar Biol., 29(4):294-302.

Hosie, G.W.; Cochran, T.G.; Pauly, T.; Beaumont, K.L.; Wright, S.W. \& Kitchener, J.A. 1997. The zooplankton community structure of Prydz Bay, Antarctica, January-February 1993. Proceedings of the NIPR Symposium on Polar Biology, 10:90-133.

Jazdzewski, K.; Jurasz, W.; Kittel, W.; Presler, E.; Presler, P. \& Sicinski, J. 1986. Abundance and biomass estimates of the benthic fauna in Admiralty Bay, King George Island, South Shetland Islands. Polar Biol., 6(1): 5-16.

Kaufmann, R.S.; Fisher, E.C.; Gill, W.H.; Kingh, A.L.; Laubacher, M. \& Sullivan, B. 2003. Temporal patterns in the distribution, biomass and community structure of macrozooplankton and micronekton within Port Foster. Deception Island, Antarctica. Deep Sea Res. II, 50:1765-1785. 
Lange, P.K.; Tenenbaum, D.R.; Braga, E.S. \& Campos, L.S. 2007. Microphytoplankton assemblages in shallow water Admiralty Bay (King George Island, Antarctica). Polar Biol., 30:1483-1492.

Legendre, L \& Legendre, P. 1983. Numerical ecology developments in environmental modelling. Amsterdam, Elsevier Scientific Publishing Company. 412p.

Lipski, M. 1987. Variations of physical conditions, nutrients and chlorophyll $a$ contents in Admiralty Bay (King George Island,South Shetland Islands, 1979). Pol. Polar Res., 8:307-332.

Marrari, M.; Daly, K.L. \& Hu, Chuanmin. 2008. Spatial and temporal variability of SeaWiFS chlorophyll- $\alpha$ distributions west of the Antarctic Peninsula: Implications for krill production. Deep-Sea Res. II, 55:377-392.

Menshenina, L. \& Rakusa-Suszczewski, S. 1992. Zooplankton changes during the year in Admiralty Bay (February 1990-January 1991). Pol. Arch. Hydrobiol., 39(1):6576.

Mileikovsky, S.A. 1971. Types of larval development in marine bottom invertebrates, their distribution and ecological significance: a reevaluation. Mar. Biol., 10:193213.

Mincks, S.L. \& Smith, C.R. 2007. Recruitment patterns in Antarctic Península shelf sediments:evidence of decoupling from seasonal phytodetritus pulses. Polar Biol., 30:587-600.

Pearse, J.S. 1994. Cold-water echinoderms break "Thorson's Rule". In: Young, C.M. \& Eckelbarger, K.J. (eds). Reproduction, larval biology and recruitment of the deepsea benthos. New York, Columbia University Press. 26-43.

Pearse, J.S.; McClintock, J.B. \& Bosch, I. 1991. Reproduction of Antarctic benthic marine invertebrates: tempos, modes and timing. Am. Zool., 31:65-80.

Pechenik, J.A. 1999. On the advantages and disadvantages of larval stages in benthic marine invertebrate life cycles. Mar. Ecol. Prog. Ser., 177:269-297.

Peck, L.S. 1993. Larval development in the Antarctic nemertean Parborlasia corrugatus (Heteronemertea: Lineidae). Mar. Biol., 116:301-310. 
Pedrotti, L.S. \& Fenaux, L. 1992. Dispersal of echinoderm larvae in a geographical area marked by upwelling (Ligurian Sea, NW Mediterranean). Mar. Ecol. Prog. Ser., $86: 217-227$.

Picken, G.B. 1980. Reproductive adaptation of Antarctic benthic invertebrates. Biol. J. Linn. Soc., 14:67-75.

Pilchlmaier, M.; Aquino, F.E.; Da Silva, C. \& Braun, M. 2004.Suspended sediments in Admiralty Bay, King George Island (Antarctica). Pesq. Antart. Bras., 4:77-85.

Poulin, É.; Palma, A.T. \& Féral, J.P. 2002. Evolutionary versus ecological success in Antarctic benthic invertebrates. Trends Ecol. Evol, 17:218-222.

Powell, D.K. 2001. Long-term reproductive cycles in Antarctic and subantarctic freespawning molluscs. VIII SCAR international biology symposium, August 27September 1. Vrije Univers, Amsterdam.

Pruszak, Z. 1980. Current circulation in the water of Admiralty Bay (region of Arctowski Station on King George Island). Pol. Polar Res., 1:55-74.

Rakusa-Suszczewski, S. 1996. Spatial and seasonal variability of température and salinity in Bransfield Strait and Admiralty Bay, Antarctica. Pol. Polar Res., $17: 29-42$.

Rivkin, R.B.; Anderson, M.R. \& Gustafson Jr, D.E. 1991. Ingestion of phytoplankton and bacterioplankton by polar and temperate echinoderm larvae. Antarct. J. US., 26:156-158.

Santos, C.C. 1995. Relação entre fatores físicos e a comunidade zooplanctônica na Baía do Almirantado e regiões costeiras da Ilha Elefante (Antártica). Dissertação de mestrado. Rio de Janeiro, Universidade Federal do Rio de Janeiro, Curso de Pós Graduação em Geografia da UFRJ. 103p.

Scheltema, R.S. 1986. Long-distance dispersal by planktonic larvae of shoal-water benthic invertebrates among central Pacific Islands. Bull. Mar. Sci., 39:241-256.

Scheltema, R.S. 1988. Initial evidence for the transport of teleplanic larvae of benthic invertebrates across the East Pacific barrier. Biol Bull., 174:145-152.

Sewell, M.A. 2005. Examination of the meroplankton community in the south-western Ross Sea, Antarctica, using a collapsible plankton net. Polar Biol., 28:119-131. 
Sewell, M.A. 2006. The meroplankton community of the northern Ross Sea: a preliminary comparison with the McMurdo Sound region. Antarct. Sci., 18(4):595-602.

Shreeve, R.S. \& Peck, L.S. 1995. Distribution of pelagic larvae of benthic marine invertebrates in the Bellingshausen Sea. Polar Biol., 15:369-374.

Simões, J.C.; Arigony-Neto, J. \& Bremer, U.F. 2004. O uso de mapas antárticos em publicações. Pesq. Antart. Bras., 4:191-197.

Skowronski, R.S.P.; Gheller, P.F.; Bromberg, S.; David, C.J.; Petti, MA.V. \& Corbisier, T.N. 2009. Distribution of microphytobenthic biomass in Martel Inlet, King George Island (Antarctica). Polar Biol., 32:839-851.

Smith D.L. 1977. A guide to marine coastal plankton and marine invertebrate larvae. Dubuque, Iowa, U.S.A, Kendall/Hunt. 161p.

Stanwell-Smith, D.; Hood, A.; Peck, L.S. 1997. A field guide to the pelagic invertebrate larvae of the maritime Antarctic. Cambridge, British Antarctic Survey. 152p.

Stanwell-Smith, D.; Peck, L.S.; Clarke, A.; Murray, A.W.A. \& Todd, C.D. 1999. The distribution, abundance and seasonality of pelagic marine invertebrate larvae in the maritime Antarctic. Philos. Trans. R. Soc. London B, 354:471-484.

Strickland, J.D. \& Parsons, T.R. 1968. A practical handbook of seawater analysis. Bull. Fish. Res. Bd. Can., 167:1-311.

Tanimura, A.; Fukuchi, M. \& Hoshiai, T. 1986. Seasonal change in the abundance of zooplankton and species composition of copepods in the ice-covered sea near Syowa station, Antarctica. Mem. Natl. Inst. Polar Res. (Spec Issue) 40:212-220.

Thorson, G. 1950. Reproduction and larval ecology of marine bottom invertebrates. Biol. Rev., 25:1-45.

Todd, C.D.; Laverack, M.S.\& Boxshall, G.A. 1996. Coastal marine zooplankton: A practical manual for students. Cambridge, Cambridge University Press. 106p.

Valentin, J.L. 2000. Ecologia numérica: uma introdução à análise multivariada de dados ecológicos. Rio de Janeiro, Interciência. 117p. 
Vázquez, E.; Ameneiro, J.; Putzeys, S.; Gordo, C. \& Sangra, P. 2007. Distribution of meroplankton communities in the Bransfield Strait, Antarctica. Mar. Ecol. Prog. Ser., 338:119-129.

Young, C.M.; Sewell, M.A. \& Rice, M.E. 2006. Atlas of Marine Invertebrate Larvae. London, Academic Press. 646p.

Zar, J.H. 1996. Biostatistical Analisys. Engewood Cliffs, N.J., Prentice-Hall. 662p. 


\section{Capitulo II. Variação batimétrica da abundância de larvas de inVertebrados NA Baía do Almirantado, IlHa ReI george, AntáRtica (2003/2004).}

INTRODUÇÃO

As grandes profundidades da plataforma continental da Antártica significam que da fauna que lá vive podem ser esperadas adaptações fisiológicas similares àquelas encontradas no mar profundo. Assim como os organismos de mar profundo, a fauna da plataforma continental Antártica também apresenta adaptações singulares às baixas temperaturas e à marcante sazonalidade de alimento (Clarke, 1996).

O Oceano Antártico é caracterizado, sobretudo, por uma combinação de baixas temperaturas, mas estáveis, e uma clara sazonalidade da produção primária. No entanto, a produção primária é causada pelas mudanças na luz mais do que variações na temperatura, fato que possibilita uma separação dos efeitos da temperatura e disponibilidade de alimento. Isso evidencia que a composição da fauna está mais sob a influência da limitação de alimento, do que os efeitos das temperaturas extremamente baixas (Clarke, 1988).

Invertebrados marinhos antárticos desenvolveram adaptações em resposta às baixas temperaturas e à forte sazonalidade de luz, em que a produção primária restringese a um curto período durante o verão austral. Baixas taxas de metabolismo, crescimento lento, longevidade e gigantismo estão entre as estratégias adaptativas apresentadas por estes organismos (Vázquez et al., 2007).

Em termos de reprodução, foram consideradas como adaptações dos organismos para as condições ambientais antárticas a forte sazonalidade com atraso da primeira maturação, a baixa fecundidade, a presença de grandes ovos e o desenvolvimento larval não pelágico (Arntz \& Gili, 2001; Poulin et al., 2002). Entretanto, estudos mais recentes sobre o meroplâncton da Antártica têm revelado a existência de elevadas abundâncias e uma relativa diversidade de formas larvais de invertebrados marinhos bentônicos (Arntz \& Gili, 2001; Absher et al., 2003; Sewell, 2005; Sewell, 2006; Freire et al., 2006; Vázquez et al., 2007; Bowden et al., 2009). 
Alguns dos invertebrados marinhos antárticos mais abundantes têm larvas pelágicas planctotróficas, cujo tempo para o desenvolvimento completo até a metamorfose pode ser muito longo. Estas espécies são particularmente predominantes em regiões produtivas de águas rasas (Pearse et al., 1991). A dominância ecológica de poucas espécies com desenvolvimento planctotrófico (sucesso ecológico) pode estar relacionada com a capacidade de suas larvas para recolonizar habitats perturbados (Poulin et al., 2002). Invertebrados bentônicos com desenvolvimento larval pelágico são os primeiros a recolonizar habitats que são destruídos fisicamente por grandes “icebergs” na Antártica (Thatje et al., 2005).

A maior proporção de espécies incubadoras em relação às espécies com larvas planctônicas entre os invertebrados da zona costeira rasa da Antártica foi tradicionalmente interpretada como uma adaptação às condições ambientais locais. Entretanto, espécies com desenvolvimento planctotrófico são ecologicamente dominantes em termos de abundância de indivíduos nas áreas costeiras. Assim, o sucesso ecológico de espécies com larvas planctônicas pode estar relacionado com o seu modo de desenvolvimento (Poulin et al., 2002).

Amostragens de meroplâncton na Antártica têm mostrado uma consistência na composição de espécies entre diferentes anos (Stanwell-Smith et al., 1999; Freire et al., 2006). Entretanto, a abundância dos tipos de larvas de diferentes espécies pode ser similar (Foster, 1989; 1991; Stanwell-Smith et al., 1999) ou mostrar mudanças entre os anos (Freire et al., 2006).

A ocorrência de larvas planctônicas depende do padrão temporal reprodutivo e do ciclo de vida característico das espécies, associado às variáveis ambientais (Giese \& Pearse, 1977 apud Absher et al., 2003) e, como consequência, a variação interanual na abundância larval torna-se então um fenômeno comum em invertebrados marinhos (Freire et al., 2006).

A dinâmica das populações adultas de invertebrados marinhos bentônicos está acoplada ao recrutamento bem sucedido das larvas e a variação no recrutamento é, frequentemente, atribuída ao suprimento larval e ao seu transporte (Sameoto et al., 2010).

A abundância e composição de larvas planctônicas foram relativamente bem estudadas na região costeira da Antártica (Foster, 1987; Shreeve \& Peck, 1995; Bhaud 
et al., 1999; Stanwell-Smith et al., 1999; Absher et al., 2003; Thatje et al., 2003; Sewell, 2005; Freire et al., 2006; Sewell, 2006; Vázquez et al., 2007; Bowden et al., 2009), mas pouco se conhece sobre os fatores físicos e/ou biológicos que controlam a distribuição vertical desses organismos do meroplâncton (Vázquez et al., 2007; Bowden et al., 2010).

O comportamento larval e a história de vida de invertebrados marinhos bentônicos podem desempenhar um papel crítico em determinar a distância de dispersão das larvas (Shanks, 2009). A maioria das larvas planctônicas é considerada uma partícula passiva na coluna de água e a sua dispersão horizontal pode ser explicada pela hidrodinâmica, principalmente pelas correntes de advecção (Sameoto et al., 2010). No entanto, as larvas podem influenciar seu transporte horizontal por meio de afundamento ou natação entre as diferentes massas de água sobrepostas (Sameoto et al., 2010) e a estratificação vertical dessas larvas planctônicas pode resultar de mecanismos físicos ou biológicos (Garland et al., 2002). Young (1995) sugeriu que o comportamento de natação pode desempenhar uma importante função, especialmente no deslocamento vertical das larvas.

Organismos do meroplâncton fazem uso da migração vertical a fim de manterse em áreas restritas de correntes horizontais, onde exista maior disponibilidade de alimento e mortalidade reduzida (Rawlinson et al., 2004). A migração vertical também é utilizada para auxiliar a dispersão e transporte para locais mais adequados para o assentamento (Garland et al., 2002). Através da migração vertical diária, as larvas podem avaliar o fundo para o assentamento durante o dia e aproveitar a maior disponibilidade de recursos alimentares na coluna de água à noite (Garland et al., 2002). Algumas larvas que migram verticalmente na coluna de água podem retardar a dispersão quando permanecem nas correntes mais profundas, as quais são geralmente mais lentas do que as correntes superficiais (Shanks, 2009).

Os efeitos dependentes da profundidade diferem entre os grupos de larvas (Garland et al., 2002). Segundo Ambrogi et al. (1989), as diferenças na composição do meroplâncton entre as camadas superficiais e mais profundas podem ser uma evidência indireta da existência de um mecanismo de exportação para o oceano aberto, o qual está relacionado à influência das correntes de maré em enseadas. Isto sugere que a estrutura da coluna de água e a hidrografia, determinadas pelas correntes, são responsáveis pelo 
padrão variável de migração vertical e distribuição do meroplâncton (Rawlinson et al., 2004).

Estudos sobre a interação entre comportamento larval e hidrodinâmica são limitados, mas os resultados indicam que tanto a hidrodinâmica pode modificar o comportamento larval, como a larva pode efetivamente alterar sua distribuição vertical na coluna de água sob os vários regimes de fluxo de correntes (Sameoto et al., 2010). No entanto, as condições do fluxo sob as quais as larvas do meroplâncton influenciam sua distribuição vertical por meio de regulagem da profundidade são ainda incertas (Sameoto et al., 2010).

Padrões de migração vertical do meroplâncton são muitas vezes difíceis de esclarecer devido à complexidade dos fatores ambientais relacionados. Além disso, o padrão de migração pode diferir entre as espécies (Vázquez et al., 2007; Bowden et al., 2009). O presente estudo investiga a distribuição vertical e horizontal, as variações de abundância e composição do meroplanctôn na Baía do Almirantado, Antártica, no período entre outubro de 2003 e abril de 2004.

\section{Objetivo Geral}

Neste estudo, teve-se como objetivo avaliar a composição e abundância do meroplâncton em áreas costeiras da Baía do Almirantado, Antártica, em duas profundidades da coluna de água e em diferentes períodos, em relação a variáveis ambientais.

As hipóteses que foram consideradas neste trabalho são:

1. Há variação espaço-temporal na abundância do meroplâncton em duas profundidades da coluna de água na Baía do Almirantado, Antártica?

2. Se existe variação batimétrica, essa variação está relacionada com que variáveis oceanográficas? 


\section{MATERIAIS E MÉtOdOS}

As coletas na Baía do Almirantado foram realizadas em quatro estações e em duas profundidades (0 a $30 \mathrm{~m}$ e 30 a $130 \mathrm{~m}$ ) (Figura 34) (Tabela III), sazonalmente. A lancha oceanográfica SKUA e um bote inflável foram utilizados para o deslocamento e amostragens.

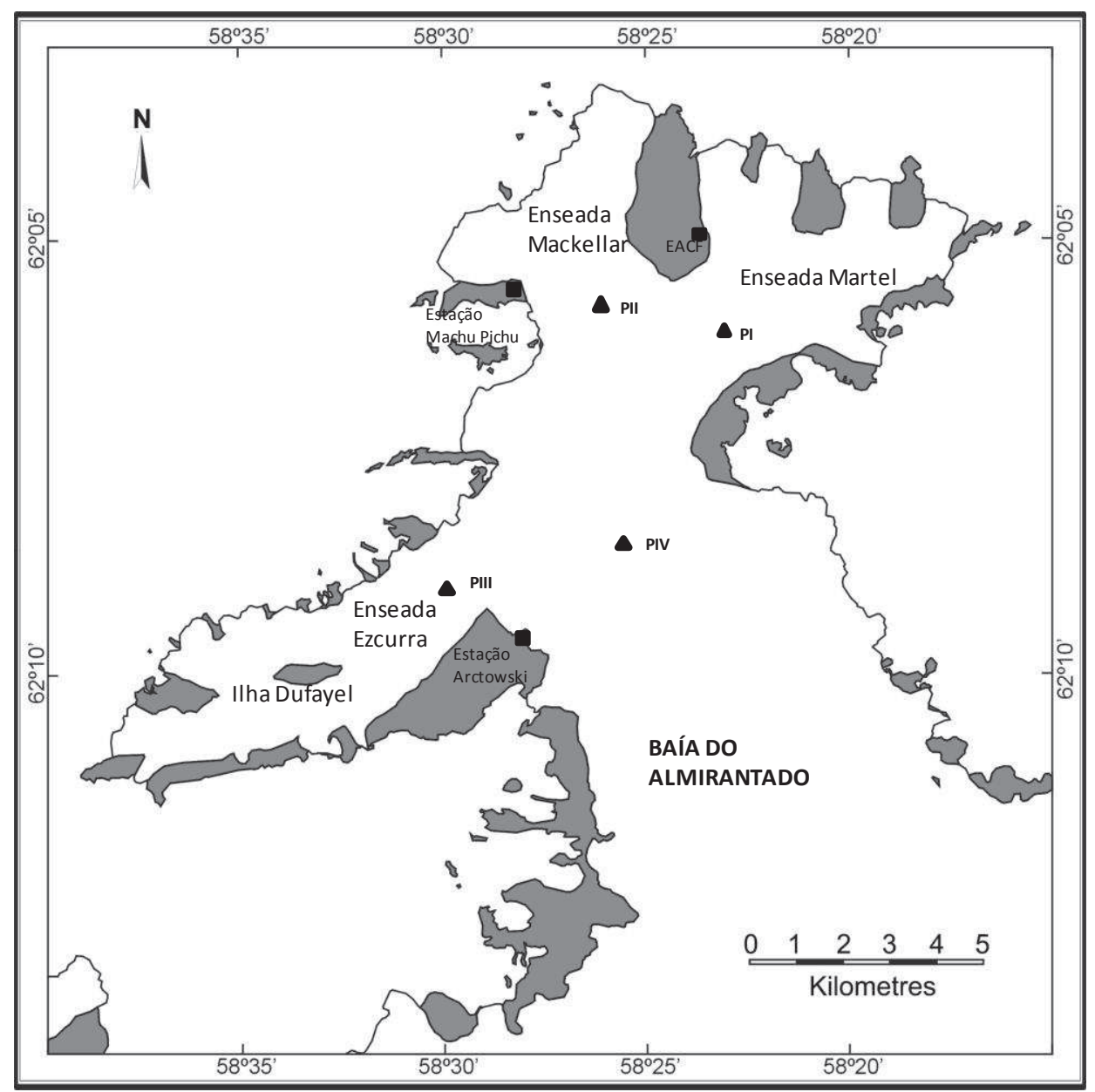

Figura 34. Baía do Almirantado com as estações e áreas de coleta. Adaptado de Simões et al., 2004. 
Tabela III. Coordenadas geográficas das estações e áreas amostradas da Baía do Almirantado, Ilha Rei George, Antártica.

\begin{tabular}{lcc}
\hline ESTAÇÃO & COORDENADA & ÁREA \\
\hline 1. PI & $62^{\circ} 06,177^{\prime} \mathrm{S}$ & Enseada Martel \\
& $58^{\circ} 26,374^{\prime} \mathrm{W}$ & \\
& & \\
2. PII & $62^{\circ} 06,482^{\prime} \mathrm{S}$ & Enseada Mackellar \\
& $58^{\circ} 26,528^{\prime} \mathrm{W}$ & \\
& & \\
3. PIII & $62^{\circ} 08,049^{\prime} \mathrm{S}$ & Enseada Ezcurra \\
& $58^{\circ} 29,013^{\prime} \mathrm{W}$ & \\
& & \\
& & \\
4. PIV & $62^{\circ} 10,039^{\prime} \mathrm{S}$ & Entrada da Baía do \\
& & \\
\hline
\end{tabular}

Para o estudo da comunidade meroplânctonica, foram coletadas e consideradas para as análises 182 amostras entre as estações na XXII Operação Antártica Brasileira (OAB) $(2003 / 2004)$.

As amostragens tiveram periodicidade mensal entre outubro de 2003 e abril de 2004. Este trabalho faz parte do projeto: Interação plâncton-bentos- Estudos de diferentes ciclos de vida de invertebrados marinhos com larvas pelágicas, bênticas ou desenvolvimento direto (CNPq, processo ${ }^{\circ}$ 680044/00-0); coordenado pela Profa Dra Theresinha Monteiro Absher da Universidade Federal do Paraná - Centro de Estudos do Mar.

\section{AMOSTRAGEM NAS ESTAÇÕES:}

Entre as estações, os arrastos diurnos foram estratificados da seguinte forma: entre 0 e $30 \mathrm{~m}$ foram feitos dois arrastos oblíquos consecutivos, a partir de $30 \mathrm{~m}$ de profundidade até a superfície, com rede cônica de plâncton de $60 \mathrm{~cm}$ de boca, $150 \mu \mathrm{m}$ de malha, provida de fluxômetro. Nas coletas, a rede foi lançada com a embarcação 
parada e arrastada a uma velocidade aproximada de dois nós, durante cinco minutos. Tais arrastos de superfície foram designados com a letra S.

$\mathrm{Na}$ camada de 30 a $130 \mathrm{~m}$ foram feitos três arrastos verticais consecutivos, utilizando-se uma rede de fechamento com boca de $60 \mathrm{~cm}$ e malha de $150 \mu \mathrm{m}$. A rede foi lançada a $130 \mathrm{~m}$ de profundidade e içada até a profundidade de $30 \mathrm{~m}$ da superfície, quando foi lançado o mensageiro para ativar o mecanismo de fechamento, amostrandose, dessa forma, $100 \mathrm{~m}$ da coluna de água. Tais arrastos de profundidade foram designados com a letra F.

\section{TRATAMENTO DAS AMOSTRAS:}

As amostras obtidas após cada arrasto foram fixadas em formaldeído a 4\% neutralizado com tetraborato de sódio e acondicionadas em frascos plásticos etiquetados para posterior triagem, identificação e quantificação. A triagem e a identificação das larvas meroplanctônicas foram feitas sob microscópio estereoscópico da Marca Nikon (com aumento de 60 a 100 vezes) no Laboratório de Bentos Antártico do Instituto Oceanográfico/USP.

As larvas foram classificadas segundo os critérios de Smith (1977), Todd et al. (1996), Stanwell-Smith et al. (1997), Boltovskoy (1999) e Young (2006).

\section{VARIÁVEIS AMBIENTAIS:}

Concomitantemente à coleta das amostras de plâncton, foram mensuradas as seguintes variáveis ambientais: temperatura e salinidade da água de superfície, a $15 \mathrm{~m}$ e a $80 \mathrm{~m}$ de profundidade; transparência da água; velocidade do vento, sendo anotada a fase da maré. Foi utilizado um termômetro simples de coluna de mercúrio para medir a temperatura e um refratômetro da marca Atago (escala de 1/100) para o registro da salinidade da água coletada com garrafa de Van Dorn. Foram utilizados um disco de Secchi de cor branca, com $25 \mathrm{~cm}$ de diâmetro, para a medida da transparência da água e um anemômetro eletrônico portátil para avaliação da velocidade e direção do vento.

Para a determinação da concentração de clorofila $a$ e feopigmentos foram obtidas amostras da água da superfície, a $15 \mathrm{~m}$ e a $80 \mathrm{~m}$ de profundidade, com uma garrafa de Van Dorn. As amostras de água de cerca de dois litros foram acondicionadas 
em garrafas plásticas e armazenadas em sacos plásticos pretos para o transporte até o laboratório de Biologia II da Estação Antártica Comandante Ferraz (EACF), onde foram filtradas em bomba a vácuo, usando-se filtros Whatman GF/C. Os filtros foram congelados e estocados para posterior extração e processamento pelo método de Strickland \& Parsons (1968) nos Laboratórios do Centro de Estudos do Mar da Universidade Federal do Paraná (CEM/UFPR).

\section{TRATAMENTO DOS DADOS:}

Visando uma melhor interpretação dos dados, os períodos do ano foram agrupados e denominados da seguinte maneira:

Período 1: outubro e novembro de 2003 - Primavera de 2003 (Pv03);

Período 2: dezembro de 2003 a fevereiro de 2004 - Verão de 2004 (Ve04);

Período 3: março e abril de 2004 - Outono de 2004 (Ot04).

As estações de coleta foram denominadas da seguinte maneira:

Enseada Martel: PI (MT);

Enseada Mackellar: PII (ML);

Enseada Ezcurra: PIII (EZ);

Entrada da Baía do Almirantado: PIV (EBA).

Os dados de abundância, obtidos com a triagem e identificação das larvas, foram expressos de acordo com o volume de água filtrada em cada arrasto, determinado através da seguinte equação:

$\mathrm{V}=\pi^{*} \mathrm{r} 2 * \mathrm{~F}^{*} \Delta$ rotação, onde:

$\mathrm{r}=$ raio da rede $(0,30 \mathrm{~m})$;

$\mathrm{F}=$ fator de aferição do fluxômetro $(0,6566)$;

$\Delta$ rotação $=$ diferença entre número de rotação inicial e final do fluxômetro em cada arrasto. 
O volume médio calculado foi de $112,3 \mathrm{~m}^{3}$. Para calcular a densidade larval, padronizada em indivíduos. $100 \mathrm{~m}^{-3}$, dividiu-se o número de indivíduos identificado pelo volume do respectivo arrasto, multiplicando-se por 100 .

A densidade total do número de larvas de invertebrados foi comparada entre as estações (considerando os períodos) e entre os períodos amostrados (considerando as estações) através de análises de variância (ANOVA TWO-WAY), com nível de significância de $\alpha=0,05$ (Zar, 1996), bem como os dados referentes às variáveis ambientais e a concentração de clorofila $a$ e feopigmentos (entre as estações e períodos amostrados). O teste de comparações múltiplas do tipo LSD foi empregado a posteriori para avaliar as diferenças (Zar, 1996).

Para comparar as estações de coleta nos períodos do ano, quanto às variáveis ambientais, foi utilizada a análise multivariada de ordenação do tipo PCA (análise de componentes principais) (Legendre \& Legendre, 1983; Valentin, 2000), com a utilização das médias das estações de coleta por período do ano. As variáveis ambientais foram padronizadas $(x-\bar{x} / \mathrm{DP})$ para essa análise.

Análise de agrupamento das estações de coleta, por período do ano, quanto à composição do meroplâncton foi realizada com o índice de Bray-Curtis, com os dados de densidade transformados por $\log (\mathrm{x}+1)$ e utilização do método da média ponderada. Foi aplicado o teste SIMPROF para verificar os grupos significantes (Clarke \& Warwick, 2001).

Diferenças na composição do meroplâncton entre estações de coleta e períodos do ano também foram analisadas por meio da análise de ordenação multidimensional não métrica (nMDS), a partir de matrizes de similaridade com a utilização do índice de Bray-Curtis (Clarke \& Warwick, 2001). Os dados referentes ao número de larvas de invertebrados foram transformados para escala logarítmica por $\log (\mathrm{x}+1)$. Os grupos formados na análise de agrupamento foram sobrepostos ao diagrama do nMDS.

Para as análises de variância foi utilizado o programa Statistica, Versão 7.0 e para as análises multivariadas (PCA e nMDS), o software PRIMER, Versão 6.1 (Clarke \& Gorley, 2006). 
VARIÁVEIS AMBIENTAIS:

A temperatura média da água ( \pm desvio padrão) durante o período amostrado variou entre $-1,0^{\circ} \mathrm{C}( \pm 0,1)$ na primavera de 2003 , na camada mais superficial da Enseada Martel, e $1,2^{\circ} \mathrm{C}$ na primavera de $2003( \pm 0,5)$ e verão de $2004( \pm 0,3)$, na camada mais profunda na entrada da baía. Houve variação significativa entre as estações amostradas $(\mathrm{F}=33,31 ; \mathrm{p}<0,001)$, entre os períodos amostrados $(\mathrm{F}=46,49$; $p<0,001)$, bem como na interação entre estações e períodos $(F=21,02 ; p<0,001)$. O teste LSD mostrou diferença significativa das estações e períodos com temperaturas médias acima de $0,8^{\circ} \mathrm{C}$ das com temperaturas médias abaixo de $0^{\circ} \mathrm{C}$ (Figura 35). De um modo geral, a temperatura média foi mais alta na camada de fundo das estações PI, PIII e PIV, na primavera de 2003 e no verão de 2004 . 


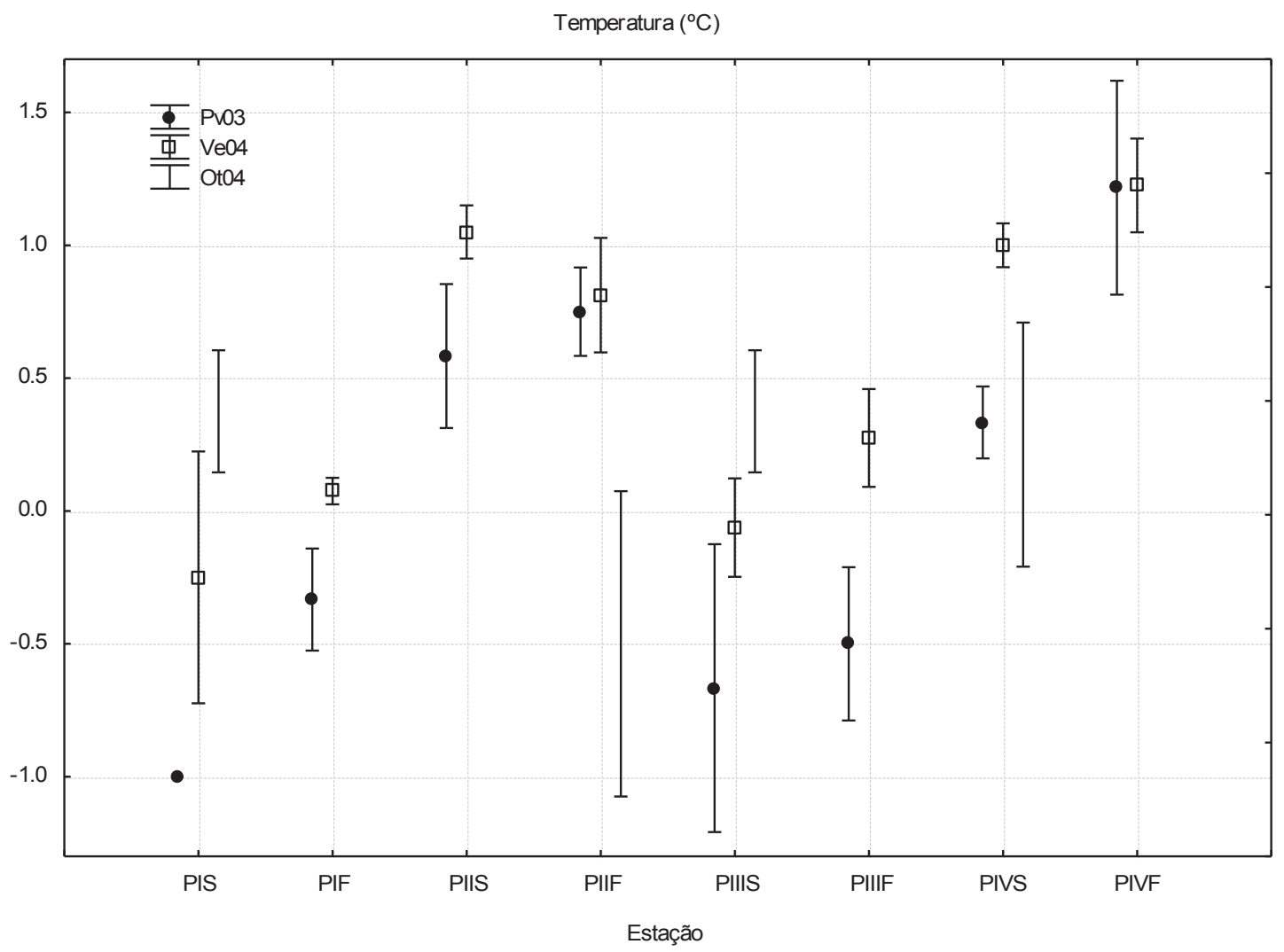

Figura 35. Variação espaço-temporal da temperatura média da água do mar $\left({ }^{\circ} \mathrm{C}\right)$ $(\bar{x} \pm$ IC). Primavera de 2003 a outono de 2004. Baía do Almirantado. PIS= Martel Superfície; PIF= Martel Fundo; PIIS= Mackellar Superfície; PIIF= Mackellar Fundo; PIIIS= Ezcurra Superfície; PIIIF= Ezcurra Fundo; PIVS= Entrada da baía Superfície; PIVF= Entrada da baía Fundo. Pv03= Primavera de 2003; Ve04= Verão de 2004; Ot04= Outono de 2004.

A salinidade média da água ( \pm desvio padrão) variou entre 35 na primavera de 2003, na superfície $( \pm 0,3)$ e na camada mais profunda $( \pm 0,5)$, na Enseada Ezcurra, e 37 $( \pm 0,3)$ no outono de 2004 , na camada mais profunda da estação localizada na entrada da baía. Houve diferença significativa entre as estações amostradas $(F=2,4 ; p<0,001)$, entre os períodos amostrados $(\mathrm{F}=41,9 ; \mathrm{p}<0,001)$, bem como na interação entre estações e períodos $(\mathrm{F}=3,2 ; \mathrm{p}<0,001)$. O teste $\mathrm{LSD}$ mostrou igualdade entre os períodos com valores médios menores (salinidade média menor que 35,5 ) e entre os períodos de valores médios maiores (média maior que 36), os quais diferiram entre si (Figura 36). 


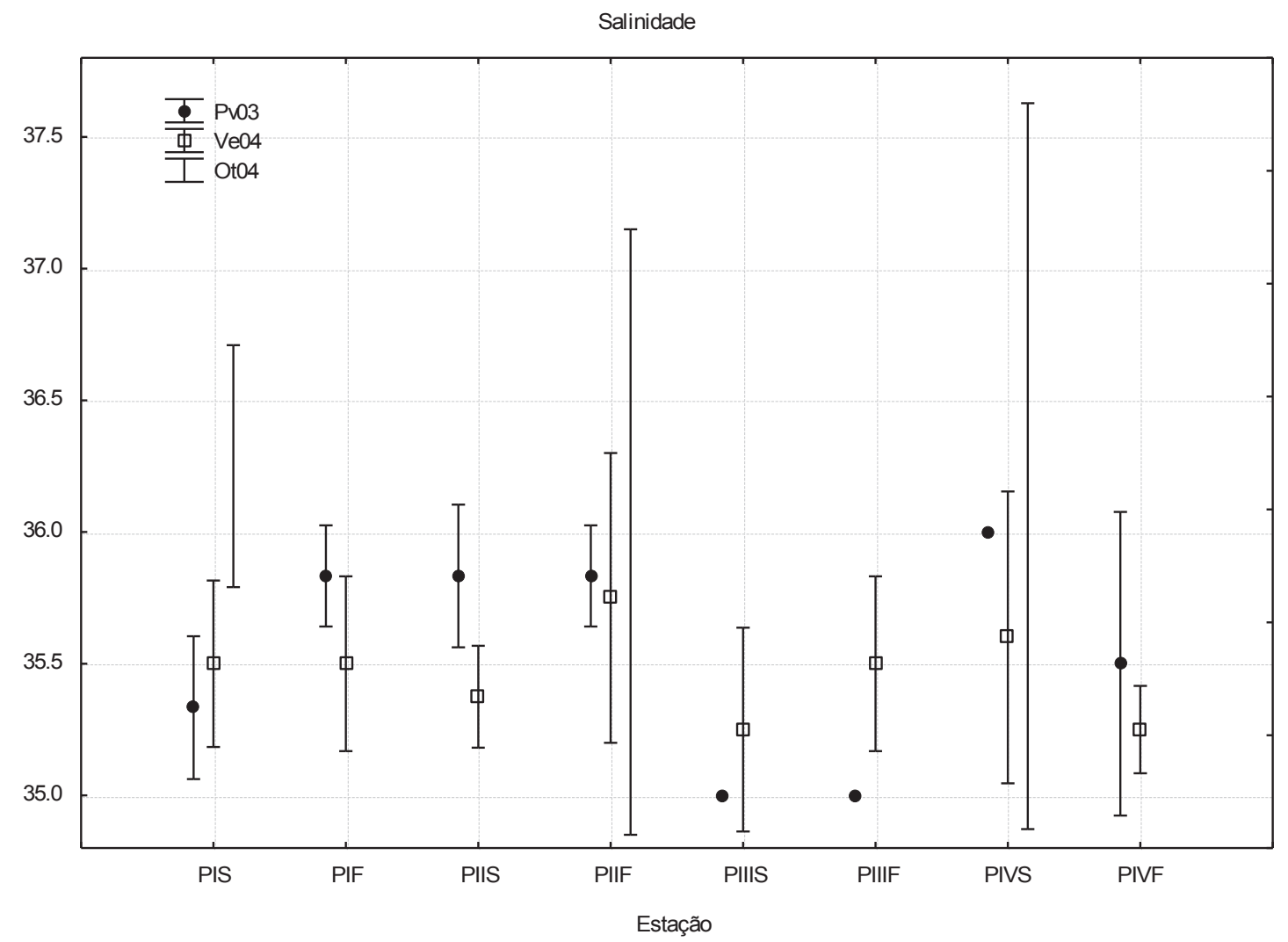

Figura 36. Variação espaço-temporal da salinidade média da água do mar ( $\bar{x} \pm \mathrm{IC})$. Primavera de 2003 a outono de 2004. Baía do Almirantado. PIS= Martel Superfície; PIF $=$ Martel Fundo; PIIS= Mackellar Superfície; PIIF= Mackellar Fundo; PIIIS= Ezcurra Superfície; PIIIF= Ezcurra Fundo; PIVS= Entrada da baía Superfície; PIVF= Entrada da baía Fundo. Pv03= Primavera de 2003; Ve04= Verão de 2004; Ot04= Outono de 2004.

Houve variação significativa na velocidade do vento quando analisadas as estações amostradas $(\mathrm{F}=6,24 ; \mathrm{p}<0,001)$, os períodos amostrados $(\mathrm{F}=11,64 ; \mathrm{p}<0,001)$, bem como na interação entre estações e períodos $(F=5,23 ; p<0,001)$. O teste LSD mostrou diferença significativa entre as estações e períodos amostrados com velocidade média do vento acima de $4,75 \mathrm{~m} \cdot \mathrm{s}^{-1}$ e as com velocidade média menor que $0,75 \mathrm{~m} . \mathrm{s}^{-1}$ (Figura 37). É preciso considerar que esses dados foram pontuais, referentes à hora da coleta. 


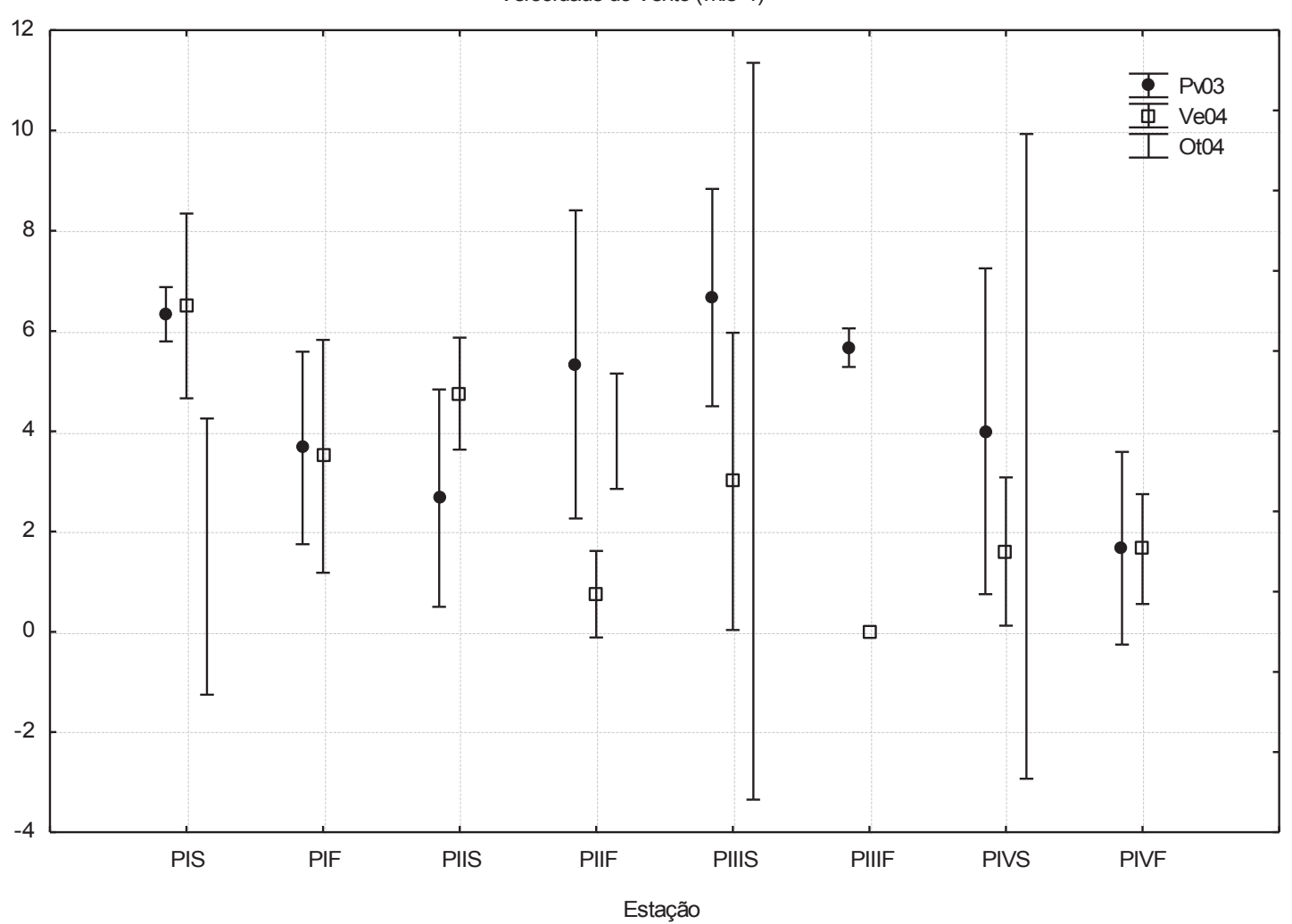

Figura 37. Variação espaço-temporal da velocidade média do vento $\left(\mathrm{m} \cdot \mathrm{s}^{-1}\right)$ (dados pontuais, referentes à hora da coleta) $(\bar{x} \pm$ IC). Primavera de 2003 a outono de 2004. Baía do Almirantado. PIS= Martel Superfície; PIF= Martel Fundo; PIIS= Mackellar Superfície; PIIF= Mackellar Fundo; PIIIS= Ezcurra Superfície; PIIIF= Ezcurra Fundo; PIVS= Entrada da baía Superfície; PIVF= Entrada da baía Fundo. Pv03= Primavera de 2003; Ve04= Verão de 2004; Ot04= Outono de 2004.

A variável transparência da água diferiu significativamente entre as estações amostradas $(F=50,30 ; p<0,001)$ e na interação entre estações e períodos $(F=9,17$; $\mathrm{p}<0,001)$; entretanto, não houve variação significativa quando comparada entre os períodos amostrados $(\mathrm{F}=2,67 ; \mathrm{p}=0,071)$. $\mathrm{O}$ teste LSD mostrou semelhança entre as estações e períodos com valores médios de transparência da água maiores que 10,75 m, e entre os períodos com valores médios menores do que $6,66 \mathrm{~m}$, semelhantes entre si e diferindo dos demais (Figura 38). 


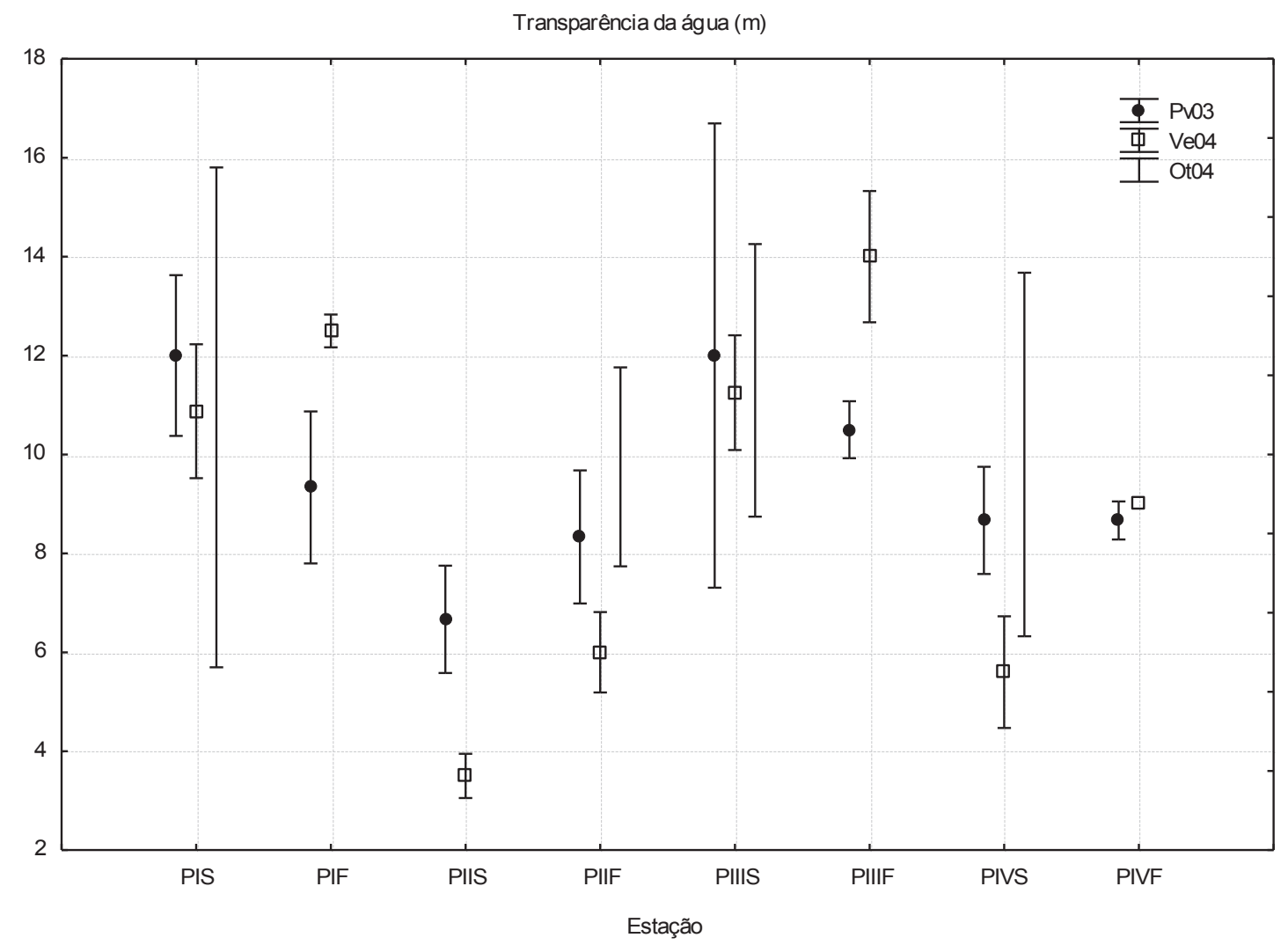

Figura 38. Variação espaço-temporal da transparência média da água (m) ( $\bar{x} \pm \mathrm{IC})$. Primavera de 2003 a outono de 2004. Baía do Almirantado. PIS= Martel Superfície; $\mathrm{PIF}=$ Martel Fundo; $\mathrm{PIIS}=$ Mackellar Superfície; PIIF= Mackellar Fundo; PIIIS= Ezcurra Superfície; PIIIF= Ezcurra Fundo; PIVS= Entrada da baía Superfície; PIVF= Entrada da baía Fundo. Pv03= Primavera de 2003; Ve04= Verão de 2004; Ot04= Outono de 2004.

A concentração média de clorofila $a$ não diferiu significativamente entre as estações amostradas $(\mathrm{F}=0,84 ; \mathrm{p}=0,54)$, tão pouco entre os períodos amostrados $(\mathrm{F}=0,23$; p=0,79). Entretanto, quando analisada a interação entre estações e períodos houve variação significativa $(\mathrm{F}=11,9 ; \mathrm{p}<0,001)$. $\mathrm{O}$ teste $\mathrm{LSD}$ mostrou diferença entre as estações com concentrações médias maiores que $0,114 \mu \mathrm{g} . \mathrm{l}^{-1}$ daquelas com menores valores de concentração média de clorofila $a$ (Figura 39). A concentração média de clorofila $a$ foi maior na camada profunda apenas das estações PI e PIII, na primavera de 2003 e, em especial, no verão de 2004.

As concentrações médias de feopigmentos diferiram entre as estações amostradas $(F=21,15 ; p<0,001)$, entre os períodos amostrados $(F=3,35 ; p<0,001)$ e na 
interação entre estações e períodos $(\mathrm{F}=17,02 ; \mathrm{p}<0,001)$. Quando comparada a concentração de feopigmentos, o teste LSD mostrou semelhança entre os maiores valores médios (acima de 0,047 $\mu \mathrm{g} . \mathrm{l}^{-1}$ ) e entre as concentrações médias abaixo de 0,031 $\mu \mathrm{g} .1^{-1}$, e estes, diferindo entre si (Figura 40).

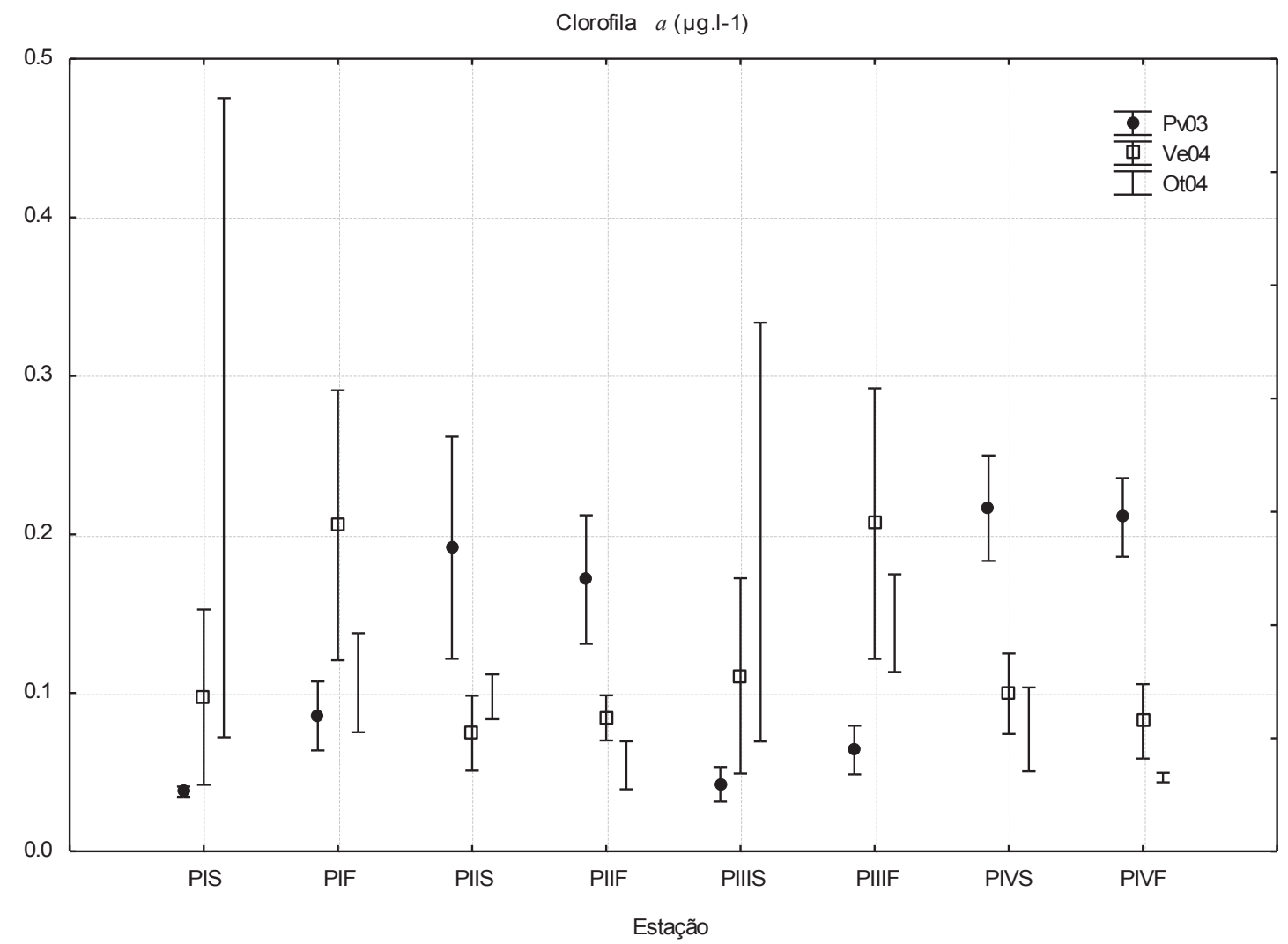

Figura 39. Concentração média de clorofila $a\left(\mu \mathrm{g} \cdot 1^{-1}\right)$ durante o período amostrado ( $\bar{x} \pm$ IC). Primavera de 2003 a outono de 2004. Baía do Almirantado. PIS= Martel Superfície; PIF= Martel Fundo; PIIS= Mackellar Superfície; PIIF= Mackellar Fundo; PIIIS= Ezcurra Superfície; PIIIF= Ezcurra Fundo; PIVS= Entrada da baía Superfície; PIVF= Entrada da baía Fundo. Pv03= Primavera de 2003; Ve04= Verão de 2004; Ot04= Outono de 2004. 


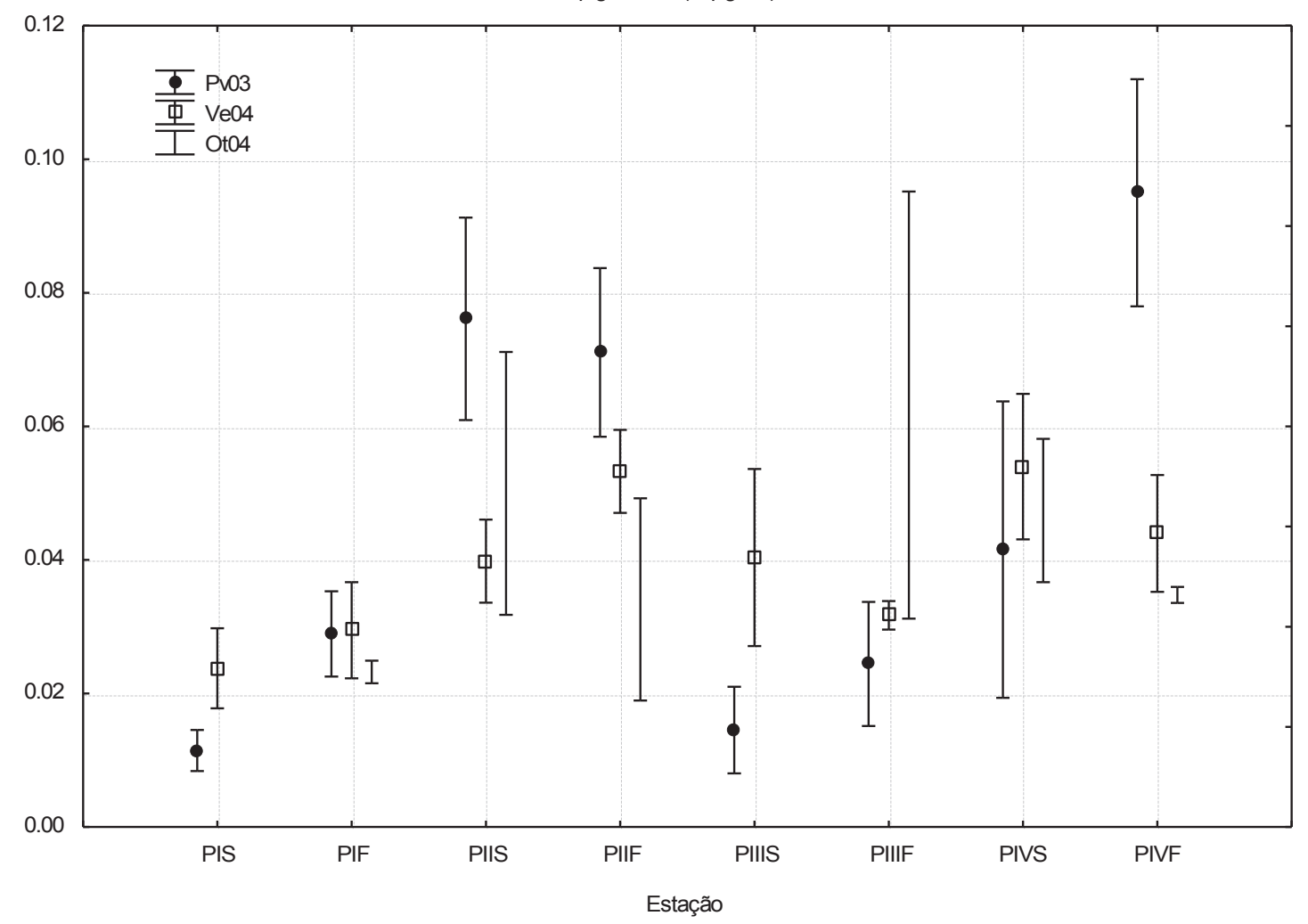

Figura 40. Concentração média de feopigmentos $\left(\mu \mathrm{g} . \mathrm{l}^{-1}\right)$ durante o período amostrado ( $\bar{x} \pm$ IC). Primavera de 2003 a outono de 2004. Baía do Almirantado. PIS= Martel Superfície; PIF= Martel Fundo; PIIS= Mackellar Superfície; PIIF= Mackellar Fundo; PIIIS= Ezcurra Superfície; PIIIF= Ezcurra Fundo; PIVS= Entrada da baía Superfície; PIVF= Entrada da baía Fundo. Pv03= Primavera de 2003; Ve04= Verão de 2004; Ot04= Outono de 2004.

$\mathrm{Na}$ análise de componentes principais (PCA), o eixo 1 explicou 43,5\% da variação dos dados, com os valores médios de feopigmentos e temperatura da água com as maiores contribuições à esquerda, enquanto que o eixo 2 explicou 21,5\% da variação, com maior influência das variáveis: transparência da água e clorofila $a$ (abaixo) (Figura 41). Mais à direita do PCA estão as estações amostradas na primavera de 2003, com maiores valores médios da velocidade do vento e transparência da água. Na porção superior do gráfico do PCA, com maiores valores de temperatura, estão as estações amostradas no verão de 2004. Na parte central do gráfico estão principalmente as estações amostradas no outono de 2004. 


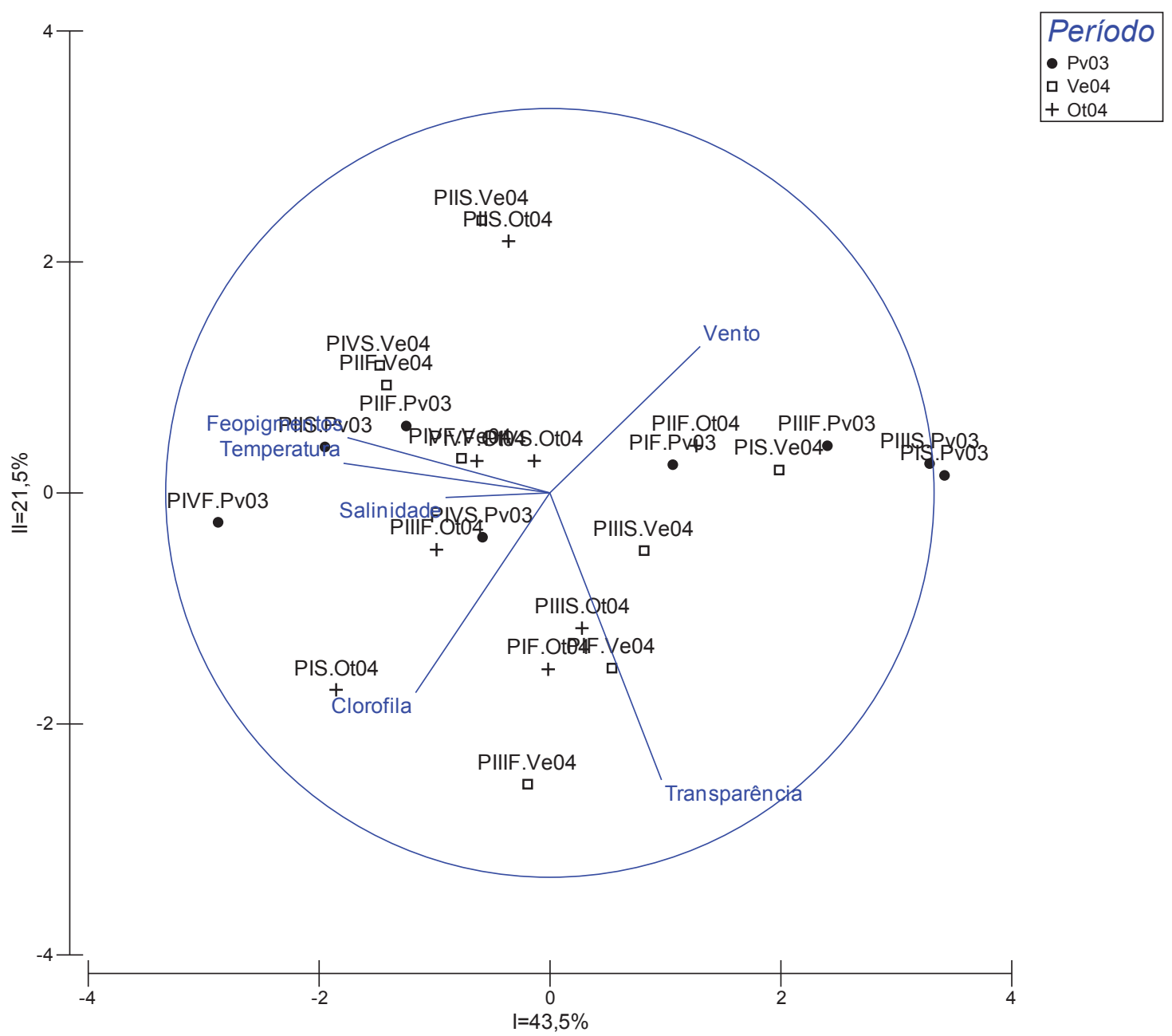

Figura 41. Análise de componentes principais (PCA) para as variáveis ambientais. Baía do Almirantado. PIS= Martel Superfície; PIF= Martel Fundo; PIIS= Mackellar Superfície; PIIF= Mackellar Fundo; PIIIS= Ezcurra Superfície; $\mathrm{PIIIF}=$ Ezcurra Fundo; PIVS= Entrada da baía Superfície; $\mathrm{PIVF}=$ Entrada da baía Fundo. Pv03= Primavera de 2003; Ve04= Verão de 2004; Ot04= Outono de 2004. 
VARIÁVEIS BIOLÓGICAS:

A densidade média do meroplâncton entre as camadas e períodos foi significativamente diferente $(\mathrm{F}=19,33 ; \mathrm{p}<0,001)$. A abundância média do meroplâncton total na Baía do Almirantado variou entre 3,12 indivíduos. $100 \mathrm{~m}^{-3}( \pm 4,8)$ no período de verão na camada superficial $(0-30 \mathrm{~m})$ e 26,69 indivíduos. $100 \mathrm{~m}^{-3}( \pm 26,54)$ na primavera na camada profunda (30-130 m) (Figura 42).

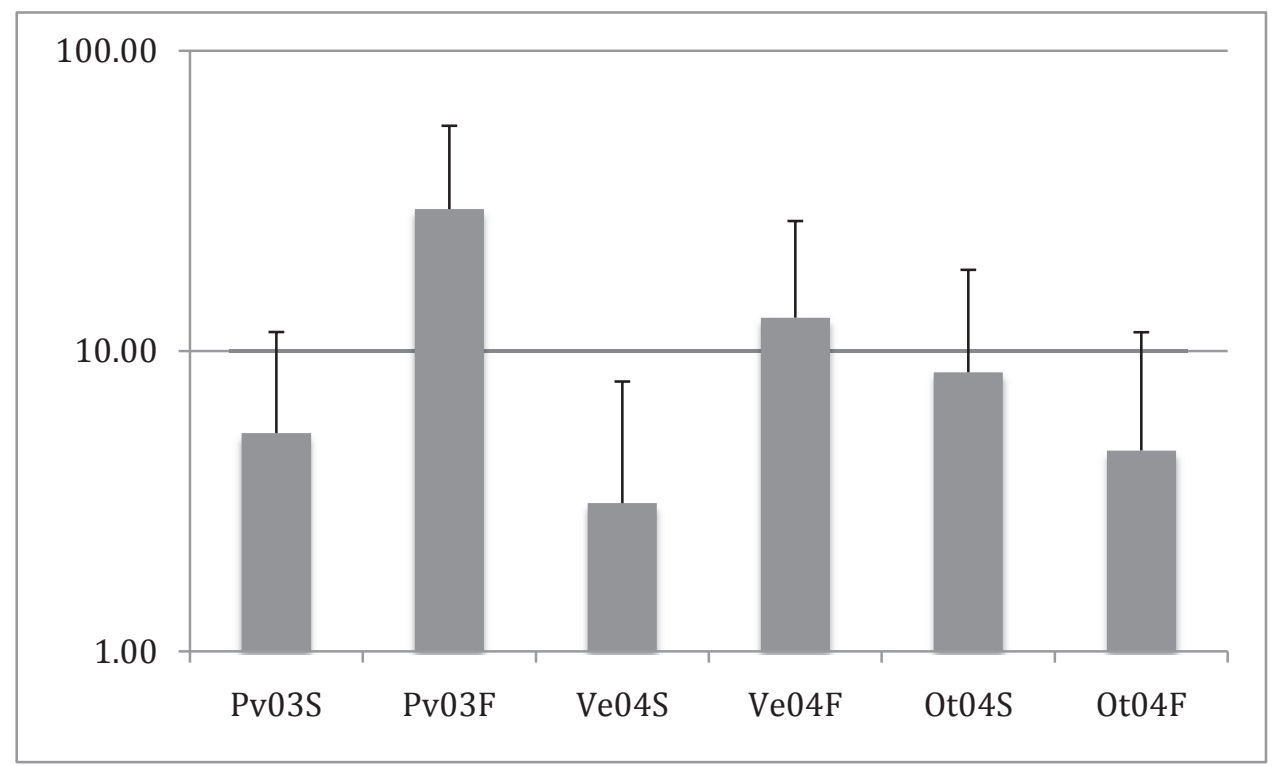

Figura 42. Abundância média de larvas de invertebrados (Dados logaritmizados) coletadas em todo o período amostrado ( $\bar{x} \pm$ DP). Primavera de 2003 a outono de 2004. Baía do Almirantado. $\mathrm{Pv}=$ Primavera de 2003; Ve= Verão de 2004; Ot= Outono de 2004; S= Superfície; F= Fundo.

As densidades do meroplâncton total variaram de 2,3 indivíduos. $100 \mathrm{~m}^{-3}$ (entrada da Baía do Almirantado, verão) a 18 indivíduos.100 $\mathrm{m}^{-3}$ (Enseada Martel, outono) na camada de água entre 0-30 m, e entre 1,8 indivíduos.100 $\mathrm{m}^{-3}$ (Enseada Ezcurra, outono) e 36,5 indivíduos.100 $\mathrm{m}^{-3}$ (entrada da Baía do Almirantado, primavera) na camada mais profunda (30-130 m) (Figura 43). 


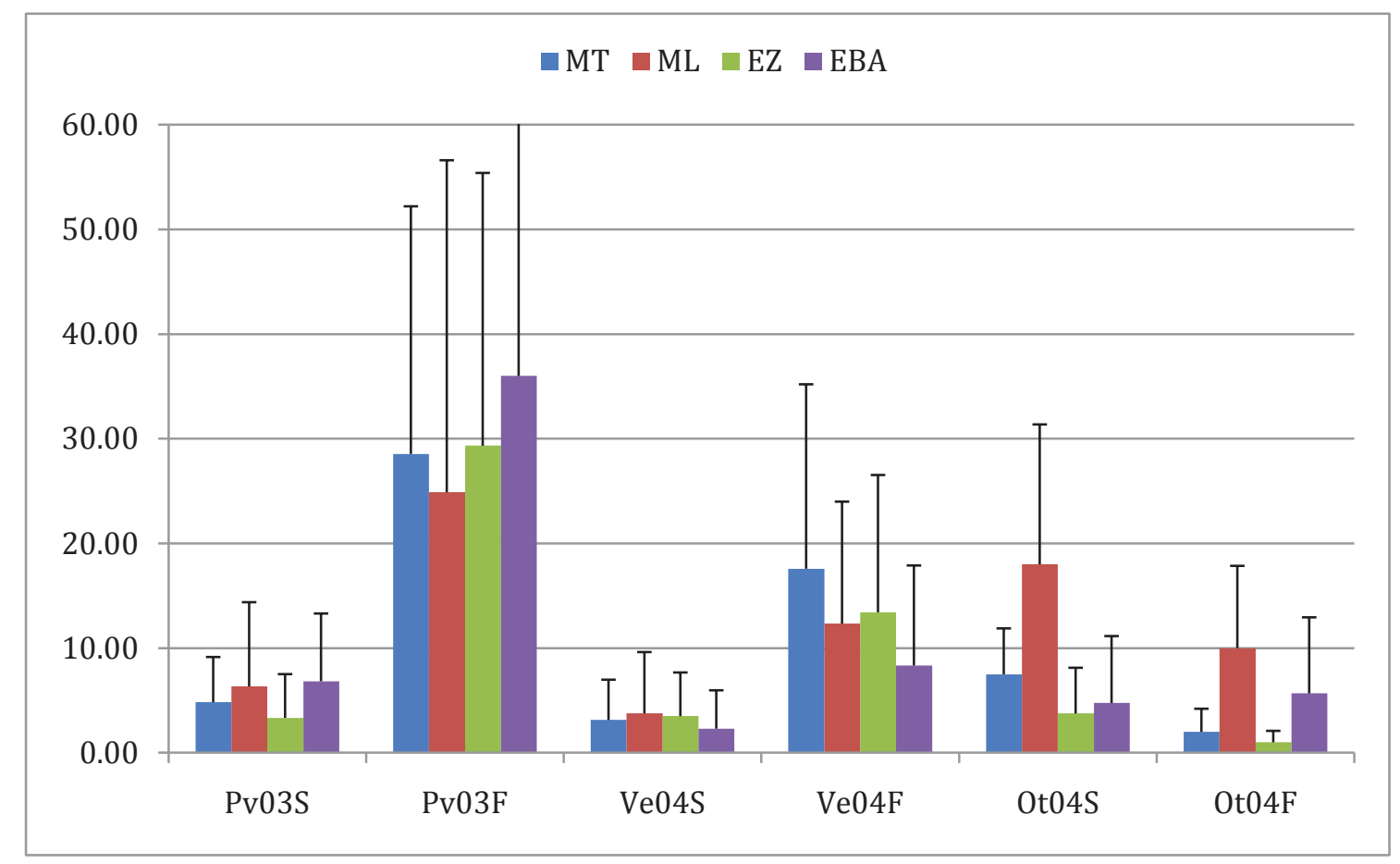

Figura 43. Abundância média dos grupos de larvas de invertebrados (indivíduos. $100 \mathrm{~m}^{-3}$ ) coletadas em todo o período amostrado nas áreas de coleta $(\bar{x} \pm$ DP). Primavera de 2003 a outono de 2004. Baía do Almirantado. $\mathrm{MT}=$ Área Martel; $\mathrm{ML}=$ Área Mackellar; $\mathrm{EZ}=$ Área Ezcurra; $\mathrm{EBA}=$ Área da entrada da baía. Pv03= Primavera de 2003; Ve04= Verão de 2004; Ot04= Outono de 2004.

O grupo de larvas de Nemertea do tipo pilidium foi dominante no meroplâncton total (61\% do total), seguido por larvas de Echinodermata (21\%) e larvas trocófora (10\%) (Figura 44). No entanto, uma grande variabilidade temporal na densidade do meroplâncton foi observada durante o período de estudo. 


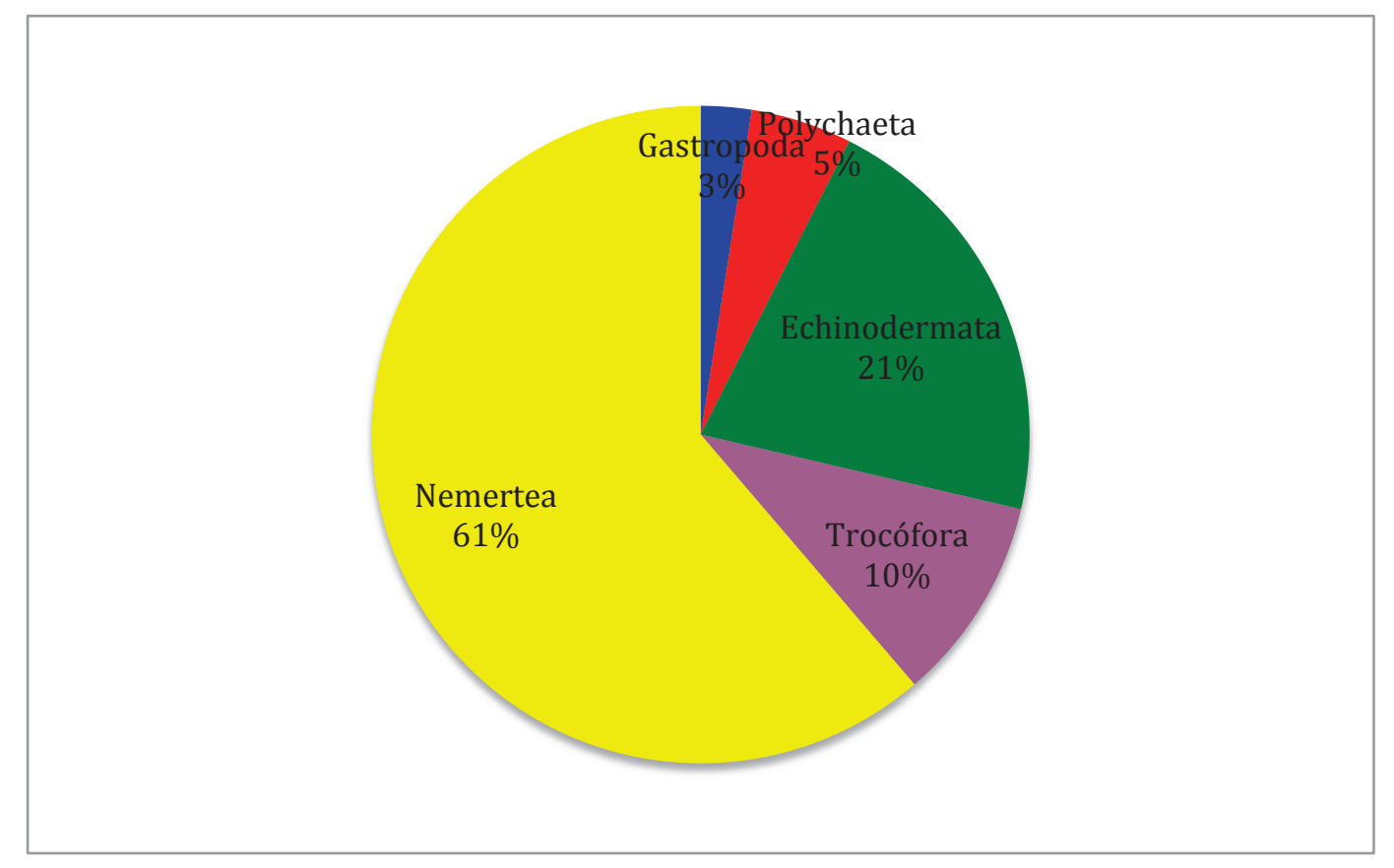

Figura 44. Percentagem relativa (\%) dos grupos de larvas de invertebrados coletadas em todo o período amostrado. Outubro de 2003 a abril de 2004. Baía do Almirantado.

As larvas do tipo pilidium de Nemertea foram predominantes nas coletas dos meses entre outubro de 2003 a fevereiro de 2004, enquanto que nos meses subsequentes, entre março e abril de 2004, as larvas trocófora foram mais representativas. As larvas de Gastropoda, apesar da baixa densidade, estiveram presentes durante todo o período, enquanto as larvas de Polychaeta foram mais representativas no final do período de amostragem, entre fevereiro e abril de 2004. Larvas de Echinodermata, apesar de presentes durante todo o período, foram mais representativas nos meses de outubro e novembro de 2003 (Figura 45). Quanto à profundidade, não houve diferença muito pronunciada no padrão de predominância dos tipos larvais entre as coletas de superfície e de profundidade. Na camada mais profunda (30-130 m), houve maior dominância de larvas de Nemertea (out/03 e jan/04) ou de larvas de Polychaeta (fev-abril/04). 


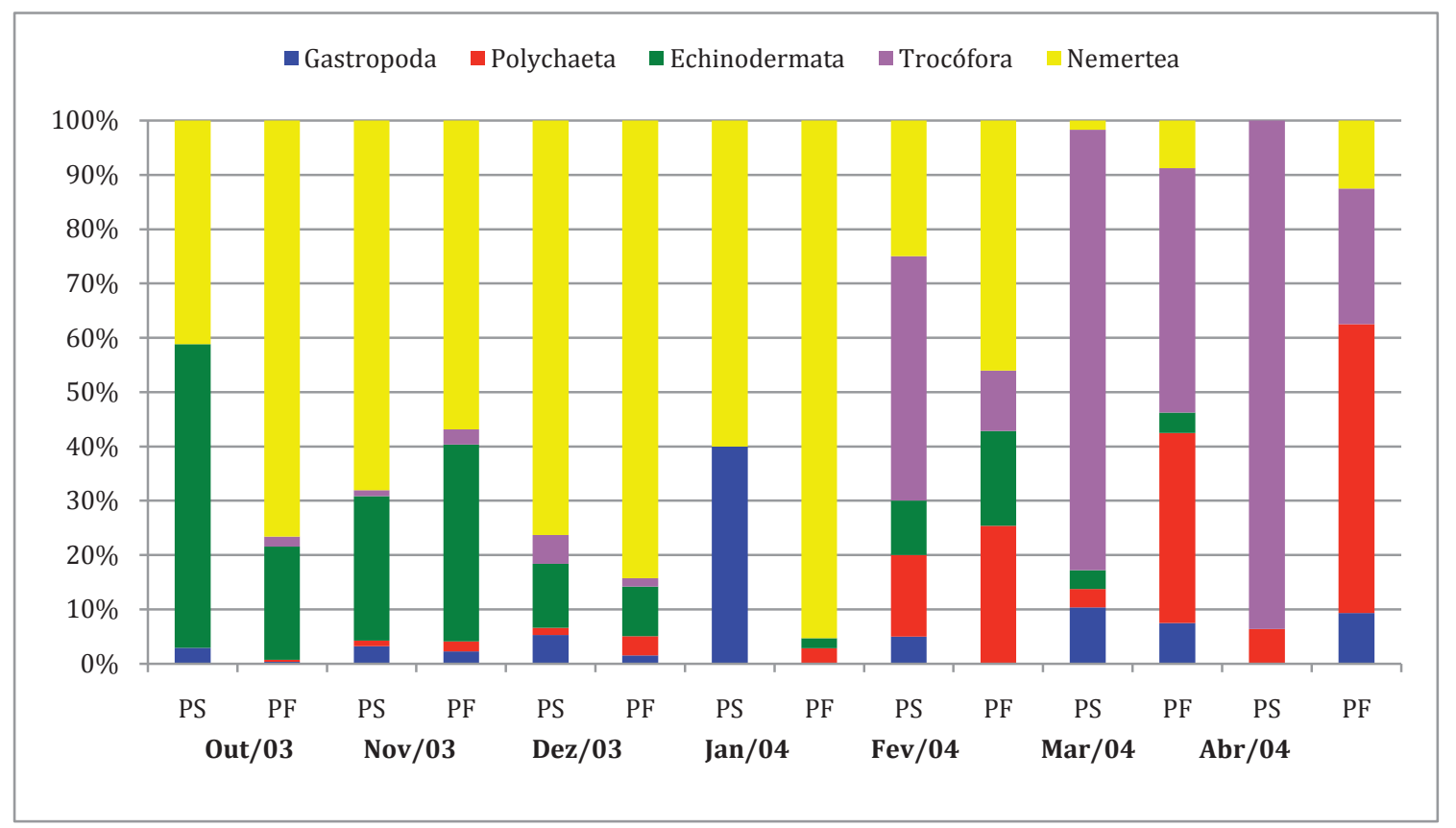

Figura 45. Percentagem relativa (\%) do número de larvas de invertebrados durante o período amostrado. Outubro de 2003 a abril de 2004. Baía do Almirantado.

A densidade de larvas véliger de Gastropoda foram significativamente diferentes quando analisadas as estações amostradas $(\mathrm{F}=2,22 ; \mathrm{p}<0,001)$. Porém, não houve variação significativa entre os períodos $(\mathrm{F}=1,10 ; \mathrm{p}=0,33)$ e na interação entre estações e períodos $(\mathrm{F}=0,88 ; \mathrm{p}=0,57)$ (Figura 46). O teste LSD mostrou a estação de maior abundância localizada na Enseada Martel, arrasto profundo, semelhante apenas com as estações cujas densidades médias durante todo o período foram acima de 0,44 indivíduos. $100 \mathrm{~m}^{-3}$. 


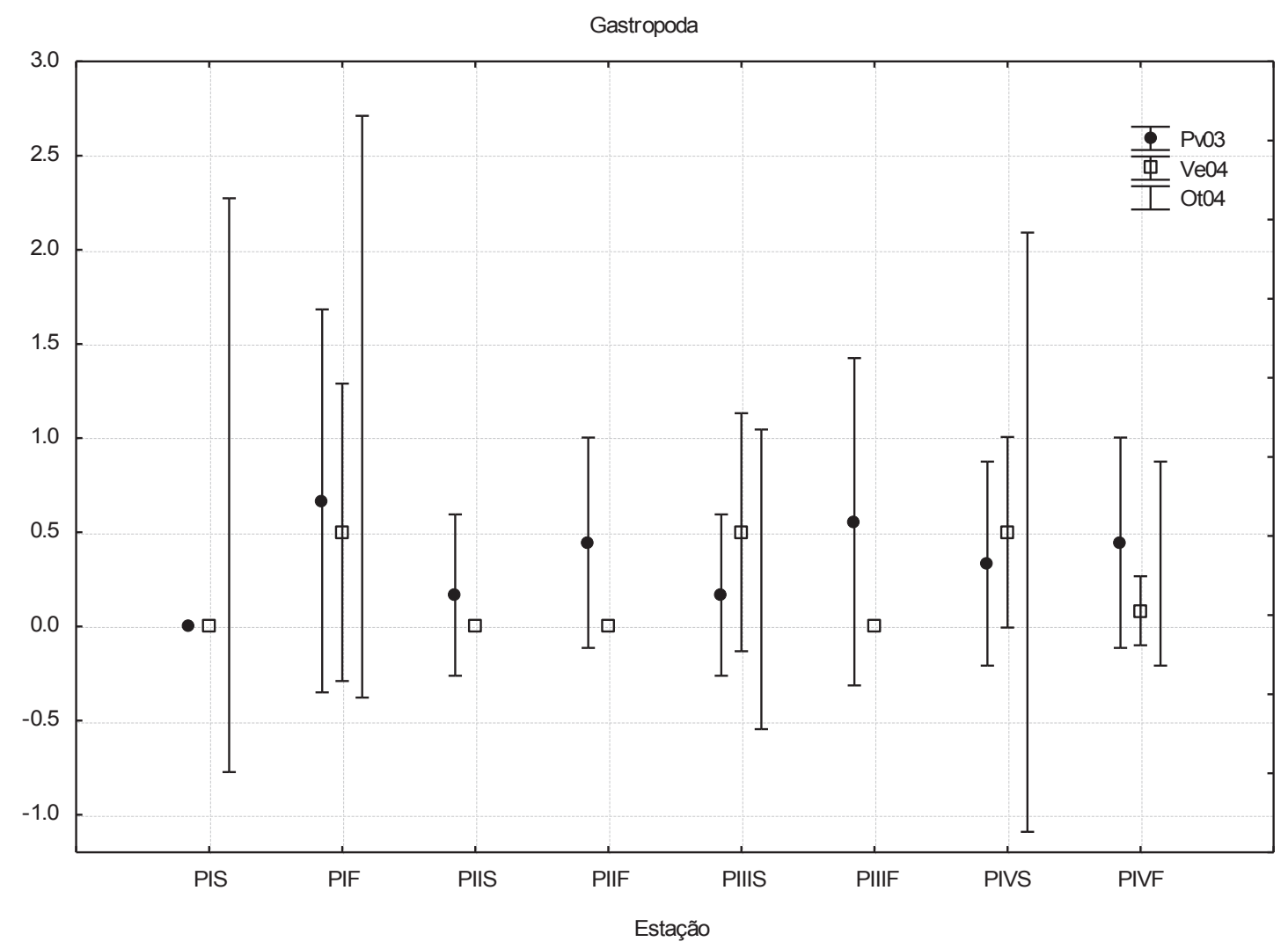

Figura 46. Número médio de larvas de Gastropoda (indivíduos. $100 \mathrm{~m}^{-3}$ ) durante o período amostrado ( $\bar{x} \pm$ IC). Primavera de 2003 a outono de 2004. Baía do Almirantado. PIS= Martel Superfície; PIF= Martel Fundo; PIIS= Mackellar Superfície; PIIF= Mackellar Fundo; PIIIS= Ezcurra Superfície; PIIIF= Ezcurra Fundo; PIVS= Entrada da baía Superfície; PIVF= Entrada da baía Fundo. Pv03= Primavera de 2003; Ve04= Verão de 2004; Ot04= Outono de 2004.

A maior densidade média no número de larvas de Polychaeta ocorreu em outubro de 2004 na estação localizada na entrada da Baía do Almirantado, arrasto profundo $\left(3,2\right.$ indivíduos. $\left.100 \mathrm{~m}^{-3}\right)$. A análise de variância indicou diferença significativa das densidades entre as estações amostradas $(\mathrm{F}=4,33 ; \mathrm{p}<0,001)$, entre os períodos $(\mathrm{F}=8,84 ; \mathrm{p}<0,001)$ e também na interação entre estações e períodos $(\mathrm{F}=2,38 ; \mathrm{p}<0,001)$. O teste LSD mostrou igualdade entre as estações da Enseada Martel e entrada da baía, arrasto profundo, no período de outono de 2004, com densidades médias maiores que 2,66 indivíduos. $100 \mathrm{~m}^{-3}$, que diferiram das demais com menores densidades (Figura 47). 


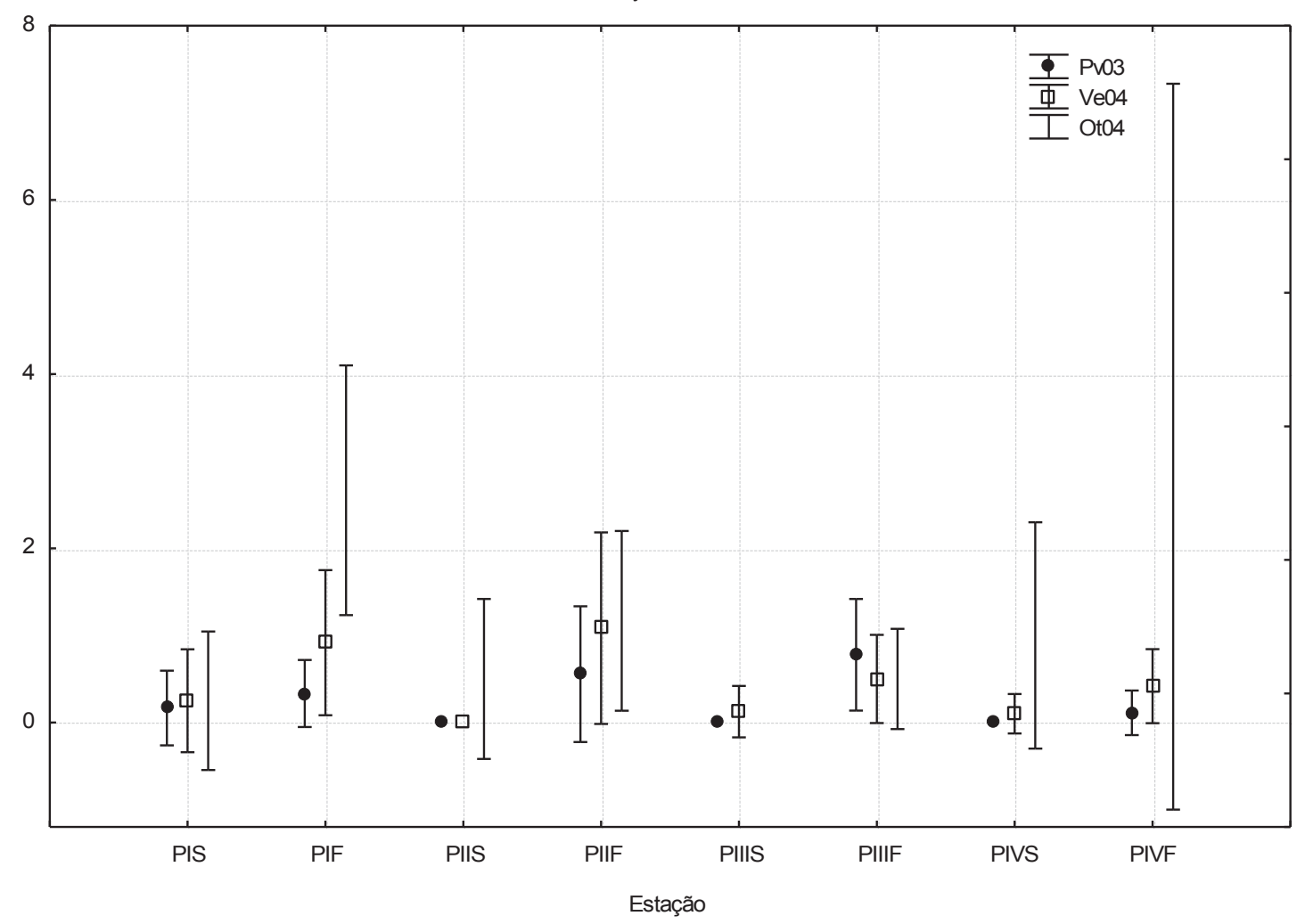

Figura 47. Número médio de larvas de Polychaeta (indivíduos.100 $\mathrm{m}^{-3}$ ) durante o período amostrado ( $\bar{x} \pm$ IC). Primavera de 2003 a outono de 2004. Baía do Almirantado. PIS= Martel Superfície; PIF= Martel Fundo; PIIS= Mackellar Superfície; PIIF= Mackellar Fundo; PIIIS= Ezcurra Superfície; PIIIF= Ezcurra Fundo; PIVS= Entrada da baía Superfície; PIVF= Entrada da baía Fundo. Pv03= Primavera de 2003; Ve04= Verão de 2004; Ot04= Outono de 2004.

Houve variação significativa nas densidades de larvas de Echinodermata quando analisadas as estações de coleta $(F=2,23 ; p<0,001)$, entre os períodos $(F=23,79$; $\mathrm{p}<0,001)$, e na interação entre estações e períodos $(\mathrm{F}=1,85 ; \mathrm{p}<0,001)$. Valores mais expressivos no número de larvas de Echinodermata foram observados nos arrastos profundos de todas as estações amostradas no período de primavera de 2003; estas diferiram estatisticamente dos demais arrastos que apresentaram densidades menores que 2,5 indivíduos. $100 \mathrm{~m}^{-3}$ (Figura 48). 


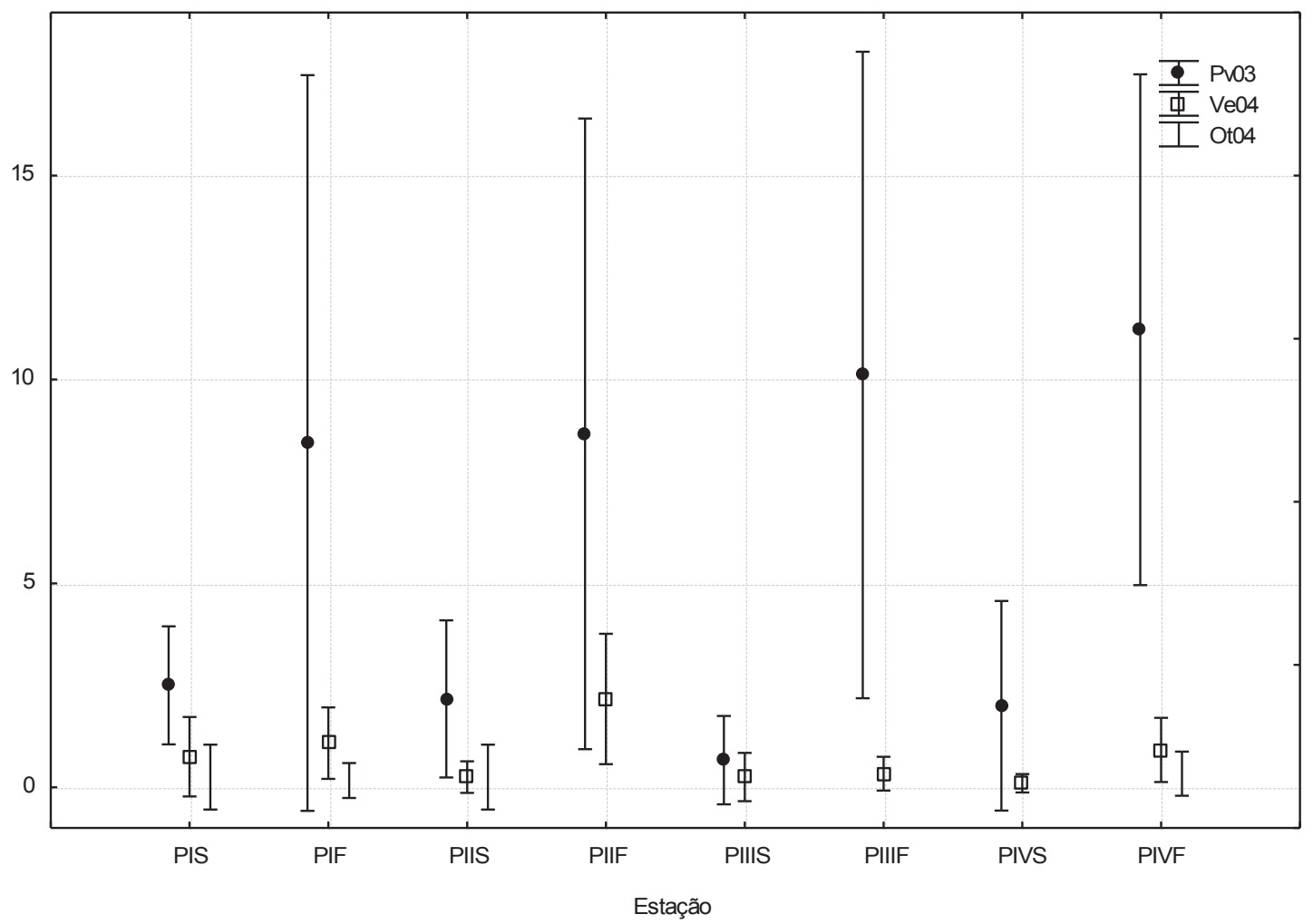

Figura 48. Número médio de larvas de Echinodermata (indivíduos. $100 \mathrm{~m}^{-3}$ ) durante o período amostrado ( $\bar{x} \pm$ IC). Primavera de 2003 a outono de 2004. Baía do Almirantado. PIS= Martel Superfície; PIF= Martel Fundo; PIIS= Mackellar Superfície; PIIF= Mackellar Fundo; PIIIS= Ezcurra Superfície; PIIIF= Ezcurra Fundo; PIVS= Entrada da baía Superfície; PIVF= Entrada da baía Fundo. Pv03= Primavera de 2003; Ve04= Verão de 2004; Ot04= Outono de 2004.

Houve diferença significativa, quando analisada a densidade média de larvas do tipo trocófora, entre as estações $(F=12,23 ; p<0,001)$, entre os períodos $(F=61,97$; $\mathrm{p}<0,001)$ e na interação entre estações e períodos $(\mathrm{F}=11,08 ; \mathrm{p}<0,001)$. De maneira geral, as coletas realizadas no período de outono de 2004, em especial na superfície $(0-30 \mathrm{~m})$, tiveram maior densidade (média maior do que 3,0 indivíduos.100 $\mathrm{m}^{-3}$ ), diferindo estatisticamente dos demais com menor densidade (média menor do que 1,77 indivíduos. $100 \mathrm{~m}^{-3}$ ) (Figura 49). 


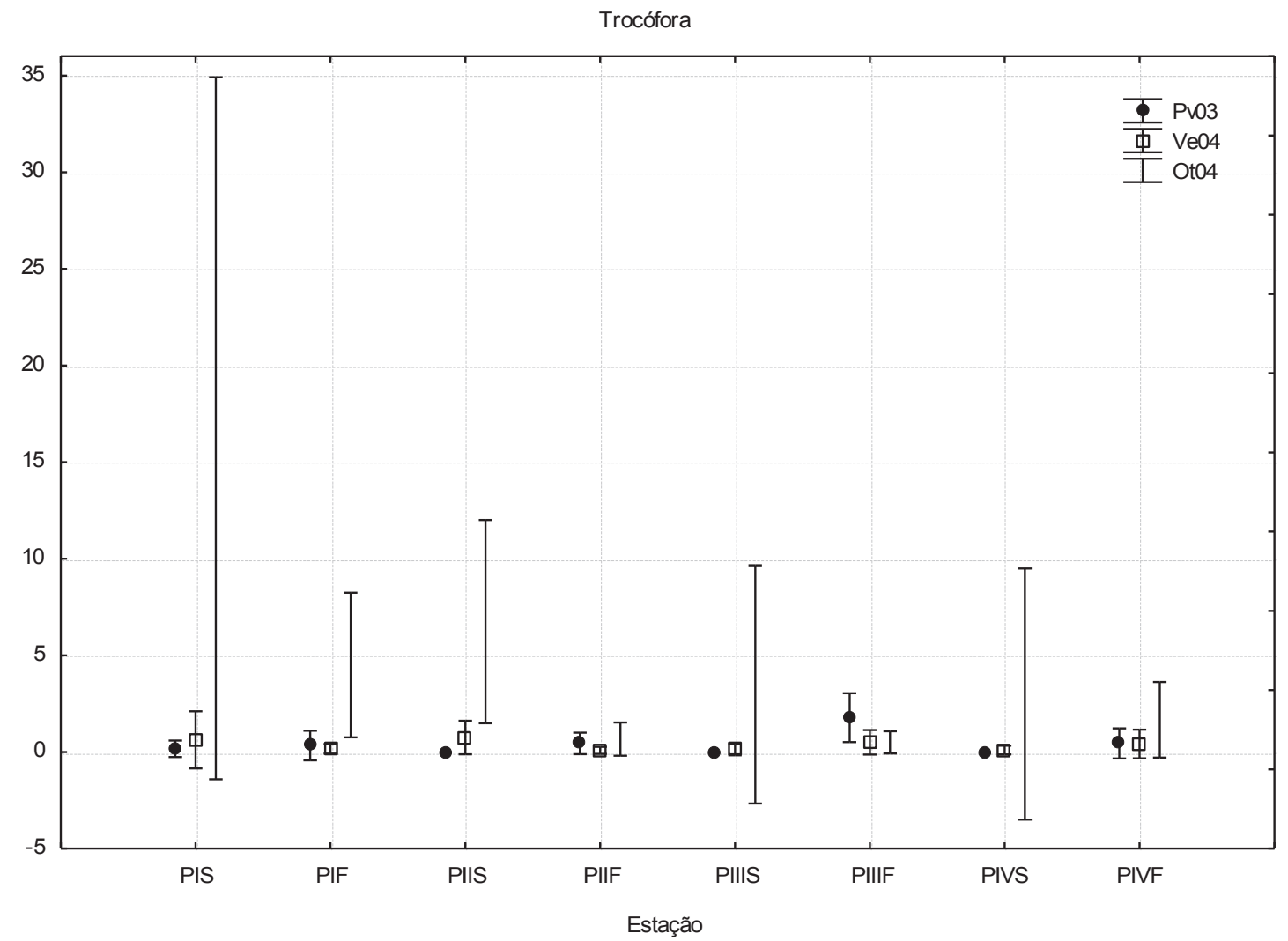

Figura 49. Número médio de larvas trocófora (indivíduos. $100 \mathrm{~m}^{-3}$ ) durante o período amostrado ( $\bar{x} \pm$ IC). Primavera de 2003 a outono de 2004. Baía do Almirantado. PIS= Martel Superfície; PIF= Martel Fundo; PIIS= Mackellar Superfície; PIIF= Mackellar Fundo; PIIIS= Ezcurra Superfície; PIIIF= Ezcurra Fundo; PIVS= Entrada da baía Superfície; PIVF= Entrada da baía Fundo. Pv03= Primavera de 2003; Ve04= Verão de 2004; Ot04= Outono de 2004.

A análise de variância mostrou diferença na densidade média de larvas do tipo pilidium de Nemertea entre as estações de coleta $(F=5,51 ; p<0,001)$, entre os períodos amostrados $(\mathrm{F}=18,65 ; \mathrm{p}<0,001)$, bem como na interação entre estações e períodos $(\mathrm{F}=2,04 ; \mathrm{p}<0,001)$. Nos períodos primavera de 2003 e verão 2004, as larvas desse grupo tiveram maiores densidades na camada mais profunda (Figura 50). O teste LSD mostrou que os meses de menor densidade (média menor do que 6,5 indivíduos.100 $\mathrm{m}^{-3}$ ) diferiram significativamente dos demais. 


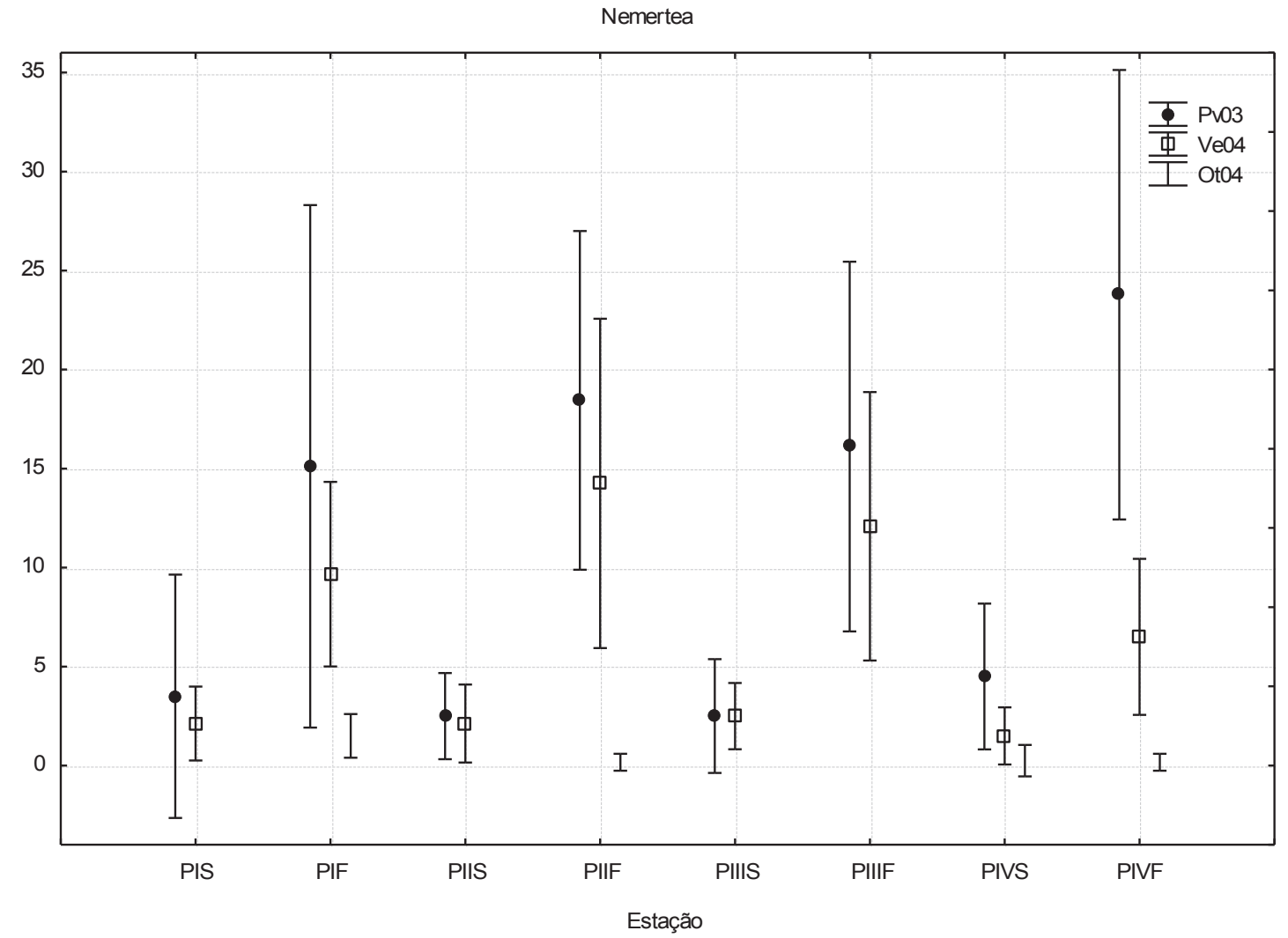

Figura 50. Número médio de larvas de Nemertea (pilidium) (indivíduos.100 $\mathrm{m}^{-3}$ ) durante o período amostrado ( $\bar{x} \pm$ IC). Primavera de 2003 a outono de 2004. Baía do Almirantado. PIS= Martel Superfície; PIF= Martel Fundo; PIIS= Mackellar Superfície; PIIF= Mackellar Fundo; PIIIS= Ezcurra Superfície; PIIIF= Ezcurra Fundo; PIVS= Entrada da baía Superfície; PIVF= Entrada da baía Fundo. Pv03= Primavera de 2003; Ve04= Verão de 2004; Ot04= Outono de 2004.

Na Figura 51 é mostrado o dendrograma resultante da análise de agrupamento das estações, com o uso do coeficiente de similaridade de Bray-Curtis. Essa análise foi realizada com todas as amostras da XXII OAB, do intervalo entre outubro de 2003 e abril de 2004, separadas por estações de coleta e período. A análise de agrupamento mostrou três grupos principais no nível de $60 \%$ de similaridade: o primeiro (G1), formado pelas estações amostradas no período de outono de 2004, em todas as enseadas, amostras de superfície (arrastos oblíquos) e de profundidade (rede de fechamento). O segundo grupo (G2) foi formado pelas amostragens de superfície, com arrastos oblíquos (0-30m), em todas as áreas nos períodos de primavera de 2003 e verão 
de 2004. O terceiro grupo (G3) foi formado pelos arrastos profundos (rede de fechamento) nos períodos de primavera de 2003 e verão de 2004, em todas as enseadas.

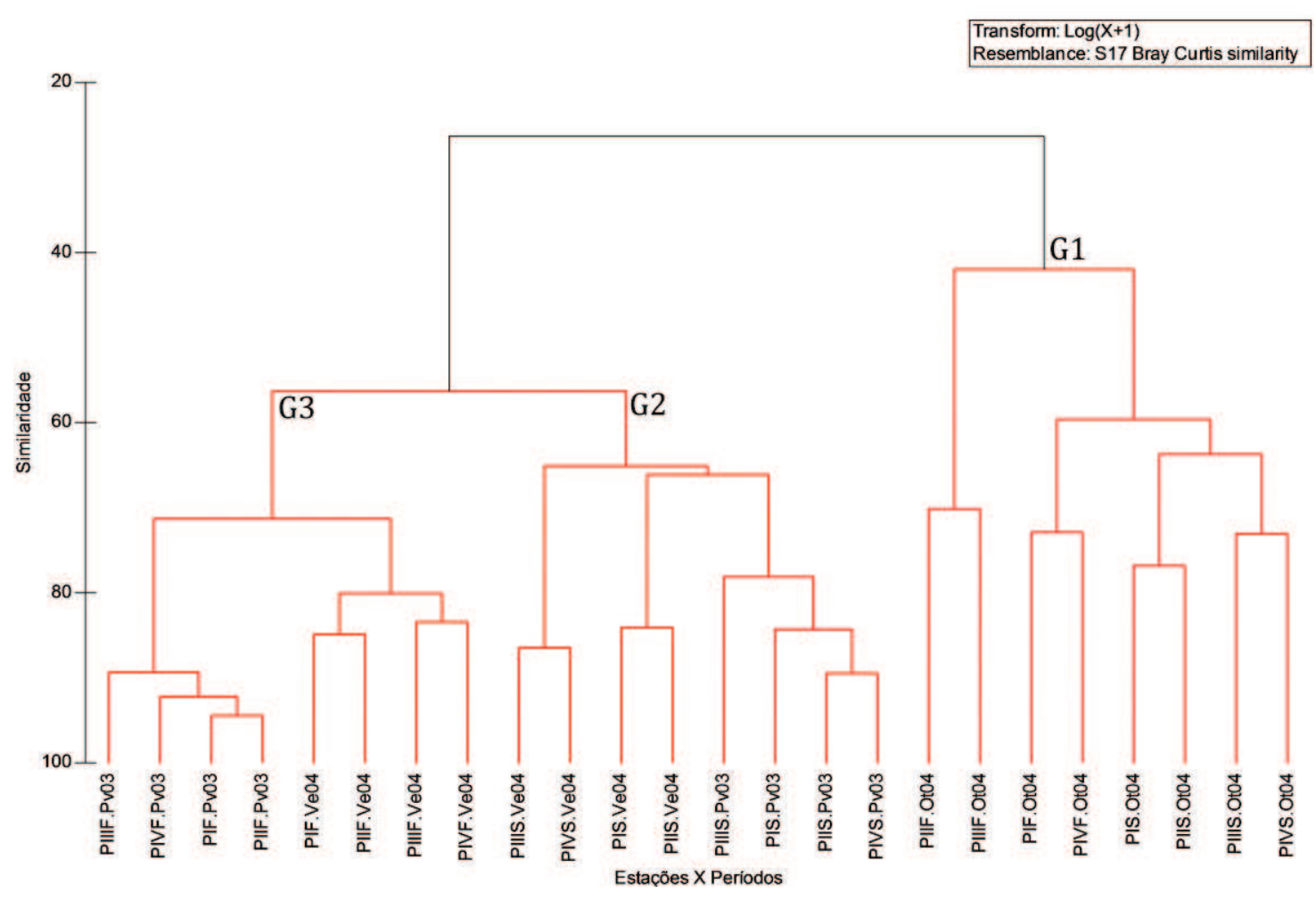

Figura 51. Análise de agrupamento por média ponderada (Índice de Bray-Curtis) considerando as densidades dos grupos do meroplâncton. Em vermelho os agrupamentos não distintos significativamente (SIMPROF). Baía do Almirantado. PIS= Martel Superfície; PIF= Martel Fundo; PIIS= Mackellar Superfície; PIIF= Mackellar Fundo; PIIIS= Ezcurra Superfície; PIIIF= Ezcurra Fundo; PIVS= Entrada da baía Superfície; PIVF= Entrada da baía Fundo. Pv03= Primavera de 2003; Ve04= Verão de 2004; Ot04= Outono de 2004.

A análise de escalonamento multidimensional não-métrica (nMDS) com a abundância dos grupos do meroplâncton separou as amostras em grupos coincidentes com os encontrados na análise de agrupamento, evidenciando as diferenças entre os grupos, com estresse de 0,1 (Figura 52). 
Em síntese, o outono ficou distinto da primavera e verão. Nestes dois períodos, o arrasto de superfície ficou mais separado do arrasto de fundo, mas no outono não se distinguiram bem os arrastos de superfície e de fundo.

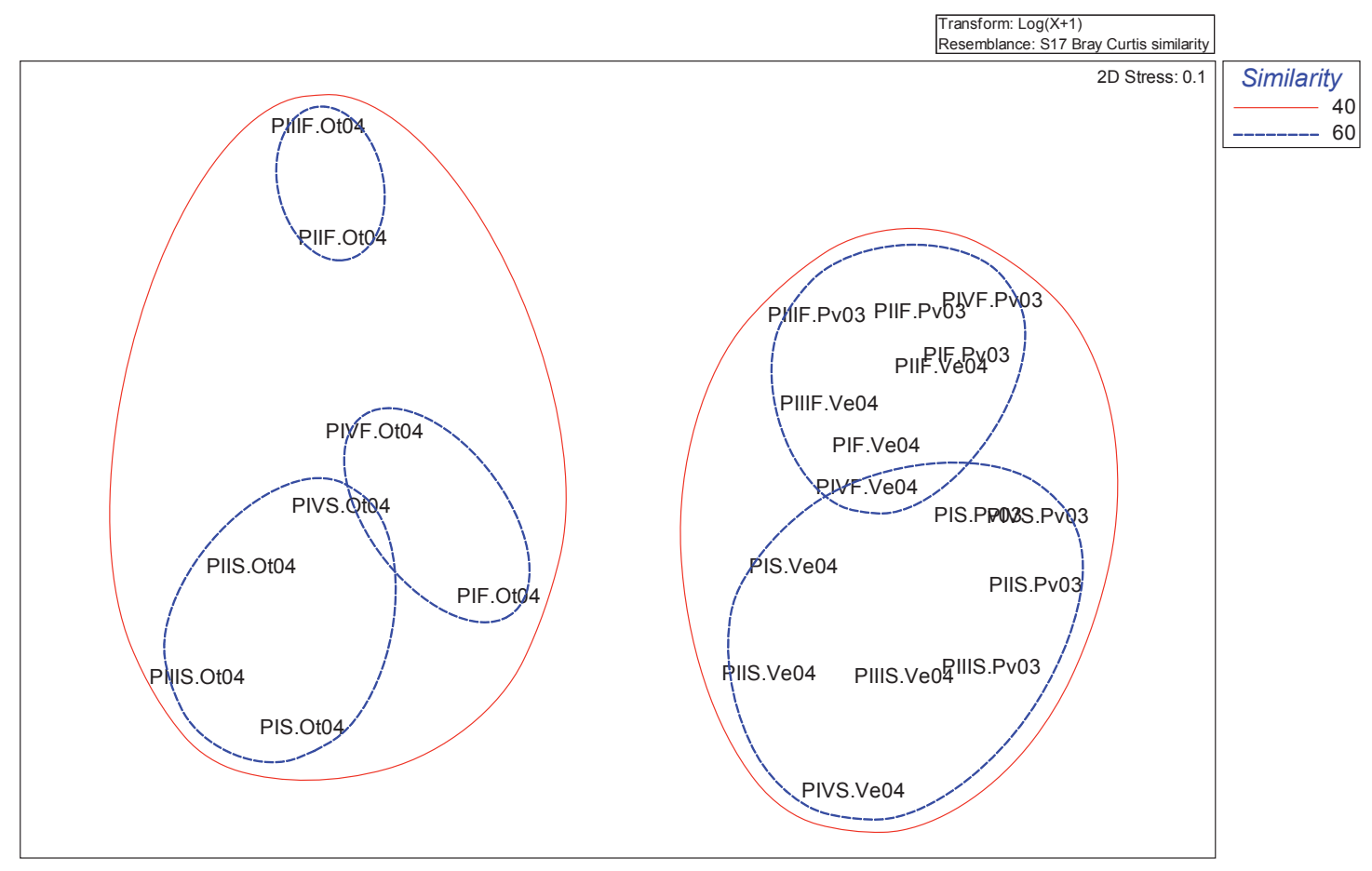

Figura 52. Análise de escalonamento multidimensional não-métrica (nMDS) para as densidades do meroplâncton. Os agrupamentos obtidos no dendrograma acima foram sobrepostos no diagrama. Baía do Almirantado. PIS= Martel Superfície; $\mathrm{PIF}=$ Martel Fundo; PIIS= Mackellar Superfície; PIIF= Mackellar Fundo; PIIIS= Ezcurra Superfície; PIIIF= Ezcurra Fundo; PIVS= Entrada da baía Superfície; PIVF= Entrada da baía Fundo. Pv03= Primavera de 2003; Ve04= Verão de 2004; Ot04= Outono de 2004.

A densidade de alguns grupos do meroplâncton foram sobrepostas ao diagrama do nMDS para analisar qual seu efeito na diferença no padrão de distribuição das estações (Figura 53). Larvas de Gastropoda foram mais representativas nas coletas do outono de 2004, na superfície, e na primavera de 2003 e verão de 2004, na camada mais profunda. Quando analisada a densidade de larvas de Polychaeta, estas tiveram valores mais representativos nas amostragens realizadas no período do outono de 2004, em 
profundidade, em todas as estações, e na superfície na estação localizada na entrada da Baía do Almirantado, além de na profundidade na primavera e verão. Na sobreposição da densidade de larvas de Echinodermata podem-se observar valores mais representativos nas estações de profundidade (rede de fechamento), nos períodos de primavera de 2003 e verão de 2004. A densidade de larvas do tipo trocófora foi maior no período do outono de 2004. Já as larvas do tipo pilidium, Nemertea, apresentaram as maiores densidades nas estações profundas (rede de fechamento), períodos de primavera de 2003 e verão de 2004.

Em síntese, o grupo G1 (Outono/04) foi caracterizado por maior densidade de larvas do tipo trocófora, Gastropoda e Polychaeta. O segundo grupo (G2), da camada de superfície, foi caracterizado pela presença de larvas de Gastropoda, Echinodermata e Nemertea, todas em baixa densidade. O terceiro grupo (G3) foi caracterizado pela presença de larvas de Nemertea e Echinodermata (maiores densidades), Gastropoda, e de Polychaeta. 

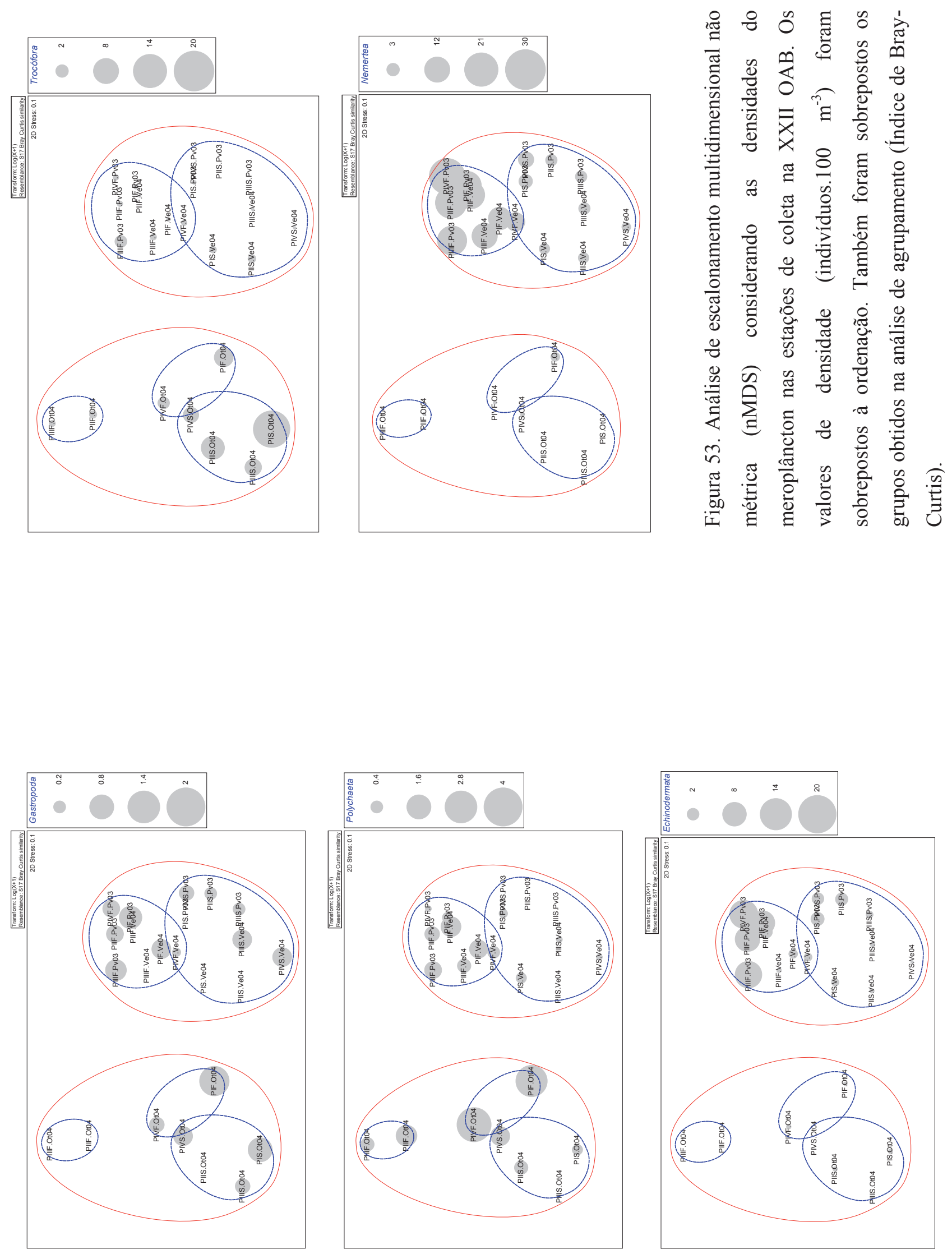


\section{DIscussão}

Uma distribuição vertical do meroplâncton na Baía do Almirantado foi observada, sendo verificados picos de abundância na camada profunda (30-130 m) na primavera-verão, enquanto que no outono, acima de $30 \mathrm{~m}$. Vázquez et al. (2007) também observaram uma maior abundância larval em camadas mais profundas. Diversos trabalhos descrevem a estratificação de larvas na coluna de água (Thatje et al., 2003; Vázquez et al., 2007; Bowden et al., 2009; Highfield et al., 2010).

Organismos do meroplâncton fazem uso da migração vertical a fim de manterse em camadas de água de correntes horizontais onde exista maior disponibilidade de alimento e mortalidade reduzida (Rawlinson et al., 2004). Na Enseada Ezcurra, Baía do Almirantado, as maiores densidades de copépodes foram observadas nos estratos mais profundos (50 a $75 \mathrm{~m}$ ) da coluna de água e relacionadas com o fitoplâncton (Chojnacki \& Weglenska, 1984). No presente estudo essa relação não pode ser evidenciada para os grupos do meroplâncton. Em relação à concentração de clorofila $a$, não houve uma distribuição muito diferenciada entre as duas camadas analisadas, embora os valores tenham sido mais altos na camada profunda em duas estações (enseadas Martel e Ezcurra) na primavera-verão. Assim, esse fator não pode ser claramente relacionado à distribuição vertical do meroplâncton na baía. Freire et al. (1993) também não observaram essa relação na distribuição vertical do zooplâncton na baía, a qual atribuíram às correntes criadas pelos ventos.

No Estreito de Bransfield, em período de verão, também foi observada uma maior abundância larval nas camadas abaixo de $40 \mathrm{~m}$, a qual foi relacionada à Massa de Água Zonal Transicional com influência do Mar de Bellinghausen (TBW), que tem temperatura mais elevada e salinidade mais baixa (Vázquez et al., 2007). No estreito, a distribuição do meroplâncton parece ser produto da desova dos adultos e da hidrografia. A desova estabelece a distribuição inicial de ovos e larvas, mas as condições hidrográficas locais podem determinar a dispersão larval (Vázquez et al., 2007).

$\mathrm{Na}$ primavera-verão, a temperatura da água foi mais elevada na camada de fundo em três das estações de coleta (enseadas Martel e Ezcurra e na entrada da baía). A hidrografia da Baía do Almirantado não é conhecida em detalhe e não há trabalho que mencione a presença da TBW na baía. Mas, na primavera, na região da costa sul da Ilha 
Rei George e a parte central do Estreito de Bransfield, pode haver influxo de água mais quente proveniente de oeste nas camadas mais profundas (Rakusa-Suszczewski, 1996). A circulação da água na baía é gerada de um lado pelas correntes de água profunda que transportam água para dentro e, de outro, por correntes de superfície que empurram a água para fora da baía em direção ao Estreito de Bransfield (Pruszak, 1980). Desse modo, há indícios que pode haver entrada da TBW na baía na primavera-verão e a maior abundância de meroplâncton na camada de fundo nesses períodos pode estar relacionada a essa massa de água.

Apesar de haver poucos estudos sobre a interação entre comportamento larval e hidrodinâmica, esses resultados evidenciam que a hidrodinâmica pode modificar o comportamento larval e que a larva pode influenciar a sua distribuição vertical na coluna de água em diferentes fluxos de correntes (Sameoto et al., 2010). A hidrografia local e a topografia podem ser então determinantes na distribuição e transporte das larvas, superando o comportamento migratório (Rawlinson et al., 2004; Mujica et al., 2010).

Na Baía do Almirantado, o modelo de circulação proposto por Robakiewicz \& Rakusa-Suszczewski (1999) indica que o fluxo das correntes pode ser modificado pelo vento e os mais intensos podem criar um fluxo bi-direcional na parte mais profunda da baía. No presente estudo ventos de intensidade média acima de $4 \mathrm{~m} . \mathrm{s}^{-1}$ foram registrados no horário das coletas, em especial na primavera de 2003, quando houve uma distribuição vertical do meroplâncton diferenciada. Ventos mais intensos do que 4 $\mathrm{m} . \mathrm{s}^{-1}$ têm maior influencia sobre a camada superior a $30 \mathrm{~m}$ do que o fluxo das marés (Pruszak, 1980) e talvez as larvas migrem para uma profundidade maior devido às correntes criadas pelos ventos mais na superfície.

A análise de componentes principais com os fatores ambientais separou principalmente os períodos de coleta, mas não as camadas da coluna de água. Entretanto, como esses dados são pontuais, não há evidências de uma clara relação com a distribuição vertical do meroplâncton.

A partir da análise de ordenação nMDS demonstrou-se que as quatro estações entre si não foram distintas, havendo, entretanto, diferença tanto batimétrica, como temporal na composição e abundância relativa dos grupos de larvas. A principal diferença na composição do meroplâncton entre as duas camadas da coluna de água na primavera-verão foi devido à dominância na camada profunda das larvas pilidium de 
Nemertea, principalmente, e de Echinodermata ou Polychaeta. No outono não houve distinção muito evidente entre as camadas, mas a composição geral mudou, sendo que as larvas trocóforas foram as mais dominantes, seguidas de larvas de Polychaeta.

As larvas pilidium de Nemertea ocorreram nas duas camadas da coluna de água, mas com maior abundância na mais profunda, em especial na primavera-verão. No Estreito de Bransfield essa distribuição vertical também foi observada em período de verão, embora essas larvas não tenham sido muito abundantes (Vázquez et al., 2007).

As larvas pilidium podem alimentar-se de bactérias, nanofitoplâncton e, talvez, de matéria orgânica dissolvida (Rivkin et al., 1991; Pearse et al., 1991) e, desse modo, não são dependentes unicamente da floração de fitoplâncton. Isto pode explicar como essas larvas ocorrem em maior profundidade e também persistem e sobrevivem em um período mais extenso no plâncton (Bowden et al., 2009).

As maiores densidades de larvas de Echinodermata foram observadas no período da primavera em todas as estações profundas, com evidentes picos de abundância. Essas larvas também foram encontradas no Estreito de Bransfield preferencialmente entre 40 e $70 \mathrm{~m}$ de profundidade, associadas à Massa de Água Zonal Transicional com influência do Mar de Bellinghausen (TBW), com temperaturas mais elevadas e salinidades mais baixas (Vázquez et al., 2007).

Larvas de Polychaeta foram mais abundantes nas estações amostradas no outono na camada de água mais profunda, abaixo de $30 \mathrm{~m}$. Vázquez et al. (2007) também relacionaram a maior densidade dessas larvas em camadas mais profundas no Estreito de Bransfield, próximo das Ilhas Shetlands do Sul, com a massa de água TBW.

Por meio da migração vertical diária, as larvas podem avaliar o fundo para o assentamento durante o dia e aproveitar a maior disponibilidade de recursos alimentares na coluna de água à noite (Garland et al., 2002). Esses autores observaram que larvas de Gastropoda e de Polychaeta estiveram concentradas próximas ao fundo durante o dia e distribuídas entre a superfície e fundo, à noite. Variações circadianas na distribuição vertical podem ter contribuído para a variabilidade observada na baía. No entanto, uma vez que as coletas foram realizadas sempre em período diurno, não se pode atribuir esse fator como um dos responsáveis pela distribuição observada. Além disso, o efeito da migração diária na Antártica é provavelmente menos importante do que as condições hidrográficas, uma vez que o período de luminosidade diária é bastante variável em 
função da época do ano. A importância das correntes criadas pelo vento na distribuição vertical do zooplâncton na baía foi observada por Freire et al. (1993).

Este foi o primeiro estudo sobre a variação batimétrica do meroplâncton na Baía do Almirantado. Essa análise preliminar sugere que na Baía do Almirantado ocorra uma variação na abundância e composição da comunidade do meroplâncton entre os estratos na coluna de água de acordo com o período do ano. Essa distribuição parece estar relacionadas à hidrografia da área de estudo. Futuros trabalhos com o uso de diferentes métodos de coleta (rede do tipo multinet, por exemplo) poderão melhor evidenciar o perfil vertical da comunidade do meroplâncton e a sua relação com as condições oceanográficas. 


\section{REFERÊNCIAS BIBLIOGRÁFICAS}

Absher, T.M.; Boehs, G.; Feijó, A.R. \& Cruz, A.C. 2003. Pelagic larvae of benthic gastropods from shallow Antarctic waters of Admiralty Bay, King George Island. Polar Biol., 26(6):359-364.

Ambrogi, R.; Ferrari, J. \& Geraci, S. 1989. Biotic exchange between river, lagoon and sea: The case of zooplankton in the Po Delta. In: Ros, J.D. (ed.), Topics in Marine Biology. Sci. Mar., 53:601-608.

Arntz, W.E. \& Gili, J.M. 2001. A Case for Tolerance in Marine Ecology: Let Us Not Put out the Baby with the Bathwater. Scientia Mar., 65(Suppl. 2): 283-299.

Bhaud, M.; Koubbi, P.; Razouls, S.; Tachon, O. \& Accornero, A. 1999. Description of planktonic polychaete larvae from Terre Adélie and the Ross Sea (Antarctica). Polar Biol., 22: 329-340.

Boltovskoy, D. 1999. South Atlantic Zooplankton. Leiden, The Netherlands, Backhuys Publishers, 1706p.

Bowden, D.A.; Clarke, A. \& Peck, L. 2009. Seasonal variation in the diversity and abundance of pelagic larvae of Antarctic marine invertebrates. Mar. Biol., 156:2033-2047.

Chojnacki, J. \& Weglenska, T. 1984. Periodicity of composition, abundance, and vertical distribution of summer zooplankton (1977/1978) in Ezcurra Inlet, Admiralty Bay (King George Island, South Shetland). J. Plankton Res., 6:9971017.

Clarke, A. 1988. Seasonality in the Antarctic Marine Environment. Comp. Biochem. Physiol., 90B: 461-473.

Clarke, A. 1996. Benthic marine habitats in Antarctica. Ant. Res. Ser., 70:123-133.

Clarke, K.R. \& Gorley, R.N. 2006. PRIMER V.6.1: User Manual/Tutorial. Plymouth, PRIMER-E Ltd. 190p.

Clarke, K.R. \& Warwick, R.M. 2001. Change in marine communities: an approach to Foster, B.A. 1987. Composition and abundance of zooplankton under the spring sea-ice of McMurdo Sound, Antarctica. Polar Biol., 8:41-48. 
Foster, B.A. 1989. Time and depth comparisons of sub-ice zooplankton in McMurdo Sound. Polar Biol., 9:431-435.

Foster, B.A. 1991. Zooplankton comparisons in McMurdo Sound. NZ. Antarct. Rec., $11: 36-47$.

Freire, A.S.; Coelho M.J.C. \& Bonecker. S.L.C. 1993. Short term spatial-temporal distribution pattern of zooplankton in Admiralty Bay (Antarctica). Polar Biol., 13(7):433-439.

Freire, A.S.; Absher, T.M.; Cruz-Kaled, A.C.; Kern, Y. \& Elbers, K.L. 2006. Seasonal variation of pelagic invertebrate larvae in the shallow Antarctic waters of Admiralty Bay (King George Island). Polar Biol., 29(4):294-302.

Garland, E.; Zimnmer, C.A. \& Lentz, S.J. 2002. Larval distributions in inner-shelf waters: The roles of wind-driven cross-shelf currents and diel vertical migrations. Limnol. Oceanogr., 47:803-817.

Highfield, J.M.; Eloire, D.; Conway, D.V.P.; Lindeque, P.K.; Attrill, M.J. \& Somerfield, P.J. 2010. Seasonal dynamics of meroplankton assemblages at station L4. J. Plankton Res. On line.

Legendre, L \& Legendre, P. 1983. Numerical ecology developments in environmental modelling. Amsterdam, Elsevier Scientific Publishing Company. 412p.

Mujica, A. \& Nava, M.L. 2010. Distribución espacial de larvas de crustáceos decápodos planctónicos en canales orientales de la isla Chiloé, Chile. Lat. Am. J. Aquat. Res., 38: 95-106.

Pearse, J.S.; McClintock, J.B. \& Bosch, I. 1991. Reproduction of Antarctic benthic marine invertebrates: tempos, modes and timing. Am. Zool., 31:65-80.

Poulin, É.; Palma, A.T. \& Féral, J.P. 2002. Evolutionary versus ecological success in Antarctic benthic invertebrates. Trends in Ecol. Evol., 17:218-222.

Pruszak, Z. 1980. Current circulation in the water of Admiralty Bay (region of Arctowski Station on King George Island). Pol. Polar Res., 1:55-74.

Rakusa-Suszczewski, S. 1996. Spatial and seasonal variability of température and salinity in Bransfield Strait and Admiralty Bay, Antarctica. Pol. Polar Res., 17:29-42. 
Rawlinson, K.A. ; Davenport, J. \& Barnes, K.A. 2004. Vertical migration strategies with respect to advection and stratification in a semi-enclosed lough: a comparison of mero- and holozooplankton. Mar. Biol., 144 :935-946.

Rivkin, R.B.; Anderson, M.R. \& Gustafson Jr, D.E. 1991. Ingestion of phytoplankton and bacterioplankton by polar and temperate echinoderm larvae. Antarct. J. US., 26:156-158.

Robakiewicz, M. \& Rakusa-Suszczewski, S. 1999. Application of 3D circulation model to Admiralty Bay, King George Island, Antarctica. Pol. Polar Res., 20:43-58.

Sameoto, J.; Ross, T. \& Metaxas, A. 2010. The effect of flow on larval vertical distribution of the sea urchin, Strongylocentrotus droebachiensis. J. Exp. Mar. Biol. Ecol., 383:156-163.

Sewell, M.A. 2005. Examination of the meroplankton community in the south-western Ross Sea, Antarctica, using a collapsible plankton net. Polar Biol., 28:119-131.

Sewell, M.A. 2006. The meroplankton community of the northern Ross Sea: a preliminary comparison with the McMurdo Sound region. Antarctic Sci., 18(4):595-602.

Shanks, A.L. 2009. Pelagic larval duration and dispersal distance revisited. Biol. Bull., 216:373-385.

Shreeve, R.S. \& Peck, L.S. 1995. Distribution of pelagic larvae of benthic marine invertebrates in the Bellingshausen Sea. Polar Biol., 15:369-374.

Simões, J.C.; Arigony-Neto, J. \& Bremer, U.F. 2004. O uso de mapas antárticos em publicações. Pesq. Antart. Bras, 4:191-197.

Smith D.L. 1977. A guide to marine coastal plankton and marine invertebrate larvae. Dubuque, Iowa, U.S.A, Kendall/Hunt. 161p.

Stanwell-Smith, D.; Hood, A.; Peck, L.S. 1997. A field guide to the pelagic invertebrate larvae of the maritime Antarctic. Cambridge, British Antarctic Survey. 152p.

Stanwell-Smith, D.; Peck, L.S.; Clarke, A.; Murray, A.W.A. \& Todd, C.D. 1999. The distribution, abundance and seasonality of pelagic marine invertebrate larvae in the maritime Antarctic. Philos. Trans. R. Soc. London B, 354:471-484. 
Strickland, J.D. \& Parsons, T.R. 1968 A practical handbook of seawater analysis. Bull. Fish. Res. Bd. Can., 167:1-311.

Thatje, S.; Schnack-Schiel, S. \& Arntz, W.E. 2003. Developmental trade-offs in SubAntarctic meroplankton communities and the enigma of low decapod diversity in high Southern latitudes. Mar. Ecol. Prog. Ser., 260:195-207.

Thatje, S.; Hillenbrand, C., \& Larter, R. 2005. On the origin of Antarctic marine benthic community structure. Trends in Ecol. Evol., 20:534-540.

Todd, C.D.; Laverack, M.S.\& Boxshall, G.A. 1996. Coastal marine zooplankton: a practical manual for students. Cambridge, Cambridge University Press. 106p.

Valentin, J.L. 2000. Ecologia numérica: uma introdução à análise multivariada de dados ecológicos. Rio de Janeiro, Interciência. 117p.

Vázquez, E.; Ameneiro, J.; Putzeys, S.; Gordo, C. \& Sangra, P. 2007. Distribution of meroplankton communities in the Bransfield Strait, Antarctica. Mar. Ecol. Prog. Ser., 338:119-129.

Young, C.M. 1995. Behaviour and locomotion during the dispersal phase of larval life. In: McEdward, L. (ed.), Ecology of marine invertebrate larvae. Florida, CRC Press, 249-277.

Young, C.M.; Sewell, M.A. \& Rice, M.E. 2006. Atlas of Marine Invertebrate Larvae. London, Academic Press. 646p.

Zar, J.H. 1996. Biostatistical Analisys. Engewood Cliffs, N.J., Prentice-Hall. 662p. 
Na Baía do Almirantado, o meroplâncton ocorreu em todos os períodos do ano, mas sua abundância foi variável entre os dois anos, dependendo da época do ano e da localização geográfica. Em termos gerais, a composição do meroplâncton coletado na Baía do Almirantado foi qualitativamente similar ao descrito anteriormente na baía e em outras partes da Antártica, embora a abundância relativa dos diferentes grupos de larvas tenha variado no período de dois anos.

Os resultados mostram uma variação interanual evidente, mas não um padrão nítido de sazonalidade para alguns grupos de larvas. A variação da abundância de grupos de invertebrados do bentos com desenvolvimento indireto na área pode determinar a composição do meroplâncton, cujos ciclos reprodutivos são afetados por características ambientais. O congelamento da baía no inverno do primeiro ano de amostragem (2002) pode ter afetado a reprodução dos invertebrados bentônicos e a produção de larvas, uma vez que as densidades do meroplâncton foram maiores do que em 2003/2004, além da variação dos grupos de larvas dominantes. A produção de larvas, principalmente de Gastropoda e Nemertea, provavelmente foi influenciada pelo congelamento.

Em termos espaciais, não houve diferença clara da composição e densidade do meroplâncton entre as enseadas e a entrada da baía em função da dinâmica oceanográfica da baía, embora as maiores densidades tenham sido observadas nas enseadas, provavelmente em função da sua geomorfologia que propicia maior retenção do plâncton.

Porém, não ficou evidente a correlação entre a composição, distribuição e abundância da comunidade do meroplâncton com as variáveis ambientais analisadas, embora a concentração de clorofila $a$, a temperatura e a intensidade de ventos distinguiram os diversos períodos do ano.

Quanto à variação batimétrica, a composição e a densidade do meroplâncton total diferiu entre as camadas de superfície e profunda, enquanto que espacialmente foi semelhante entre as estações de coleta nas distintas camadas. Picos de abundância foram verificados na camada profunda $(30-130 \mathrm{~m})$ na primavera-verão, enquanto que no outono, acima de $30 \mathrm{~m}$. Essa variação batimétrica parece estar relacionada com a 
hidrografia da baía, como correntes geradas por vento que atuam na camada d'água até $30 \mathrm{~m}$ e/ou massa de água presente em maior profundidade.

Como os organismos meroplanctônicos estão sujeitos a processos passivos de transporte na coluna de água, um melhor conhecimento da hidrografia da Baía do Almirantado é necessário para uma interpretação mais clara dos padrões de variação. Além disso, um conhecimento mais aprofundado da biologia reprodutiva dos invertebrados bentônicos da área também é importante. 
Apêndice I. Resultados da ANOVA para verificar a hipótese que as variáveis ambientais foram significativamente diferentes entre períodos e áreas.

\begin{tabular}{llll}
\hline & Fator 1 & Fator 2 & Interação \\
& PERÍODO & ÁREA & PERÍODO X ÁREA \\
\hline Temperatura & $*$ & $*$ & $*$ \\
Salinidade & $*$ & NS & $*$ \\
Transparência & $*$ & $*$ & $*$ \\
Velocidade do Vento & $*$ & $*$ & $*$ \\
Clorofila $a$ & $*$ & NS & NS \\
Feopigmentos & $*$ & NS & NS \\
\hline$* \mathrm{p}<0,001$ & & &
\end{tabular}

Apêndice II. Resultados da ANOVA para verificar a hipótese que as densidades do meroplâncton foram significativamente diferentes entre períodos e áreas.

\begin{tabular}{llll}
\hline & Fator 1 & Fator 2 & Interação \\
& PERÍODO & ÁREA & PERÍODO X ÁREA \\
\hline Gastropoda & NS & NS & NS \\
Polychaeta & $*$ & NS & $*$ \\
Echinodermata & $*$ & NS & NS \\
Trocófora & $*$ & NS & $*$ \\
Nemertea & $*$ & NS & NS \\
\hline$* \mathrm{p}<0,001$ & & &
\end{tabular}


Apêndice III. Data e local de coleta. Baía do Almirantado, Ilha Rei George, Antártica.

\begin{tabular}{|c|c|c|}
\hline ESTAÇÃO & DATA DA COLETA & PERIODO \\
\hline 3. Stenhouse & 04.10 .02 & \\
\hline 5. Precious Point & 04.10 .02 & \\
\hline 1. Ferraz & 15.10 .02 & Primavera02 \\
\hline 2. Yellow Point & 15.10 .02 & \\
\hline 4. Punta Ullman & 15.10 .02 & \\
\hline 6. Lussish & 15.10 .02 & \\
\hline 12. Punta Plaza & 15.10 .02 & \\
\hline 11. Machu Pichu & 16.10 .02 & \\
\hline 7. Vieville & 29.10 .02 & \\
\hline 8. Sphinx & 29.10 .02 & \\
\hline 9. Arctowski & 31.10 .02 & \\
\hline 10. Dufayel & 31.10 .02 & \\
\hline 6. Lussish & 04.12 .02 & \\
\hline 11. Machu Pichu & 04.12 .02 & \\
\hline 12. Punta Plaza & 04.12 .02 & Verão03 \\
\hline 1. Ferraz & 07.12 .02 & \\
\hline 2. Yellow Point & 07.12 .02 & \\
\hline 3. Stenhouse & 07.12 .02 & \\
\hline 4. Punta Ullman & 07.12 .02 & \\
\hline 5. Precious Point & 07.12 .02 & \\
\hline 10. Dufayel & 12.12 .02 & \\
\hline 7. Vieville & 20.12 .02 & \\
\hline 8. Sphinx & 20.12 .02 & \\
\hline 9. Arctowski & 21.12 .02 & \\
\hline 10. Dufayel & 21.12 .02 & \\
\hline 11. Machu Pichu & 21.12 .02 & \\
\hline 12. Punta Plaza & 21.12 .02 & \\
\hline 1. Ferraz & 23.12 .02 & \\
\hline 3. Stenhouse & 23.12 .02 & \\
\hline 4. Punta Ullman & 23.12 .02 & \\
\hline 5. Precious Point & 23.12 .02 & \\
\hline 6. Lussish & 23.12 .02 & \\
\hline 7. Vieville & 26.12 .02 & \\
\hline 8. Sphinx & 26.12 .02 & \\
\hline 9. Arctowski & 26.12 .02 & \\
\hline 2. Yellow Point & 27.12 .02 & \\
\hline 8. Sphinx & 28.12 .02 & \\
\hline 9. Arctowski & 28.12 .02 & \\
\hline 10. Dufayel & 28.12 .02 & \\
\hline 1. Ferraz & 30.12 .02 & \\
\hline 2. Yellow Point & 30.12 .02 & \\
\hline 3. Stenhouse & 30.12 .02 & \\
\hline
\end{tabular}


4. Punta U1lman

6. Lussish

5. Precious Point

12. Punta Plaza

7. Vieville

8. Sphinx

9. Arctowski

10. Dufayel

11. Machu Pichu

12. Punta Plaza

11. Machu Pichu

3. Stenhouse

4. Punta Ullman

5. Precious Point

6. Lussish

7. Vieville

1. Ferraz

2. Yellow Point

1. Ferraz

2. Yellow Point

3. Stenhouse

4. Punta Ullman

5. Precious Point

6. Lussish

7. Vieville

11. Machu Pichu

12. Punta Plaza

8. Sphinx

9. Arctowski

10. Dufayel

1. Ferraz

2. Yellow Point

4. Punta Ullman

5. Precious Point

3. Stenhouse

6. Lussish

11. Machu Pichu

12. Punta Plaza

7. Vieville

8. Sphinx

9. Arctowski

10. Dufayel

1. Ferraz

2. Yellow Point

3. Stenhouse

4. Punta Ullman

5. Precious Point

11. Machu Pichu
30.12 .02

30.12 .02

31.12 .02

31.12 .02

02.01 .03

02.01 .03

02.01 .03

03.01 .03

03.01 .03

03.01 .03

06.01 .03

07.01 .03

07.01 .03

07.01 .03

07.01 .03

07.01 .03

08.01 .03

08.01 .03

21.03 .03

21.03 .03

21.03 .03

21.03 .03

21.03 .03

21.03 .03

23.03 .03

23.03 .03

23.03 .03

26.03 .03

26.03 .03

26.03 .03

14.04 .03

14.04 .03

14.04 .03

14.04 .03

15.04 .03

15.04 .03

15.04 .03

15.04 .03

17.04 .03

17.04 .03

17.04 .03

17.04 .03

10.05 .03

10.05 .03

10.05 .03

10.05 .03

10.05 .03

10.05 .03

Outono03 
1. Ferraz

02.10 .03

2. Yellow Point

14.10 .03

3. Stenhouse

14.10 .03

Primavera03

4. Punta U1lman

14.10 .03

11. Machu Pichu

14.10 .03

12. Punta Plaza

14.10 .03

1. Ferraz

22.10 .03

2. Yellow Point

22.10 .03

3. Stenhouse

22.10 .03

7. Vieville

26.10 .03

8. Sphinx

26.10 .03

9. Arctowski

26.10 .03

10. Dufayel

26.10 .03

4. Punta Ullman

01.11 .03

5. Precious Point

01.11 .03

6. Lussish

01.11 .03

12. Punta Plaza

01.11 .03

1. Ferraz

02.11 .03

2. Yellow Point

02.11 .03

3. Stenhouse

02.11 .03

5. Precious Point

03.11 .03

6. Lussish

03.11 .03

7. Vieville

04.11 .03

8. Sphinx

06.11 .03

9. Arctowski

06.11 .03

10. Dufayel

06.11 .03

11. Machu Pichu

06.11 .03

4. Punta Ullman

08.11 .03

5. Precious Point

08.11 .03

6. Lussish

08.11 .03

12. Punta Plaza

08.11 .03

10. Dufayel

10.11 .03

7. Vieville

15.11 .03

8. Sphinx

15.11 .03

9. Arctowski

15.11 .03

11. Machu Pichu

15.11 .03

1. Ferraz

19.12.03

6. Lussish

19.12.03

21.12 .03

11. Machu Pichu

22.12 .03

7. Vieville

22.12 .03

8. Sphinx

22.12 .03

10. Dufayel

26.12 .03

Verão04

7. Vieville 
10. Dufayel

26.12 .03

11. Machu Pichu

26.12 .03

1. Ferraz

27.12 .03

6. Lussish

27.12 .03

8. Sphinx

29.12 .03

11. Machu Pichu

30.12 .03

1. Ferraz

02.01 .04

6. Lussish

02.01 .04

7. Vieville

05.01 .04

8. Sphinx

05.01 .04

10. Dufayel

07.01 .04

6. Lussish

16.02 .04

7. Vieville

17.02 .04

8. Sphinx

17.02 .04

1. Ferraz

19.02.04

11. Machu Pichu

23.02 .04

10. Dufayel

25.02 .04

1. Ferraz

14.03 .04

5. Precious Point

14.03 .04

6. Lussish

14.03 .04

Outono04

7. Vieville

2. Yellow Point

15.03 .04

16.03 .04

3. Stenhouse

16.03 .04

4. Punta Ullman

16.03 .04

11. Machu Pichu

16.03 .04

8. Sphinx

19.03 .04

10. Dufayel

19.03 .04

2. Yellow Point

05.04 .04

3. Stenhouse

05.04 .04

4. Punta Ullman

05.04 .04

5. Precious Point

05.04 .04

10.04 .04

1. Ferraz

10.04 .04

6. Lussish

10.04 .04

11. Machu Pichu

17.04 .04

10. Dufayel

20.04 .04

7. Vieville

24.04 .04

4. Punta Ullman

24.04 .04

5. Precious Point

24.04 .04

8. Sphinx

03.05 .04

2. Yellow Point

03.05 .04

3. Stenhouse

26.05 .04

1. Ferraz

26.05 .04

2. Yellow Point

26.05 .04

3. Stenhouse

31.05 .04

7. Vieville

31.05 .04

8. Sphinx

31.05 .04 

4. Punta Ullman
04.06 .04
5. Precious Point
04.06 .04
6. Lussish
04.06 .04
Inverno04
10. Dufayel
20.06 .04
11. Machu Pichu
20.06 .04
1. Ferraz
10.08 .04
2. Yellow Point
10.08 .04
3. Stenhouse
10.08 .04
4. Punta Ullman
13.08 .04
5. Precious Point
13.08 .04
6. Lussish
13.08 .04

Apêndice IV. Abundância média (indivíduos. $100 \mathrm{~m}^{-3}$ ) e desvio-padrão do meroplâncton em toda a Baía do Almirantado durante as Operações Antárticas Brasileiras (OAB) XXI (2002/2003) e XXII (2003/2004).

\begin{tabular}{|c|c|c|c|c|}
\hline & ÁREA 1 & ÁREA 2 & ÁREA 3 & ÁREA 4 \\
\hline & MARTEL (MT) & $\begin{array}{r}\text { MACKELLAR } \\
(\mathrm{ML})\end{array}$ & EZCURRA (EZ) & $\begin{array}{r}\text { ENTRADA DA } \\
\text { BAÍA (EBA) }\end{array}$ \\
\hline \multicolumn{5}{|c|}{ GASTROPODA } \\
\hline XXI & $1,84 \pm 4,73$ & $124,53 \pm 526,98$ & $5,50 \pm 8,05$ & $43,47 \pm 187,95$ \\
\hline XXII & $1,56 \pm 3,32$ & $5,35 \pm 24,62$ & $0,19 \pm 0,65$ & $1,02 \pm 2,25$ \\
\hline \multicolumn{5}{|c|}{ POLYCHAETA } \\
\hline XXI & $0,13 \pm 0,42$ & $1,29 \pm 3,94$ & $0,08 \pm 0,29$ & $1,13 \pm 4,23$ \\
\hline XXII & $1,96 \pm 3,79$ & $0,54 \pm 1,14$ & $0,44 \pm 1,07$ & $0,54 \pm 1,86$ \\
\hline \multicolumn{5}{|c|}{ ECHINODERMATA } \\
\hline XXI & $1,04 \pm 2,55$ & $1,16 \pm 2,53$ & $0,07 \pm 0,26$ & $1,79 \pm 2,72$ \\
\hline XXII & $1,53 \pm 3,52$ & $2,93 \pm 4,51$ & $0,42 \pm 0,79$ & $1,05 \pm 1,99$ \\
\hline \multicolumn{5}{|l|}{ TROCÓFORA } \\
\hline XXI & $0,41 \pm 1,47$ & $1,59 \pm 5,26$ & $1,63 \pm 2,39$ & $1,85 \pm 5,15$ \\
\hline XXII & $4,15 \pm 7,93$ & $1,70 \pm 2,33$ & $1,29 \pm 1,82$ & $1,16 \pm 1,91$ \\
\hline \multicolumn{5}{|l|}{ NEMERTEA } \\
\hline XXI & $2,55 \pm 5,44$ & $1,39 \pm 2,36$ & $4,80 \pm 5,93$ & $6,75 \pm 11,20$ \\
\hline XXII & $1,03 \pm 2,77$ & $1,23 \pm 1,76$ & $1,05 \pm 2,15$ & $3,11 \pm 4,71$ \\
\hline
\end{tabular}


Apêndice V. Abundância média (indivíduos. $100 \mathrm{~m}^{-3}$ ) e desvio-padrão do meroplâncton em toda a Baía do Almirantado durante as Operações Antárticas Brasileiras (OAB) XXI (2002/2003) e XXII (2003/2004).

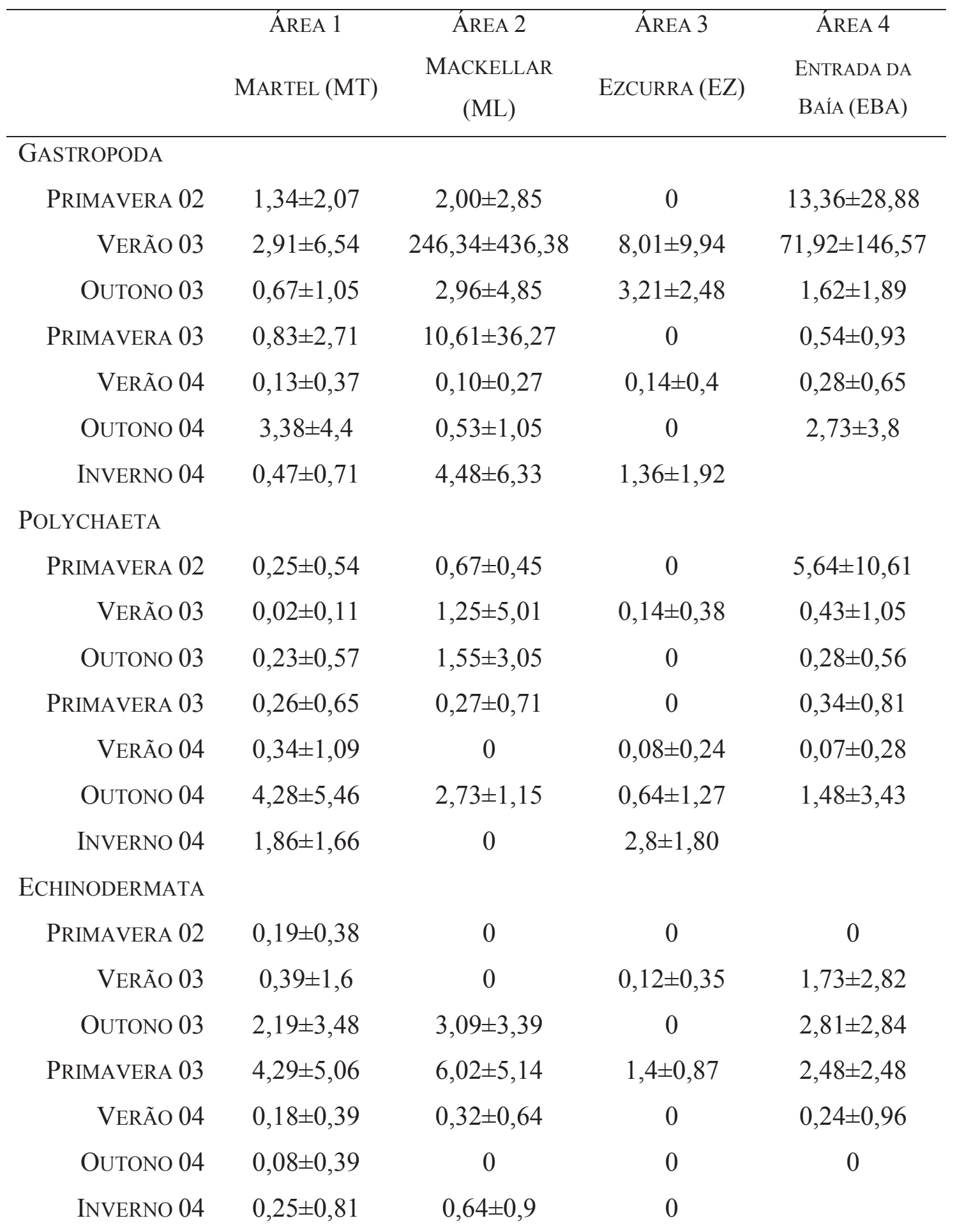


TROCÓFORA

$\begin{array}{rcccc}\text { PRIMAVERA 02 } & 0,19 \pm 0,38 & 0 & 0 & 0,74 \pm 1,82 \\ \text { VERÃO 03 } & 0,18 \pm 0,47 & 2,74 \pm 7,34 & 2,13 \pm 2,98 & 2,54 \pm 6,62 \\ \text { OUtONO 03 } & 0,79 \pm 2,3 & 0,57 \pm 0,79 & 1,46 \pm 1,24 & 1,02 \pm 1,78 \\ \text { PRIMAVERA 03 } & 0,96 \pm 2,66 & 0,7 \pm 1,43 & 0,61 \pm 0,79 & 0,23 \pm 0,7 \\ \text { VERÃO 04 } & 0,56 \pm 0,97 & 2,14 \pm 3,05 & 0,36 \pm 0,73 & 0,71 \pm 1,2 \\ \text { OUtONO 04 } & 9,56 \pm 11,22 & 1,89 \pm 0,88 & 4,42 \pm 1,34 & 3,14 \pm 2,48 \\ \text { INVERNO 04 } & 2,29 \pm 1,91 & 5,63 \pm 1,08 & 0,77 \pm 1,08 & \end{array}$

NEMERTEA

$\begin{array}{rcccc}\text { PRIMAVERA 02 } & 0 & 0 & 0 & 0 \\ \text { VERÃO 03 } & 3,78 \pm 7,22 & 1,75 \pm 2,37 & 4,98 \pm 6,12 & 8,63 \pm 13,95 \\ \text { OUTONO 03 } & 1,98 \pm 2,91 & 1,37 \pm 2,66 & 6,82 \pm 6,64 & 6,37 \pm 5,27 \\ \text { PRIMAVERA 03 } & 2,43 \pm 4,36 & 1,51 \pm 1,78 & 2,84 \pm 3,26 & 5,01 \pm 5,45 \\ \text { VERÃO 04 } & 1,22 \pm 1,44 & 1,72 \pm 2,1 & 0,5 \pm 0,93 & 3,27 \pm 4,57 \\ \text { OUTONO 04 } & 0,03 \pm 0,17 & 0 & 0 & 0,05 \pm 0,16 \\ \text { INVERNO 04 } & 0,16 \pm 0,47 & 0 & 0 & \end{array}$

Apêndice VI. Resultados da ANOVA para verificar a hipótese que as variáveis ambientais foram significativamente diferentes entre períodos e estações.

\begin{tabular}{llll}
\hline & Fator 1 & Fator 2 & Interação \\
& ESTAÇÃO & PERÍODO & ESTAÇÃO X PERÍODO \\
\hline Temperatura & $*$ & $*$ & $*$ \\
Salinidade & $*$ & $*$ & $*$ \\
Transparência & $*$ & NS & $*$ \\
Velocidade do Vento & $*$ & $*$ & $*$ \\
Clorofila $a$ & NS & NS & $*$ \\
Feopigmentos & $*$ & $*$ & $*$ \\
$* \mathrm{p}<0,001$ & & &
\end{tabular}


Apêndice VII. Resultados da ANOVA para verificar a hipótese que as densidades do meroplâncton foram significativamente diferentes entre períodos e estações.

\begin{tabular}{llll}
\hline & Fator 1 & Fator 2 & Interação \\
& ESTAÇÃO & PERÍODO & ESTAÇÃO X PERÍODO \\
\hline Gastropoda & $*$ & NS & NS \\
Polychaeta & $*$ & $*$ & $*$ \\
Echinodermata & $*$ & $*$ & $*$ \\
Trocófora & $*$ & $*$ & $*$ \\
Nemertea & $*$ & $*$ & $*$ \\
$*{ }^{*}<0,001$ & & &
\end{tabular}

Apêndice VIII. Data e local de coleta. Baía do Almirantado, Ilha Rei George, Antártica. Variação batimétrica.

\begin{tabular}{lcc}
\hline \multicolumn{1}{c}{ ESTAÇÃO } & DATA DA COLETA & PERIODO \\
\hline 1. PI. Martel & 20.10 .03 & \\
2. PII. Mackellar & 20.10 .03 & Primavera03 \\
4. PIV. Entrada da Baía do & 26.10 .03 & \\
Almirantado (EBA) & 01.11 .03 & \\
1. PI. Martel & 03.11 .03 & \\
3. PIII. Ezcurra & 06.11 .03 & \\
2. PII. Mackellar & 06.11 .03 & \\
4. PIV. EBA & 08.11 .03 & \\
1. PI. Martel & 10.11 .03 & \\
3. PIII. Ezcurra & 15.11 .03 & \\
2. PII. Mackellar & 15.11 .03 & \\
3. PIII. Ezcurra & 15.11 .03 & \\
4. PIV. EBA & & \\
& 19.12 .03 & \\
1. PI. Martel & 21.12 .03 & \\
2. PII. Mackellar & 21.12 .03 & \\
3. PIII. Ezcurra & 22.12 .03 & \\
4. PIV. EBA & 26.12 .03 & \\
2. PII. Mackellar & 26.12 .03 & \\
3. PIII. Ezcurra & 29.12 .03 & \\
1. PI. Martel & 29.12 .03 & \\
4. PIV. EBA & 30.12 .03 & \\
2. PII. Mackellar & 02.01 .04 & \\
1. PI. Martel & 05.01 .04 & \\
3. PIII. Ezcurra & &
\end{tabular}



4. PIV. EBA
05.01 .04
4. PIV. EBA
17.02 .04
1. PI. Martel
23.02 .04
2. PII. Mackellar
23.02 .04
3. PIII. Ezcurra
25.02 .04
4. PIV. EBA
25.02 .04
1. PI. Martel
15.03 .04
2. PII. Mackellar
16.03 .04
3. PIII. Ezcurra
16.03 .04
Outono04
4. PIV. EBA
19.03 .04
1. PI. Martel
10.04 .04
2. PII. Mackellar
10.04 .04
3. PIII. Ezcurra
17.04 .04
4. PIV. EBA
20.04 .04

Apêndice IX. Abundância média (indivíduos. $100 \mathrm{~m}^{-3}$ ) e desvio-padrão do meroplâncton em toda a Baía do Almirantado durante a Operação Antártica Brasileira (OAB) XXII $(2003 / 2004)$.

\begin{tabular}{|c|c|c|c|c|}
\hline & PI & PII & PIII & PIV \\
\hline & MARTEL & MACKELLAR & EZCURRA & $\begin{array}{c}\text { ENTRADA DA } \\
\text { BAÍA }\end{array}$ \\
\hline \multicolumn{5}{|l|}{ GASTROPODA } \\
\hline OBLÍQUO & $0,17 \pm 0,51$ & $0,06 \pm 0,24$ & $0,33 \pm 0,59$ & $0,45 \pm 0,69$ \\
\hline VERTICAL & $0,70 \pm 1,30$ & $0,15 \pm 0,46$ & $0,19 \pm 0,68$ & $0,26 \pm 0,53$ \\
\hline \multicolumn{5}{|l|}{ POLYCHAETA } \\
\hline OBLÍQUO & $0,22 \pm 0,55$ & $0,11 \pm 0,32$ & $0,06 \pm 0,24$ & $0,25 \pm 0,55$ \\
\hline VERTICAL & $1,11 \pm 1,40$ & $0,93 \pm 1,36$ & $0,59 \pm 0,75$ & $0,93 \pm 2,18$ \\
\hline \multicolumn{5}{|c|}{ ECHINODERMATA } \\
\hline OBLÍQUO & $1,22 \pm 1,44$ & $0,89 \pm 1,41$ & $0,33 \pm 0,77$ & $0,65 \pm 1,57$ \\
\hline VERTICAL & $3,33 \pm 7,54$ & $3,85 \pm 6,83$ & $3,52 \pm 7,45$ & $4,22 \pm 6,83$ \\
\hline \multicolumn{5}{|l|}{ TROCÓFORA } \\
\hline OBLÍQUO & $4,06 \pm 8,55$ & $1,83 \pm 3,13$ & $0,83 \pm 2,2$ & $0,65 \pm 2,03$ \\
\hline VERTICAL & $1,19 \pm 2,47$ & $0,33 \pm 0,62$ & $0,93 \pm 1,3$ & $0,70 \pm 1,35$ \\
\hline \multicolumn{5}{|l|}{ NemerteA } \\
\hline OBLÍQuo & $2,11 \pm 3,72$ & $1,78 \pm 2,13$ & $1,94 \pm 2,24$ & $2,15 \pm 2,81$ \\
\hline VERTICAL & $9,67 \pm 11,8$ & $12,52 \pm 12,62$ & $10,74 \pm 11,45$ & $10,85 \pm 13,28$ \\
\hline
\end{tabular}


Apêndice X. Abundância média (indivíduos. $100 \mathrm{~m}^{-3}$ ) e desvio-padrão do meroplâncton em toda a Baía do Almirantado durante a Operação Antártica Brasileira (OAB) XXII $(2003 / 2004)$.

gastropoda Polychaeta Echinodermata trocófora nemertea

\begin{tabular}{|c|c|c|c|c|c|}
\hline \multicolumn{6}{|c|}{ PRIMAVERA 03} \\
\hline OBLÍQUO & $0,17 \pm 0,38$ & $0,04 \pm 0,2$ & $1,83 \pm 1,79$ & $0,04 \pm 0,2$ & $3,25 \pm 3,66$ \\
\hline VERTICAL & $0,53 \pm 0,97$ & $0,44 \pm 0,73$ & $9,61 \pm 9,77$ & $0,75 \pm 1,25$ & $18,36 \pm 13,81$ \\
\hline \multicolumn{6}{|l|}{ VERÃO 04} \\
\hline OBLÍQUO & $0,26 \pm 0,57$ & $0,12 \pm 0,41$ & $0,32 \pm 0,73$ & $0,38 \pm 1,02$ & $2,03 \pm 2,08$ \\
\hline VERTICAL & $0,15 \pm 0,65$ & $0,73 \pm 1,2$ & $1,13 \pm 1,68$ & $0,29 \pm 0,8$ & $10,63 \pm 9,84$ \\
\hline \multicolumn{6}{|l|}{ OUTONO 04} \\
\hline OBLÍQUO & $0,38 \pm 0,72$ & $0,44 \pm 0,63$ & $0,13 \pm 0,34$ & $7,5 \pm 8,2$ & $0,06 \pm 0,25$ \\
\hline VERTICAL & $0,38 \pm 0,88$ & $1,88 \pm 2,31$ & $0,13 \pm 0,34$ & $1,83 \pm 2,53$ & $0,46 \pm 0,83$ \\
\hline
\end{tabular}

